\title{
Modeling of Single Char Combustion, Including CO Oxidation in Its Boundary Layer
}

by

\author{
Chun-Hyuk Lee
}

\author{
B.S. in Chemical Engineering \\ Seoul National University, Seoul, Korea
}

(1989)

Submitted to the Department of Chemical Engineering in Partial Fulfillment of the Requirements for the Degree of

Doctor of Philosophy in Chemical Engineering

at the

Massachusetts Institute of Technology

$$
\text { May } 1994
$$

(C) 1994 Massachusetts Institute of Technology All rights reserved

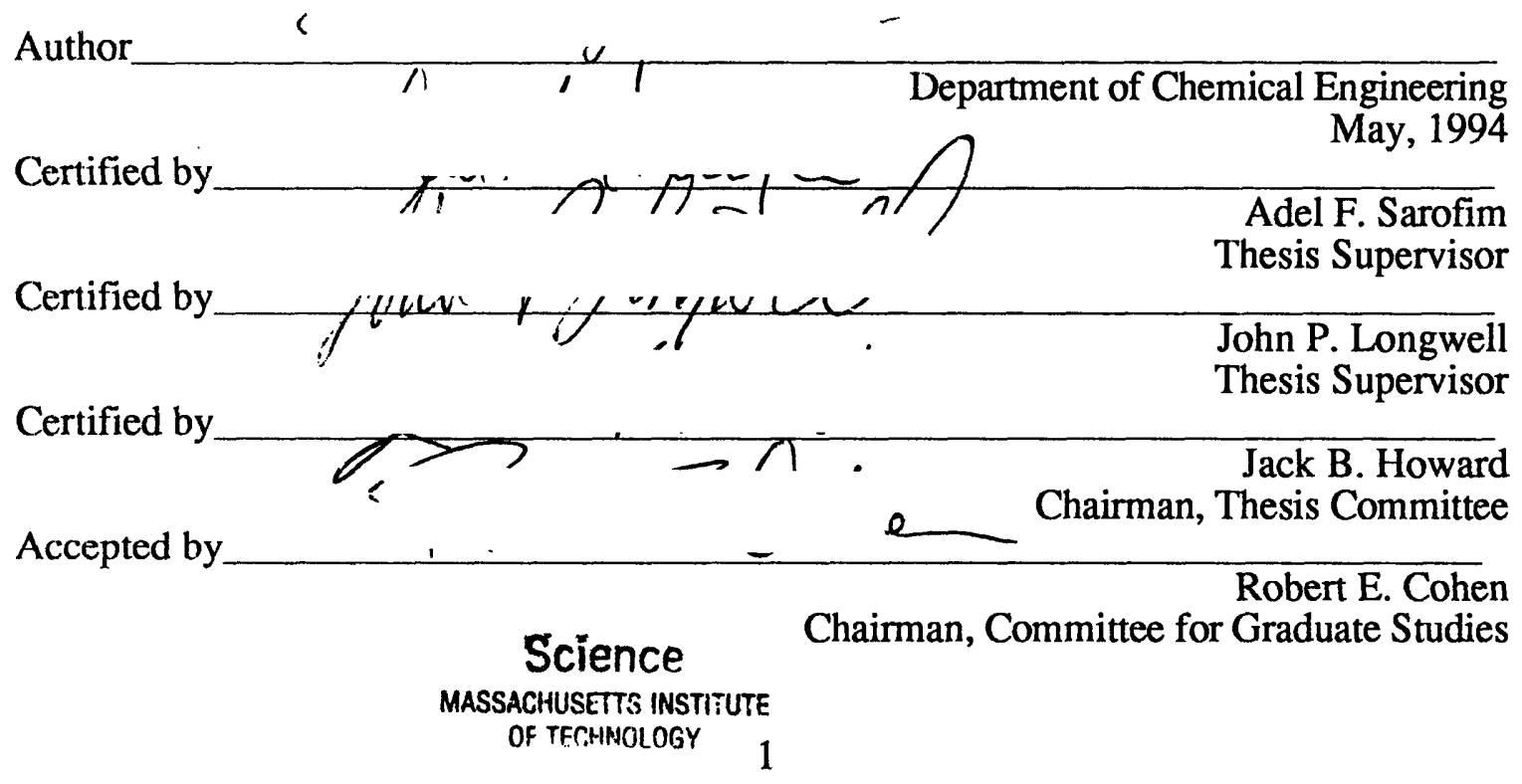




\title{
Modeling of Single Char Combustion, Including CO Oxidation in Its Boundary Layer
}

\author{
by \\ Chun-Hyuk Lee \\ Submitted to the Department of Chemical Engineering \\ in May 17, 1994 in partial fulfillment of the \\ requirements for the Degree of \\ Doctor of Philosophy in Chemical Engineering
}

\begin{abstract}
s
A model incorporating intrinsic surface reaction, internal pore diffusion, and external mass transfer was developed to predict a transient temperature profile during a single char particle combustion. This model provides useful information for particle ignition, burning temperature profile, combustion time, and carbon consumption rate.

A gas phase reaction model incorporating the full set of 28 elementary $\mathrm{C} / \mathrm{H} / \mathrm{O}$ reactions was developed. This model calculated the gas phase $\mathrm{CO}$ oxidation reaction in the boundary layer at particle temperatures of $1250 \mathrm{~K}$ and $2500 \mathrm{~K}$ by using the carbon consumption rate and the burning temperature at the pseudo-steady state calculated from the temperature profile model, but the transient heating was not included. This gas phase model can predict the gas species and the temperature distributions in the boundary layer, the $\mathrm{CO}_{2} / \mathrm{CO}$ ratio, and the location of $\mathrm{CO}$ oxidation.

These models were applied to the ignition temperature profile and the $\mathrm{CO}_{2} / \mathrm{CO}$ ratio obtained by Tognotti (Tognotti et al., 1990) in an electrodynamic balance for $180 \mu \mathrm{m}$ Spherocarb particles and to the combustion rate data measured by Tullin (Tullin et al., 1993) in a fluidized bed combustor for $4 \mathrm{~mm}$ Newlands char particles.

The temperature profile model reproduced the experimental measurement of Spherocarb combustion temperatures in an electrodynamic balance, including the dependence of particle ignition on the oxygen partial pressure. Increasing the oxygen partial pressure reduces the combustion time and increases the maximum temperature. The internal diffusion limitation could be treated by using macropore surface area. The particle diameter does not have a large impact on the maximum temperature rise, but has a considerable effect on the combustion time. The addition of mineral catalyst promotes heterogeneous $\mathrm{CO}_{2}$ formation and raises the particle temperature.

A gas phase reaction model was used to calculate the $\mathrm{CO}_{2} / \mathrm{CO}$ ratio measured by Tognotti. Different water vapor concentrations at low and high particle surface temperatures $(1250 \mathrm{~K}$ and $2500 \mathrm{~K})$ were used to see the effect of hydrogen containing species on CO oxidation in the gas phase. The particle diameter was $180 \mu \mathrm{m}$. The bulk gas was a mixture of $100 \%$ oxygen and water vapor.

At a temperature of $1250 \mathrm{~K}$, there was no significant $\mathrm{CO}$ oxidation in the gas phase even with $3.5 \%$ water vapor due to the small size of the particle and the steep temperature gradient. Estimates of gas phase reaction in the macropore could not account for the high $\mathrm{CO}_{2} / \mathrm{CO}$ ratio indicating that the presence of water vapor may enhance the rate of heterogeneous oxidation of $\mathrm{CO}$.

At a high temperature of $2500 \mathrm{~K}$, without hydrogen containing molecules the gas phase oxidation of $\mathrm{CO}$ is negligible. The effect of the hydrogen containing component on
\end{abstract}


the $\mathrm{CO}$ oxidation was significant. Spherocarb particles have $0.74 \%$ of ' $\mathrm{H}$ ' internally. This internal hydrogen source was enough to explain the observed $\mathrm{CO}_{2} / \mathrm{CO}$ ratio.

A mechanistic heat and mass transfer model was added to the temperature profile model to predict combustion behavior in a fluidized bed. A half order intrinsic reaction, and the activation energy of $20 \mathrm{kcal} / \mathrm{mol}$ were found to be appropriate to represent the experimental measurement of char combustion in a fluidized bed at temperatures of 1023$1123 \mathrm{~K}$, and the oxygen partial pressures of $2-20 \%$. The initial temperature rise is approximately proportional to the oxygen partial pressure and influenced by the bed particle size and the operating conditions.

The gas phase reaction of a single char in a fluidized bed was modeled. Due to the heat of $\mathrm{CO}$ oxidation, gas phase ignition occurs for particle with sizes bigger than $1 \mathrm{~mm}$. The difference between the maximum gas temperature and the particle temperature is up to $60-70 \mathrm{~K}$ depending the particle size. This gas phase ignition will be terminated only if the particle diameter decreases below a critical diameter. At $1 \mathrm{~mm}$ particle size, the temperature overshoot decreases to several degrees. The extinction diameter is between $1.0 \mathrm{~mm}$ and 0.5 $\mathrm{mm}$. The surrounding gas temperature has a significant effect on the gas phase ignition.

The models proved to be powerful tools for achieving more detailed understanding of char particle combustions and $\mathrm{CO}$ oxidation in the gas phase boundary layer.

Thesis advisors:

Professor Adel F. Sarofim

Title: Professor of Chemical Engineering

Professor John P. Longwell

Title: Professor of Chemical Engineering 


\section{Acknowledgements}

I would like to thank Professor Sarofim for all the guidance of the study and the encouragement when I was frustrated. I thank Professor Longwell for his invaluable advises and consistent interests. Without their help, this thesis would never have been completed. I also want to thank my thesis committee members, Professor Howard, Professor Beer, and Professor Levendis for their suggestions and helpful criticisms during the course of this study.

I am happy to write this statement, not because I will get a Ph.D. but because I overcame all the troubles and won a battle with myself. I had lost two of my good friends during my study here in Boston. I'll always remember Sun-Jae who shared many hard times during the first one and half years in MIT and Seung-Joon for his philosophy. It was really hard to do a Ph.D. with a backpain which had bothered me during last three years. I got a lot of help from many Korean friends in Boston. I am afraid to miss somebody, so let me thank all of you now. Let me also thank Mr. Modestino and Professor Bar-ziv for setting up the EDB, although I didn't get any results out of it. I will remember all my fellow students who shared the thoughts and discussions during my stay in MIT. I would like to thank Dr. Hindmarsh and Dr. Rupley for the DASSL and CHEMKIN software.

The financial supports from the Department of Energy and Hitachi Corporation are gratefully acknowledged.

Above all, let me thank you my father and mother who always worried about my health and showed me such a deep affection. I also thank Joon-Kyu and his family, and my wife's family for giving me the emotional supports. I like to thank my loving wife, Sanghee, who did the hard work instead of me and gave me a smile by giving me a son, Jongsuh. 


\section{Table of Contents}

Title Page

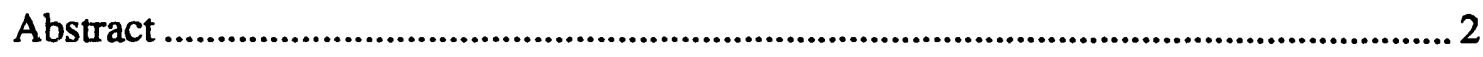

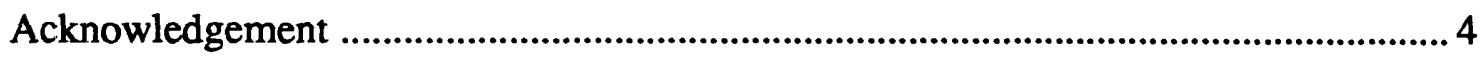

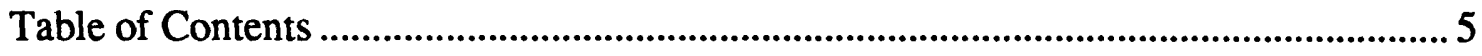

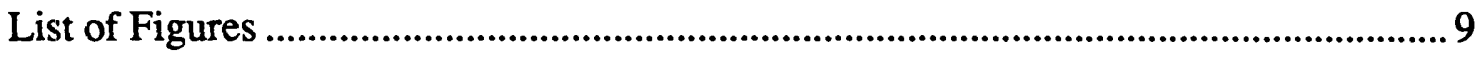

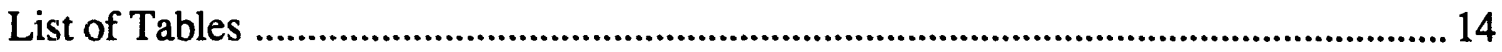

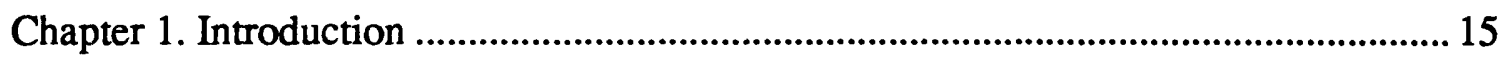

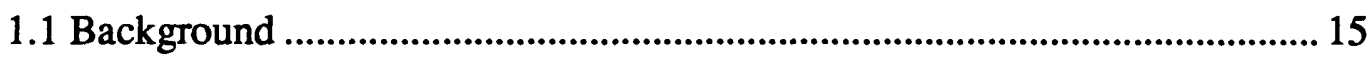

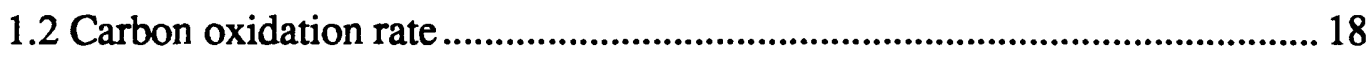

$1.3 \mathrm{CO} / \mathrm{CO}$ ratio

1.4 Apparatus and material for a single char combustion ..................................... 23

1.4.1 Electrodynamic balance .................................................................... 23

1.4.2 Fluidized bed combustion .................................................................. 25

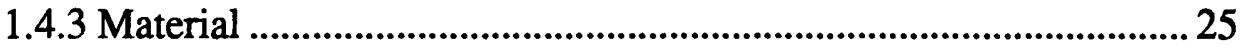

Chapter 2. Modeling of a Temperature Profile during a Char Combustion .................... 27

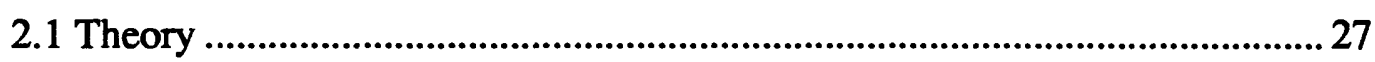

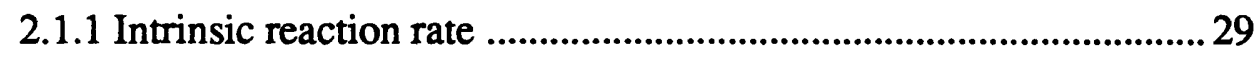

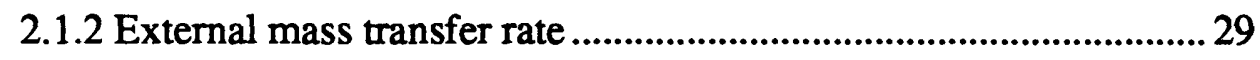

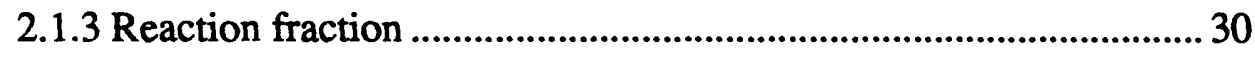

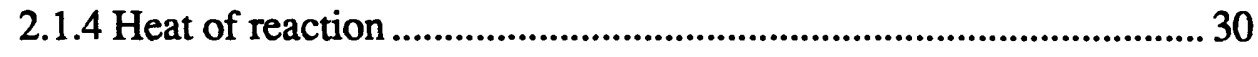

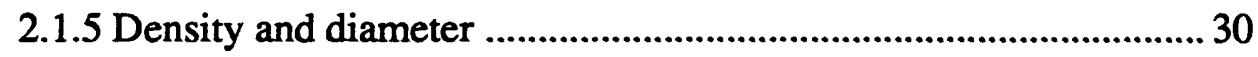

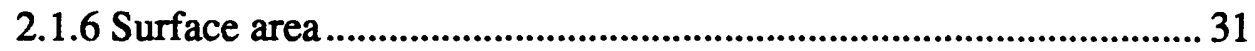

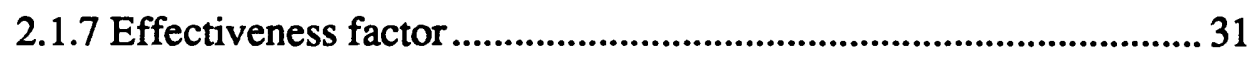




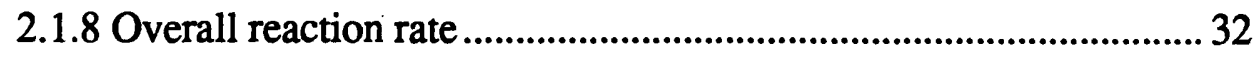

2.1.9 Convective heat transfer coefficient ............................................... 32

2.1.10 Emissivity, absorption efficiency, and heating flux...................... 33

2.2 Negligible internal diffusion limitation case.................................................. 34

2.2.1 Effects of oxygen pressure on temperature profile .......................... 37

2.2.2 Effects of particle diameter .............................................................. 38

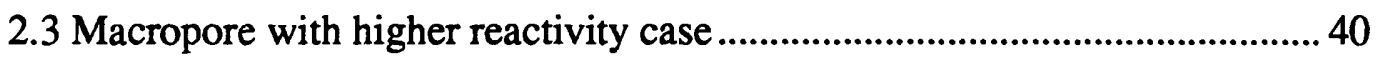

2.4 Effects of mineral catalyst................................................................................. 43

Chapter 3. Combustion and Temperature Profile in the Fluidized Bed Reactor ............. 46

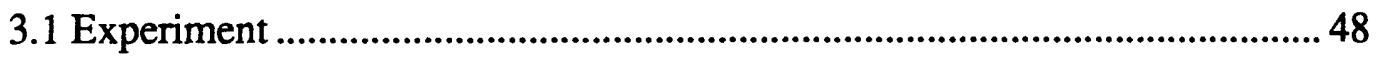

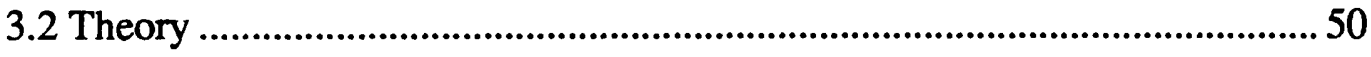

3.2.1 Heat and mass transfer model .......................................................... 50

3.2.2 Temperature gradient inside particle ................................................ 54

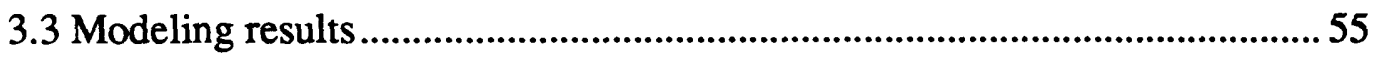

3.3.1 Burning time, and intrinsic reaction kinetic parameters (using

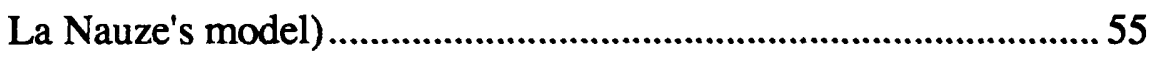

3.3.2 Temperature profile and excess temperature (using Agarwal's

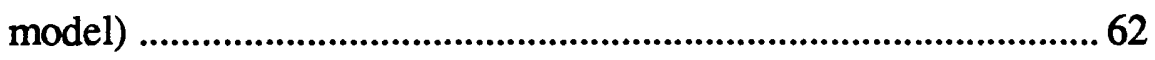

3.3.3 Effects of fluidized bed conditions ................................................... 70

Chapter 4. Modeling of CO Oxidation in the Gas Phase .................................................... 73

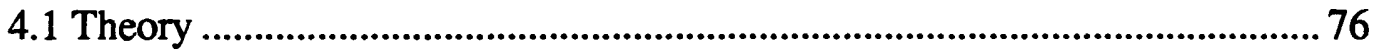

4.1.1 Governing equations ......................................................................... 76

4.1.2 Galerkin finite elements method ...................................................... 78

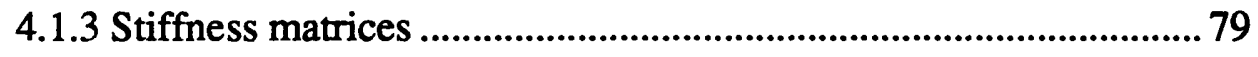

4.1.4 Diffusion velocity .......................................................................... 82 


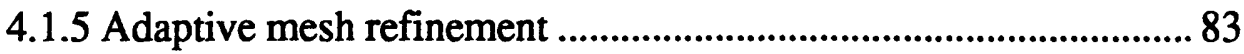

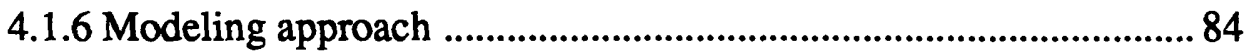

4.2 Experimental measurement of $\mathrm{CO} 2 / \mathrm{CO}$.......................................................... 86

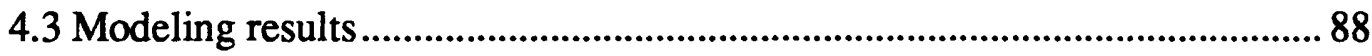

4.3.1 Elementary gas phase reaction mechanism...................................... 88

4.3.2 Low surrounding gas temperature with water vapor ...................... 89

4.3.3 High surrounding gas temperature without water vapor.................. 93

4.3.4 High surrounding gas temperature with water vapor ....................... 96

4.3.5 High surrounding gas temperature with internal ' $\mathrm{H}$ ' ....................... 101

4.3.6 Time scale of gas phase diffusion and reaction ............................... 104

4.3.7 Location of CO oxidation .............................................................. 105

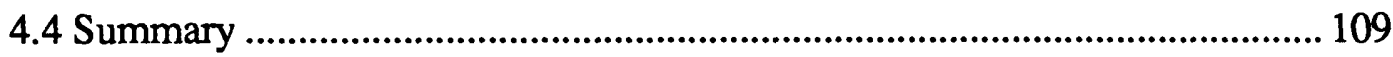

Chapter 5. CO Oxidation in the Fluidized Bed ................................................................. 111

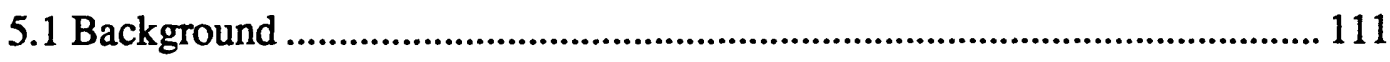

5.2 Experimental measurement of $\mathrm{CO} 2 / \mathrm{CO}$ ratio ................................................. 114

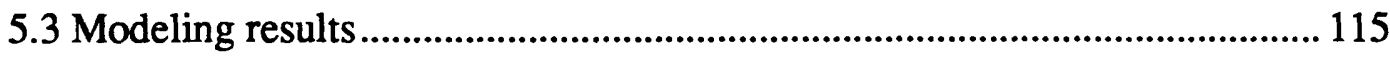

5.3.1 A 4mm particle with 3.5\% water vapor ........................................... 115

5.3.2 A 4mm particle without water vapor ............................................... 117

5.3.3 A 3mm particle with water vapor .................................................... 120

5.3.4 Particle size of $1 \mathrm{~mm}, 0.5 \mathrm{~mm}, 0.25 \mathrm{~mm}$ with water vapor ............ 122

5.3.5 Effects of lower bulk gas temperature ............................................. 127

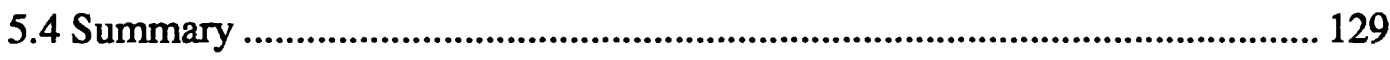

Chapter 6. Summary, Conclusion, and Recommendation .............................................. 130

6.1 A temperature profile model and a gas phase model ..................................... 130 
6.2 Temperature profile of a single char combustion in an electrodynamic balance

6.3 Modeling of $\mathrm{CO}$ oxidation in the gas phase in an electrodynamic balance

6.4 Combustion and temperature profile in a fluidized bed reactor 134

6.5 $\mathrm{CO}$ oxidation in the gas phase in a fluidized bed reactor. 135

6.6 Recommendations 136

Appendices 137

A.1 Program for the temperature profile model ................................................... 137

A.2 Program for the temperature profile in the fluidized bed................................ 141

A.3 Program for the gas phase model .............................................................. 149

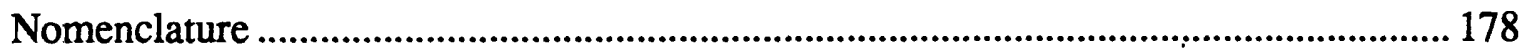

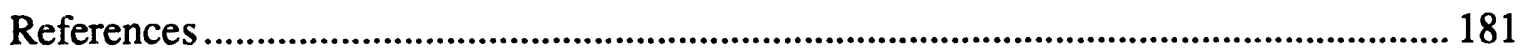




\section{List of Figures}

Fig.1.1 An overview of electrodynamic balance

Fig.2.1 Particle temperature as a function of time for $100 \%$ oxygen under ignition condition. 28

Fig.2.2 Temperature as a function of time ( Laser turned off at 1300K. 1st order intrinsic reaction. Particle diameter is $180 \mathrm{~mm}$. Effectiveness factor is one. $100 \%$ oxygen)

Fig.2.3 Overall reaction rate versus surface temperature ( Laser turned off at $1300 \mathrm{~K} .1 \mathrm{st}$ order intrinsic reaction. Particle diameter is $180 \mathrm{~mm}$. Effectiveness factor is one. $100 \%$ oxygen)

Fig.2.4 Effects of oxygen partial pressure on temperature profile ( Laser turned off at $1300 \mathrm{~K} .1 \mathrm{st}$ order intrinsic reaction. Particle diameter is $180 \mathrm{~mm}$. Effectiveness factor is one.)

Fig.2.5 Effects of particle diameter on temperature profile ( Laser turned off at 1300K.1st order intrinsic reaction. Effectiveness factor is one. $100 \%$ oxygen).

Fig.2.6 Cumulative pore size distribution on volume basis (dashed line) and on surface basis (solid line), (after d'Amore et. al)

Fig.2.7 Temperature profile using macropore with higher reactivity (Laser turned off at $1350 \mathrm{~K} .1$ st order intrinsic reaction. $100 \%$ oxygen)

Fig.2.8 Effects of Ca on temperature profile (Laser turned off at 1350K.1st order intrinsic reaction. Particle diameter is $180 \mathrm{~mm}$. $100 \%$ oxygen.)

Fig.2.9 Effects of oxygen partial pressure on temperature profile (with Ca) ( Laser turned off at $1350 \mathrm{~K} .1$ st order intrinsic reaction. Particle diameter is $180 \mathrm{~mm}$.)

Fig.3.1 Fluidized bed reactor 
Fig.3.2 Mass transfer of oxygen to the surface of a large particle 50

Fig.3.3 Particle motion in the fluidized bed 52

Fig.3.4 Temperature profile and conversion curve ( $8 \%$ oxygen partial pressure, 1st order intrinsic reaction, surrounding gas temperature of $1023 \mathrm{~K}$, diameter $=4 \mathrm{~mm}$ )

Fig.3.5 Conversion curves at different oxygen partial pressure (First order intrinsic reaction, $\mathrm{Tg}=1023 \mathrm{~K}, \mathrm{dp}=4 \mathrm{~mm}$ )

Fig.3.6 Conversion curves at different oxygen partial pressure (First order intrinsic reaction, $\mathrm{Ea}=33 \mathrm{kcal}, \mathrm{Tg}=1023 \mathrm{~K}, \mathrm{dp}=4 \mathrm{~mm}$ )

Fig.3.7 Conversion curves at different oxygen partial pressure (First order intrinsic reaction, $\mathrm{Ea}=20 \mathrm{kcal}, \mathrm{Tg}=1023 \mathrm{~K}, \mathrm{dp}=4 \mathrm{~mm}$ )

Fig.3.8 Conversion curves at different oxygen partial pressure (Zero order intrinsic reaction, $\mathrm{Ea}=20 \mathrm{kcal}, \mathrm{Ao}=4.8 * 10-4, \mathrm{Tg}=1073 \mathrm{~K}, \mathrm{dp}=4 \mathrm{~mm}$ )

Fig.3.9 Conversion curves at different oxygen partial pressure (Half order intrinsic reaction, $\mathrm{Ea}=20 \mathrm{kcal}, \mathrm{Ao}=0.35, \mathrm{Tg}=1073 \mathrm{~K}, \mathrm{dp}=4 \mathrm{~mm}$ )

Fig.3.10 Mean heat transfer coefficient and components of heat transfer coefficients in the fluidized bed (Half order intrinsic reaction, $\mathrm{P} \mathrm{O} 2=8 \%$, $\mathrm{Tg}=1073 \mathrm{~K}, \mathrm{dp}=4 \mathrm{~mm}$ )

Fig.3.11 Sherwood and Nusselt number in the fluidized bed (Half order intrinsic reaction, $\mathrm{P} \mathrm{O} 2=8 \%, \mathrm{Tg}=1073 \mathrm{~K}, \mathrm{dp}=4 \mathrm{~mm}$ ).

Fig.3.12 Conversion curves at different oxygen partial pressure (Half order intrinsic reaction, $\mathrm{Ea}=20 \mathrm{kcal}, \mathrm{Ao}=0.39, \mathrm{Tg}=1073 \mathrm{~K}, \mathrm{dp}=4 \mathrm{~mm}$ ).

Fig.3.13 Conversion curves at different oxygen partial pressure (Half order intrinsic reaction, $\mathrm{Ea}=20 \mathrm{kcal}, \mathrm{Ao}=0.39, \mathrm{Tg}=1123 \mathrm{~K}, \mathrm{dp}=4 \mathrm{~mm}$ )

Fig.3.14 Conversion curves at different oxygen partial pressure (Half order intrinsic reaction, $\mathrm{Ea}=20 \mathrm{kcal}, \mathrm{Ao}=0.39, \mathrm{Tg}=1023 \mathrm{~K}, \mathrm{dp}=4 \mathrm{~mm}$ ) 
Fig.3.15 Temperature profiles of different oxygen partial pressures (Half order intrinsic reaction, $\mathrm{Ea}=20 \mathrm{kcal}, \mathrm{Ao}=0.39, \mathrm{Tg}=1073 \mathrm{~K}, \mathrm{dp}=4 \mathrm{~mm}$ )

Fig.3.16 Excess temperature as a function of surrounding gas temperature with different oxygen partial pressures

Fig.3.17 Excess temperature vs. particle diameter $(\mathrm{Tg}=1073 \mathrm{~K})$.................................. 70

Fig.3.18 Excess temperature vs. superficial velocity $(\mathrm{d}=4 \mathrm{~mm}, 1073 \mathrm{~K}, 8 \% \mathrm{O} 2) \ldots \ldots \ldots . . .72$

Fig.4.1 Linear basis functions ....................................................................................... 79

Fig.4.2 Schematic diagram of modeling approach ......................................................... 85

Fig.4.3 $\mathrm{CO} 2 / \mathrm{CO}$ ratio as a function of inverse temperature for $100 \%$ oxygen for

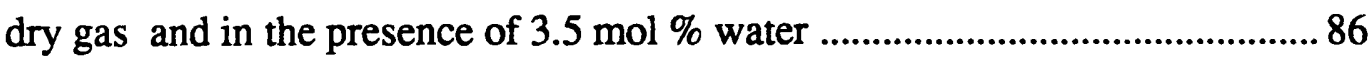

Fig.4.4 Temperature and mass fraction distribution $\left(T_{p}=1250 \mathrm{~K}, \mathrm{rc}=0.005 \mathrm{gC} / \mathrm{cm} 2 \mathrm{~s}\right.$,

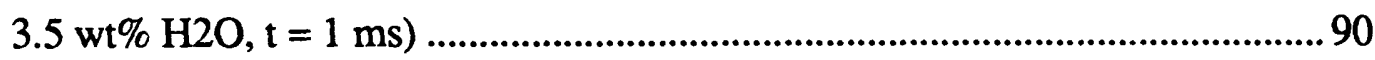

Fig.4.5 $\mathrm{CO} 2$ and $\mathrm{CO}$ mass fraction distribution as a function of time $(\mathrm{Tp}=1250 \mathrm{~K}$, $\mathrm{rc}=0.005 \mathrm{gC} / \mathrm{cm} 2 \mathrm{~s}, 3.5 \mathrm{wt} \% \mathrm{H} 2 \mathrm{O}$ )

Fig.4.6 CO2/CO ratio as a function of time $(\mathrm{Tp}=1250 \mathrm{~K}, \mathrm{rc}=0.005 \mathrm{gC} / \mathrm{cm} 2 \mathrm{~s}, 3.5$ wt\% H2O) 92

Fig.4.7 $\mathrm{CO} 2$ and $\mathrm{CO}$ mass fraction distribution as a function of time $(\mathrm{Tp}=2500 \mathrm{~K}$, $\mathrm{rc}=0.05 \mathrm{gC} / \mathrm{cm} 2 \mathrm{~s}, 100 \% \mathrm{O} 2$, no $\mathrm{H} 2 \mathrm{O}$ ). 94

Fig.4.8 CO2/CO ratio as a function of time $(\mathrm{Tp}=2500 \mathrm{~K}, \mathrm{rc}=0.05 \mathrm{gC} / \mathrm{cm} 2 \mathrm{~s}, 100 \%$ $\mathrm{O} 2$, no $\mathrm{H} 2 \mathrm{O}$ ). 95

Fig.4.9 $\mathrm{CO} 2$ and $\mathrm{CO}$ mass fraction distribution as a function of time $(\mathrm{Tp}=2500 \mathrm{~K}$, $\mathrm{rc}=0.05 \mathrm{gC} / \mathrm{cm} 2 \mathrm{~s}, \mathrm{O} 2$ with $3.5 \% \mathrm{H} 2 \mathrm{O}$ ).

Fig.4.10 Temperature distribution as a function of time $(\mathrm{Tp}=2500 \mathrm{~K}, \mathrm{rc}=$ $0.05 \mathrm{gC} / \mathrm{cm} 2 \mathrm{~s}, \mathrm{O} 2$ with $3.5 \% \mathrm{H} 2 \mathrm{O}$ ) 97

Fig.4.11 CO2/CO ratio as a function of time $(\mathrm{Tp}=2500 \mathrm{~K}, \mathrm{rc}=0.05 \mathrm{gC} / \mathrm{cm} 2 \mathrm{~s}, \mathrm{O} 2$ with $3.5 \% \mathrm{H} 2 \mathrm{O}$ ) 98 
Fig.4.12 Temperature and mass fraction distribution after $1 \mathrm{~ms}(\mathrm{Tp}=2500 \mathrm{~K}$, $\mathrm{rc}=0.05 \mathrm{gC} / \mathrm{cm} 2 \mathrm{~s}, \mathrm{O} 2$ with $3.5 \% \mathrm{H} 2 \mathrm{O}$ )

Fig.4.13 Mass fraction distributions including radicals after $1 \mathrm{~ms}(\mathrm{Tp}=2500 \mathrm{~K}$, $\mathrm{rc}=0.05 \mathrm{gC} / \mathrm{cm} 2 \mathrm{~s}, \mathrm{O} 2$ with $3.5 \% \mathrm{H} 2 \mathrm{O}$ )

Fig.4.14 Mass fractions of $\mathrm{CO}$ and $\mathrm{CO} 2$ as a function of time $(\mathrm{T} p=2500 \mathrm{~K}$, $\mathrm{rc}=0.05 \mathrm{gC} / \mathrm{cm} 2 \mathrm{~s}, \mathrm{O} 2$ with internal ' $\mathrm{H}$ ')

Fig.4.15 CO2/CO ratio as a function of time $(\mathrm{Tp}=2500 \mathrm{~K}, \mathrm{rc}=0.05 \mathrm{gC} / \mathrm{cm} 2 \mathrm{~s}, \mathrm{O} 2$ with internal ' $\mathrm{H}$ ')

Fig.4.16 Temperature and mass fraction distribution after $1 \mathrm{~ms}(\mathrm{~T} p=2500 \mathrm{~K}$, $\mathrm{rc}=0.05 \mathrm{gC} / \mathrm{cm} 2 \mathrm{~s}, \mathrm{O} 2$ with internal ' $\mathrm{H}$ ')

Fig.4.17 Mass fraction distributions including radicals after $1 \mathrm{~ms}(\mathrm{Tp}=2500 \mathrm{~K}$, $\mathrm{rc}=0.05 \mathrm{gC} / \mathrm{cm} 2 \mathrm{~s}, \mathrm{O} 2$ with internal ' $\mathrm{H}$ ')

Fig.4.18 CO2 production rate distribution $(\mathrm{Tp}=1250 \mathrm{~K}, \mathrm{rc}=0.005 \mathrm{gC} / \mathrm{cm} 2 \mathrm{~s}, 3.5$ wt\% $\mathrm{H} 2 \mathrm{O}$ ) 106

Fig.4.19 $\mathrm{CO} 2$ production rate distribution $(\mathrm{Tp}=2500 \mathrm{~K}, \mathrm{rc}=0.05 \mathrm{gC} / \mathrm{cm} 2 \mathrm{~s}, 100 \%$ $\mathrm{O} 2$, no $\mathrm{H} 2 \mathrm{O}$ ) 107

Fig.5.1 Experimental measurement of $\mathrm{CO} / \mathrm{CO} 2$ ratio as a function of conversion (1073 K, 4mm particle).

Fig.5.2 Temperature profile as a function of time $(\mathrm{do}=4 \mathrm{~mm}, 20 \% \mathrm{P} \mathrm{O}, 3.5 \%$ $\mathrm{H} 2 \mathrm{O}, \mathrm{rc}=2.2 \mathrm{e}-4 \mathrm{gC} / \mathrm{cm} 2 \mathrm{~s}$ )

Fig.5.3 Temperature and Mass fraction distributions after $5.6 \mathrm{~ms}(\mathrm{do}=4 \mathrm{~mm}, 20 \%$ $\mathrm{P} \mathrm{O} 2, \mathrm{rc}=2.2 \mathrm{e}-4 \mathrm{gC} / \mathrm{cm} 2 \mathrm{~s})$.

Fig.5.4 Temperature profile as a function of time $(\mathrm{do}=4 \mathrm{~mm}, 20 \% \mathrm{P} \mathrm{O} 2$, no $\mathrm{H} 2 \mathrm{O}$, $\mathrm{rc}=2.2 \mathrm{e}-4 \mathrm{gC} / \mathrm{cm} 2 \mathrm{~s})$.

Fig.5.5 CO2/CO ratio as a function of time $(\mathrm{do}=4 \mathrm{~mm}, 20 \% \mathrm{P} \mathrm{O2,} \mathrm{no} \mathrm{H} 2 \mathrm{O}$, $\mathrm{rc}=2.2 \mathrm{e}-4 \mathrm{gC} / \mathrm{cm} 2 \mathrm{~s})$. 
Fig.5.6 Temperature as a function of time $(\mathrm{do}=3 \mathrm{~mm}, 20 \% \mathrm{P} \mathrm{O2,} 3.5 \% \mathrm{H} 2 \mathrm{O}$,

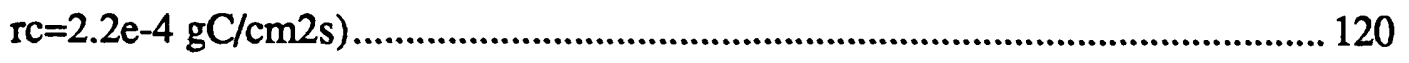

Fig.5.7 $\mathrm{CO} 2 / \mathrm{CO}$ ratio and $\mathrm{CO} / \mathrm{CO} 2$ ratio at a distance of $0.2 \mathrm{~cm}$ from surface as a function of time (do=3 mm, $20 \% \mathrm{O}, 3.5 \% \mathrm{H} 2 \mathrm{O})$

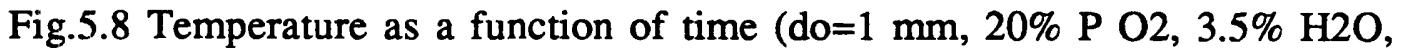
$\mathrm{rc}=2.2 \mathrm{e}-4 \mathrm{gC} / \mathrm{cm} 2 \mathrm{~s})$

Fig.5.9 $\mathrm{CO} 2 / \mathrm{CO}$ ratio as a function of time $(\mathrm{do}=1 \mathrm{~mm}, 20 \% \mathrm{O} 2,3.5 \% \mathrm{H} 2 \mathrm{O})$ 124

Fig.5.10 Temperature as a function of time $(\mathrm{do}=0.5 \mathrm{~mm}, 20 \% \mathrm{P} \mathrm{O}, 3.5 \% \mathrm{H} 2 \mathrm{O}$, $\mathrm{rc}=2.2 \mathrm{e}-4 \mathrm{gC} / \mathrm{cm} 2 \mathrm{~s})$

Fig.5.11 CO2/CO ratio as a function of time at a distance of $0.5 \mathrm{~mm}$ from the surface $(\mathrm{do}=0.5 \mathrm{~mm}, 20 \% \mathrm{O}, 3.5 \% \mathrm{H} 2 \mathrm{O})$.

Fig.5.12 Temperature as a function of time $(\mathrm{do}=0.25 \mathrm{~mm}, 20 \% \mathrm{P} \mathrm{O}, 3.5 \% \mathrm{H} 2 \mathrm{O}$, $\mathrm{rc}=2.2 \mathrm{e}-4 \mathrm{gC} / \mathrm{cm} 2 \mathrm{~s})$.

Fig.5.13 Temperature as a function of time $(\mathrm{do}=3 \mathrm{~mm}, 20 \% \mathrm{P} \mathrm{O}, 3.5 \% \mathrm{H} 2 \mathrm{O}$, $\mathrm{rc}=0.74 \mathrm{e}-4 \mathrm{gC} / \mathrm{cm} 2 \mathrm{~s}, \mathrm{Tg}=873 \mathrm{~K}$ ) 128 


\section{List of Tables}

Table 1.1 Summary of intrinsic reaction activation energy ...................................... 18

Table 1.2 Summary of $\mathrm{CO} 2 / \mathrm{CO}$ ratio of heterogeneous reaction ................................ 20

Table 4.1 Reaction mechanism rate coefficients (units are mole/cm3, sec, $\mathrm{K}$,

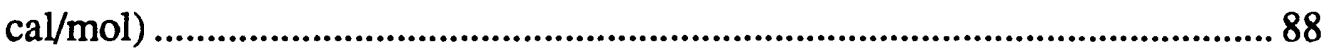

Table 4.2 Summary of modeling results (100\% oxygen partial pressure) .................... 109 


\section{Chapter 1}

\section{Introduction}

\subsection{Background}

Coal combustion is composed of two major steps. First, coal particles are heated by an external heating source, which is usually recirculated hot surrounding reactive gas. During the heating of the coal, the volatile matter in coal evolves and reacts first with the gas often forming a volatile flame. Usually, the volatile combustion is short in duration compared to that of the char combustion. The resultant coal char reacts in the flame at temperatures between $1000-2500 \mathrm{~K}$. The main focus of this thesis is the combustion behavior of the char and the gas phase reaction near the particle surface.

The high temperature oxidation of a char is of interest in a number of applications in which coal must be burned in confined spaces. These include: the development of a new generation of pulverized-coal-fired cyclone burners, the injection of coal into the tuyeres of blast furnaces, the use of coal as a fuel in direct-fired gas turbines and in largebore low-speed diesels, the development of efficient fluidized beds, and entrained flow gasifiers. 
There is a need to understand the temperature history of char particles in conventional pulverized-coal-fired boilers to better explain the processes governing the formation of pollutants and the transformation of mineral matter. Also, the burning temperature of a carbonaceous particle in the fluidized bed is important, because the particle temperature is an important factor not only for the operation of a fluidized bed but also for assessing formation of pollutants such as NOx and SOx. The adhesive behavior of ash is also highly sensitive to the particle temperature.

The burning temperature of a char particle is the product of a strongly coupled balance between particle size and physical properties, heat transfer, surface reactivity, $\mathrm{CO}_{2} / \mathrm{CO}$ ratio, and gas phase diffusion in the surrounding boundary layer and within the particle. The particle temperature has major effects not only on char burning rate, but also on ash properties and mineral matter vaporization. Measurements of the temperature of individual burning char particles have become available in recent years and have clearly demonstrated large particle-to-particle temperature variations which depend strongly on particle size and on surrounding gas composition.

The $\mathrm{CO}_{2} / \mathrm{CO}$ ratio has a major impact on observed particle temperatures. It has generally been assumed that $\mathrm{CO}$ is the only product of the carbon-oxygen reaction and that $\mathrm{CO}_{2}$ is formed by subsequent gas phase reaction. Recently, it has been found that $\mathrm{CO}$ and $\mathrm{CO}_{2}$ are both the primary products of the heterogeneous reaction. $\mathrm{CO}$ is further oxidized to $\mathrm{CO}_{2}$ in the gas phase. It is necessary to take $\mathrm{CO}_{2}$ production into consideration in order to account for observed particle temperatures. The importance of the $\mathrm{CO}_{2} / \mathrm{CO}$ ratio is illustrated by examination of the heats of reaction for formation of these two products:

$$
\begin{array}{ll}
\mathrm{C}+1 / 2 \mathrm{O}_{2}=\mathrm{CO} & \Delta \mathrm{H}_{\mathrm{f}}=27.2 \mathrm{kcal} / \mathrm{mol} \\
\mathrm{C}+\mathrm{O}_{2}=\mathrm{CO}_{2} & \Delta \mathrm{H}_{\mathrm{f}}=94 \mathrm{kcal} / \mathrm{mol}
\end{array}
$$


The heat released by the formation of $\mathrm{CO}_{2}$ is a factor of 3.5 higher than that of $\mathrm{CO}$, so the temperature of a particle will depend strongly on the $\mathrm{CO} / \mathrm{CO}_{2}$ ratio produced. If gas diffusion through the boundary layer is fast, the increased direct production of $\mathrm{CO}_{2}$ produces a higher temperature and a higher burning rate.

$$
\mathrm{CO}+1 / 2 \mathrm{O}_{2}=\mathrm{CO}_{2} \quad \Delta \mathrm{H}_{\mathrm{f}}=66.8 \mathrm{kcal} / \mathrm{mol}
$$

The $\mathrm{CO}$ oxidation via subsequent homogeneous reaction has significant effects on the observed particle temperature. Because the heat of formation of $\mathrm{CO}_{2}$ from $\mathrm{CO}$ in the gas phase is more than 2.5 times that of $\mathrm{CO}$ generation from the heterogeneous reaction, it is important to know the amount of $\mathrm{CO}_{2}$ generation and the location of the reaction to assess the heat feedback. There are two possibilities of the location where the additional $\mathrm{CO}_{2}$ generation occurs: One is in the macro or meso pores inside the char particle, and the other is in the gas phase. By setting up a model which can predict the gas phase reaction, we can predict how much $\mathrm{CO}_{2}$ is produced from the homogeneous reaction and from the heterogeneous reaction, respectively. If the $\mathrm{CO}$ oxidation happens near the particle surface, the convective heat loss from the hot particle is affected and so is the particle temperature. 


\subsection{Carbon oxidation rate}

The carbon burning rate is controlled by relative rates of intrinsic reaction and pore diffusion. Measuring the burning rate of a coal or a char particle has been the subject of a number of studies.

[Table 1.1] Summary of intrinsic reaction activation energy

\begin{tabular}{|c|c|c|c|c|}
\hline Researchers & $\begin{array}{c}\text { Kind of } \\
\text { material used } \\
\end{array}$ & Temperature & $\begin{array}{c}\text { Activation } \\
\text { Energy }\end{array}$ & Comments \\
\hline Smith (1978) & $\begin{array}{c}\text { many carbonaceous } \\
\text { material } \\
\end{array}$ & $\begin{array}{l}\text { low and high } \\
\text { temperature }\end{array}$ & $\mathrm{E}_{\mathrm{a}}=43 \mathrm{kcal} / \mathrm{mol}$ & $\begin{array}{l}\text { significant } \\
\text { scatter } \\
\end{array}$ \\
\hline Tyler (1986) & petroleum coke & $\begin{array}{c}670-770 \mathrm{~K} \\
1200-2300 \mathrm{~K} \\
\end{array}$ & $\mathrm{E}_{\mathrm{a}}=38 \mathrm{kcal} / \mathrm{mol}$ & $\begin{array}{l}\text { low surface } \\
\text { area } \sim 1 \mathrm{~m}^{2} / \mathrm{g}\end{array}$ \\
\hline Floess (1988) & Spherocarb & $750-870 \mathrm{~K}$ & & $\begin{array}{c}\text { TGA, } \\
\text { 1st order }\end{array}$ \\
\hline $\begin{array}{l}\text { Waters } \\
\text { (1988) }\end{array}$ & Spherocarb & $700-2300 \mathrm{~K}$ & $\mathrm{E}_{\mathrm{a}}=42 \mathrm{kcal} / \mathrm{mol}$ & $\begin{array}{l}\text { entrained } \\
\text { flow } \\
\text { zero order }\end{array}$ \\
\hline Hurt (1987) & Spherocarb & $700-900 \mathrm{~K}$ & $\mathrm{E}_{\mathrm{a}}=36 \mathrm{kcal} / \mathrm{mol}$ & $21 \%$ oxygen \\
\hline $\begin{array}{l}\text { Tognotti } \\
\text { (1989) }\end{array}$ & Spherocarb & $700-1200 \mathrm{~K}$ & $\mathrm{E}_{\mathrm{a}}=33 \mathrm{kcal} / \mathrm{mol}$ & EDB \\
\hline
\end{tabular}

Tyler (Tyler,1986) has measured combustion rates for a low surface area petroleum coke at both high (1200 to $2300 \mathrm{~K}$ ) and low (670 to $770 \mathrm{~K})$ temperatures and has shown that the intrinsic kinetic rate inferred from both set of data may be represented 
by one line on an Arrhenius plot $\left(\mathrm{E}_{\mathrm{a}}=38 \mathrm{kcal} / \mathrm{mole}\right)$. Smith (Smith,1978) has correlated intrinsic combustion rates measured at low temperature and those calculated from high temperature data for many carbonaceous materials. But he reported that there exists a significant scattering in the reactivity among different carbons. Floess ( Floess et al.,1988) examined the intrinsic reactivity of Spherocarb at temperature from 750 to 870 $\mathrm{K}$ in air. They reported an oxygen reaction order of 1 . Waters (Waters et al., $1988 \mathrm{a}$ ) measured the intrinsic reaction rate at temperatures from 1300 to $2300 \mathrm{~K}$ in an entrainedflow reactor and they used data from the literature (Floess et al.,1988) to calculate the low temperature intrinsic reactivity. They assumed an oxygen reaction order of zero, and they calculated the intrinsic activation energy as $42 \mathrm{kcal} / \mathrm{mol}$. Hurt ( Hurt, 1987 ) measured in a thermo-gravimetric apparatus the intrinsic rate of Spherocarb and fitted the data by $3000 \mathrm{e}^{-18118 / \mathrm{T}}\left[\mathrm{gm} / \mathrm{sec}-\mathrm{m}^{2}\right]$ for an oxygen partial pressure of $0.21 \mathrm{~atm}$. The rate of Spherocarb oxidation measured in the electrodynamic balance by Tognotti ( Tognotti et al. ,1990) was found to be correlated by $1840 \mathrm{e}^{-16980 / \mathrm{T}}\left[\mathrm{gm} / \mathrm{sec}-\mathrm{m}^{2}\right.$ ] for pure oxygen.

There are many inorganic materials which have catalytic effect on carbon gasification reaction. The minerals like calcium and iron are abundant in many natural coals, and have been studied. Active catalysts include alkali metal oxides and salts and the alkaline earth oxides and salts. Dudek (Dudek, 1989) tested three different catalysts ( $\mathrm{Ca}, \mathrm{Fe}, \mathrm{K})$ on Spherocarb, and he observed catalyzed Spherocarb has a much faster

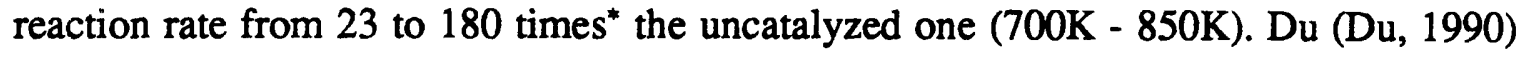
tested $2 \mathrm{wt} \%$ Ca catalyzed Spherocarb and found a 50 fold increase of reactivity around 763K. He revealed that the addition of $\mathrm{Ca}$ had little effect on the rate of $\mathrm{CO}$ formation and the increase of overall reactivity was primarily attributed to the increase in the rate of $\mathrm{CO}_{2}$ formation.

* Particle temperatures (700-800K) 


\section{$1.3 \mathrm{CO}_{2} / \mathrm{CO}$ ratio}

Due to the complexity of coal combustion reaction mechanisms, the primary products of heterogeneous reaction has been a subject of coal combustion for a long period of time. Because of the importance of the $\mathrm{CO} / \mathrm{CO}_{2}$ ratio on the particle burning temperature, and carbon consumption rate, there are many studies available on this subject. The experimental measurements of $\mathrm{CO}_{2} / \mathrm{CO}$ ratio are summarized in Table 1.1.

[Table 1.2] Summary of $\mathrm{CO}_{2} / \mathrm{CO}$ ratio of heterogeneous reaction

\begin{tabular}{|c|c|c|c|c|c|c|}
\hline $\begin{array}{c}\text { Researcher } \\
\mathrm{s}\end{array}$ & Material & $\begin{array}{c}\text { Experimental } \\
\text { Device }\end{array}$ & $\begin{array}{c}\text { Temperature } \\
(\mathrm{K})\end{array}$ & $\begin{array}{c}\mathrm{P} \mathrm{O}_{2} \\
(\mathrm{~atm})\end{array}$ & $\mathrm{E}_{\mathrm{a}} / \mathrm{R}$ & $\mathrm{n}$ \\
\hline \hline Tognotti & Spherocarb & $\begin{array}{c}\text { Electro- } \\
\text { dynamic } \\
\text { Balance }\end{array}$ & $670-1670$ & $\begin{array}{c}0.05 \\
0.20 \\
1.0\end{array}$ & $\begin{array}{c}2980 \\
3070 \\
3070\end{array}$ & 0.21 \\
\hline Otterbein & $\begin{array}{c}\text { Vitreous } \\
\text { Carbon }\end{array}$ & Flow system & $770-920$ & $0.025-0.15$ & 3000 & 0.18 \\
\hline Philips & Graphon & Static system & $800-950$ & $0.013 * 10^{-3}$ & 3200 & 0.22 \\
\hline Du & Soot & TGA & $670-890$ & $0.05-1.0$ & 3200 & 0.27 \\
\hline Arthur & $\begin{array}{c}\text { Natural } \\
\text { Graphite, } \\
\text { Coal char }\end{array}$ & Flow System & $730-1170$ & $0.05-0.25$ & 6240 & \\
\hline Rossberg & $\begin{array}{c}\text { Electrode } \\
\text { Carbons }\end{array}$ & Flow system & $790-1690$ & & 7200 & \\
\hline
\end{tabular}

$\mathrm{CO}_{2} / \mathrm{CO}=\mathrm{A} \exp \left(\mathrm{E}_{\mathrm{a}} / \mathrm{RT}\right), \mathrm{A}=\mathrm{A}_{\mathrm{o}} \mathrm{PO}_{2}{ }^{\mathrm{n}}$ 
$\mathrm{CO}$ has been believed to be the primary product of the heterogeneous reaction at temperatures exceeding $1500 \mathrm{~K}$ for a long time, and $\mathrm{CO}_{2}$ has been assumed to be formed by subsequent gas phase reactions. More recent work (Mitchell et al. 1990), however, has pointed out the need to take $\mathrm{CO}_{2}$ production at the surface into consideration for particle temperatures less than $1700 \mathrm{~K}$ in order to explain the observed particle temperature. Our measurements using an electrodynamic balance show that both $\mathrm{CO}$ and $\mathrm{CO}_{2}$ are formed by heterogeneous reactions. $\mathrm{CO}_{2} / \mathrm{CO}$ ratio showed an Arrhenius type dependence according with temperature variation and an activation energy of $5.9 \sim 6.1 \mathrm{kcal} / \mathrm{mol}$. The $\mathrm{CO}_{2} / \mathrm{CO}$ ratio decreases as the temperature increases. Oxygen concentration was varied and the $\mathrm{CO}_{2} / \mathrm{CO}$ ratio was found to increase with the 0.21 power of oxygen concentration. $\mathrm{Du}$ (Du et al.1990) studied oxidation of an uncatalyzed carbon and catalyzed carbon at different temperatures and several oxygen partial pressures. It was found that both $\mathrm{CO}$ and $\mathrm{CO}_{2}$ are primary products during carbon oxidation, but they are generated via different mechanisms. The separate examination of the $\mathrm{CO}$ and $\mathrm{CO}_{2}$ formation brought new insights about the carbon oxidation. $\mathrm{CO}$ formation involves the reaction at sites with a wide range of activation energies due to the complex structure of carbon. The rate of $\mathrm{CO}$ formation was found to be of fractional order with respect to the oxygen partial pressure, and to be insensitive to $\mathrm{Ca}$ catalysis. The rate of $\mathrm{CO}_{2}$ formation was found to be first order with respect to the oxygen partial pressure and can be effectively catalyzed by $\mathrm{Ca}$. The observed increase in $\mathrm{CO} / \mathrm{CO}_{2}$ ratio with reaction temperature increase can be explained by the activation energy difference between the rates of $\mathrm{CO}$ and $\mathrm{CO}_{2}$ formation. In general, the apparent activation energy for $\mathrm{CO}$ production is about $35 \mathrm{kcal} / \mathrm{mol}$ within the temperature range of $773-873 \mathrm{~K}$, but the activation energy of $\mathrm{CO}_{2}$ production was found to be $28.6 \mathrm{kcal} / \mathrm{mol}$. Since the $\mathrm{CO}$ production has a stronger dependence on temperature than that of $\mathrm{CO}_{2}$, the $\mathrm{CO} / \mathrm{CO}_{2}$ will increase as the reaction temperature rises. 
The $\mathrm{CO} / \mathrm{CO}_{2}$ ratios in a fluidized bed have not been studied as extensively as that of pulverized coal combustion. Basu (Basu et al., 1975) measured $\mathrm{CO} / \mathrm{CO}_{2}$ product ratio from a batch of anthracite coal particles burning in fluidized and fixed beds of sands at $1123 \mathrm{~K}$. A CO/CO 2 ration of 0.38 was reported. Prins ( Prins, 1987) studied $\mathrm{CO} / \mathrm{CO}_{2}$ ration of graphite particles. He found that $\mathrm{CO} / \mathrm{CO}_{2}$ ratio of 0.28 at $1110 \mathrm{~K}$ and 0.36 at 985K. The particle sizes in his experiments were $3 \mathrm{~mm}$ to $1.3 \mathrm{~cm}$, and the bed particle size was $669 \mu \mathrm{m}$. He also found that $\mathrm{CO}$ oxidation in the emulsion phase or in the free board is negligible. Both the investigators measured $\mathrm{CO}$ and $\mathrm{CO}_{2}$ content of effluent gas stream by an infrared analyzer. 


\subsection{Apparatus and material for a single char combustion}

\subsubsection{Electrodynamic balance}

The electrodynamic balance has been developed to study single particle kinetics since the early 80 's. The historical basis of this device is originated from the suspension techniques by Wilson(1903) and Millikan(1911). In MIT, Spjut (Spjut, 1985) and Dudek (Dudek,1989) have worked on the electrodynamic balance. A schematic view of an electrodynamic balance is presented in Fig.1.1. The electrodynamic balance has three electrodes, two end caps with DC providing an opposing electric force to gravity and an AC ring electrode. The combined DC-AC field creates a dynamic electric field which can hold a particle stably. A photo-diode array and 386 computer provide the position control system capable of $500 \mathrm{~Hz}$ sampling frequency. The $\mathrm{CO}_{2}$ laser beam is splitted and introduced from the both side of the chamber to minimize photophoretic effects. Temperature measurement and imaging are made through the side holes. A stainless steel enclosure can hold pressures up to $25 \mathrm{~atm}$.

The traditional devices such as conventional TGA's, laminar flow furnaces, or entrained flow reactors have limitations because they can measure only a group of particles and can not separate the heterogeneous reaction and the gas-phase reaction. The laser heating method of an electrodynamic balance has an advantage of heating only the particle itself. The rapid temperature gradient developing surrounding the particle prevent $\mathrm{CO}$ from undergoing further oxidation to $\mathrm{CO}_{2}$. Due to the rapid quenching ability of $\mathrm{CO}$ oxidation in the gas phase, the electrodynamic balance makes it possible to study a single particle gas-solid reaction kinetics. 


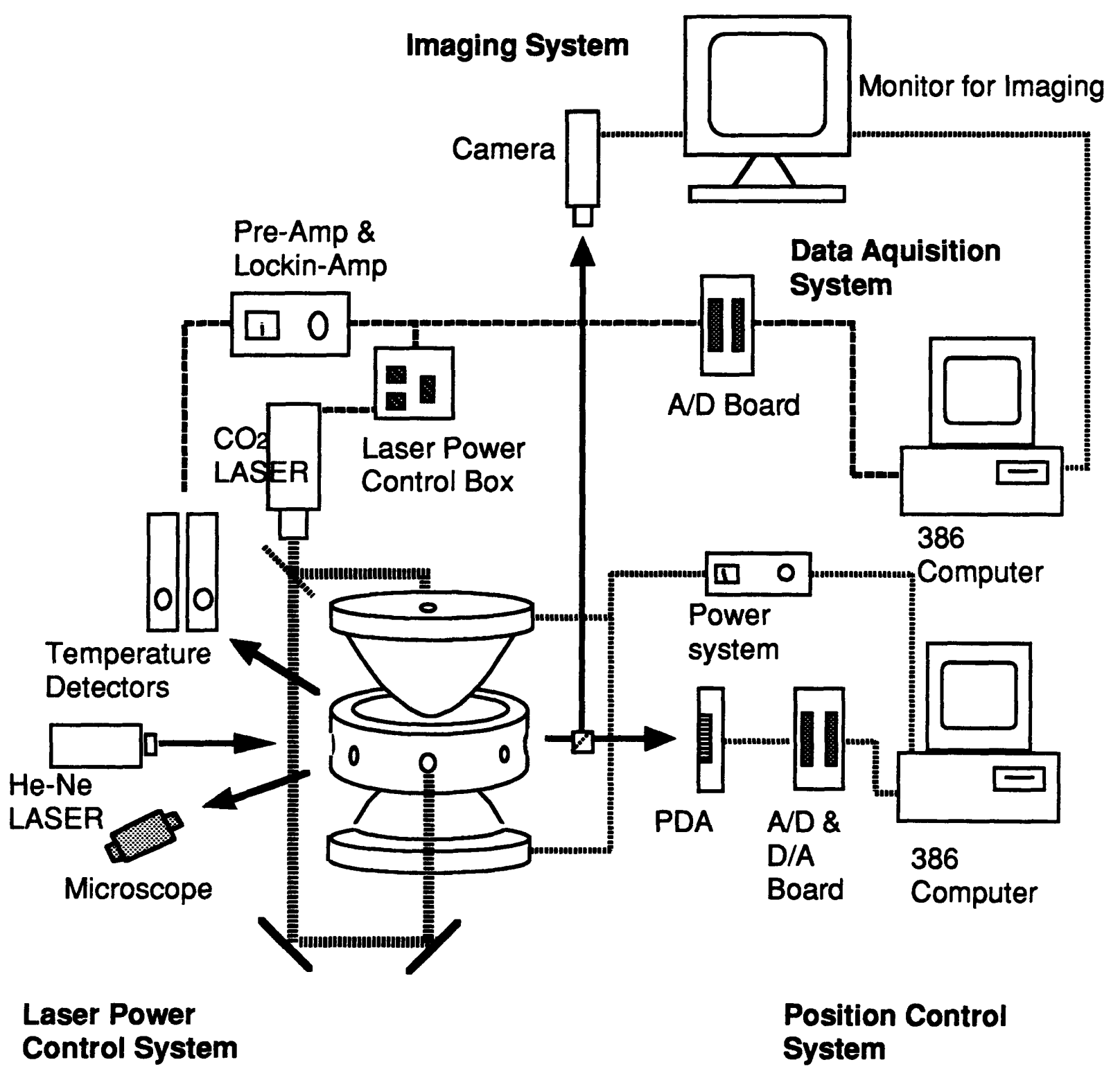

Fig.1.1 An overview of electrodynamic balance 


\subsubsection{Fluidized bed combustion}

Fluidized bed combustion is a relatively new technique for burning coal cleanly and efficiently. Coal particles constitute less than $5 \%$ of the whole bed material. The bed material is usually between $5 \times 10^{-4} \mathrm{~m}$ and $1 \times 10^{-3} \mathrm{~m}$ long and has a role of conducting heat to the heat exchanger tubes immersed in the bed and capturing $\mathrm{SO}_{2}$. The size of the coal particles feed in the fluidized bed combustion is normally between $1 \mathrm{~mm}$ and $1 \mathrm{~cm}$ for small scale combustor but may be up to $3 \mathrm{~cm}$ in large combustors (La Nauze, 1985). Typical operating conditions are a bed temperature of between $1023 \mathrm{~K}$ and $1223 \mathrm{~K}$ at fluidization velocities ranging from $40 \mathrm{~cm} / \mathrm{s}$ to $4 \mathrm{~m} / \mathrm{s}$ depending primarily on the size of the inert bed particle.

\subsubsection{Material}

Spherocarb is a synthetic char from Analab inc.. This char is believed to be the activated product of the pyrolysis of an organic binder and pore former. Its highly spherical nature has been photographed by using SEM. (Hurt, 1987, Waters, 1988) Due to its sphericity, uniformity, and low ash content, Spherocarb has been used as a model char in many previous studies (Dudek et al., 1988, Waters et al. 1988, Hurt et al., 1988). Spherocarb is a microporous char with macropore network, and its size is about 177-250 $\mu \mathrm{m}(60 / 80 \mathrm{mesh})$ with following properties.

Particle density

Helium density

BET surface area
$0.56-0.63 \mathrm{~g} / \mathrm{cm}^{3}$

$2.10-2.15 \mathrm{~g} / \mathrm{cm}^{3}$

$860-1000 \mathrm{~m}^{2} / \mathrm{g}$

Its ultimate analysis is : $96.84 \% \mathrm{C}, 0.73 \% \mathrm{H}, 2.43 \% \mathrm{O}, 760 \mathrm{PPM}$ ash.

A bituminous coal called Newlands coal was used for fluidized bed combustion experiments and it has following properties. Its proximate analysis is: $17.44 \%$ ash, 
$26.49 \%$ volatile matter, $56.07 \%$ fixed carbon, heating value of $6490 \mathrm{cal} / \mathrm{g}$ (with $2.44 \%$ $\mathrm{H} 2 \mathrm{O}$ ). Its ultimate analysis is $17.44 \%$ ash, $68.83 \%$ carbon, $4.38 \%$ hydrogen, $7.71 \%$ oxygen, $1.2 \%$ nitrogen, $0.54 \%$ sulfur. 


\section{Chapter 2}

\section{Modeling of a Temperature Profile during a Char Combustion}

\subsection{Theory}

The temperature history of carbon particle ignition is important for predicting carbon consumption rate, $\mathrm{CO} / \mathrm{CO} 2$ ratio, and burning time. Surrounding gas temperature, particle diameter, and oxygen partial pressure are important parameters affecting the temperature history. Calculated temperature profiles provide important information for the purpose of estimating pollutant formation or ash formation during the carbon oxidation reaction.

The results of Tognotti ( Tognotti, 1990) in Fig.2.1 show the particle temperature variation including heating, ignition, and extinction in the temperature range from 1000 to 2500K. Bar-ziv (Bar-ziv et al., 1989) also measured the ignition profile of the Spherocarb

particle. Jones (Jones, 1989) simulated the temperature profile of ignition assuming only heterogeneous reactions. Maloney (Maloney et al., 1990) measured temperature histories and modeled the temperature profiles below the ignition temperature. He assumed spherical particle, radial heat flux, incident absorption of heating flux, and uniform distribution of heating flux over the particle. 


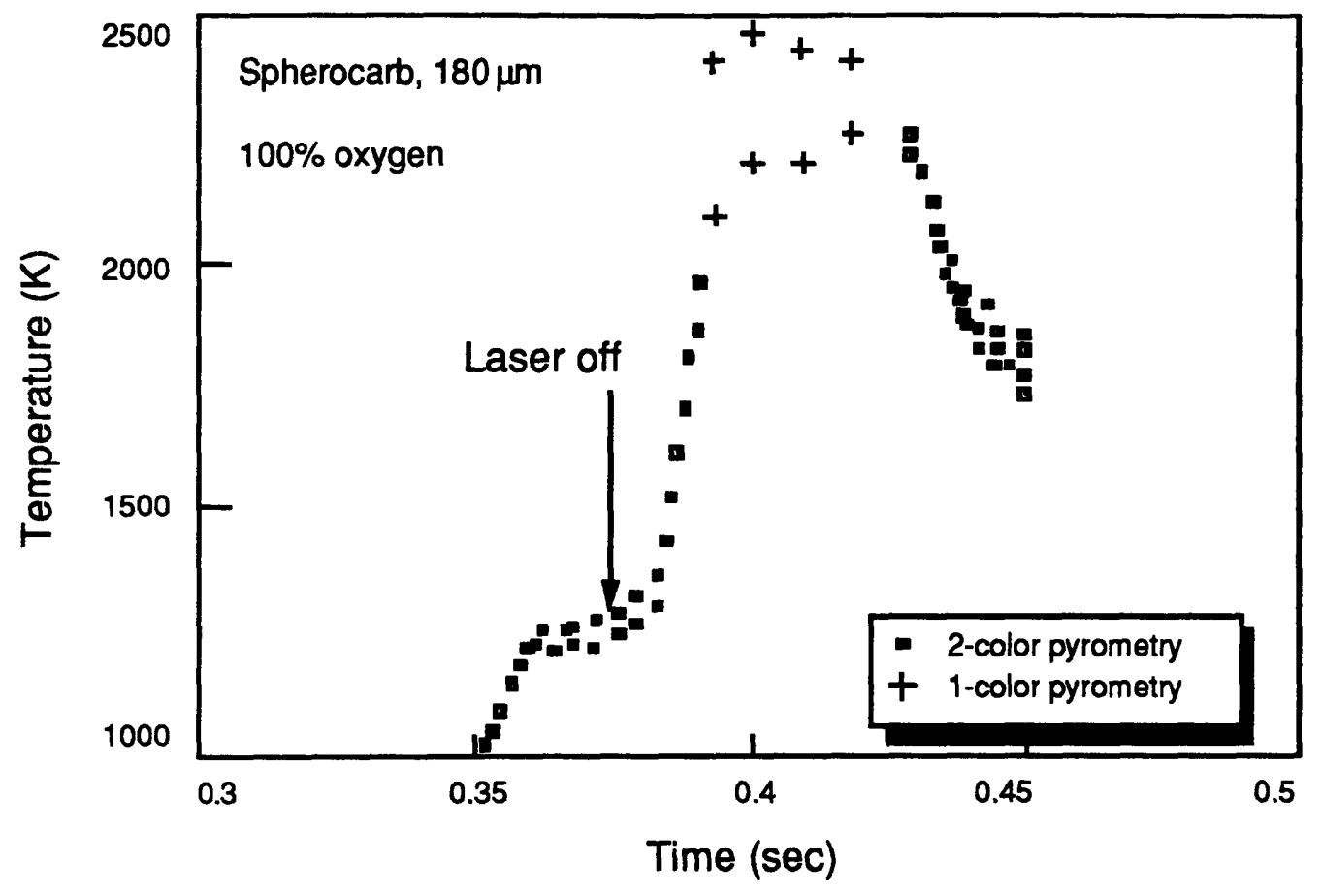

Fig.2.1 Particle temperature as a function of time for $100 \%$ oxygen under ignition condition.

Our objective is to develop a model to reproduce the major features in the experimental results. The assumptions made in the model are: (1) uniform temperature inside the particle, (2) constant ambient gas temperature, (3) power law relationship between density and diameter. These assumptions enable us to use a simple lumped parameter model. Heat or mass transfer due to gas phase reaction adjacent to the solid-gas interface are not considered for this model. The main energy balance is

$$
m C_{p} \frac{d T_{p}}{d t}=Q_{a b s}{ }^{A} c^{I}+r_{c^{(}}(-\Delta H) A-h A\left(T_{p}-T_{m}\right)-\sigma \varepsilon A\left(T_{p}^{4}-T_{g}^{4}\right)
$$

The left hand side represents the temperature change of the particle as the time changes. The first and second terms of the right hand side represent the heat gain from the laser and reaction respectively, and third and fourth terms represent heat loss via convective 
and radiative heat transfer. The following sections include the theories and the equations for each of the parameters and variables.

\subsubsection{Intrinsic reaction rate}

The intrinsic reaction rate $\left[\mathrm{gC} / \mathrm{cm}^{2} \mathrm{~s}\right]$ has been measured by many researchers, but the differences between the data are large. Furthermore the order of the reaction is uncertain. We will assume here first order reaction kinetics, because first order intrinsic reaction order has been shown to be a good choice for the Spherocarb combustion Hurt, 1987).

$$
\begin{aligned}
\mathrm{r}_{\mathrm{s}} & =\mathrm{k}_{\mathrm{s}}^{\prime} \mathrm{C}_{\mathrm{s}} \chi \\
& =\mathrm{k}_{\mathrm{s}} \mathrm{P}_{\mathrm{s}}
\end{aligned}
$$

where $\chi$ represents grams of carbon consumed per mole of $\mathrm{O}_{2}$ reacted. This $\chi$ can be calculated from $\mathrm{X}_{\mathrm{CO}^{*}}$.

$$
\chi=\mathrm{M}_{\mathrm{c}}\left(1+\mathrm{X}_{\mathrm{CO}}\right)
$$

where $\mathbf{M}_{c}$ is molecular weight of carbon.

\subsubsection{External mass transfer rate}

The external mass transfer rate $\left[\mathrm{gC} / \mathrm{cm}^{2} \mathrm{~s}\right]$ is based on the particle external surface area. The Nusselt number of the sphere for mass transfer is assumed as 2 . The film temperature** is used to calculate bulk gas diffusivity.

$$
\begin{aligned}
r_{g} & =k_{g}^{\prime}\left(C_{b}-C_{s}\right) \chi \\
& =k_{g}\left(P_{b}-P_{s}\right) \\
k_{g}^{\prime} & =\frac{2 D_{b}}{d}
\end{aligned}
$$

\footnotetext{
* refer to Section 2.1.3

${ }^{* *} \mathrm{~T}_{\mathrm{m}}=\left(\mathrm{T}_{\mathrm{p}}+\mathrm{T}_{\mathrm{g}}\right), \mathrm{T}_{\mathrm{g}}$ is $298.15 \mathrm{~K}$.
} 
where $d$ is the diameter of the particle. The factor that comes from Stefan flow is derived by Graham (Graham, 1990).

$$
\mathrm{f}_{\mathrm{m}}=\frac{1}{1 / \psi-1} \ln \frac{1+\mathrm{y}_{\mathrm{b}}(1 / \psi-1)}{1+\mathrm{y}_{\mathrm{s}}(1 / \psi-1)}
$$

where $\psi$ is moles of $\mathrm{O}_{2}$ reacted per one mole $\mathrm{C}$ consumed, and which is related to reaction fraction by

$$
\psi=1-\frac{X_{C O}}{2}
$$

Therefore, the mass transfer coefficient based on oxygen partial pressure is

$$
k_{g}=\frac{k_{g}^{\prime} \chi f_{m}}{R T_{m}}
$$

\subsubsection{Reaction fraction}

The concentration ratio of $\mathrm{CO}_{2}$ and $\mathrm{CO}$ in the absence of gas phase reaction was measured by Tognotti. Du (Du et al., 1991) also reported both experimental values of the $\mathrm{CO} / \mathrm{CO}_{2}$ ratio and a theoretical analysis based on the activation energy distribution model, which shows similar temperature dependence. The fraction of oxidation products appearing as $\mathrm{CO}$ is the result of competition between the two reactions. The ratio can be described empirically by:.

$$
\mathrm{X}_{\mathrm{CO}}=\left(1+\mathrm{A}_{\mathrm{O}} \mathrm{P}_{\mathrm{O} 2}{ }^{\left.\mathrm{n}_{\exp }(\mathrm{E} / \mathrm{RT} \mathrm{p})\right)^{-1}}\right.
$$

where $A_{o}=0.02 \quad n=0.21 \quad R=1.987 \quad E=6000$.

\subsubsection{Heat of reaction}

We can calculate the heat of reaction $[\mathrm{J} / \mathrm{g}]$ if we use the reaction fraction, and we can calculate the temperature dependence of heat of reaction from $\mathrm{C}_{\mathrm{p}}$ data of $\mathrm{CO}$ and $\mathrm{CO}_{2}$.

$$
-\Delta \mathrm{H}=\left[\left(-\Delta \mathrm{H}_{\mathrm{CO}}\right) \mathrm{X}_{\mathrm{CO}}+\left(-\Delta \mathrm{H}_{\mathrm{CO} 2}\right)\left(1-\mathrm{X}_{\mathrm{CO}}\right)\right] 4.184 / \mathrm{M}_{\mathrm{c}}
$$

\subsubsection{Density and diameter}


The relationship between normalized apparent density and normalized particle density can be represented as a power law (Waters,1988). Because $m=\frac{\pi}{6} \rho d^{3}$, following equations can be derived if we divide the both side with $m_{o}=\frac{\pi}{6} \rho_{o} d_{o}^{3}$.

$$
\begin{array}{ll}
\frac{\rho}{\rho_{\mathrm{o}}}=\left(\frac{\mathrm{m}}{\mathrm{m}_{\mathrm{o}}}\right)^{\mathrm{a}} & \frac{\mathrm{d}}{\mathrm{d}_{\mathrm{o}}}=\left(\frac{\mathrm{m}}{\mathrm{m}_{\mathrm{o}}}\right)^{\mathrm{b}} \\
a+3 b=1 &
\end{array}
$$

From the experimental results of Spherocarb oxidation (Waters, 1988), the values of $a, b$ were found to be equal to 0.25 .

\subsubsection{Surface area}

The surface area $\left[\mathrm{cm}^{2} / \mathrm{gC}\right]$ which is responsible for the reaction is not yet clear. Micropore surface area measured by $\mathrm{CO}_{2}$ adsorption (Dudek,1989) or BET $\mathrm{N}_{2}$ method are generally used. The surface area variation during the reaction is available from Dudek (Dudek, 1989) and also from Waters (Waters, 1988a). These da.a can be represented by 7 th order polynomial of conversion to be used in modeling.

$$
\begin{aligned}
\mathrm{Sg}= & \left(920.9089+2661.0706 * \mathrm{x}-27273.1303^{*} \mathrm{x} * * 2+112965.3388^{*} \mathrm{x} * * 3\right. \\
& -253322.8987 * \mathrm{x} * * 4+312434.9020 * \mathrm{x} * * 5-199151.1856 * \mathrm{x} * * 6 \\
& +51245.1435 * \mathrm{x} * * 7) * 10^{4}
\end{aligned}
$$

where ' $x$ ' is the conversion of Spherocarb.

\subsubsection{Effectiveness factor}

In order to calculate the effectiveness factor, we need to know the tortuosity and porosity as a function of conversion. Here we assume tortuosity to have a constant value of 3 during the reaction. Porosity as a function of conversion can be calculated from the power law relationship of density to the mass. The Thiele modulus is calculated using the following equation. 


$$
\phi=\frac{d}{6} \sqrt{\frac{\rho S_{\mathrm{g}} \mathrm{k}_{\mathrm{s}} R T}{\mathrm{D}_{\mathrm{e}} \chi}}
$$

The mean diffusivity is calculated from bulk gas diffusivity and Knudsen diffusivity. Then effective diffusivity can be calculated by multiplying the porosity to the mean diffusivity and dividing it by the tortuosity. The effectiveness factor is calculated from the following equation.

$$
\eta=\frac{1}{\phi}\left(\frac{1}{\tanh (3 \phi)}-\frac{1}{3 \phi}\right)
$$

\subsubsection{Overall reaction rate}

The overall reaction rate, based on external surface area, $\mathrm{r}_{\mathrm{c}}\left[\mathrm{gC} / \mathrm{cm}^{2} \mathrm{~s}\right]$ is determined by the relative rate between intrinsic reaction and oxygen transfer. Pore diffusion effects can be expressed by the effectiveness factor. With the assumption of 1 st order reaction, the overall reaction rate is given as:

$$
r_{c}=\frac{P_{O 2}}{\left(1 / k_{g}+6 / \eta k_{s} S_{g} \rho d\right)}
$$

\subsubsection{Convective heat transfer coefficient}

We can assume $\mathrm{Nu}=2$ in the case of a sphere. The convective heat transfer coefficient can be calculated from the thermal conductivity of gas phase.

$$
\mathrm{h}=\frac{2 \underline{k}_{\mathrm{b}}}{\mathrm{d}}
$$

The additional convective heat transfer factor coming from Stefan flow was calculated by Bird et al.(1960) and Waters et al.(1988).

$$
\begin{aligned}
f_{h} & =\frac{B}{\exp (B)-1} \\
B & =-\frac{X_{C^{r}{ }_{c}^{d} C_{p}}}{4 M_{c} k_{b}}
\end{aligned}
$$




\subsubsection{Emissivity, absorption efficiency, and heating flux}

Data on emissivity and absorption efficiency of laser heat flux as a function of conversion and temperature are not available, $A$ value of 0.85 seems to be most appropriate based on the available literature. A heating flux of $300 \mathrm{~W} / \mathrm{cm}^{2}$ was assumed and turned off when the particle temperature reached $1300 \mathrm{~K}$. 


\subsection{Negligible internal diffusion limitation case}

The major uncertainties in the modeling of Spherocarb ignition are the intrinsic reaction order and the pore sizes which participate in the reaction. First, we assume 1st order reaction kinetics and micropore surface area. If we set the effectiveness factor at a value of 1.0, which means no diffusion limitation to the micropore, the result is Fig.2.2.

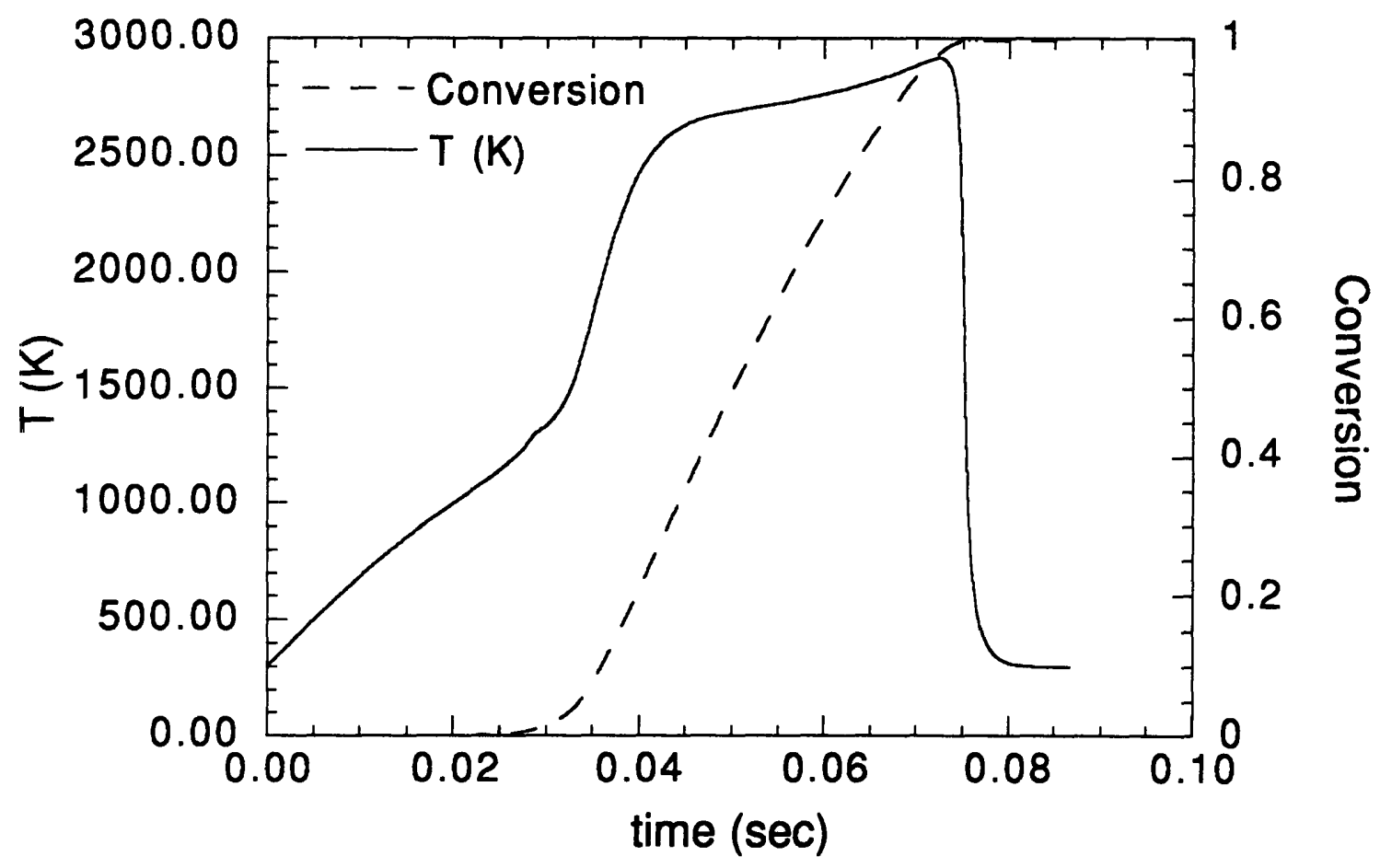

Fig.2.2 Temperature as a function of time ( Laser turned off at $1300 \mathrm{~K}$ $1 \mathrm{st}$ order iltrinsic reaction. Particle diameter is $180 \mu \mathrm{m}$. Effectiveness factor is one. $100 \%$ oxygen)

If we compare Fig.2.2 to Fig.2.1, we discover the similarity between the two curves. The time spent until the ignition occurs does not mean much, because it is hard to decide when the data acquisition begins in the experiment. The time scale in Fig 2.1 better represent a relative time scale. It is, therefore, more reasonable to compare the duration of pseudo steady state burning around the maximum temperature of the particle. The durations 
of steady state burning where most of the carbon consumption occurs are almost the same in both cases. It is 0.038 second in Fig.2.1 and 0.034 second in Fig.2.2. This means the carbon consumption rate calculated from the model is close to the experimental value.

The overall reaction rate* versus surface temperature is shown in Fig 2.3. The overall reaction rate is almost zero in the beginning, and the rate increases rapidly after temperature passes $1000 \mathrm{~K}$. As the surface temperature reaches the maximum particle temperature, the temperature rises slowly although the reaction rate more than doubles. Because the overall reaction rate is based on the external surface of the particle, carbon consumption rate $[\mathrm{g} / \mathrm{s}]$ (the product of the reaction rate and the external surface area) increases slowly and so does the maximum temperature.

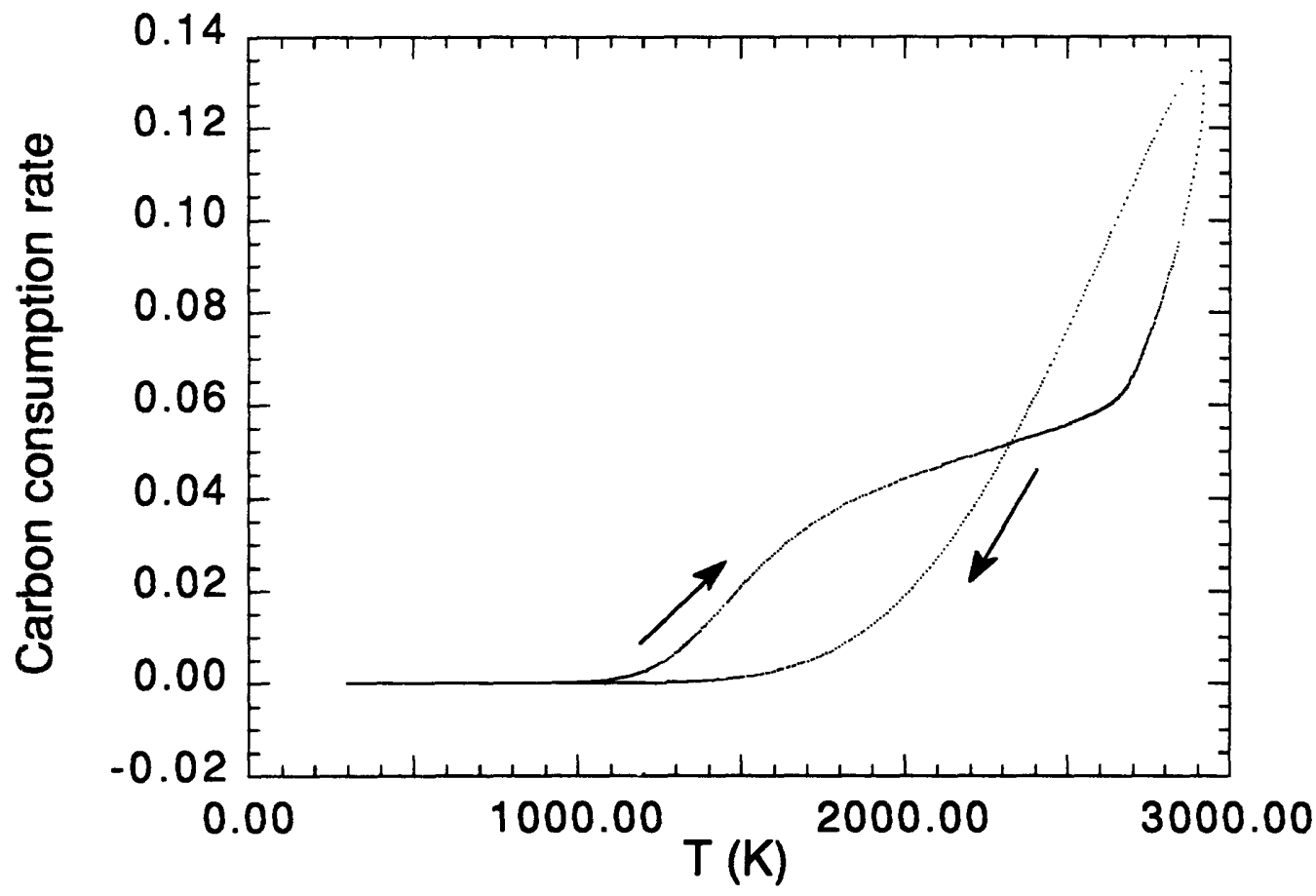

Fig.2.3 Overall reaction rate versus surface temperature ( Laser turned off at 1300K.1st order intrinsic reaction. Particle diameter is $180 \mu \mathrm{m}$. Effectiveness factor is one. $100 \%$ oxygen)

* refer to section 2.1.8 
There exist a couple of differences we need to consider. The maximum temperature rise in Fig. 2.2 is about 500 K higher, and the extinction curve is steeper than what is observed experimentally. This steep extinction is caused by the total conversion of the carbon particle. The higher maximum temperature may be due to the underestimation of the heat loss term. In the experiment there may exist some additional heat loss by $\mathrm{O}_{2}$ disassociation in the high temperature environment. This effect increases the thermal heat conductivity, and therefore the heat loss. Oxygen begins to disassociate significantly at temperature as low as $2200 \mathrm{~K}$ at $1 \mathrm{~atm}$ of pressure. Graham (Graham, 1990) calculated the effective thermal conductivity of mixture of oxygen, and found out the $\mathrm{O}_{2}$ disassociation increased the conductivity by factors of 2 5.

An effectiveness factor of one was used for Fig.2.2. The use of an effectiveness factor greater than 0.1 was found necessary to get ignition, which can be explained in two different ways. First we can adopt Hurt's micrograin idea, which considers the Spherocarb as a conglomerate of small micrograins. If we assume no oxygen diffusion limitations to the micrograin, we get an ignition curve similar to the experimental result. We can refine the analysis to include an effectiveness factor for the intergrain pores and coupled it to the intragrain effectiveness factor; however, such a model needs more data on macropore structure.

The other idea which can explain this high effectiveness factor is that only the macropores ${ }^{*}$ participate in the reaction. Because the macropore surface area is about $1 \%$ of total surface area and the macropore volume fraction is about 0.4 , the effectiveness factor retains the value about $0.1 \sim 1.0$ which can ignite the particle. The detailed process of macropore surface area or volume evolution during the reaction is uncertain yet, and needs to be studied. There is controversy over this surface area issue. Many explanations, like

\footnotetext{
* pore size bigger than $100 \mathrm{~nm}$
} 
different reactivity of pores or activated diffusion, have been proposed. The average diameter of the Spherocarb micropores is of the order of $1 \mathrm{~nm}$. So, at the temperature of ignition, it is questionable that oxygen could diffuse freely in the micropores in very short time available. Maybe the oxygen occurring naturally inside the particle plays a significant role in the early stage of combustion. The answer to this issue could be acquired through both simulation and experiment.

Gas phase models which include $\mathrm{CO}$ oxidation in the boundary layer (Gas phase model will be discussed in Chapter 4) will be necessary to study the effects of gas phase reaction, because the $\mathrm{CO}_{2} / \mathrm{CO}$ ratio deviates from the pseudo Arrhenius plot due to the homogeneous reaction of $\mathrm{CO}$ after ignition. The heat of reaction of $\mathrm{CO}$ oxidation is 66.8 $\mathrm{kcal} / \mathrm{mol}$, therefore, the heat feedback to the particle may not be neglected. A standard kinetic code (including reactions of $\mathrm{H}, \mathrm{H}_{2}, \mathrm{H}_{2} \mathrm{O}, \mathrm{HO}, \mathrm{HO} 2, \mathrm{H}_{2} \mathrm{O}_{2}, \mathrm{HCO}, \mathrm{CO}, \mathrm{CO}_{2}, \mathrm{O}$, $\mathrm{O}_{2}$, and $\mathrm{N}_{2}$ ) will be used to estimate this effect.

\subsubsection{Effects of oxygen pressure on temperature profile}

The oxygen partial pressure has a large effect on the shape of the temperature profile. Increasing partial pressure reduces combustion time and increases maximum temperature. Temperature profiles for four different partial pressures are shown in Fig.2.4. The total combustion time for the $60 \%$ oxygen case is more than two times longer than that of $100 \%$ case. Also, the maximum temperature is about $600 \mathrm{~K}$ lower than the $100 \%$ case. When the oxygen partial pressure drops to $40 \%$, the particle can not be ignited after the laser heating is turned off at $1300 \mathrm{~K}$. It is interesting to note that high carbon content char (low volatile contents) like Spherocarb does not ignite even at this high temperature $(1300 \mathrm{~K})$ with moderate oxygen concentration (40\%). 


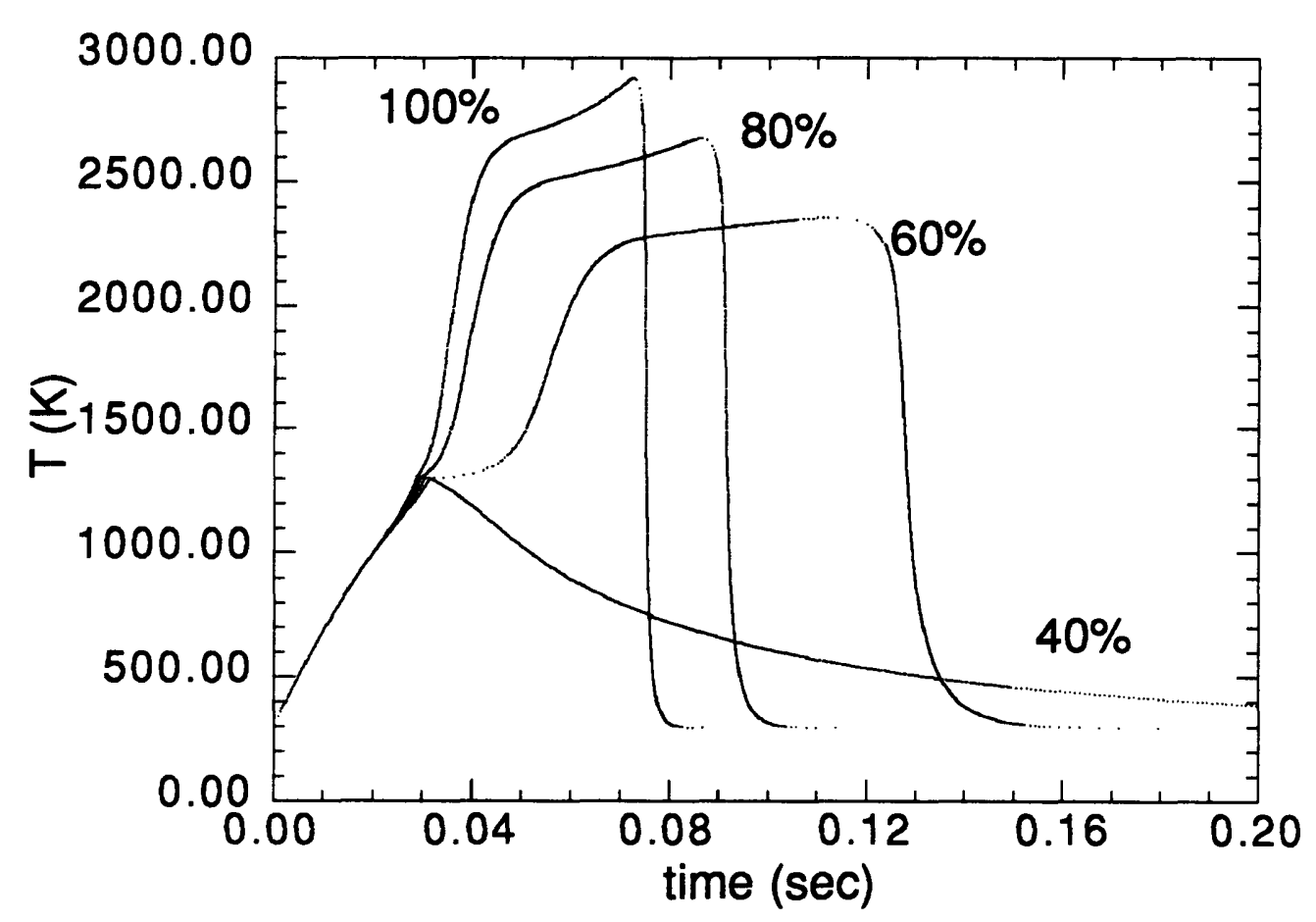

Fig.2.4 Effects of oxygen partial pressure on temperature profile ( Laser turned off at 1300K.1st order intrinsic reaction. Particle diameter is $180 \mu \mathrm{m}$. Effectiveness factor is one.)

\subsubsection{Effects of particle diameter}

Changes in particle diameter do not have a large impact on the maximum temperature rise, but have a considerable impact on the combustion time. Temperature profiles calculated for particle diameters of 150,180 and $210 \mu \mathrm{m}$ are shown in Fig 2.5. If we calculate the volume of the particle for each diameter, the combustion time is approximately proportional to the volume although the other factors like heat and mass transfer changes due to changes in particle size also play a role in determining the combustion time. 


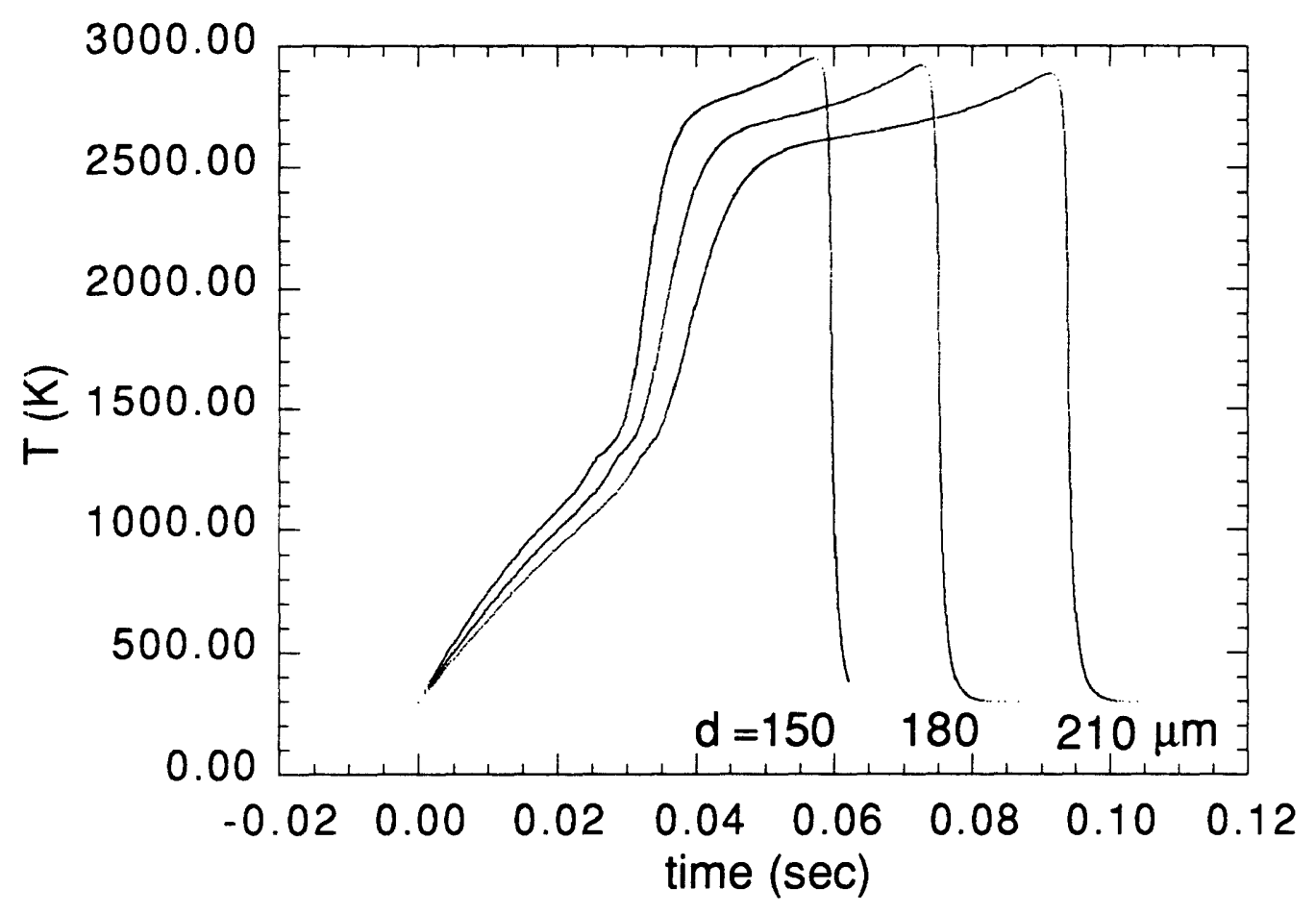

Fig.2.5 Effects of particle diameter on temperature profile

( Laser turned off at $1300 \mathrm{~K} .1$ st order intrinsic reaction.

Effectiveness factor is one. $100 \%$ oxygen) 


\subsection{Macropore with higher reactivity case}

As we discussed in Section 2.2, it is still unclear what size of pores are responsible for the reaction. It is possible two different types of pores have different reactivities. The structure of Spherocarb has been investigated by others (Waters et. al, 1988a, also by Hurt, 1987), and most of the internal surface area belongs to the pores less than $1 \mathrm{~nm}$. Waters showed that oxygen penetration is essentially restricted to surface macropores during combustion at pulverized fuel combustor conditions. The cumulative pore size distribution of Spherocarb is shown in Fig.2.6.

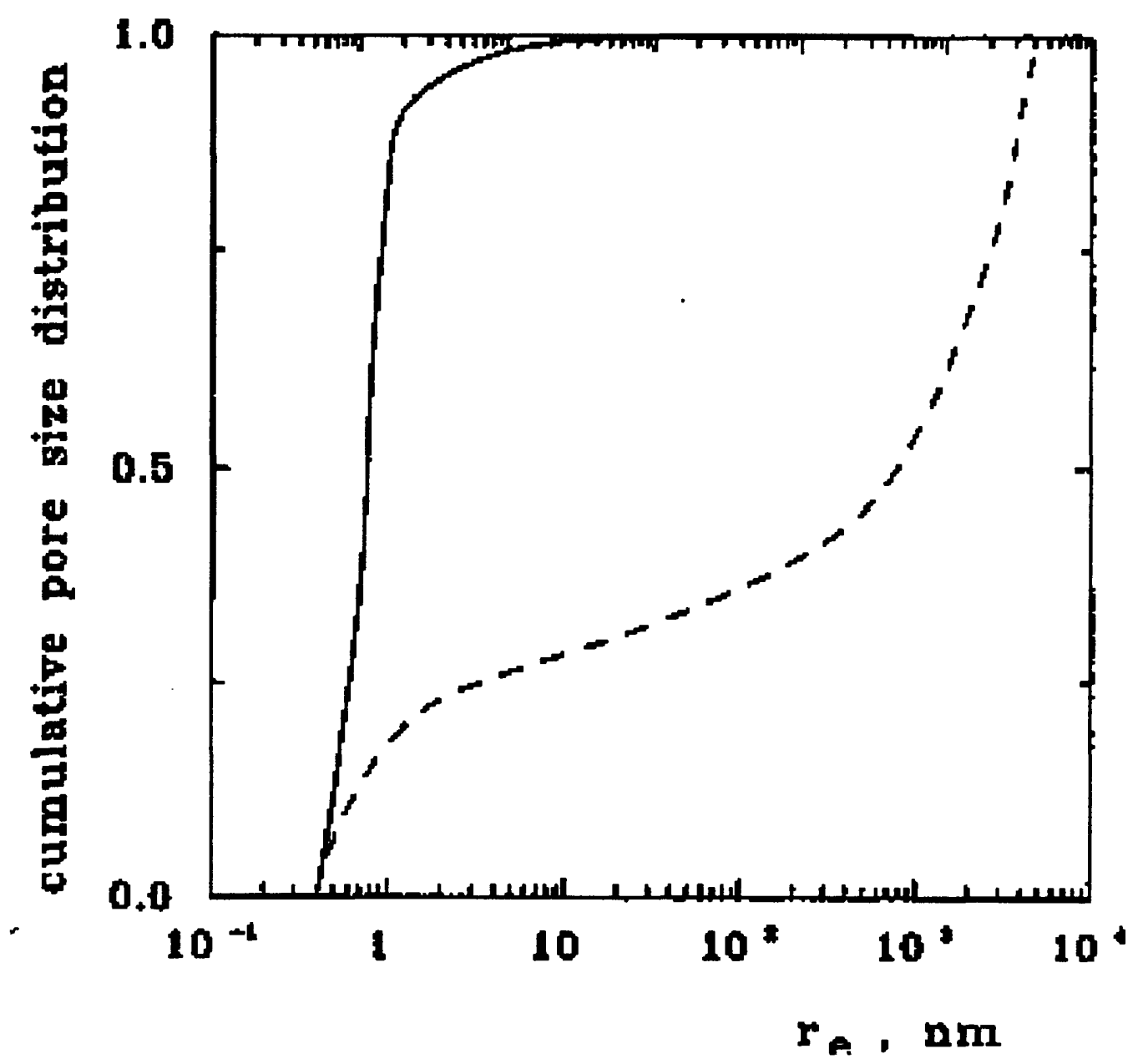

Fig.2.6 Cumulative pore size distribution on volume basis (dashed line) and on surface basis (solid line), (after d'Amore et. al) 
Based on the hypothesis of a lower reactivity of the micropores, we constrained the reaction to pores bigger than $10 \mathrm{~nm}$ which include the meso and macropores. If we assume that most of the reactivity of the carbon is coming from these larger pores, the intrinsic surface reaction rate based on their area should be much higher. The meso and macropore surface area is less than $1 \%$ of the total internal surface area from Fig 2.6.

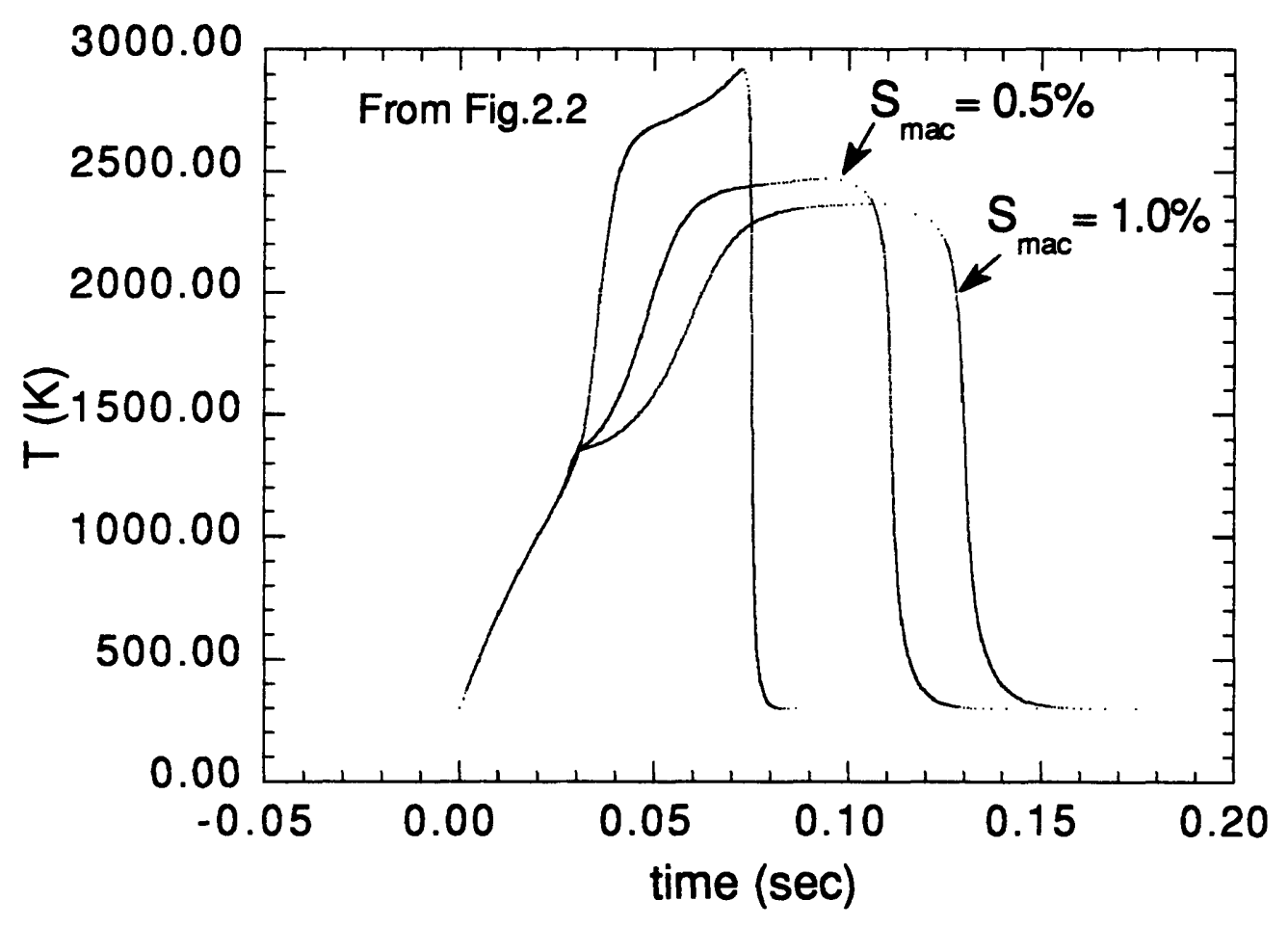

Fig.2.7 Temperature profile using macropore with higher reactivity ( Laser turned off at $1350 \mathrm{~K} .1$ st order intrinsic reaction. $100 \%$ oxygen)

The results of selecting two different percentages of the total surface area are shown in Fig.2.7. When $S_{\text {mac }}$ (the percentage of larger pore surface area) is $0.5 \%$, the profile is more close to the experimental data better than when it is $1 \%$ case. The case of negligible internal diffusion limitation is also plotted in Fig 2.7. For this value of $\mathbf{S}_{\mathrm{mac}}$ the porosity of the larger pores is determined as 0.37 from Fig. 2.6. To keep the apparent reaction rate 
same, the intrinsic reaction rate is obtained by dividing the original intrinsic reaction rate by $S_{\text {mac }}$. Except for the longer duration of steady state combustion than in the experiment, the temperature profile for the $0.5 \%$ case shows good agreement with experiment. We can adjust $S_{\text {mac }}$ to fit the experimental temperature profile, and the optimum value should be a little lower than $0.5 \%$. There is a need for additional studies of the role of internal structure on carbon reactivity, as the current results suggest that provides possible explanation of the observed temperature profile during the combustion. 


\subsection{Effects of mineral catalyst}

The effects of mineral catalyst on the temperature profile has been studied by using a reaction kinetics model developed by $\mathrm{Du}$ (Du et al., 1991). He developed expressions for the reaction rate of carbon using a continuous site activation energy distribution model for $\mathrm{CO}$ and $\mathrm{CO}_{2}$ reactions. The model gave results for the $\mathrm{CO} / \mathrm{CO}_{2}$ ratio that were consistent with Tognotti's. He further developed the model for catalyzed carbon. There are few sites that generates $\mathrm{CO}_{2}$ in the uncatalyzed carbon, but these sites can be increased by adding a mineral catalyst like $\mathrm{Ca}$. The $\mathrm{CO} / \mathrm{CO}_{2}$ ratio decreases significantly by adding $\mathrm{Ca}$ even at a low temperature and can be fitted by following equation.

$$
\left.\mathrm{CO} / \mathrm{CO}_{2}=\mathrm{A}_{\mathrm{o}} \mathrm{P}_{\mathrm{O}_{2}}{ }^{\mathrm{n}_{\mathrm{exp}}(-\mathrm{E} / \mathrm{RT}} \mathrm{p}\right)
$$

where $A_{o}=0.28 \quad n=-0.21 \quad E / R=2575$.

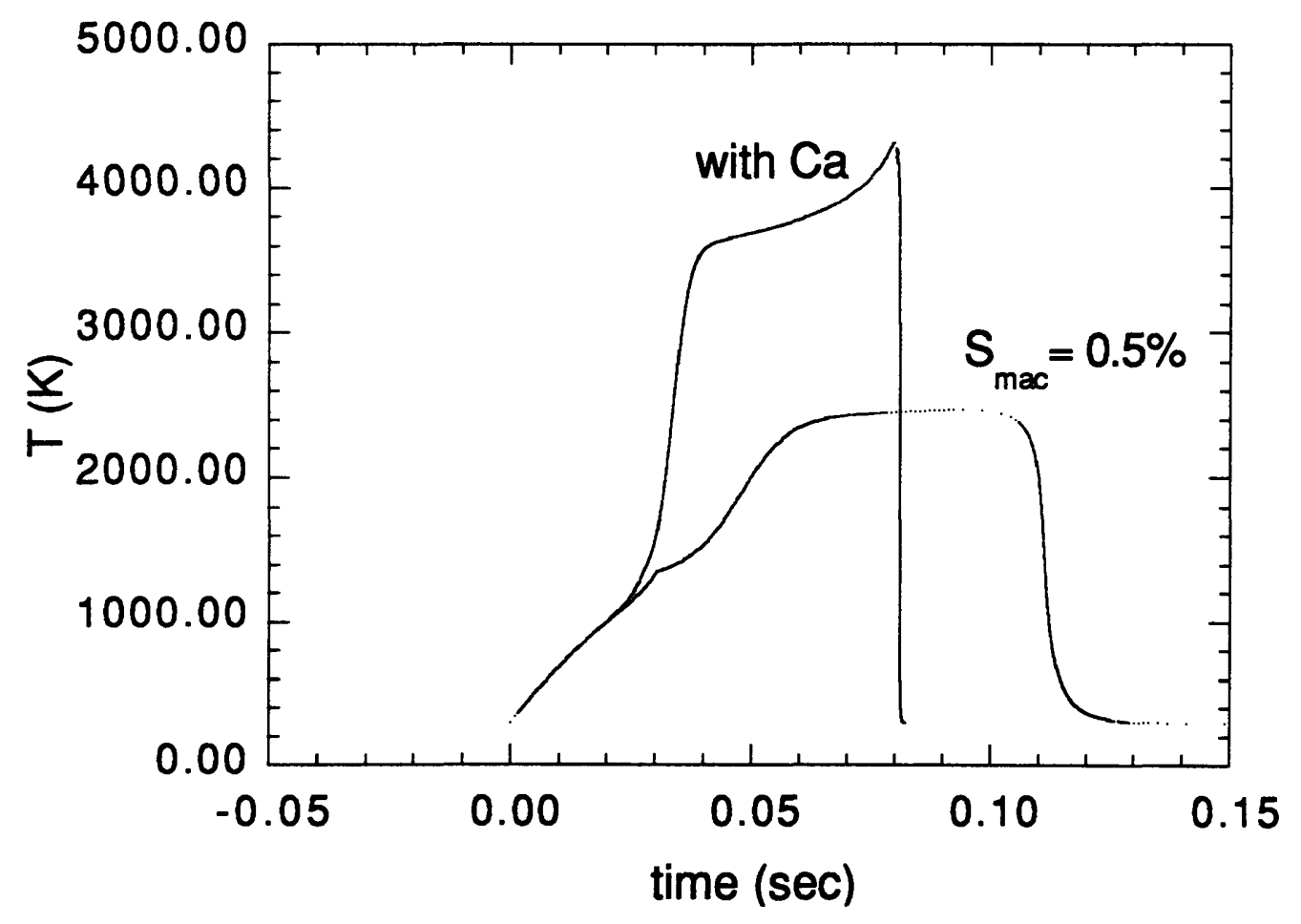

Fig.2.8 Effects of $\mathrm{Ca}$ on temperature profile

( Laser turned off at 1350K.1st order intrinsic reaction.

Particle diameter is $180 \mu \mathrm{m} .100 \%$ oxygen.) 
The results of adding $\mathrm{Ca}$ is therefore to significantly increase $\mathrm{CO}_{2}$ generation and the maximum temperature, as shown in Fig 2.8. If we consider gas phase reactions, the maximum temperature will be lower than the predicted value due to $\mathrm{O} 2$ disassociation and other radical generation reactions. The addition of mineral catalyst promotes heterogeneous $\mathrm{CO}_{2}$ formation and raises the particle temperature. However, the duration of the carbon combustion does not decrease much since mass transfer is limiting in this temperature range. In other words, the combustion time decreases in proportion to the increase in oxygen transfer rate to the particle surface, which increases only slightly.

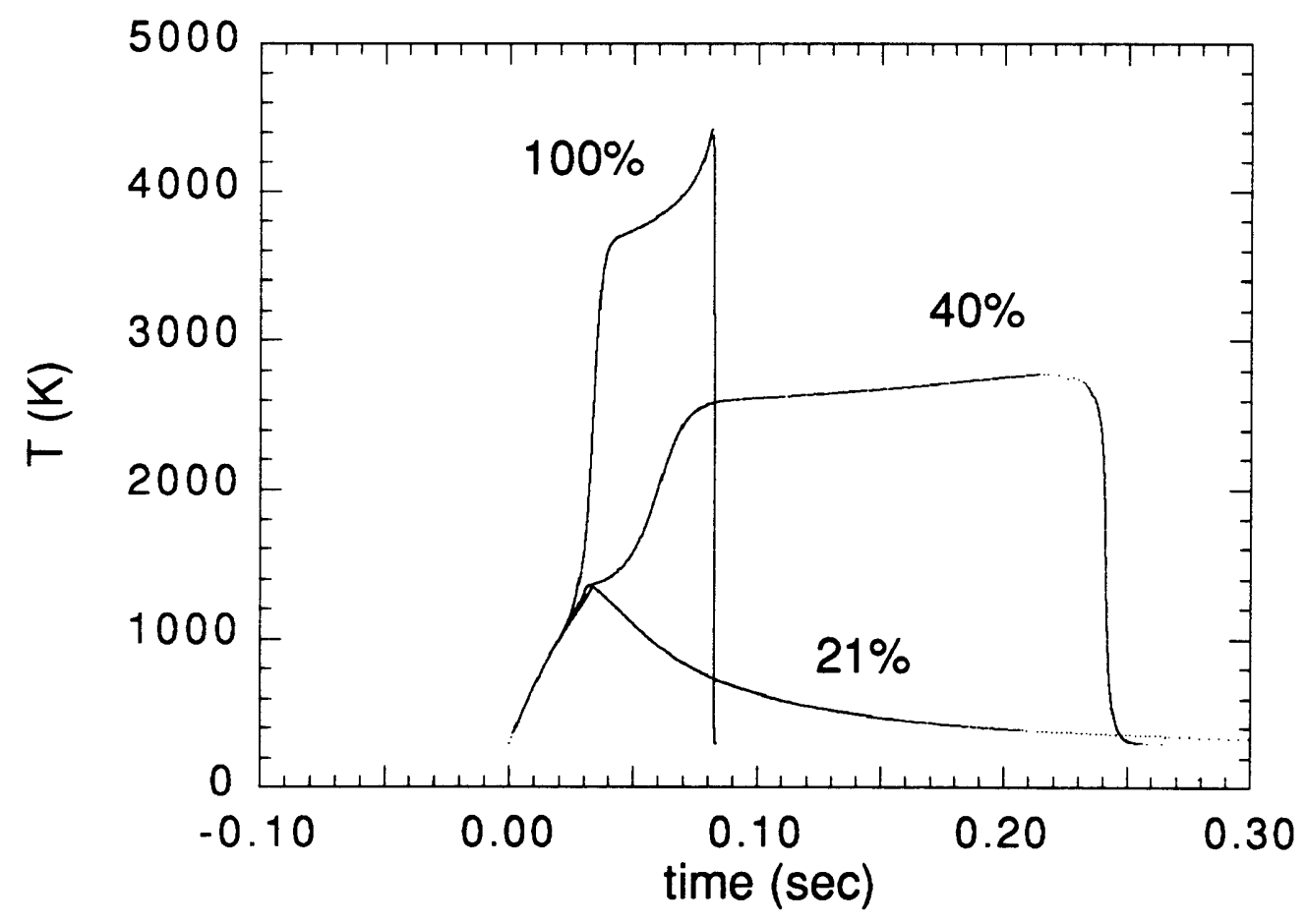

Fig.2.9 Effects of oxygen partial pressure on temperature profile (with $\mathrm{Ca}$ )

( Laser turned off at 1350K.1st order intrinsic reaction. Particle diameter is $180 \mu \mathrm{m}$.)

The particle with $\mathrm{Ca}$ can be ignited even at $40 \%$ of oxygen partial pressure. In Fig.2.9, the duration of combustion increases to 0.17 second. Increased heterogeneous 
phase $\mathrm{CO}_{2}$ formation produce higher heat of reaction, enables the ignition. Further study about the catalytic effects will be useful for the combustion of natural coal which has much mineral constituents. 


\section{Chapter 3}

\section{Combustion and Temperature Profile in the Fluidized Bed Reactor}

The modeling of the burning temperature of a carbonaceous particle in a fluidized bed is important, because the particle temperature is a key parameter needed to unravel the coal combustion mechanism in a fluidized bed. The temperature difference between a particle and gas is an important factor not only for the operation of a fluidized bed but also for assessing the formation of pollutants such as NOx and SOx. The adhesive behavior of ash is also highly sensitive to the particle temperature and can cause the defluidization in the worst case. Researchers using various techniques to measure the particle temperature have found particle temperatures up to $260 \mathrm{~K}$ higher than the bed temperature depending on oxygen concentration, bed temperature, particle size, etc.. Therefore, it is necessary to establish a model which can predict the particle temperature profile during the combustion. Such a model will provide useful information about the optimal operation condition and minimizing the gaseous pollutants in fluidized bed combustion.

The char combustion model in the previous chapter has been modified to simulate the combustion behavior in the fluidized bed. Different heat and mass transfer rates should be applied to calculate the char combustion in the fluidized bed. A model developed by La 
Nauze (La Nauze, 1985) is based on a non-steady state model for the heat and mass transfer coefficients. The model is good at considering non-steady state heat and mass transfer in the fluidized bed. However, it neglects the effect of bed particle properties on the heat and mass transfer to the carbonaceous particle. A heat and mass transfer model developed by Agarwal (1991) considers the effects of the particle motion inside the bed and calculates contributions due to gas convection in the bubble and to dense phase transfer in the emulsion phase according to the particle location. Both transfer models were combined with the char combustion model to reproduce the experimental results performed by Tullin (Tullin et al.). 


\subsection{Experiment}

The experiments were performed in a small quartz fluidized bed reactor (i.d. $=57 \mathrm{~mm}$, total height $=590 \mathrm{~mm}$, height above the quartz frit $=387 \mathrm{~mm}$ ) as shown in Fig. 3.1. The detailed procedures of experiment can be found in the literature (C.J. Tullin et al.). Batch combustion experiments with a bituminous coal were performed in the fluidized bed of $\mathrm{SiO}_{2}$ sand fluidized with $\mathrm{He} / \mathrm{O}_{2}$ mixtures. A static bed height was approximately 50 $\mathrm{mm}$. The total volumetric flow rate in the experiment was $2.5 \mathrm{l} / \mathrm{min}$ NTP $(273 \mathrm{~K}, 1 \mathrm{~atm})$, which corresponds to a residence time of 3.6-4.0 seconds. Batches of $100-200 \mathrm{mg}$ of $4 \mathrm{~mm}$ size coal particles were reacted, and the off-gas composition was monitored as a function of time using an FTIR analyzer. The concentration profile for each component was measured and the volatile combustion part was separated. Different oxygen pressures (4-20\%) and bed gas temperatures (1023-1123K) were examined. 


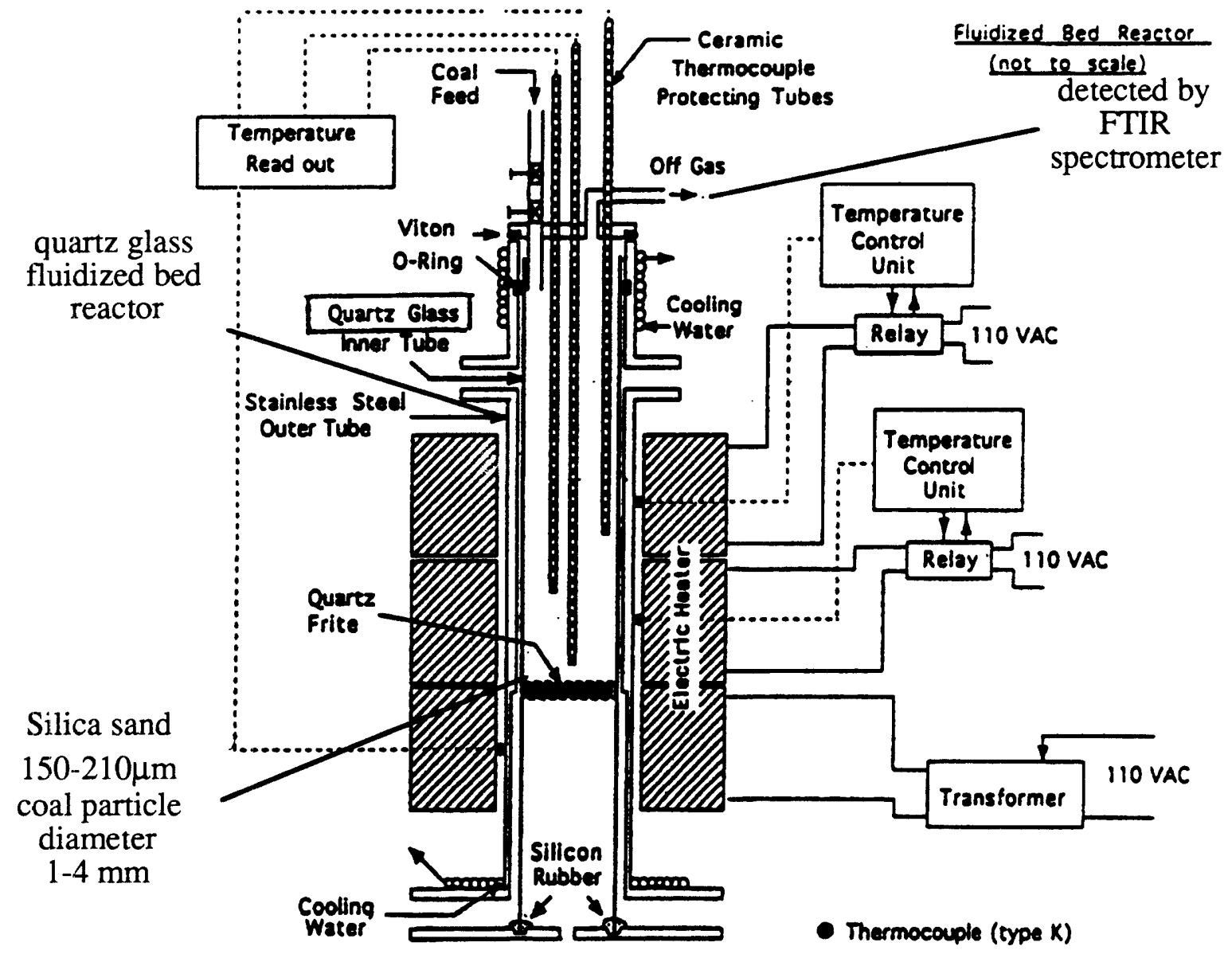

Fig.3.1 Fluidized bed reactor 


\subsection{Theory}

In this section, theories about the heat and mass transfer in the fluidized bed will be introduced. Theories other than gas phase heat and mass transfer were mentioned in chapter two. Because the internal surface area evolution as a function of conversion for the bituminous coal used in the experiment was not measured, the normalized distribution for Spherocarb is multiplied by $500 \mathrm{~m}^{2} / \mathrm{g}$ and is used for the bituminous coal.

\subsubsection{Heat and mass transfer model}

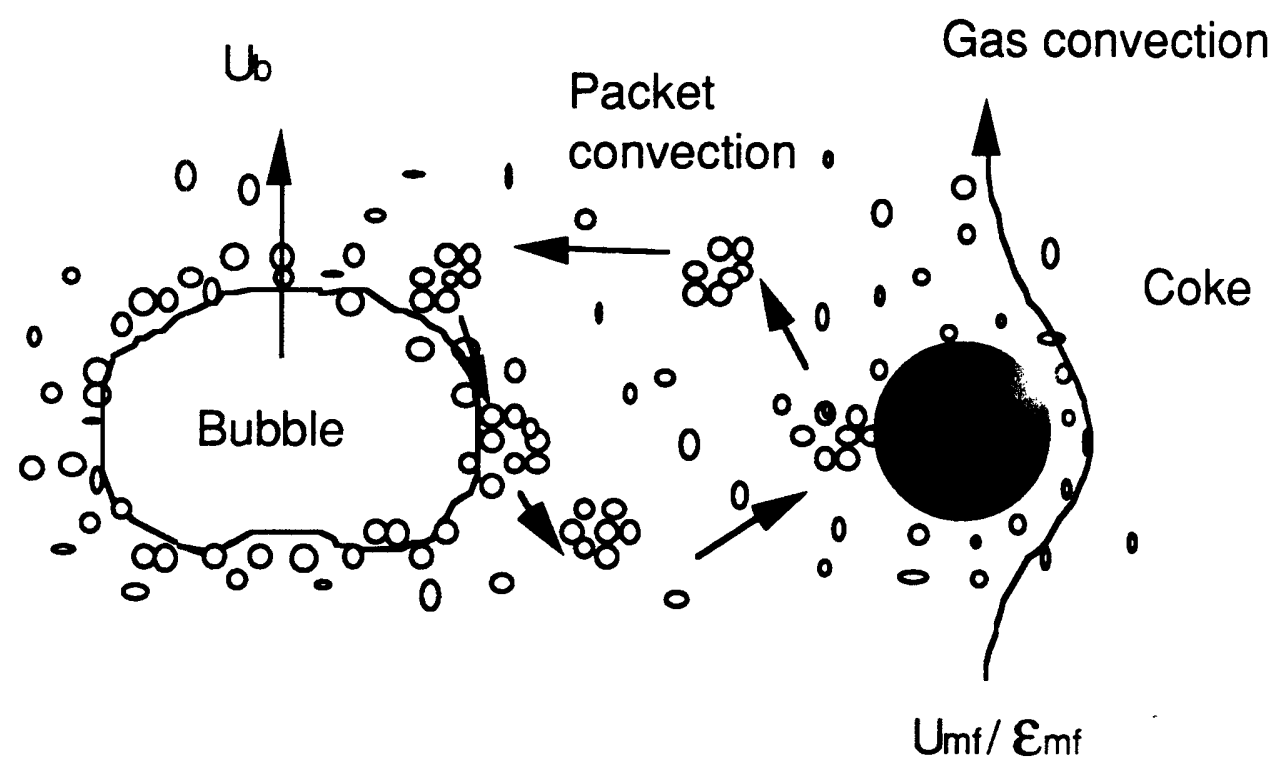

Fig.3.2 Mass transfer of oxygen to the surface of a large particle

To calculate the heat and mass transfer coefficients, we tried two different models. The non-steady state heat and mass transfer theory is based on the frequency of the renewal of oxygen at the surface of the particle (La Nauze, 1985). In contrast to earlier models based on the steady state, this model introduced the idea that the bubbles may play a role in the heat and mass transfer by moving the burning particle into a fresh oxygen environment. 
They proposed that the total mass transfer of oxygen to the burning particle is made up of : (1) the mass transfer induced by bubble motion from aggregates of particles containing fresh gas, the particle convective component, and (2) the mass transfer of gas percolating through the bed at the minimum fluidizing condition, the gas convective component. The theory assumes non-steady state transfer of the gas to the gas-solid interface where the gas is being replaced at a characteristic frequency $f$.

$$
f=f_{g}+f_{p}=\frac{U_{m f}}{\varepsilon_{m f} d}+\frac{u_{b}}{d}
$$

The characteristic frequency $f$ is composed of $f_{g}$, the gas convective component, and $f_{p}$ the particle convective component. The mass transfer coefficient and the convective heat transfer coefficient can be represented as followings.

$$
\begin{aligned}
& k_{g}=2 \frac{D_{g} \varepsilon_{m f}}{d}+\left(\frac{4 D_{g} \varepsilon_{m f} f}{\pi}\right)^{1 / 2} \\
& h=2 \frac{k_{e}}{d}+\left(\frac{4 k_{e}^{2} f}{\pi \alpha_{e}}\right)^{1 / 2}
\end{aligned}
$$

The experimental observation of Nienow et al. (1978) indicates that a circulation pattern is set up due to the slow sinking of the particles in the downward motion in the dense phase and a upward short ride by the bubbles as shown in Fig.3.3.

A model developed by Agarwal (Agarwal,1991) calculates the mean heat transfer coefficient in the fluidized bed by adding up each contribution of gas convective and particle convective component. These terms are multiplied by the probability calculated from the residence time of the particle stayed in each phase.

The average heat transfer coefficient can be approximated by the following.

$$
\bar{h}=p^{\prime} h_{p c, a}+\left(p-p^{\prime}\right) h_{p c, d}+p h_{g c}+(1-p) h_{b u b}
$$




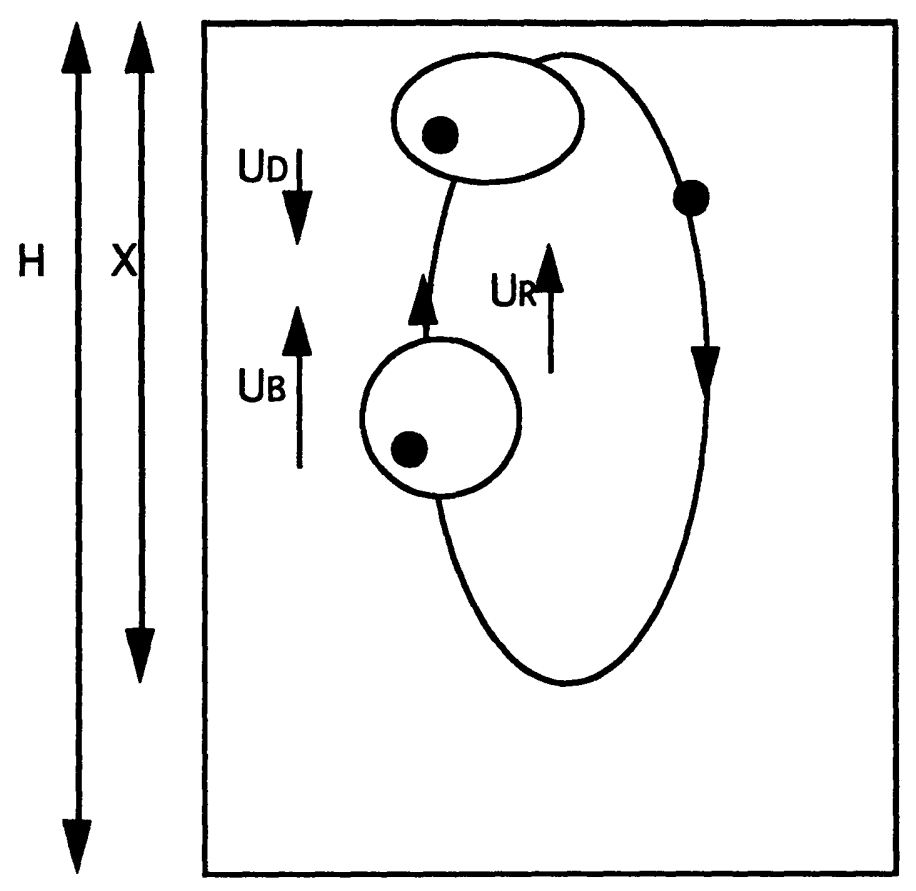

Fig.3.3 Particle motion in the fluidized bed

The probability that the particle is in the emulsion phase during one whole circulation is $p$, and the probability that it is in the emulsion phase during its rise is denoted as $p^{\prime}$.

$$
\begin{aligned}
& p=\frac{U_{B}}{U_{B}+U_{D}} \\
& p^{\prime}=\frac{\left(U_{B}-U_{R}\right) U_{D}}{\left(U_{B}+U_{D}\right)\left(U_{R}+U_{D}\right)}
\end{aligned}
$$

The average rise velocity $U_{R}[\mathrm{~m} / \mathrm{s}]$ can be calculated from following equation.

$U_{R}=0.19\left(U_{o}-U_{m f}\right)^{1 / 2}$

The average descending velocity of an active particle in the emulsion phase is

$U_{D}=\frac{\alpha \varepsilon_{b} U_{B}}{1-\varepsilon_{b}-\alpha \varepsilon_{b}}$ 
,where $\alpha$ is the wake fraction, assumed to have a value of $1 / 3$ for the present calculations. $\varepsilon_{b}$ is the bubble fraction which can be calculated from

$$
\varepsilon_{b}=\frac{U_{o}-U_{m f}}{U_{B}+2 U_{m f}} .
$$

A particle convective heat transfer coefficient when the particle rises during its circulation is

$$
h_{p c, u}=\left\{\frac{d_{p}}{\phi k_{g}}+0.5\left(\frac{\pi t_{2}}{k_{e} \rho_{e} C_{p p}}\right)^{0.5}\right\}^{-1} .
$$

A particle convective heat transfer coefficient when the particle moves down during its circulation is

$$
h_{p c, d}=\left\{\frac{d_{p}}{\phi k_{g}}+0.5\left(\frac{\pi X}{U_{D} k_{e} \rho_{e} C_{p p}}\right)^{0.5}\right\}^{-1} .
$$

A gas convective heat transfer coefficient when the particle is in the emulsion phase is

$$
h_{g c}=\frac{k_{g}}{d}\left\{2 \frac{k_{e}}{k_{g}}+0.693 \frac{\left(1+\operatorname{Re}_{e} \operatorname{Pr}\right)^{1 / 3}-1}{\left(\operatorname{Re}_{e} \operatorname{Pr}\right)^{1 / 3}}\left(\frac{C_{D E a}}{8}\right)^{1 / 3}\left(\frac{q}{\varepsilon_{m f}} \operatorname{Re}_{e}\right)^{2 / 3} \operatorname{Pr}^{1 / 3}\right\} .
$$

A gas convective heat transfer coefficient when the particle is in the bubble phase is

$$
h_{b u b}=\frac{k_{g}}{d}\left\{2+0.693 \frac{\left(1+\operatorname{Re}_{b} \operatorname{Pr}\right)^{1 / 3}-1}{\left(\operatorname{Re}_{b} \operatorname{Pr}\right)^{1 / 3}}\left(\frac{C_{D a}}{8}\right)^{1 / 3}\left(\operatorname{Re}_{b}\right)^{2 / 3} \operatorname{Pr}^{1 / 3}\right\} .
$$

Detailed equations for evaluating the parameters in the particle and gas convective heat transfer coefficients can be found in the literature. (Linjewile and Agarwal, 1990)

The Sherwood number can be estimated from the summation of the contributions from the emulsion phase and the bubble phase.

$$
S h=\frac{k_{m} d}{D}=p S h_{e}+(1-p) S h_{b}
$$




$$
\begin{aligned}
& S h_{b}=\left\{2+0.693 \frac{\left(1+\operatorname{Re}_{b} S c\right)^{1 / 3}-1}{\left(\operatorname{Re}_{b} S c\right)^{1 / 3}}\left(\frac{C_{D a}}{8}\right)^{1 / 3}\left(\operatorname{Re}_{b}\right)^{2 / 3} S c^{1 / 3}\right\} \\
& S h_{e}=\left\{2 \frac{D_{A, e}}{D_{A}}+0.693 \frac{\left(1+\operatorname{Re}_{e} S C\right)^{1 / 3}-1}{\left(\operatorname{Re}_{e} S c\right)^{1 / 3}}\left(\frac{C_{D E a}}{8}\right)^{1 / 3}\left(\frac{q}{\varepsilon_{m f}} \operatorname{Re}_{e}\right)^{2 / 3} S c^{1 / 3}\right\} .
\end{aligned}
$$

\subsubsection{Temperature gradient inside particle}

One fundamental question to be answered before modeling the temperature profile of a coal burning in the fluidized bed is whether there exist a considerable temperature gradient inside particle or not. We can easily check the uniform temperature assumption by using the analytic method developed by Finlayson* (Finlayson, 1980).

The temperature difference between the center and the surface of the particle can be represented by

$$
T(0)-T(R)=\beta\{C(R)-C(0)\}
$$

,where $\beta$ is dimensionless heat of reaction.

$$
\beta=\frac{(-\Delta H) C_{b} D_{e}}{k_{e} T_{g}}
$$

If $\beta$ is small enough, the assumption of uniform temperature inside the particle is acceptable. The thermal conductivity for the char varies according to the char property, but it's in the range of 0.04-0.002 J/cm.s.K. If we calculate the value of $\beta$, it is in the order of $10^{-3}-10^{-4}$ which is small enough to validate the uniform temperature assumption inside the particle.

* pp 79-83 


\subsection{Modeling results}

The coal used in the experiment was a bituminous coal called Newland coal. It has an ash content of about $20 \%$ of the total nonvolatile matter. Considering the fact that the ash is usually composed of mineral matters that are heavy, it is reasonable to assume that the ash does not occupy significant volume. It is also assumed that the ash at the particle surface is removed by the rigorous contacts between the coal and the bed particles. Therefore, the heat and mass transfer to the particle do not change much with changing ash content. However, the heat generation will be lower than that of the pure carbon combustion, and the temperature profile will be affected. In the experiment, the volatile combustion occurred first, and the residual char reacted subsequent to the depletion of volatiles. The char conversion was calculated by measun.ng all the carbon containing gas products and calculating their balances. The earlier volatile combustion part was excluded by the time resolving method (Tullin et al.,1993). In this section, the heat and mass transfer models in the fluidized bed will be applied to predict the temperature profile during the char combustion by using a pure carbon assumption.

\subsubsection{Burning time, and intrinsic reaction kinetic parameters (using La Nauze's model)}

Fig.3.4 shows a typical temperature and conversion curve during reaction. The calculations are for a first order intrinsic reaction and $8 \%$ oxygen partial pressure. The shape of temperature profile depends on the diameter of the particle, the oxygen partial pressure, and the surrounding gas temperature. For the conditions used in the experiment, the particle temperature rises suddenly in a short time period (initial temperature rise), then decreases slowly at a low conversion (pseudo steady state). After the conversion reaches 
about 0.9 , the particle temperature falls steeply as the particle approaches complete conversion (steep temperature drop).

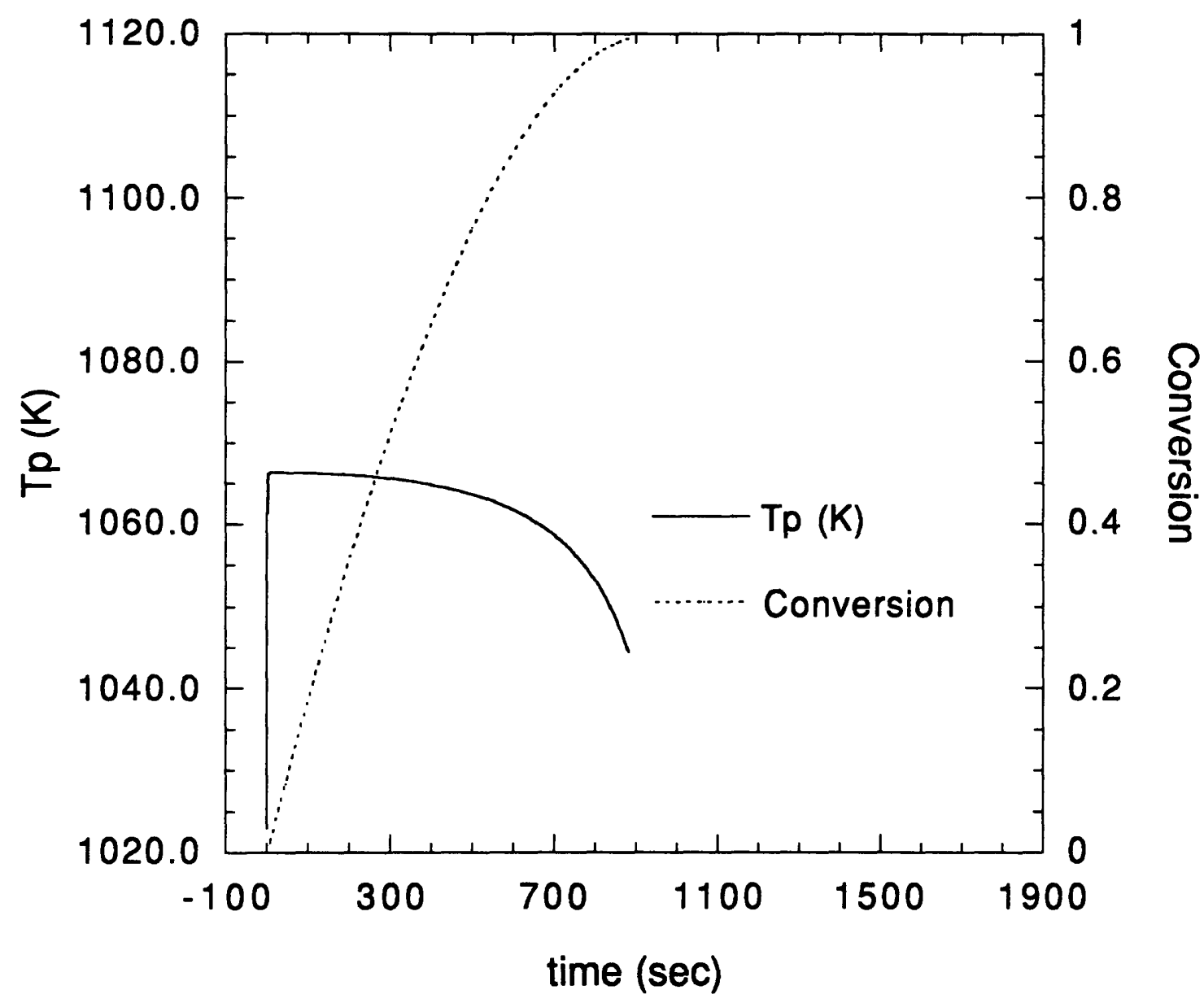

Fig.3.4 Temperature profile and conversion curve (8\% oxygen partial pressure, 1 st order intrinsic reaction, surrounding gas temperature of $1023 \mathrm{~K}$, diameter $=4 \mathrm{~mm}$ )

The conversion increases very steadily until 0.9 and after that the conversion slowly increases toward unity. Increasing oxygen partial pressure increases the initial temperature rise $(\Delta T)$, so does increasing the surrounding gas temperature. The particle temperature 
will decrease or further increase after the initial temperature rise toward the maximum particle temperature depending on the conditions. The relative magnitude of heat generation and heat loss determines the shape of the carbon oxidation which depends on the particle diameter and the surrounding gas temperature.

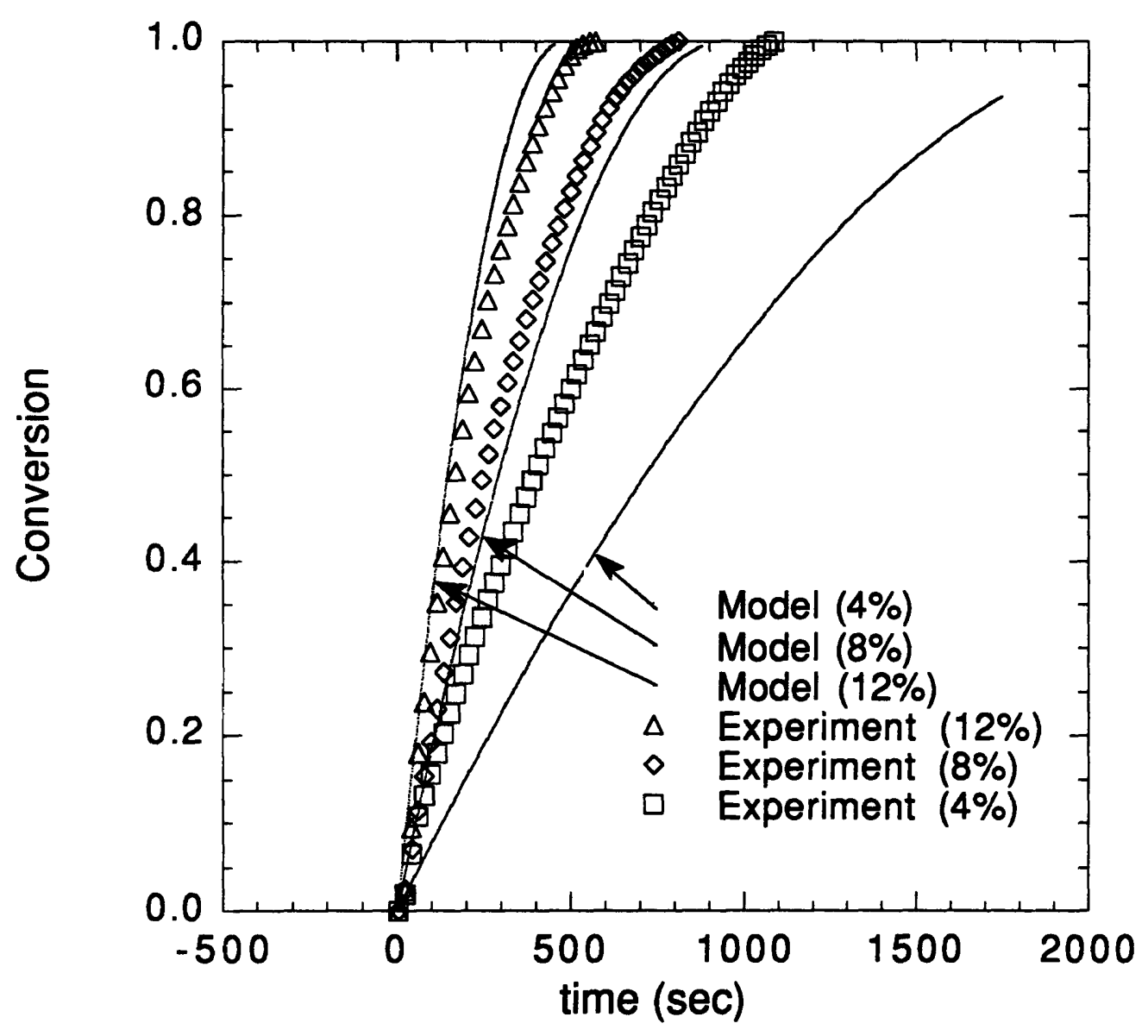

Fig.3.5 Conversion curves at different oxygen partial pressure (First order intrinsic reaction, $\mathrm{T}_{\mathrm{g}}=1023 \mathrm{~K}, \mathrm{~d}_{\mathrm{p}}=4 \mathrm{~mm}$ )

Modeling the conversion curves of different oxygen partial pressures can be used to find out the actual intrinsic reaction order. The first order reaction coefficient of $305 \exp (-$ 42/RT) (Smith, 1978) was used in Fig.3.5. The use of the first order intrinsic reaction predicts a broader spectrum of conversion curves as the oxygen partial pressure changes. 
The different activation energies of 36 and $20 \mathrm{kcal} / \mathrm{mol}$ were used to see the effect of the activation energy in Fig.3.6 and Fig.3.7, and the pre-exponential factors were adjusted to produce the same reaction rate at the pseudo-steady state combustion temperature of $8 \%$ oxygen partial pressure. Changing the activation energy only does not have a profound effect on the combustion times. Using a lower activation energy produces a narrower spectrum of conversion curves, which are not narrow enough to follow the changes of different oxygen partial pressures. This means that the initial temperature rise changes due to the different oxygen partial pressure are larger than they should be, that suggests the need to use a lower oxygen intrinsic reaction order.

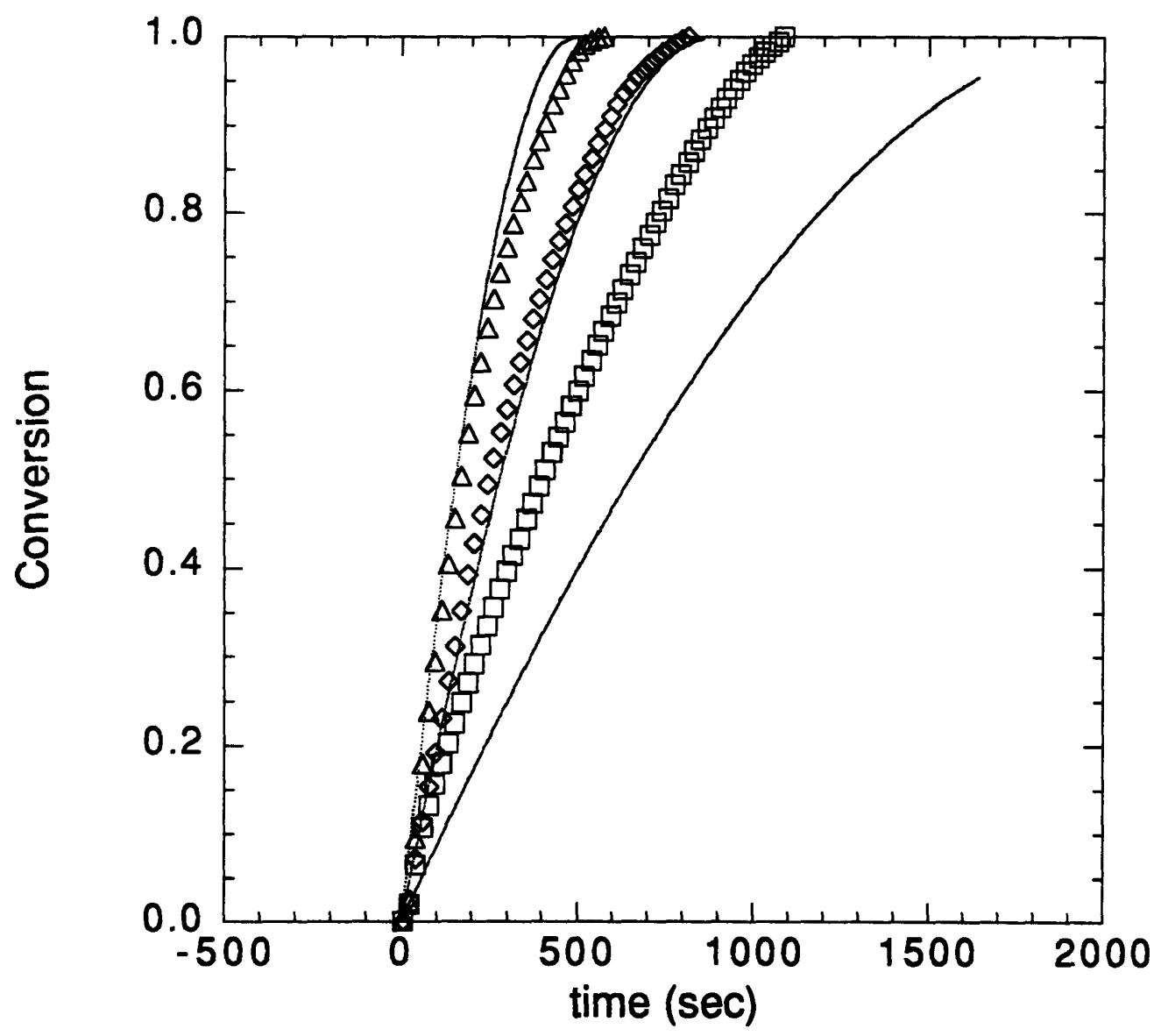

Fig.3.6 Conversion curves at different oxygen partial pressure

(First order intrinsic reaction, $E_{a}=33 \mathrm{kcal}, \mathrm{T}_{\mathrm{g}}=1023 \mathrm{~K}, \mathrm{~d}_{\mathrm{p}}=4 \mathrm{~mm}$ ) 


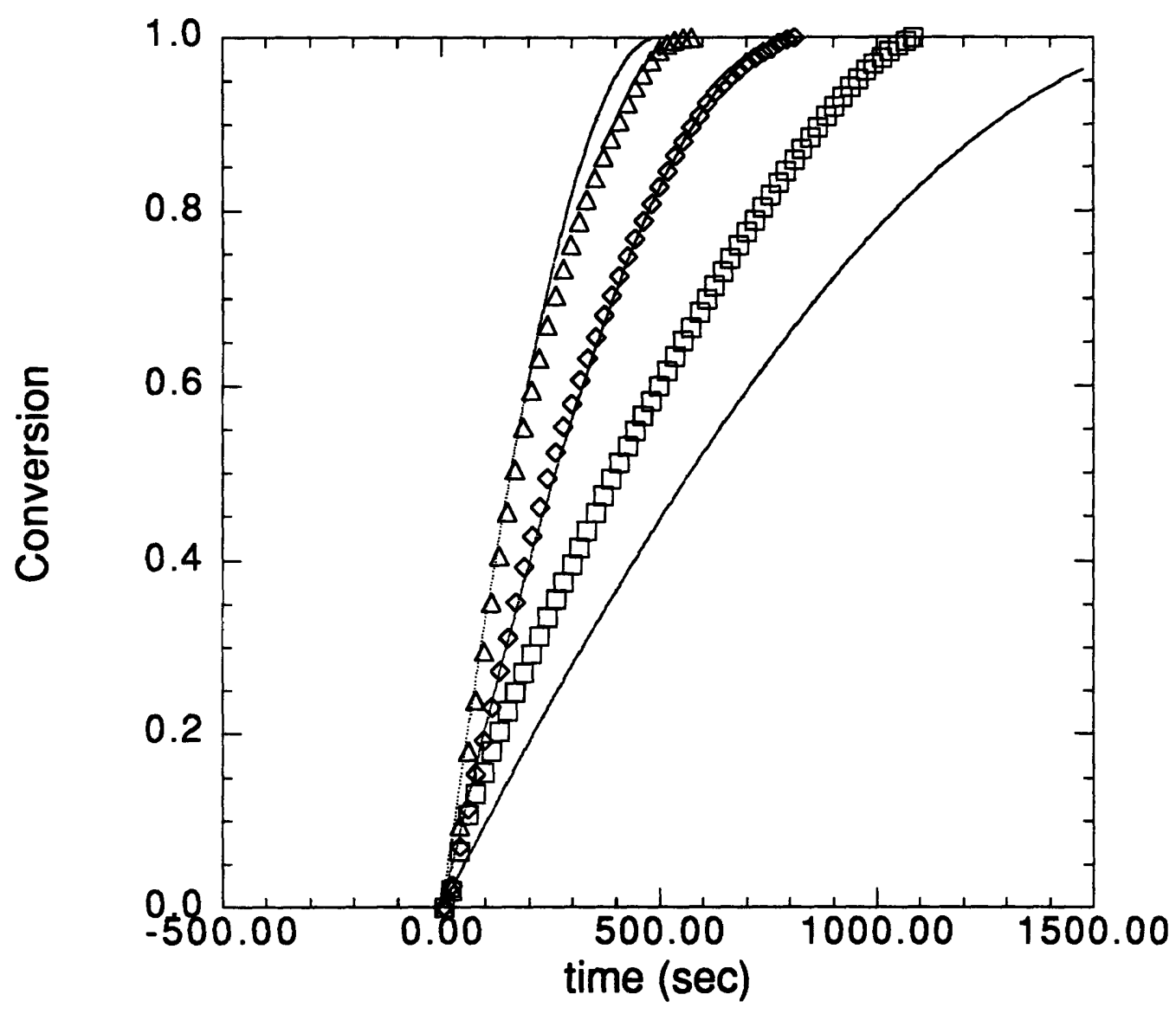

Fig.3.7 Conversion curves at different oxygen partial pressure

(First order intrinsic reaction, $E_{a}=20 \mathrm{kcal}, \mathrm{T}_{\mathrm{g}}=1023 \mathrm{~K}, \mathrm{~d}_{\mathrm{p}}=4 \mathrm{~mm}$ )

Fig.3.8 shows results for a zero intrinsic reaction order case. The conversion curves of the experiments and the modeling for oxygen partial pressure from $2 \%$ to $20 \%$ at $1073 \mathrm{~K}$ are shown. The activation energy used for the modeling was $20 \mathrm{kcal} / \mathrm{mol}$. Using the zero intrinsic reaction rate produces conversion curves narrower than the experimental conversion curves. 


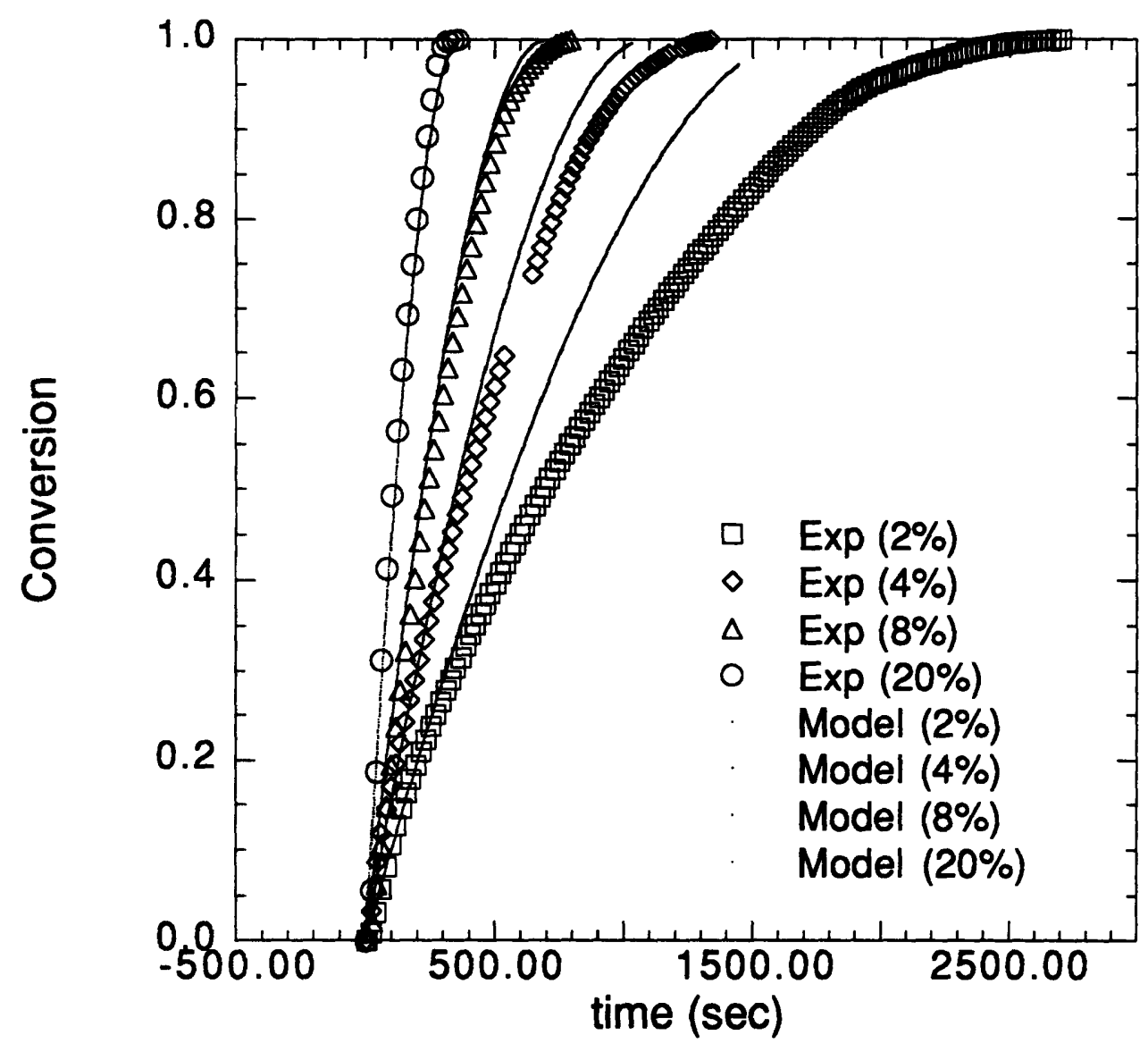

Fig.3.8 Conversion curves at different oxygen partial pressure

(Zero order intrinsic reaction, $\mathrm{E}_{\mathrm{a}}=20 \mathrm{kcal}$,

$$
A_{0}=4.8 * 10^{-4}, T_{g}=1073 \mathrm{~K}, \mathrm{~d}_{\mathrm{p}}=4 \mathrm{~mm} \text { ) }
$$

The use of the half order intrinsic reaction and an activation energy of $20 \mathrm{kcal} / \mathrm{mol}$ shows a good agreement between the calculated and experimental results in Fig.3.9. The activation energy of a char is highly dependent on char characteristics and structures, and the mineral impurities in the char. Usually the char obtained from a low rank coal exhibit a 
higher activation energy than that obtained from a high rank coal. There exists a wide range of activation energies for the carbon-oxygen reaction in the literature ranging from 4 $\mathrm{kcal} / \mathrm{mol}$ to $80 \mathrm{kcal} / \mathrm{mol}$. The review by Smith (Smith, 1980) showed that the apparent activation energy for coal chars (size $13-89 \mu \mathrm{m}$ ) is in the range of $16-34 \mathrm{kcal} / \mathrm{mol}$ and the apparent order of reaction is between 0.5 and 1 . The activation energy of petroleum coke varies from 15 to $42 \mathrm{kcal} / \mathrm{mol}$ and the intrinsic reaction order is close to 0.5 . Because the size of the particle affects the activation energy and the order of reaction, the values for the pulverized coal particles can not be used directly for the coal used in the fluidized bed but can be used as reference.

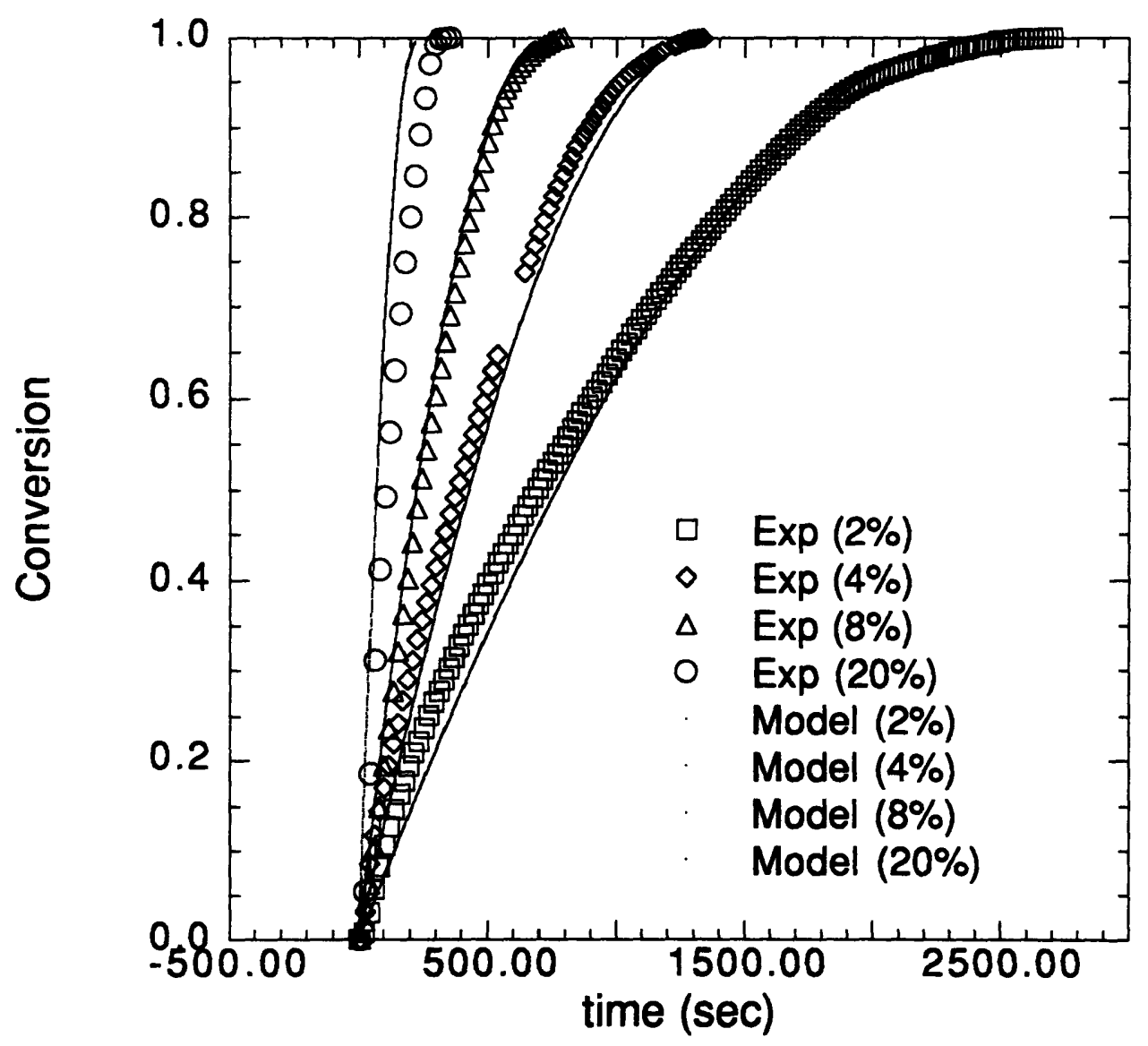

Fig.3.9 Conversion curves at different oxygen partial pressure

(Half order intrinsic reaction, $E_{a}=20 \mathrm{kcal}, A_{0}=0.35, T_{g}=1073 \mathrm{~K}, \mathrm{~d}_{\mathrm{p}}=4 \mathrm{~mm}$ ) 
Because there are particle-particle variations and experimental error, we need more data to determine the exact reaction rate coefficient and reaction order. However, a half order intrinsic reaction, a pre-exponential factor of 0.35 , and an activation energy of $20 \mathrm{kcal} / \mathrm{mol}$ are suitable values to represent Newland char combustion in the fluidized bed combustion in this temperature range.

There exists a tendency of a reduced reaction rate in the experimental results especially with low oxygen concentration, as the particle approaches a high conversion. The discrepancy between the modeling and experimental curves at the high conversion may be due to the effect of decreasing reactivity during the reaction by graphitization at high burn out (Hurt, 1993). The loss of reactivity seems to be proportional to the length of time the particle stayed in the reactor. For the $2 \%$ experimental case, we can observe the slope of conversion is changing at a relatively low conversion. This is contrary to the steady conversion behavior for a high oxygen concentration case. Because the total conversion time for $2 \%$ is about $2500 \mathrm{sec}$ (more than $\mathbf{4 0} \mathrm{min}$ ), the carbon particle may have enough time to suffer physical or chemical structure changes affecting its reactivity. Further studies will verify this effect in carbon oxidation reaction.

\subsubsection{Temperature profile and excess temperature (using Agarwal's model)}

A more sophisticated heat and mass transfer model developed by Agarwal was used to better describe the combustion behavior of the char particle. Each component of the mean heat transfer coefficient is calculated by Eq.3.10-13 to determine their relative contributions. The results for conditions of $8 \%$ oxygen partial pressure, $4 \mathrm{~mm}$ particle size, and a surrounding gas temperature of $1073 \mathrm{~K}$ are shown in Fig.3.10. The magnitude of the each component is in the order of $h_{p c, u}, h_{p c, d}, h_{g c}$, and $h_{b u b}$. However, if we multiply the probability term to the component, the relative contribution of the each component is in the order of $\left(p-p^{\prime}\right){ }^{*} h_{p c, d}, p^{\prime} h_{p c, u}, p^{*} h_{g c}$, and $(1-p) * h_{b u b}$. The probability that a 
particle is in the emulsion phase during one whole circulation, $p$, is 0.92 , and the probability that it is in the emulsion phase during its rise, $p^{\prime}$, is 0.27 at these conditions.

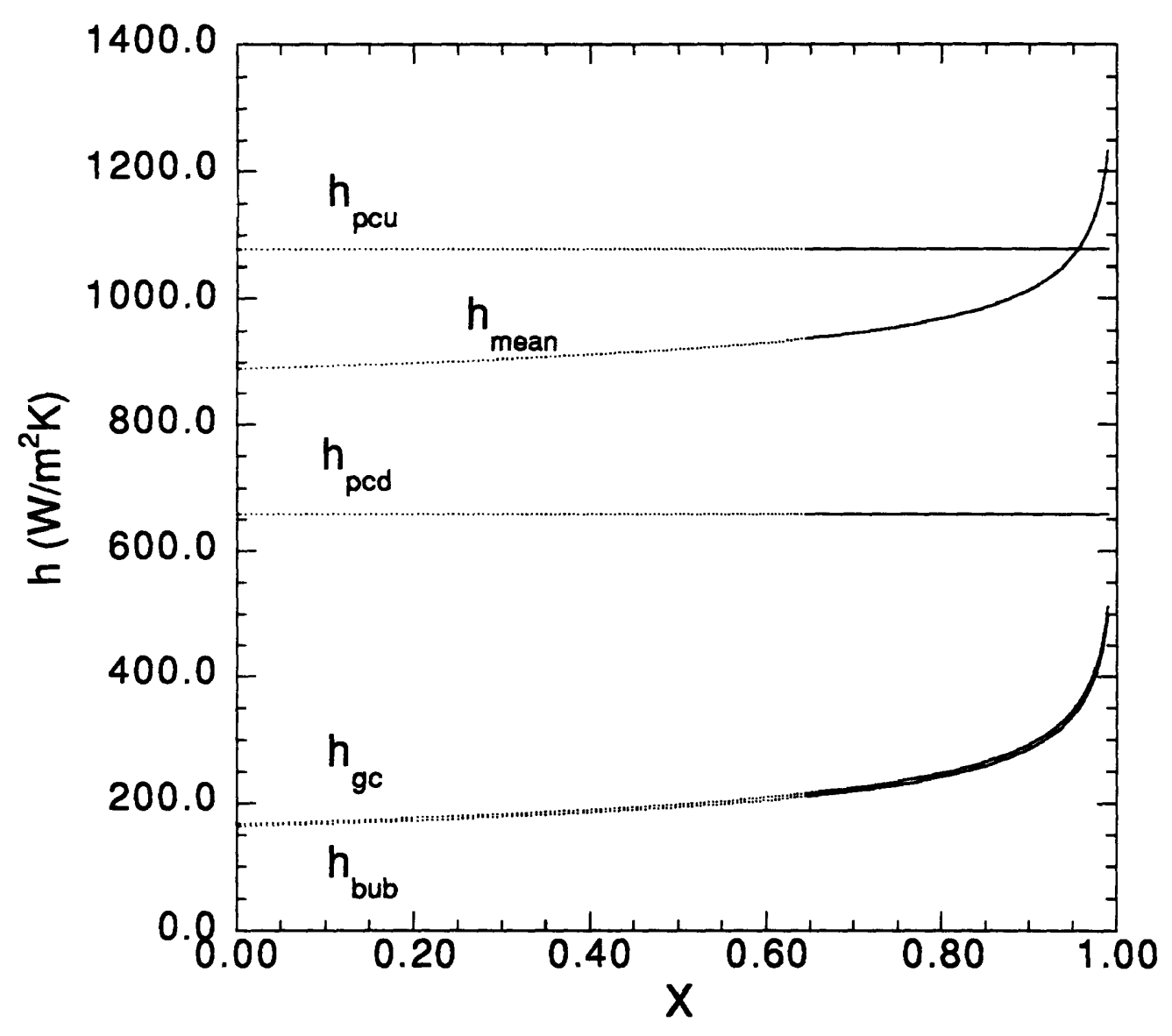

Fig.3.10 Mean heat transfer coefficient and components of heat transfer coefficients in the fluidized bed (Half order intrinsic reaction, $\mathrm{PO}_{2}=8 \%, \mathrm{~T}_{\mathrm{g}}=1073 \mathrm{~K}, \mathrm{~d}_{\mathrm{p}}=4 \mathrm{~mm}$ )

Nusselt and Sherwood numbers from the model are calculated as a function of conversion in Fig.3.11. Sherwood number is about 0.8, which means that the external mass transfer to the particle surface is limited by the bed particles which are smaller than the char particle. On the contrary, the Nusselt number is high, because the small size bed 
particles enhance the heat removal from the particle by making the contact to the particle surface easier.

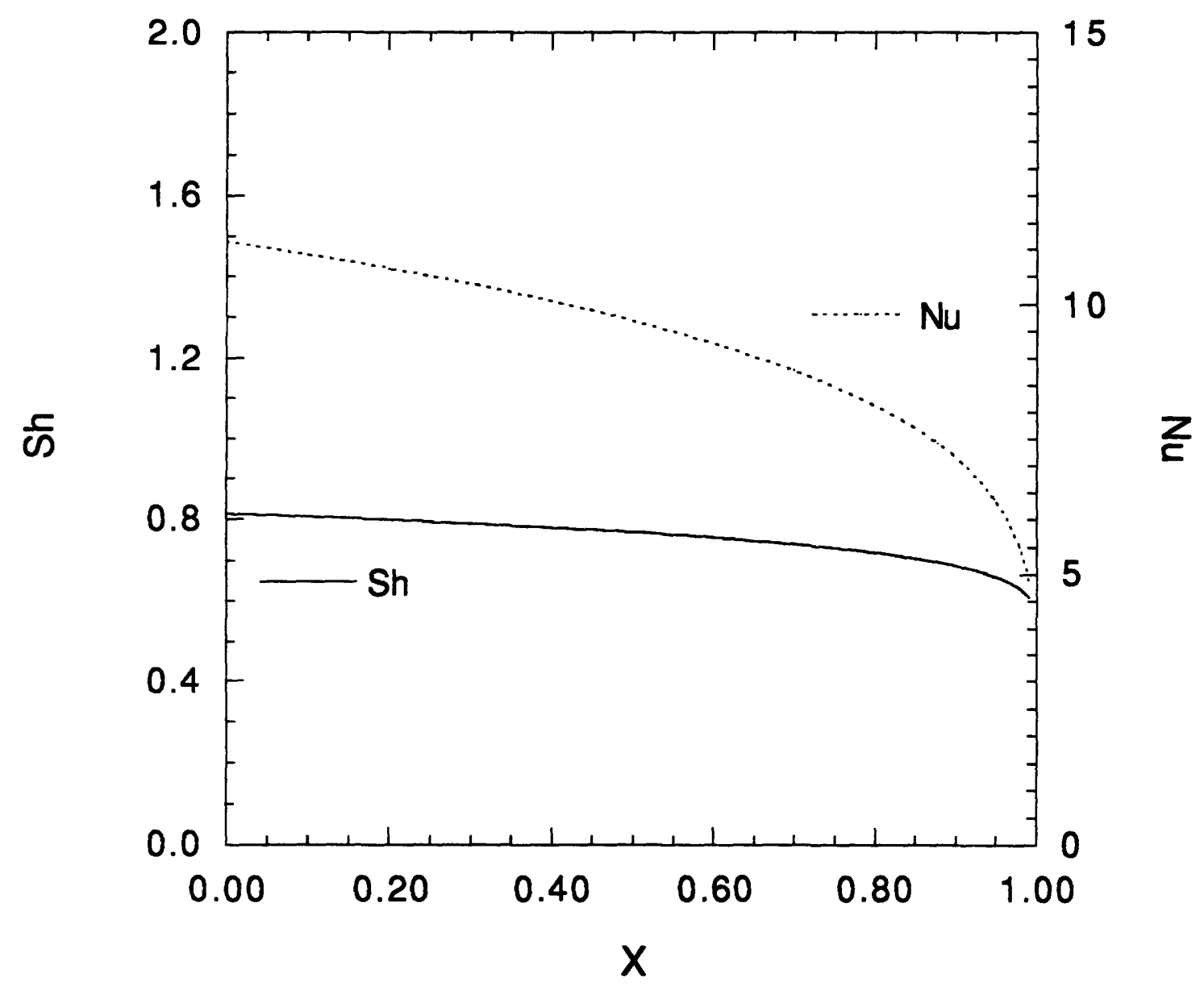

Fig.3.11 Sherwood and Nusselt number in the fluidized bed (Half order intrinsic reaction, $\mathrm{PO}_{2}=8 \%, \mathrm{~T}_{\mathrm{g}}=1073 \mathrm{~K}, \mathrm{~d}_{\mathrm{p}}=4 \mathrm{~mm}$ )

The half order intrinsic reaction, of oxygen with carbon the pre-exponential factor of 0.39 , and the activation energy of $20 \mathrm{kcal} / \mathrm{mol}$ were used in Fig.3.12. The surrounding gas temperature was $1073 \mathrm{~K}$. The results at $1123 \mathrm{~K}$ and $1023 \mathrm{~K}$ are shown in Fig.3.13 and Fig.3.14. Despite a small discrepancy at $1023 \mathrm{~K}$, these values seem to be reasonable at this temperature range (1023-1123 K), and the oxygen partial pressures (2-20\%). The heat 
transfer coefficient calculated by this model is higher than the value predicted by Eq.3.3. That is why we need higher pre-exponential factor of 0.39 to fit the data. Therefore, the initial temperature rise is smaller than the value predicted by La Nauze's model.

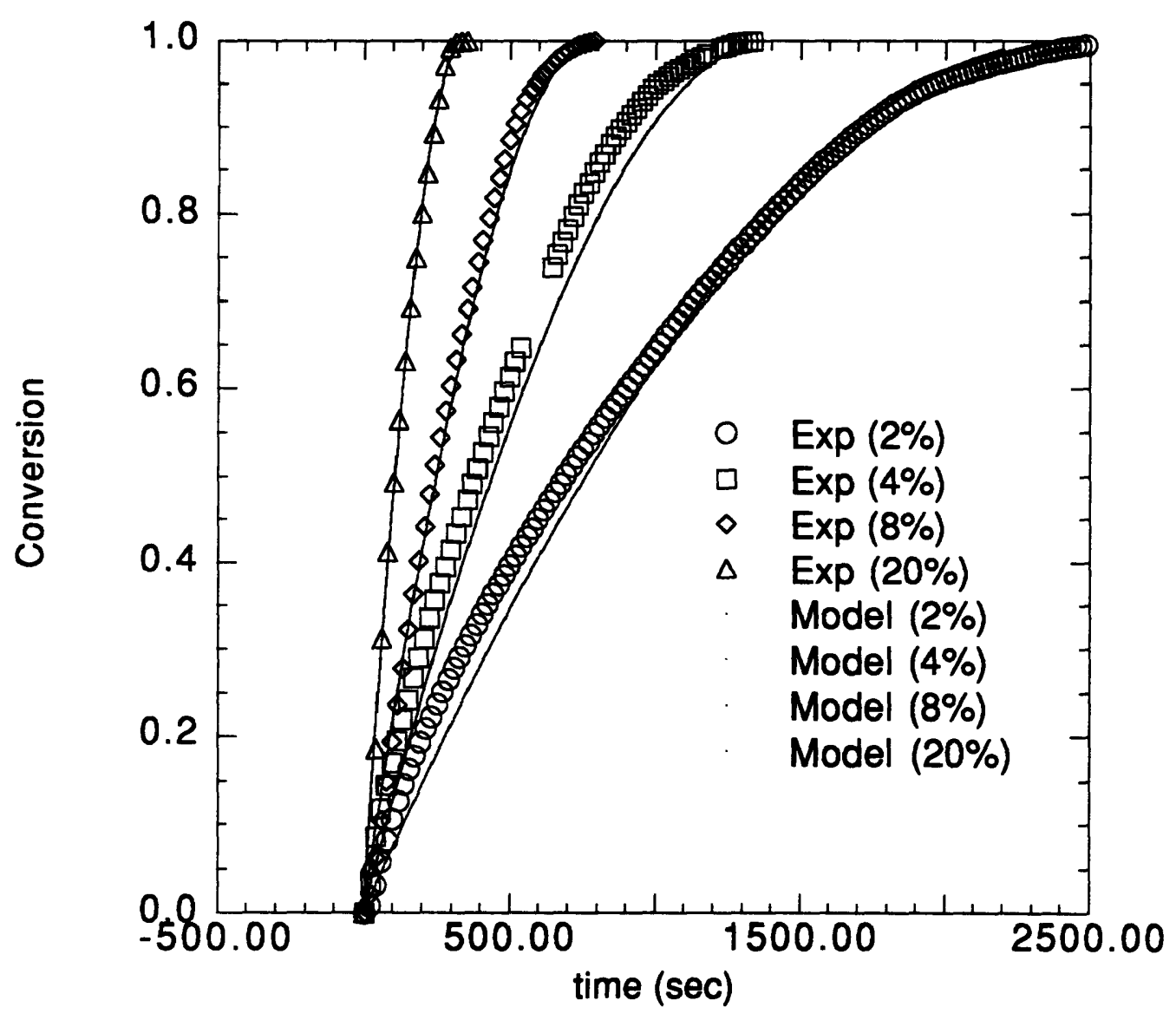

Fig.3.12 Conversion curves at different oxygen partial pressure (Half order intrinsic reaction, $E_{a}=20 \mathrm{kcal}, A_{0}=0.39, T_{g}=1073 \mathrm{~K}, d_{p}=4 \mathrm{~mm}$ ) 


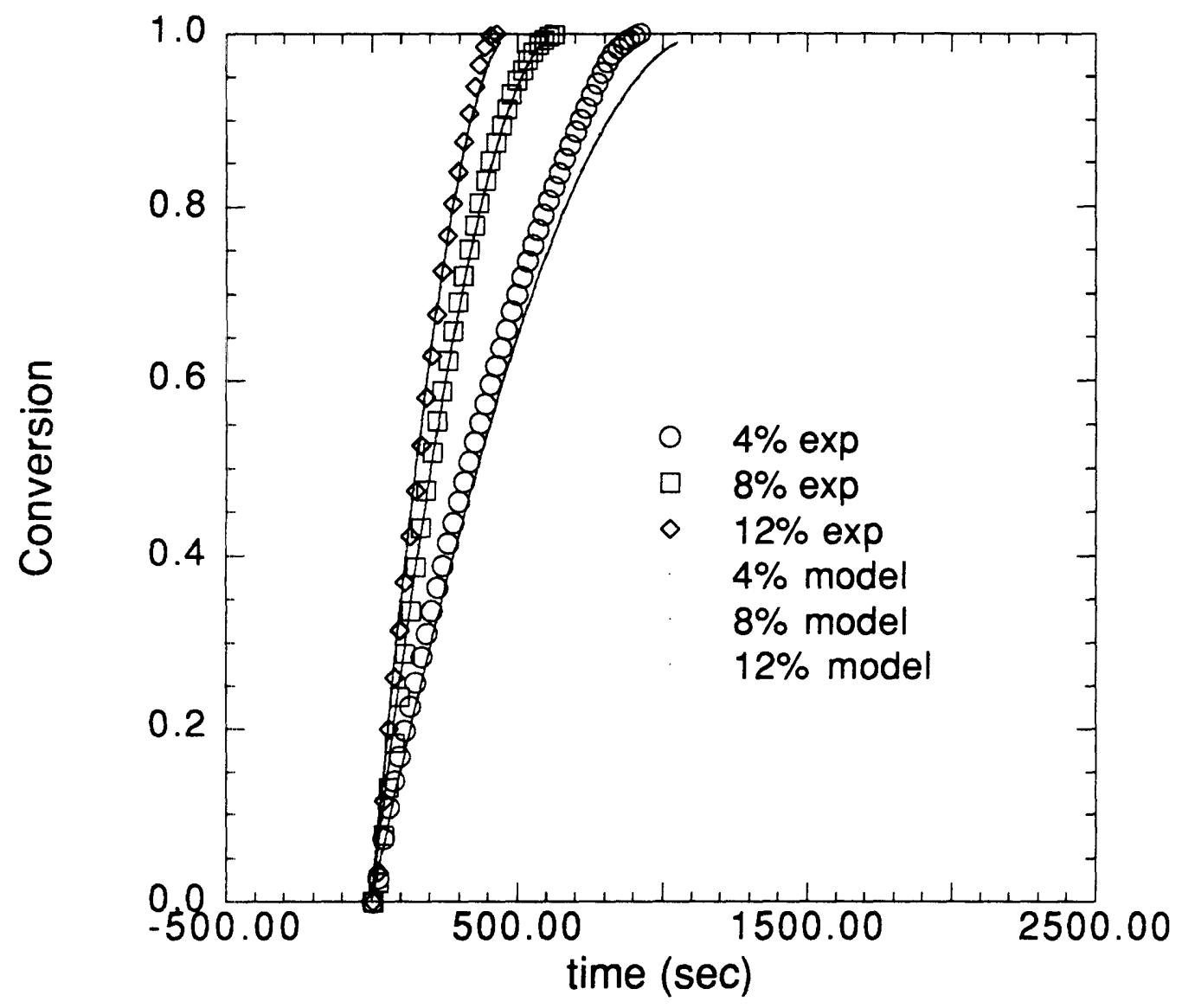

Fig.3.13 Conversion curves at different oxygen partial pressure (Half order intrinsic reaction, $E_{a}=20 \mathrm{kcal}, A_{0}=0.39, T_{g}=1123 \mathrm{~K}, d_{p}=4 \mathrm{~min}$ ) 


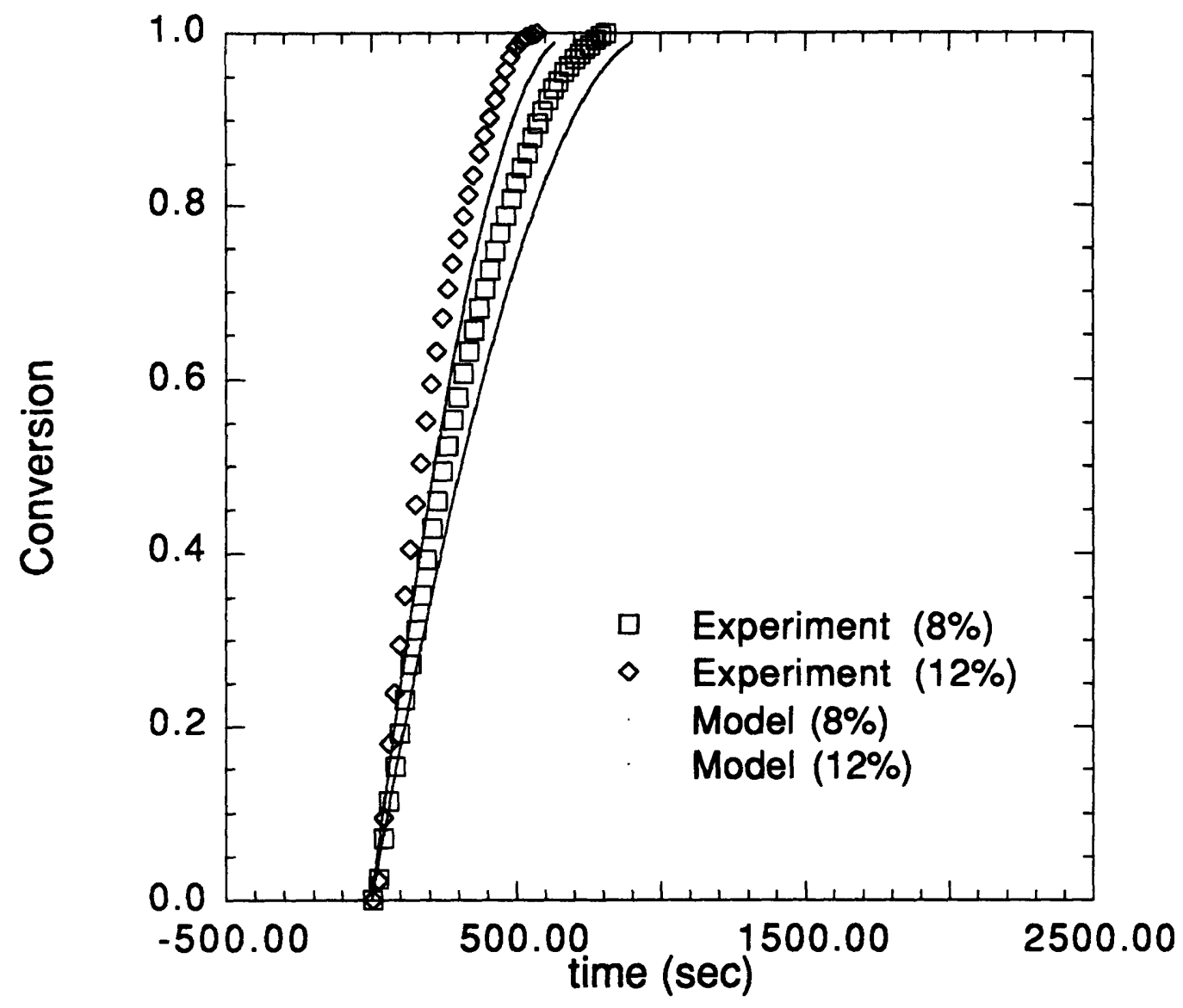

Fig.3.14 Conversion curves at different oxygen partial pressure (Half order intrinsic reaction, $E_{a}=20 \mathrm{kcal}, A_{0}=0.39, T_{g}=1023 \mathrm{~K}, \mathrm{~d}_{\mathrm{p}}=4 \mathrm{~mm}$ ) 
The temperature profiles of different oxygen partial pressures at 1073K are shown in Fig.3.15. At low oxygen partial pressure - 2\% case- the initial temperature rise is negligible. The initial temperature rise is approximately proportional to the oxygen partial pressure, and the slope is $300 \mathrm{~K} / \mathrm{atm}$ at $1073 \mathrm{~K}$.

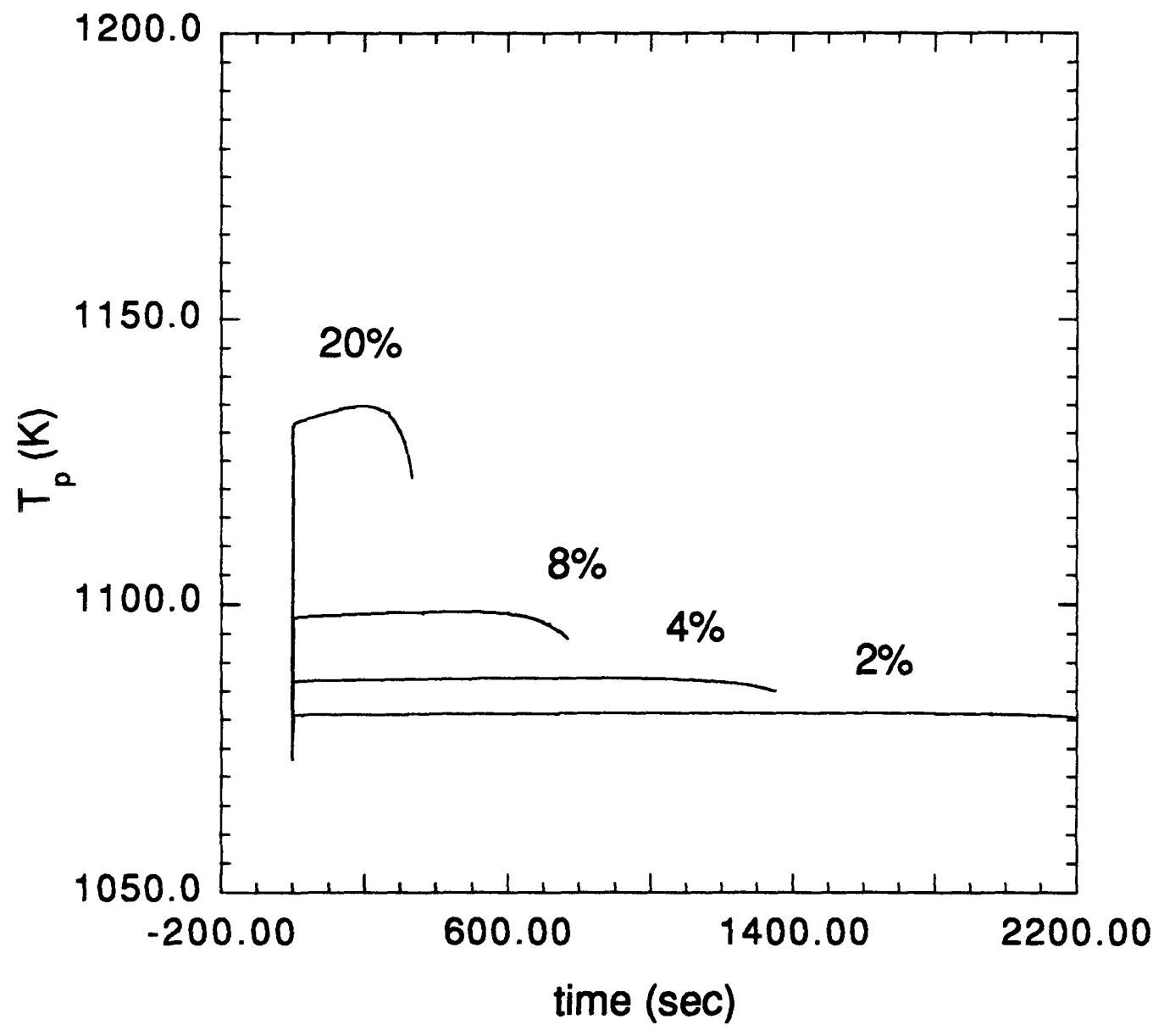

Fig.3.15 Temperature profiles of different oxygen partial pressures (Half order intrinsic reaction, $E_{a}=20 \mathrm{kcal}, A_{0}=0.39, T_{g}=1073 \mathrm{~K}, \mathrm{~d}_{\mathrm{p}}=4 \mathrm{~mm}$ ) 
The excess temperatures (the difference between the maximum particle temperature and the surrounding gas temperature, $T_{\max }-T_{g}$ ) for different oxygen partial pressures and surrounding gas temperatures are shown in Fig.3.16. The excess temperature increases as the oxygen partial pressure and the surrounding gas temperature increase, and it is as big as $83 \mathrm{~K}$ at $21 \%$ and $1123 \mathrm{~K}$.

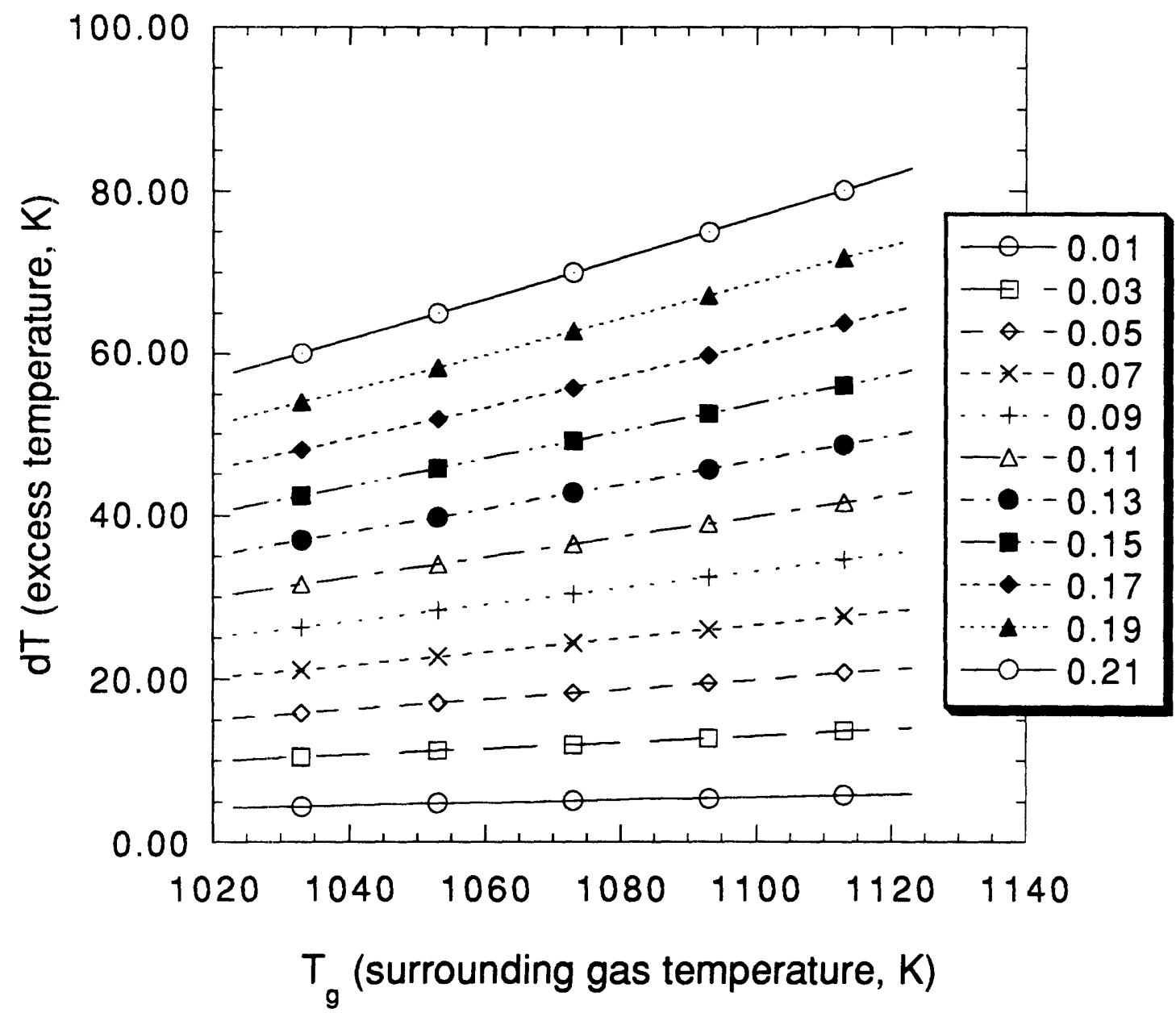

Fig.3.16. Excess temperature as a function of surrounding gas temperature with different oxygen partial pressures 


\subsubsection{Effects of fluidized bed conditions}

The particle size, the superficial velocity, and other fluidized bed combustion conditions will effect the temperature profile and the burning time of a char particle. The bed particle size used in our experiments was $180 \mu \mathrm{m}$. The excess temperature of char particles of 1-6 mm size are calculated to see the effect of the particle size in Fig.3.17. The excess temperature keeps increasing as the particle size grows, but the magnitude of the increase is decreasing. At an higher oxygen partial pressure of $20 \%$, the temperature rise is greater and its dependence on particle size is steeper than those at $8 \%$.

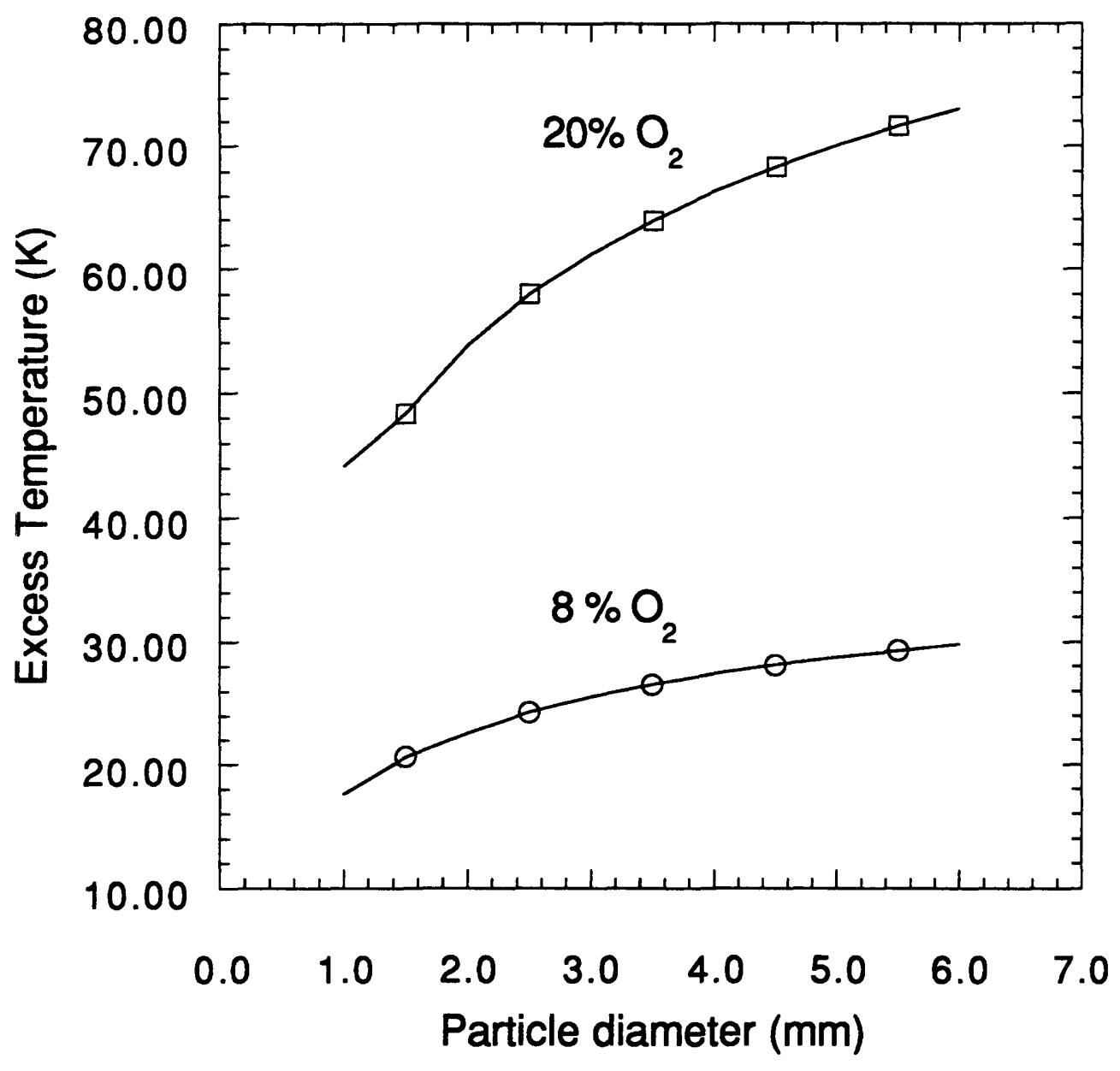

Fig.3.17 Excess temperature vs. particle diameter $\left(T_{g}=1073 \mathrm{~K}\right)$ 
Two opposing factors exist as the particle size increases. The positive factor is the increased reaction rate due to the bigger particle size, and the negative one is the higher heat transfer rate due to the size difference between the char particle and the bed particle. Sh and $\mathrm{Nu}$ numbers decrease as the conversion approaches one as shown in Fig.3.11, which means that a bigger particle has higher a Sh number. Because the external mass transfer is limiting in the fluidized bed combustion condition, the higher Sh number for the bigger particle size means the higher reaction rate. If the additional heat loss from the increase in the particle size is bigger than the heat gain from the increased external oxygen transfer rate, the excess temperature of the particle can decreases as the particle size increases.

Why Sh \& Nu increases as the particle size increases? Although the plot of 'Sh \& $\mathrm{Nu}$ number in the fluidized bed' was made after calculations of complex equations, the import factor determining the Sherwood number is the increased $\operatorname{Re}(=\mathrm{Ud} / \mathrm{v})$ and the one determining the $\mathrm{Nu}$ is the reduced contact resistance. (which decreases as the ratio of bed particle size to the char particle size decreases)

The effect of superficial velocity on the excess temperature is calculated in Fig.3.18. As the superficial velocity increases, the excess temperature drops due to the increased heat transfer. It approaches to a asymptotic value as the superficial velocity increases. 


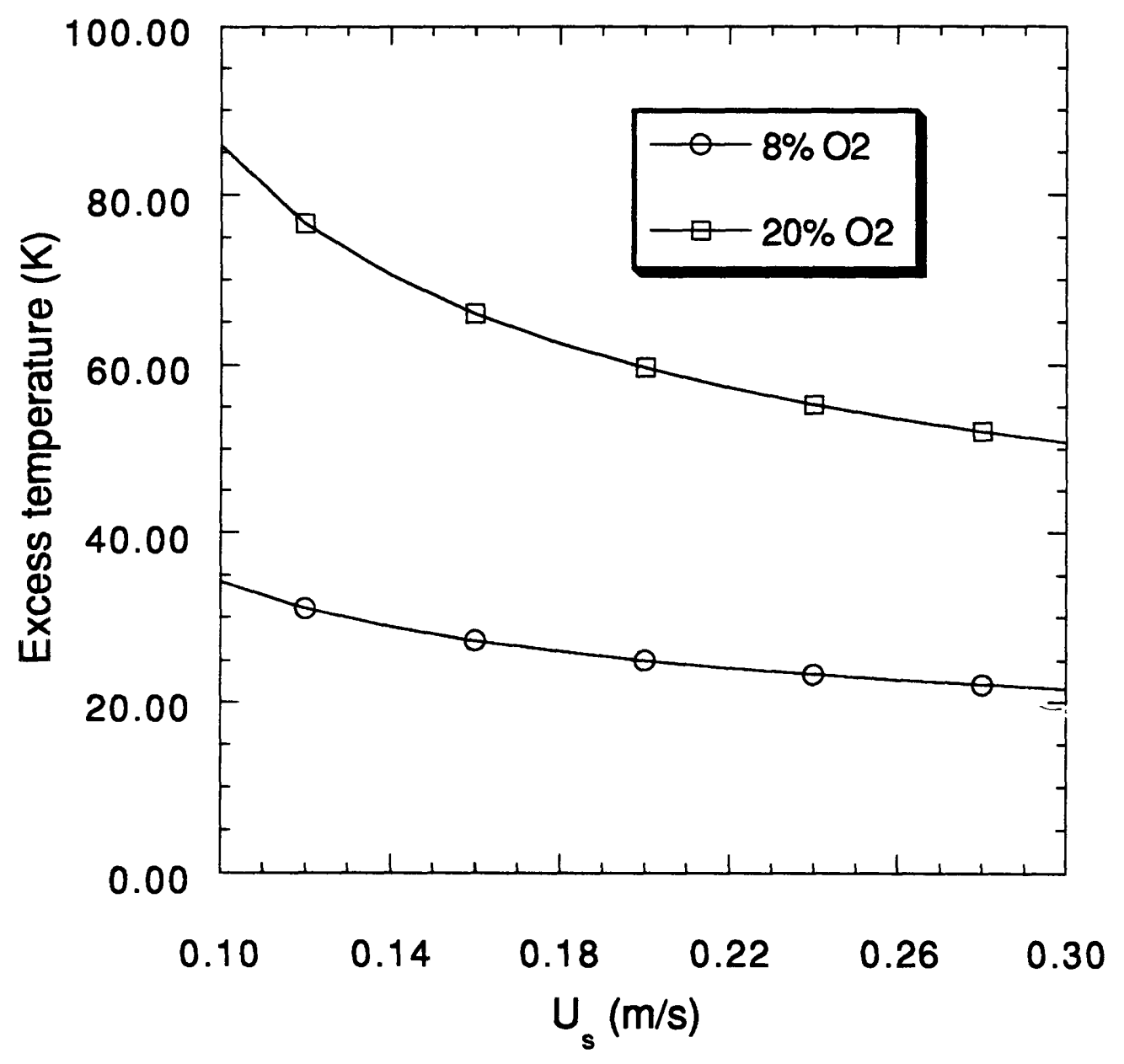

Fig.3.18 Excess temperature vs. superficial velocity $\left(\mathrm{d}=4 \mathrm{~mm}, 1073 \mathrm{~K}, 8 \% \mathrm{O}_{2}\right)$ 


\section{Chapter 4}

\section{Modeling of CO Oxidation}

\section{in the Gas Phase}

$\mathrm{CO}$ and $\mathrm{CO}_{2}$ are found to be the two most important primary products of the heterogeneous reaction. $\mathrm{CO}$ will be further oxidized to $\mathrm{CO}_{2}$ by the subsequent reactions. There are two possibilities of the location where the additional $\mathrm{CO}_{2}$ generation occurs: One is in the macro or meso pores inside the char particle, and the other is in the gas phase. Because the energy balance of the particle is changed according to the location of $\mathrm{CO}$ oxidation, it is important to determine where the $\mathrm{CO}$ oxidation happens. Modeling of gas phase reaction around the burning particle has been a difficult problem due to several reasons including high temperatures, complex coupling between the partial differential equations, and high degree of numerical stiffness. Until recently, most of the modeling studies assume quasi-steady state, constant gas thermodynamic and transport properties, and global reaction kinetics.

Amundson and his coworkers (Sundaresan et al.,1981) calculated CO oxidation as a function of temperature, particle size, and water vapor concentration. The water vapor in the gas phase participate in the combustion through carbon-steam reaction and by 
accelerating homogeneous oxidation in the boundary layer. They found that small particles (diameter smaller than $200 \mu \mathrm{m}$ ) benefit very little from the presence of the water vapor, while for big particles there is significant increase in the combustion rate and $\mathrm{CO}$ oxidation in the boundary layer. The weak points of their results are using of global kinetics for $\mathrm{CO}$ oxidation and neglecting any reaction in the pores. They used the quasi-steady-state assumption and the average heat capacity of the gas mixture and the solid for modeling. Essenhigh (Kurylko et al., 1973) calculated the effect of the reaction inside the particle but they considered a much larger particle of a size of the order of one centimeter. They developed a finite-element model to simulate combustion behavior, and showed that more $\mathrm{CO}$ burned in the boundary layer at higher temperatures and the temperature profile was highly dependent upon the penetration of the reacting gases. Mitchell (Mitchell et al., 1990) used the correct complete reaction set, and concluded that the $\mathrm{CO}$ oxidation in the boundary layer for their condition (gas temperature $1500-1700 \mathrm{~K}$, oxygen partial pressure $12 \%$ or less) could be neglected. They found that a simple one film reaction model was applicable for particles in the condition of pulverized-coal combustor, but they also neglected the reaction in the pores. Cho and coworkers (Cho et al. 1992, Lee et al., 1993) suggested a general approach to the carbon combustion problem. The moving boundary has been treated by the density coordinate transformation. Unlike the usual assumptions made in the previous modeling, e.g., steady state, some constant values of thermal properties, and selective set of gas phase reactions, they tried to develop a general model which is applicable to many problems. But the assumption of surface reaction may not be suitable for the non-diffusion limited case (low surface temperature or when macro or mesopores are responsible for the heterogeneous reaction), where the oxygen penetrates into the entire particle. The surface reaction mechanism they used for the calculation is 5 step mechanism proposed by Bradley, which lacks the reaction producing $\mathrm{CO}_{2}$ and produce lower carbon consumption rate. They varied the ambient gas temperature and used dry oxygen and $1 \%$ 
water concentration. They found that only moist-air enhanced the $\mathrm{CO}$ oxidation in the gas phase.

In this model, we use a fully time-dependent approach to model the dynamic behavior of gas phase reactions. Galerkin finite elements method is employed to resolve the spatial discretization. By incorporating all elementary reactions and species and using the time dependent approach, this modeling study will predict the gas species and the temperature distributions in the gas phase around the particle and will accomplish more accurate understanding about $\mathrm{CO}_{2}$ formation during char combustion. 


\subsection{Theory}

\subsubsection{Governing equations}

The problem of interest is modeling of gas phase reactions around a single char particle. The carbon consumption rate is calculated from the temperature profile model introduced earlier in chapter two. The total combustion time of the model was almost the same as that of the experimental result. That means the carbon consumption rate calculated by the model is close to the actual carbon consumption rate. Because more than $90 \%$ of carbon consumption occurs at the quasi-steady state burning temperature, most of the gas phase reactions take place at this particle surface temperature. The $\mathrm{CO}_{2} / \mathrm{CO}$ ratio measured by the experiment is the summation of generations at all the temperatures during the reaction. It is reasonable to assume that the $\mathrm{CO}_{2} / \mathrm{CO}$ ratio measured experimentally represents the $\mathrm{CO}_{2} / \mathrm{CO}$ ratio at the quasi-steady state burning temperature, because most of the carbon consumption happens at this temperature. Therefore, we can calculate experimental measurements of $\mathrm{CO}_{2} / \mathrm{CO}$ ratio with less than $10 \%$ error by giving the pseudo-steady state burning temperature and carbon consumption rate as boundary conditions. Here we assume the constant particle diameter when we calculate $\mathrm{CO}_{2} / \mathrm{CO}$ ratio from the gas phase reaction. During the reaction the particle diameter shrinks, and this makes less $\mathrm{CO}_{2}$ in a real situation. Before reaching the steady state burning temperature, there is more $\mathrm{CO}_{2}$ from the heterogeneous reaction at lower temperatures than that of higher temperatures. These two effects have opposite influences on $\mathrm{CO}_{2} / \mathrm{CO}$ ratio and mitigate the effect of shrinking particle. Also, spherocarb exhibit a relatively constant diameter burning until the end of reaction (Waters,1988). For example, the particle diameter is $74 \%$ of the original value when the conversion reaches $70 \%$. 
The governing equations for conservation of species and energy are one dimensional and time dependent. The geometry is that the char particle, located at the left side of the model domain, is in contact with reactive gas species of infinite thickness. All the detailed multi-component gas phase diffusions and reactions are considered. Because the case of uniform pressure is considered here, the momentum equation is satisfied trivially and the radial velocity is calculated from the continuity equation. The governing equations for species, energy, and overall mass balance in the gas phase are as follows:

(i) Conservation equation for species $i$

$\rho_{g} \frac{\partial Y_{i}}{\partial t}+\rho_{g} v_{r} \frac{\partial Y_{i}}{\partial r}=-\frac{1}{r^{2}} \frac{\partial}{\partial r}\left(r^{2} \rho_{g} Y_{i} V_{i}\right)+R_{i}$

(ii) Energy balance equation for the gas phase

$$
\begin{aligned}
& \rho_{g} C_{p, g} \frac{\partial T}{\partial t}+\rho_{g} C_{p, g} v_{r} \frac{\partial T}{\partial r}=\frac{1}{r^{2}} \frac{\partial}{\partial r}\left(r^{2} \lambda_{g} \frac{\partial T}{\partial r}\right)-\rho_{g} \sum_{i=1}^{n}\left(Y_{i} V_{i} C_{p, i}\right) \\
& -\sum_{i=1}^{n} R_{i} H_{i}
\end{aligned}
$$

(iii) Conservation equation for mass

$$
\frac{\partial \rho_{g}}{\partial t}+\frac{1}{r^{2}} \frac{\partial}{\partial r}\left(r^{2} \rho_{g} v_{r}\right)=0
$$




\subsubsection{Galerkin finite elements method}

To calculate the spatial dependence of temperature and concentration, it is necessary to use a numerical method capable of spatial discretization. Among many methods Galerkin finite elements method is well established for solving partial differential equations. Detailed theories are available in the literature (Finlayson, 1980, and Johnson, 1987).

First we need to define basis functions. The space domain will be divided by $\mathrm{N}$ elements, and $\mathrm{N}+1$ basis functions can be defined as in Fig.4.1. These functions have a value of one at each node, but are zero at the other nodes. The trial function is compose of a linear combination of these basis function. For higher accuracy, we can use higher order basis functions. Here, linear basis functions will be used for the simplicity and faster computation time.

$$
\begin{aligned}
& T(r)=\sum_{k=1}^{N+1} T_{k} \Phi^{k}(r) \\
& Y_{i}(r)=\sum_{k=1}^{N+1} Y_{i k} \Phi^{k}(r)
\end{aligned}
$$

By multiplying the basis function to the residual equation after substituting these trial functions to it and integrating the residual equation, we can get simple tridiagonal matrices. During the integration, natural boundary conditions (flux boundary condition) can be easily incorporated. Essential boundary conditions can be added by changing conditions at the specific node to satisfy boundary condition. 

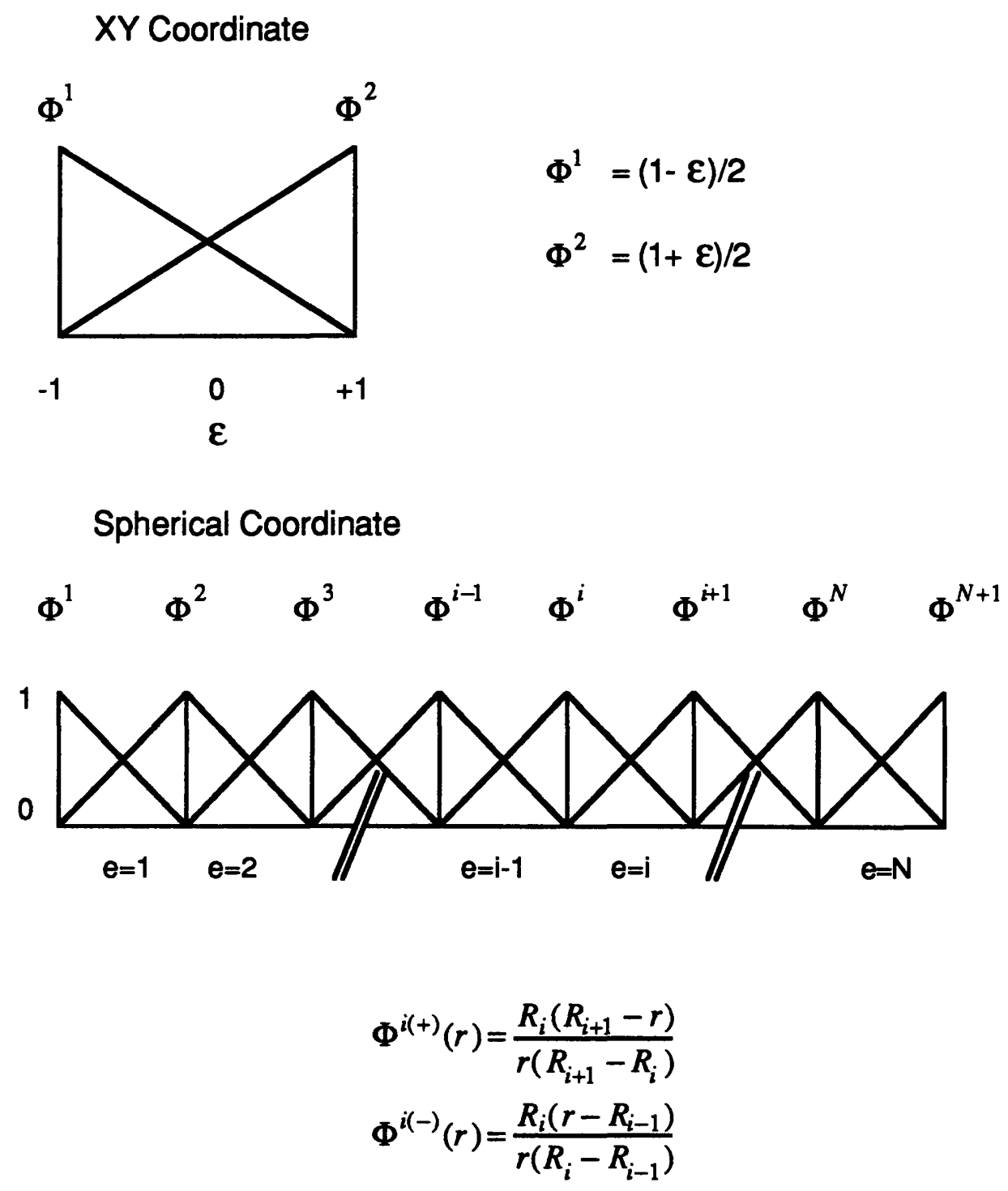

Fig.4.1 Linear basis functions

\subsubsection{Stiffness matrices}

Based on the governing equations and the Galerkin finite elements method we can construct tridiagonal matrices. Matrices for species conservation equation are 


$$
\underline{\underline{M}} \frac{d \underline{Y_{i}}}{d t}=-\underline{\underline{A}} \underline{Y_{i}}+\underline{B}
$$

where $\underline{\underline{A}}=\rho v_{r} \int_{R_{o}}^{R_{\infty}} \Phi^{l} \frac{d \Phi^{k}}{d r} r^{2} d r-\rho V_{i} \int_{R_{o}}^{R_{\infty}} \frac{d \Phi^{l}}{d r} \Phi^{k} r^{2} d r$

$$
\begin{aligned}
& \underline{B}=R_{i} \int_{R_{o}}^{R_{\infty}} \Phi^{k} \Phi^{l} r^{2} d r \text {, and } \\
& \underline{\underline{M}}=\rho_{g} \int_{R_{o}}^{R_{\infty}} \Phi^{k} \Phi^{l} r^{2} d r .
\end{aligned}
$$

Boundary conditions for $\mathrm{O}_{2}, \mathrm{CO}$, and $\mathrm{CO}_{2}$ should be considered at the solid-gas interface. The term of $\left.\rho v_{r}\right]_{r=R_{o}} R_{o}{ }^{2}$ is added to the diagonal element of $\underline{\underline{A}}$ and $R_{o}{ }^{2} * f l u x$ is added to the corresponding element of residual vector. The values for the flux of $\mathrm{O}_{2}, \mathrm{CO}, \mathrm{CO}_{2}$ are $r_{c} \frac{4}{3}\left(f_{c o}-2\right), r_{c} \frac{7}{3} f_{c o}$, and $r_{c} \frac{11}{3}\left(1-f_{c o}\right)$.

A matrix for an energy conservation equation is

$$
\underline{\underline{M}} \frac{d \underline{T}}{d t}=-\underline{\underline{A}} \underline{T}+\underline{B}
$$

where $\underline{\underline{A}}=\rho\left(v_{r} C_{p, g}+\sum Y_{i} V_{i} C_{p, i}\right) \int_{R_{o}}^{R_{\infty}} \Phi^{l} \frac{d \Phi^{k}}{d r} r^{2} d r+\lambda_{g} \int_{R_{o}}^{R_{-}} \frac{d \Phi^{k}}{d r} \frac{d \Phi^{l}}{d r} r^{2} d r$

$$
\begin{aligned}
& \underline{B}=-\left(R_{i} H_{i}\right) \int_{R_{o}}^{R_{\infty}} \Phi^{k} \Phi^{l} r^{2} d r, \text { and } \\
& \underline{\underline{M}}=\rho_{g} C_{p, g} \int_{R_{o}}^{R_{\infty}} \Phi^{k} \Phi^{l} r^{2} d r
\end{aligned}
$$

Essential boundary conditions can be incorporated by setting a diagonal element as one, and changing the corresponding value of the residual vector to the essential condition value.

Boundary conditions at $R=R_{\propto}$ for the mass fractions and the temperature are 


$$
\begin{aligned}
& Y_{i}=Y_{i \infty} \\
& T=T_{\infty}
\end{aligned}
$$

During the process of partial integration of $\mathrm{Eq}(4.1)$ and $\mathrm{Eq}(4.2)$, we need to evaluate terms like following.

$$
\int f\left(T(r), Y_{i}(r)\right) * \alpha_{i}(r) \Phi^{i} \Phi^{j} r^{2} d r
$$

To solve the problem, it is essential to evaluate these terms. The difficulty is, however, that $f(r)$ is highly dependent on the temperature and the mass fraction of each species. We can usually use the nodal value of $f(r)$ and integrate the equation. If the temperature and mass fraction distribution are given by initial guesses, $f(r)$ can be calculated at each nodal point and new $Y_{i}(r), T(r)$ can be calculated. New values of $Y_{i}(r)$, $\mathrm{T}(\mathrm{r})$ will be used to update $f(\mathrm{r})$.

If $f(r)$ represents a reaction term, it needs special consideration due to the exponential dependence on temperature. If a linear combination of temperature or mass fraction is used to represent nodal value of reaction rate, the whole integration simplifies to be following by using the fact that only $\Phi^{k}\left(r_{k}\right)=1$.

$$
\begin{aligned}
& \int R\left(\sum_{i=1}^{N} \alpha_{i}(r) \Phi^{i}\right) * \Phi^{j} r^{2} d r \\
& =\int \sum_{k=1}^{N} R\left(\sum_{i=1}^{N} \alpha_{i}\left(r_{k}\right) \Phi^{i}\left(r_{k}\right)\right) \Phi^{k} * \Phi^{j} r^{2} d r \\
& =\int \sum_{k=1}^{N} R\left(\alpha_{k}\left(r_{k}\right)\right) \Phi^{k} * \Phi^{j} r^{2} d r
\end{aligned}
$$

This interpolation approach not only proved to be convenient but also gave numerical results that appear to be consistent with the behavior that would be expected. 


\subsubsection{Diffusion velocity}

The diffusion velocity $V_{i}$ is calculated by following.

$$
V_{i}=-\frac{1}{X_{i}} D_{i m} \frac{d X_{i}}{d r}-\frac{D^{T}}{\rho Y_{i} T} \frac{d T}{d r}
$$

There are two ways of calculating multi-component diffusion coefficient $D_{\mathrm{im}}$. One is mixture-average formulation based on the binary diffusion coefficient, and the other is using ordinary multi-component diffusion coefficients.

$$
\begin{aligned}
& D_{i m}=\frac{1-Y_{i}}{\sum_{j \neq i}^{K} X_{j} / D_{j i}} \\
& D_{i m}=-\frac{\sum_{j \neq i}^{K} M_{j} D_{i j} \nabla X_{j}}{\bar{M} \nabla X_{i}}
\end{aligned}
$$

A problem with mixture averaged formulation is that it is not well defined if the mixture goes to a pure species. To satisfy the constraint of $\sum_{i=1}^{K} V_{i} Y_{i}=0$, a corrective term $V_{c}$ defined by $V_{c}=-\sum_{i=1}^{K} V_{i} Y_{i}$ is used. And updated value of $V_{i}$ satisfying the restriction condition is obtained by $V_{i}$ (new) $=V_{i}($ old $)+V_{c}$. An alternative approach can be used if one species is present in excess. An excess component mass fraction is computed simply by subtracting the sum of the remaining mass fractions from one.

Because it has a differential term, the formulation of the diffusion velocity reduces the order of the differential equation from second to first. When we solve the equations, we first evaluate the diffusion velocities from an initial guess of the mass fractions and temperature distribution. Then the diffusion velocities are updated from the computed values. If we can neglect the thermal diffusion related term, the structure of the stiffness matrices reduces to the form which is similar to the one from energy conservation equation. Because this thermal diffusion effect is not negligible if the temperature gradient is 
substantial, it is necessary to include this term for this case. An alternative is to use the Eq 4.18 to calculate the diffusion velocity which is needed for the energy balance equation and to evaluate the each term in Eq. 4.18 separately when it is used for the species conservation equation.

\subsubsection{Adaptive mesh refinement}

It has some advantages to start the iteration on coarse meshes. The most important benefit is the reduced computation time. For example, the computation time of using 20 mesh points is less than half the time of using 40 mesh points. However it requires more iterations and sometimes fails to converge if coarse meshes are used. As the time progresses, the reaction front moves from the particle surface to the outside due to the gas phase reaction. Where finer meshes are required to resolve the steep gradient, the position of the steep gradient changes with iteration. Therefore, it is necessary to redefine the mesh points from time to time according to changes in gradient of the major dependent variables. The adaptive placement of the mesh points to form the finer meshes and to remove unnecessary meshes is done in such a way that the total number of meshes used to represent the solution accurately is minimized. The maximum and the minimum variation of the major dependent variable, which is usually the temperature, are set at values to restrict a sudden change in temperature and to prevent the instability caused by that disturbance.

$$
\delta_{\min }\left(T_{\max }-T_{\min }\right) \leq\left|T_{i+1}-T_{i}\right| \leq \delta_{\max }\left(T_{\max }-T_{\min }\right)
$$

To resolve the curvature of the solution, the maximum variation of the variable's derivatives between the mesh points is set.

$$
\left|\left(\frac{d T}{d r}\right)_{i+1}-\left(\frac{d T}{d r}\right)_{i}\right| \leq \gamma\left(\left(\frac{d T}{d r}\right)_{\max }-\left(\frac{d T}{d r}\right)_{\min }\right)
$$


If the inequalities are not satisfied, the new meshes are added or the redundant meshes are removed. And if the new meshes are inserted, the interpolated values using the linear basis functions are used for the intermediate solutions.

\subsubsection{Modeling approach}

For purposes of calculating of thermodynamic and transport properties including specific heat, enthalpy, multi-component diffusion coefficient, thermal diffusion coefficient and thermal conductivity, it is necessary to develop subroutines to calculate these. But there exist well built libraries for this purpose in the CHEMKIN II and TRANSPORT available from Sandia National Laboratory.

The integration of a set of differential-algebraic equations after Galerkin finite elements methods are performed using DASSL, a package from Lawrence Livermore National Laboratory. This package uses a combination of Backwaro Differentiation Formula methods, which is known to be a very stable and efficient implicit integration method. 


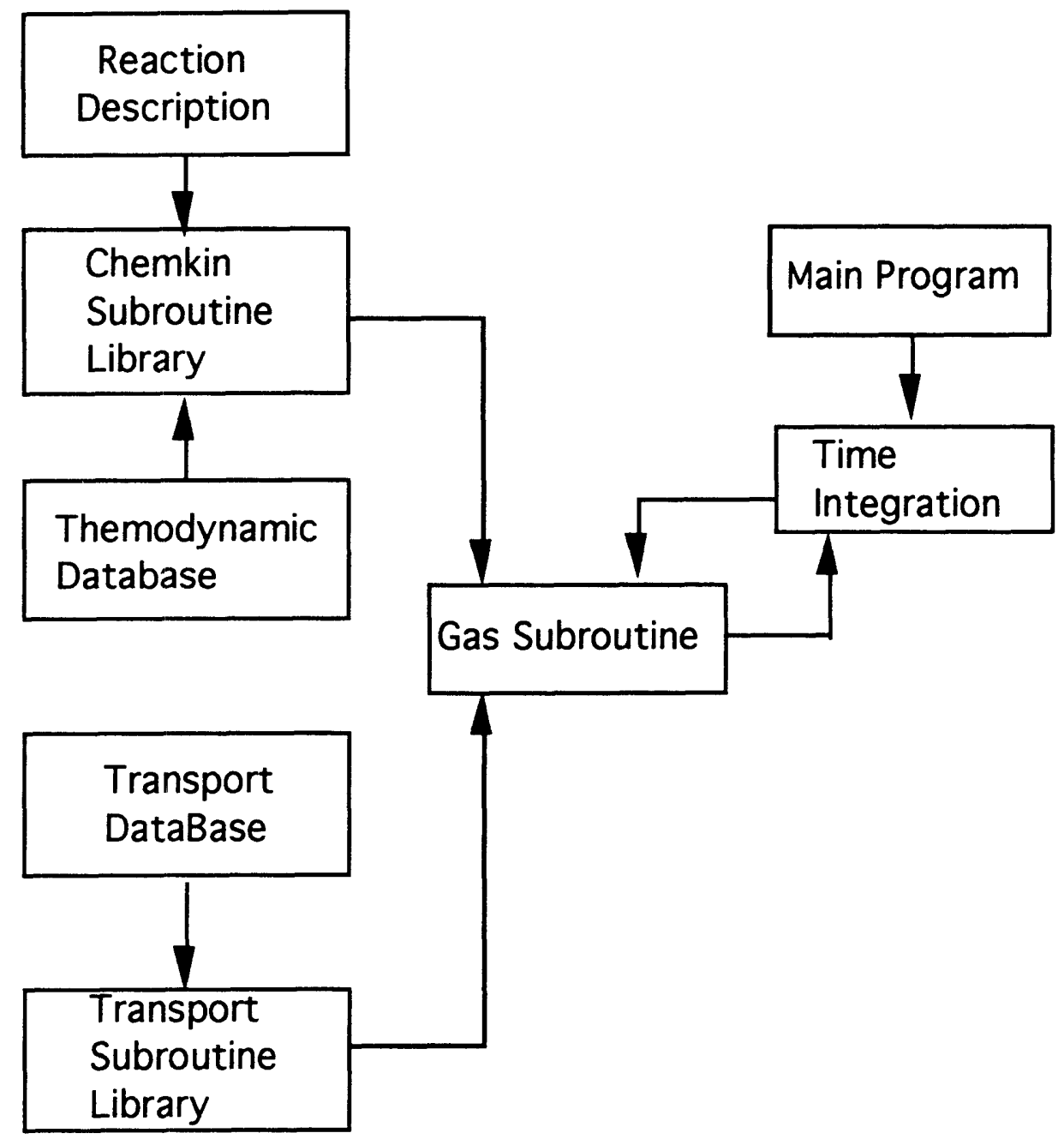

Fig.4.2 Schematic diagram of modeling approach 


\subsection{Experimental measurement of $\mathrm{CO}_{2} / \mathrm{CO}$}

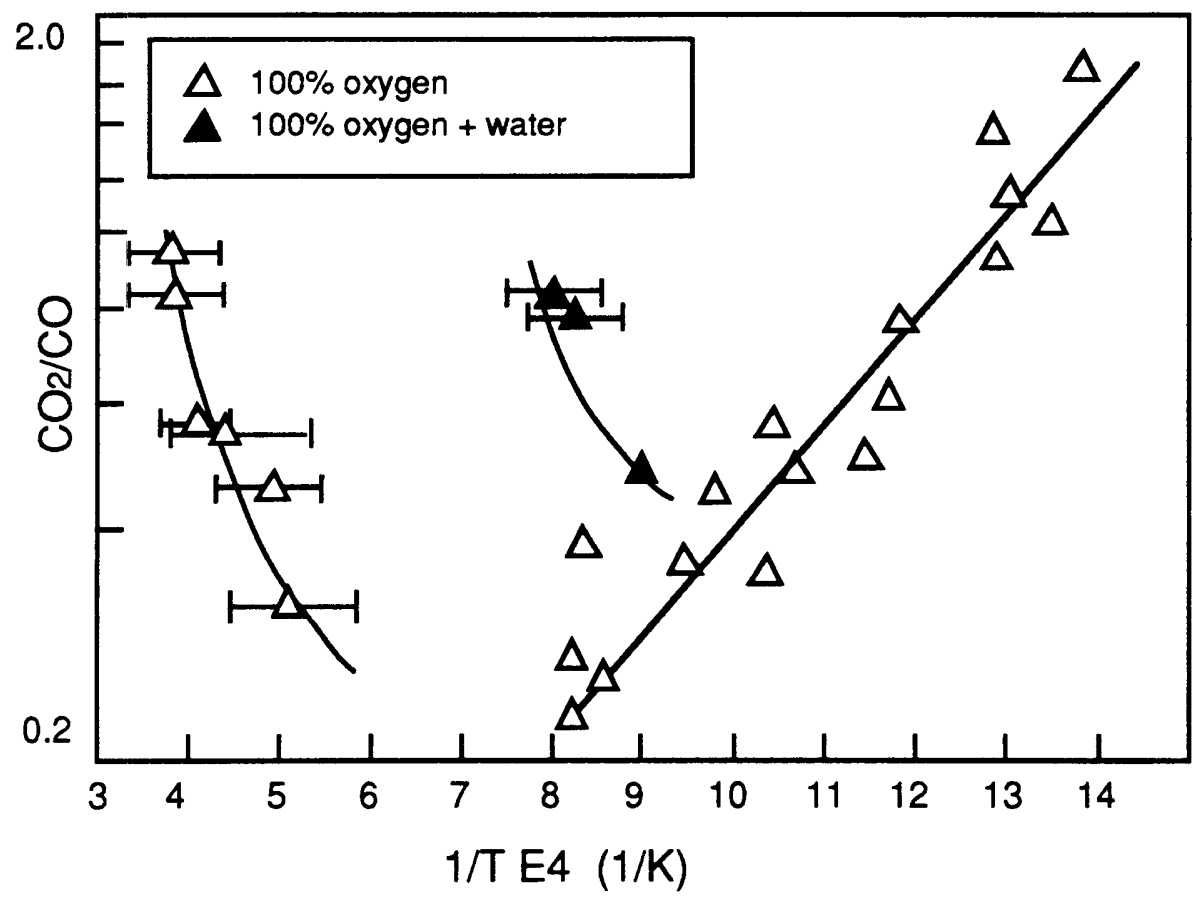

Fig.4.3 $\mathrm{CO}_{2} / \mathrm{CO}$ ratio as a function of inverse temperature for $100 \%$ oxygen for dry gas and in the presence of $3.5 \mathrm{~mol} \%$ water

The recent work of Tognotti (Tognotti et al. 1990) found that the $\mathrm{CO}_{2}$ formed by heterogeneous reactions by measuring the $\mathrm{CO}_{2} / \mathrm{CO}$ ratio for a dry oxidant stream. The results showed an Arrhenius type temperature dependence according with an activation energy of $5.9 \sim 6.1 \mathrm{kcal} / \mathrm{mol}$. Tognotti varied the oxygen concentration and found the $\mathrm{CO}_{2} / \mathrm{CO}$ ratio to increase with the 0.21 power of oxygen concentration. The value for $\mathrm{E}_{\mathrm{a}} / \mathrm{R}$ at $100 \%$ oxygen partial pressure is 3070 and the pre-exponential factor is 0.02 in Table 1.1. The $\mathrm{CO}_{2} / \mathrm{CO}$ ratio decreases as the temperature went up as we can seen in Fig.4.3. This ratio increases suddenly after a threshold temperature of $2000 \mathrm{~K}$, because of the 
additional $\mathrm{CO}$ oxidation in the boundary layer or pores as the temperature goes above the threshold temperature. That the $\mathrm{CO}$ oxidation occurred in the gas phase was confirmed by showing that the addition of water vapor to catalyze the gas phase oxidation reaction resulted in a decrease in the threshold temperature. 


\subsection{Modeling results}

\subsubsection{Elementary gas phase reaction mechanism}

To model gas phase reaction, 28 elementary reactions and 12 species were considered. Reaction kinetics data were from Yetter et al. (Yetter et al., 1991).

[Table 4.1] Reaction mechanism rate coefficients (units are $\mathrm{mole} / \mathrm{cm}^{3}, \mathrm{sec}, \mathrm{K}, \mathrm{cal} / \mathrm{mol}$ )

\begin{tabular}{|c|c|c|c|}
\hline REACTIONS CONSIDERED & $\begin{array}{l}(k=A \\
A\end{array}$ & $\begin{array}{c}T \star \star b \\
b\end{array}$ & $\begin{array}{c}o(-E / R T)) \\
E\end{array}$ \\
\hline 1. $\mathrm{CO}+\mathrm{O}+\mathrm{M}=\mathrm{CO} 2+\mathrm{M}$ & $2.51 E+13$ & 0.0 & -4540.0 \\
\hline 2. $\mathrm{CO}+\mathrm{O} 2=\mathrm{CO} 2+\mathrm{O}$ & $2.51 \mathrm{E}+12$ & 0.0 & 47690.0 \\
\hline 3. $\mathrm{CO}+\mathrm{OH}=\mathrm{CO} 2+\mathrm{H}$ & $1.51 E+07$ & 1.3 & -765.0 \\
\hline 4. $\mathrm{CO}+\mathrm{HO} 2=\mathrm{CO} 2+\mathrm{OH}$ & $6.03 E+13$ & 0.0 & 22950.0 \\
\hline 5. $\mathrm{H}+\mathrm{O} 2=\mathrm{OH}+\mathrm{O}$ & $1.91 E+14$ & 0.0 & 16440.0 \\
\hline 6. $\mathrm{O}+\mathrm{H} 2=\mathrm{OH}+\mathrm{H}$ & $5.13 E+04$ & 2.7 & 6290.0 \\
\hline 7. $\mathrm{OH}+\mathrm{H} 2=\mathrm{H} 2 \mathrm{O}+\mathrm{H}$ & $2.14 \mathrm{E}+08$ & 1.5 & 3430.0 \\
\hline 8. $\mathrm{O}+\mathrm{H} 2 \mathrm{O}=\mathrm{OH}+\mathrm{OH}$ & $1.23 E+04$ & 2.6 & -1878.0 \\
\hline 9. $\mathrm{H}+\mathrm{O} 2+\mathrm{M}=\mathrm{HO} 2+\mathrm{M}$ & $6.76 E+19$ & -1.4 & 0.0 \\
\hline 10. $\mathrm{H}+\mathrm{HO} 2=\mathrm{H} 2+\mathrm{O} 2$ & $6.61 E+13$ & 0.0 & 2130.0 \\
\hline 11. $\mathrm{HO} 2+\mathrm{H}=\mathrm{OH}+\mathrm{OH}$ & $1.70 E+14$ & 0.0 & 870.0 \\
\hline 12. $\mathrm{O}+\mathrm{HO} 2=\mathrm{O} 2+\mathrm{OH}$ & $1.74 \mathrm{E}+13$ & 0.0 & -400.0 \\
\hline 13. $\mathrm{OH}+\mathrm{HO} 2=\mathrm{H} 2 \mathrm{O}+\mathrm{O} 2$ & $1.45 \mathrm{E}+16$ & -1.0 & 0.0 \\
\hline 14. $\mathrm{H} 2+\mathrm{M}=\mathrm{H}+\mathrm{H}+\mathrm{M}$ & $4.57 E+19$ & -1.4 & 104380.0 \\
\hline 15. $\mathrm{O}+\mathrm{O}+\mathrm{M}=02+\mathrm{M}$ & $6.17 \mathrm{E}+15$ & -0.5 & 0.0 \\
\hline 1.6. $\mathrm{O}+\mathrm{H}+\mathrm{M}=\mathrm{OH}+\mathrm{M}$ & $4.68 E+18$ & -1.0 & 0.0 \\
\hline 1.7. $\mathrm{H}+\mathrm{OH}+\mathrm{M}=\mathrm{H} 2 \mathrm{O}+\mathrm{M}$ & $2.24 E+22$ & -2.0 & 0.0 \\
\hline 1.8. $\mathrm{HO} 2+\mathrm{HO} 2=\mathrm{H} 2 \mathrm{O} 2+\mathrm{O} 2$ & $3.02 E+12$ & 0.0 & 1390.0 \\
\hline 19. $\mathrm{H} 2 \mathrm{O} 2+\mathrm{M}=\mathrm{OH}+\mathrm{OH}+\mathrm{M}$ & $1.20 \mathrm{E}+17$ & 0.0 & 45500.0 \\
\hline
\end{tabular}




\begin{tabular}{|c|c|c|c|}
\hline 20. $\mathrm{H} 2 \mathrm{O} 2+\mathrm{H}=\mathrm{H} 2 \mathrm{O}+\mathrm{OH}$ & $1.00 \mathrm{E}+13$ & 0.0 & 3590.0 \\
\hline 21. $\mathrm{H} 2 \mathrm{O} 2+\mathrm{H}=\mathrm{HO} 2+\mathrm{H} 2$ & $4.79 E+13$ & 0.0 & 7950.0 \\
\hline 22. $\mathrm{H} 2 \mathrm{O} 2+\mathrm{O}=\mathrm{OH}+\mathrm{HO} 2$ & $9.55 \mathrm{E}+06$ & 2.0 & 3970.0 \\
\hline 23. $\mathrm{H} 2 \mathrm{O} 2+\mathrm{OH}=\mathrm{H} 2 \mathrm{O}+\mathrm{HO} 2$ & $7.08 \mathrm{E}+12$ & 0.0 & 1430.0 \\
\hline 24. $\mathrm{HCO}+\mathrm{M}=\mathrm{H}+\mathrm{CO}+\mathrm{M}$ & $1.86 \mathrm{E}+17$ & -1.0 & 17000.0 \\
\hline 25. $\mathrm{HCO}+\mathrm{O} 2=\mathrm{HO} 2+\mathrm{CO}$ & $4.17 \mathrm{E}+12$ & 0.0 & 0.0 \\
\hline 26. $\mathrm{HCO}+\mathrm{H}=\mathrm{CO}+\mathrm{H} 2$ & 7.? $2 \mathrm{E}+13$ & 0.0 & 0.0 \\
\hline 27. $\mathrm{HCO}+\mathrm{O}=\mathrm{OH}+\mathrm{CO}$ & $3.02 E+13$ & 0.0 & 0.0 \\
\hline 28. $\mathrm{HCO}+\mathrm{OH}=\mathrm{CO}+\mathrm{H} 2 \mathrm{O}$ & $3.02 \mathrm{E}+13$ & 0.0 & 0.0 \\
\hline
\end{tabular}

\subsubsection{Low surrounding gas temperature with water vapor}

The first question is why the $\mathrm{CO}_{2} / \mathrm{CO}$ ratio at $1250 \mathrm{~K}$ increased suddenly by adding water vapor. Is it really due to the gas phase $\mathrm{CO}$ oxidation as Tognotti claimed?

First, we set up conditions to calculate the $\mathrm{CO}$ oxidation at low particle surface temperature with water vapor in the bulk gas. The temperature profile model developed in the chapter two was used to calculate the carbon consumption rate at a given surface temperature. The bulk gas temperature was constant during the reaction, and the value was $298.15 \mathrm{~K}$. The particle surface temperature of $1250 \mathrm{~K}$ was used to compare the calculated results with the experimental measurements. The initial conditions of the simulation were: the initial mass fractions of $\mathrm{O}_{2}$ and $\mathrm{H}_{2} \mathrm{O}$ were the same as the bulk mass fractions of them, $\mathrm{CO}$ and $\mathrm{CO}_{2}$ mass fluxes at the particle surface were calculated form the $\mathrm{CO}_{2} / \mathrm{CO}$ ratio of heterogeneous reactions. The temperature and mass fraction distribution curves are shown in Fig.4.4. In the figure, where the curves begin in the left side represents the particle surface. The particle radius is $0.009 \mathrm{~cm}$. To represent the region near the particle surface well, where the most of the changes happen, the values of radial coordinates from 0.009 to $0.1 \mathrm{~cm}$ are shown in the figure. In the calculation, an outer boundary condition 100 times the radius of the particle is used. The mass fractions of $\mathrm{CO}$ and $\mathrm{CO}_{2}$ are not much affected by the gas phase reaction, nor is the temperature profile. 


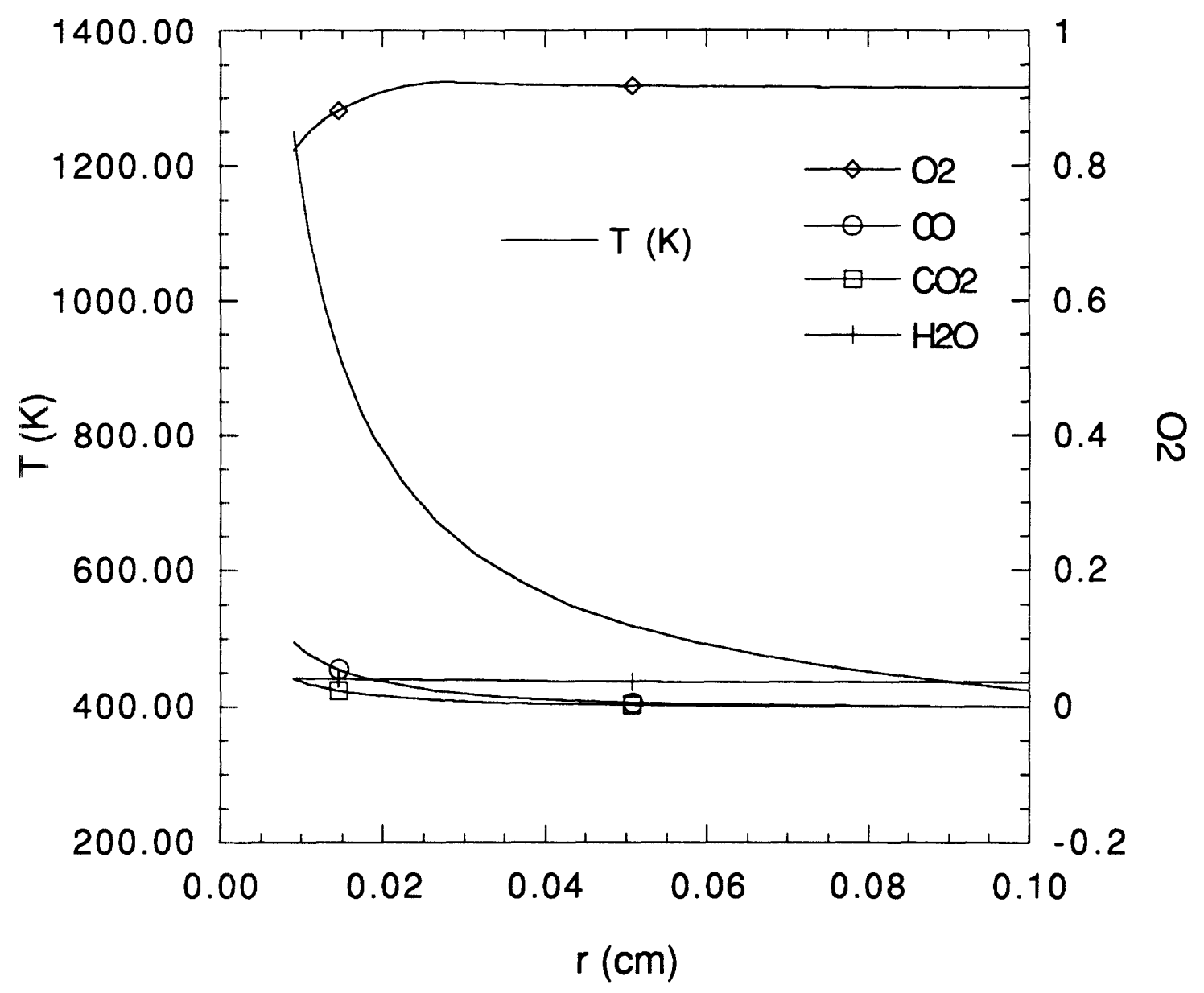

Fig.4.4 Temperature and mass fraction distribution $\left(\mathrm{T}_{\mathrm{p}}=1250 \mathrm{~K}, \mathrm{r}_{\mathrm{c}}=0.005 \mathrm{gC} / \mathrm{cm}^{2} \mathrm{~s}, 3.5 \mathrm{wt} \% \mathrm{H} 2 \mathrm{O}, \mathrm{t}=1 \mathrm{~ms}\right)$ 


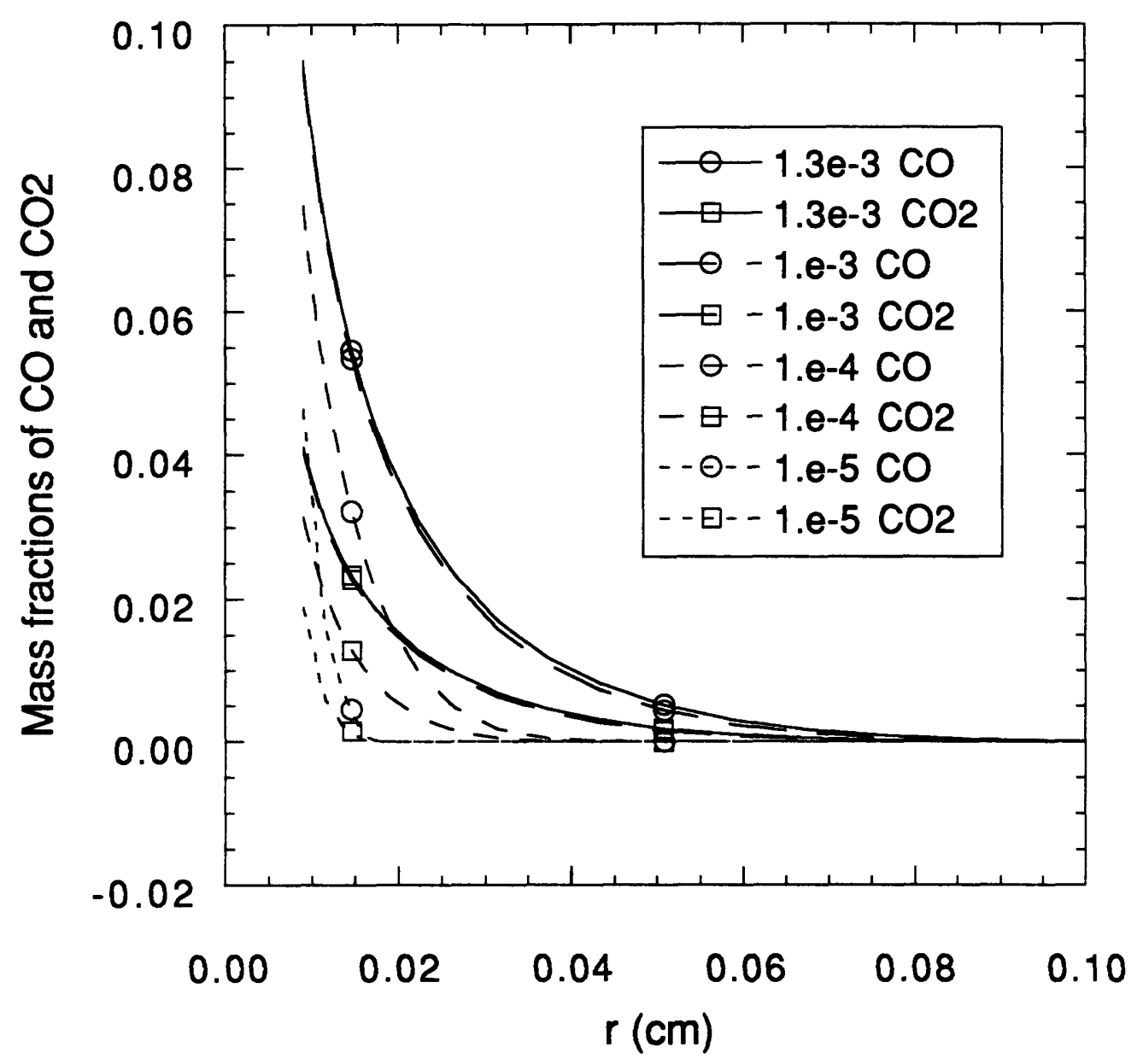

Fig.4.5 $\mathrm{CO} 2$ and $\mathrm{CO}$ mass fraction distribution as a function of time $\left(\mathrm{T}_{\mathrm{p}}=1250 \mathrm{~K}, \mathrm{r}_{\mathrm{c}}=0.005 \mathrm{gC} / \mathrm{cm}^{2} \mathrm{~s}, 3.5 \mathrm{wt} \% \mathrm{H} 2 \mathrm{O}\right)$

The calculated mass fraction distributions of $\mathrm{CO}$ and $\mathrm{CO}_{2}$ as a function of time are shown in Fig.4.5. The $\mathrm{CO}$ and $\mathrm{CO}_{2}$ mass fractions keep increasing fast toward a steady state value as the time progresses. After about one milli-second the values of mass fractions approach the steady state value. The results of Tognotti's experiment show that considerable $\mathrm{CO}$ oxidation occurs at $1250 \mathrm{~K}$ and the resulting $\mathrm{CO}_{2} / \mathrm{CO}$ ratio is about 0.8 . This additional $\mathrm{CO}_{2}$ was believed to be generated from the gas phase reaction. 


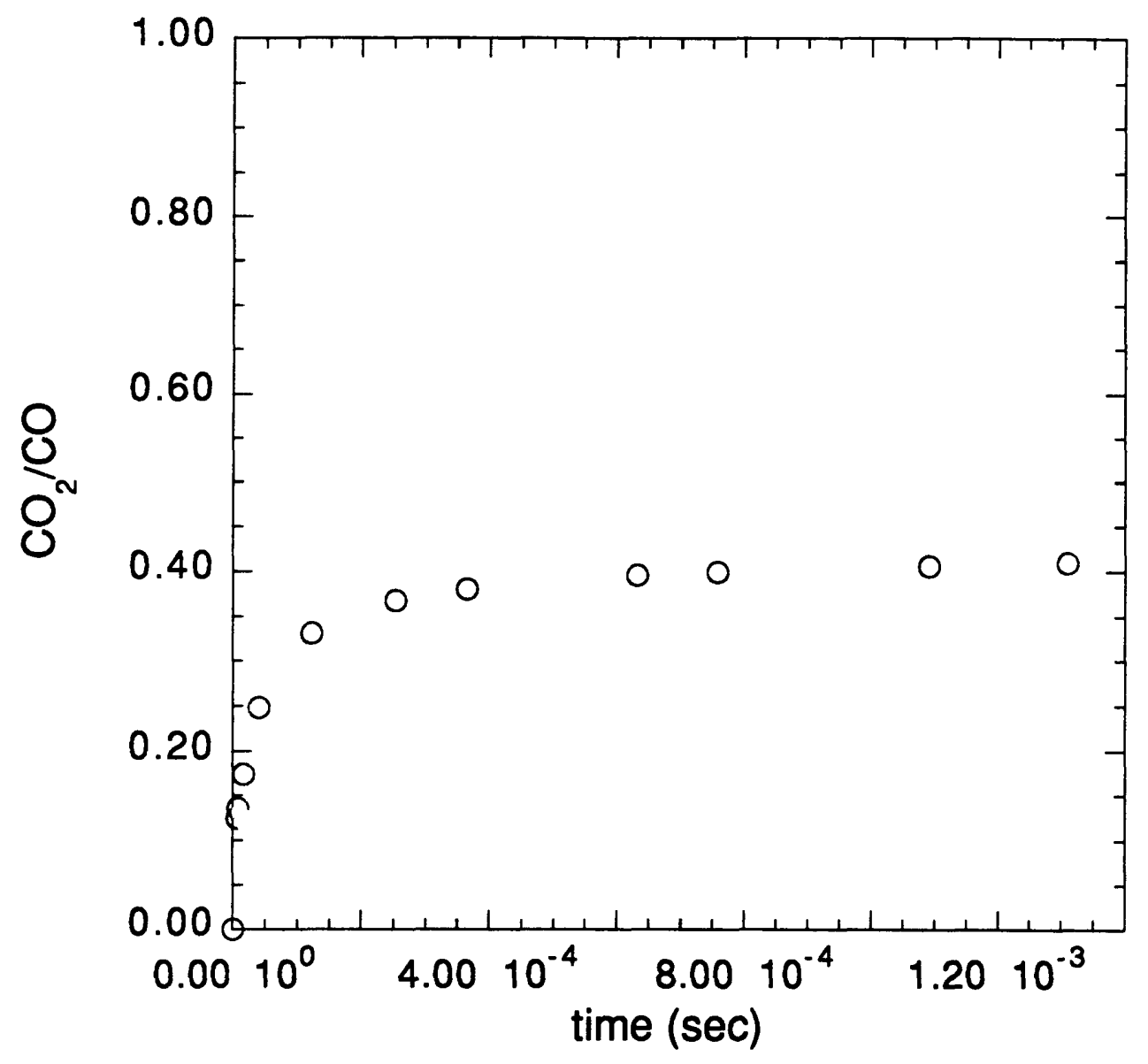

Fig.4.6 $\mathrm{CO} 2 / \mathrm{CO}$ ratio as a function of time $\left(\mathrm{T}_{\mathrm{p}}=1250 \mathrm{~K}, \mathrm{r}_{\mathrm{c}}=0.005 \mathrm{gC} / \mathrm{cm}^{2} \mathrm{~s}, 3.5 \mathrm{wt} \% \mathrm{H} 2 \mathrm{O}\right)$

To calculate the amount of $\mathrm{CO}_{2}$ generation from the gas phase reaction, we calculated the time change of $\mathrm{CO}_{2} / \mathrm{CO}$ ratio at $\mathrm{r}=\mathrm{R}_{\mathrm{O}}+\mathrm{d}_{\mathrm{O}}$. The $\mathrm{CO}_{2} / \mathrm{CO}$ ratio as a function of time is shown in Fig.4.6. The modeling results show that $\mathrm{CO}_{2} / \mathrm{CO}$ ratio of mass fraction is 0.42 at its steady state. This correspond to 0.267 in mole fraction ratio. The $\mathrm{CO}_{2} / \mathrm{CO}$ ratio from the heterogeneous reaction at $1250 \mathrm{~K}$ is 0.233 . This calculation suggest that there is a very little $\mathrm{CO}$ oxidation in the gas phase and that most of $\mathrm{CO}_{2}$ is from the heterogeneous reaction. About $2.7 \%$ of $\mathrm{CO}$ was converted to $\mathrm{CO}_{2}$. The water vapor is 
known to have a significant effect to enhance gas phase reaction, but there is no significant $\mathrm{CO}$ oxidation at this particle size of $180 \mu \mathrm{m}$ and the surface temperature of $1250 \mathrm{~K}$. The particle diameter is too small to have a significant gas phase $\mathrm{CO}$ oxidation even with the water vapor and the steep temperature gradient quenches the gas phase reaction. The water vapor is believed to react directly with carbon and the high $\mathrm{CO}_{2} / \mathrm{CO}$ ratio measured by the experiment was due to the enhanced $\mathrm{CO}_{2}$ production in the heterogeneous reaction.

\subsubsection{High surrounding gas temperature without water vapor}

The role of hydrogen containing species is known to be critical to $\mathrm{CO}$ oxidation. The case of $100 \%$ oxygen without water vapor is calculated for a surface temperature of $2500 \mathrm{~K}$ to see how much $\mathrm{CO}$ oxidation can occur without water vapor. The mass fraction distributions of $\mathrm{CO}$ and $\mathrm{CO}_{2}$ as a function of time are shown in Fig.4.7. Both $\mathrm{CO}$ and $\mathrm{CO}_{2}$ are increasing to steady state values as the time passes. The results show that there is a little $\mathrm{CO}$ oxidation at this surface temperature but too little to explain the $\mathrm{CO}_{2} / \mathrm{CO}$ ratio measured by the experiment.

The $\mathrm{CO} 2 / \mathrm{CO}$ ratio as a function of time is shown in Fig.4.8. The $\mathrm{CO}_{2} / \mathrm{CO}$ ratio approached a steady state value of 0.14 after about 0.2 milli-second. This ratio correspond to 0.089 in mole fraction ratio. The $\mathrm{CO}_{2} / \mathrm{CO}$ ratio from the heterogeneous reaction is 0.068 at $2500 \mathrm{~K}$. Only about $2 \%$ of $\mathrm{CO}$ from the heterogeneous reaction was converted to $\mathrm{CO}_{2}$ in the gas phase. Therefore, without hydrogen containing molecule the gas phase $\mathrm{CO}$ oxidation is negligible even at a very high surface temperature. 


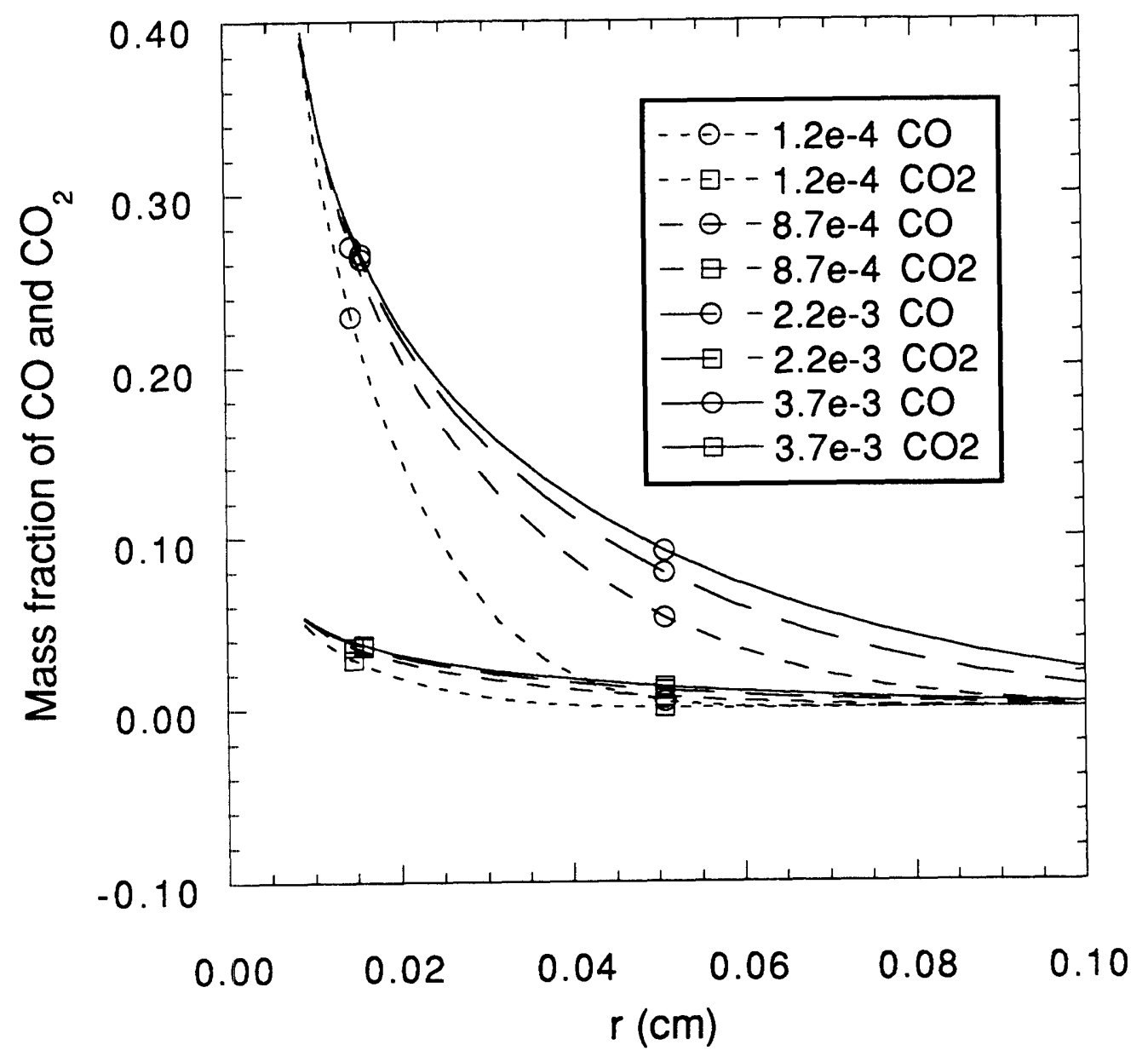

Fig.4.7 $\mathrm{CO} 2$ and $\mathrm{CO}$ mass fraction distribution as a function of time $\left(\mathrm{T}_{\mathrm{p}}=2500 \mathrm{~K}, \mathrm{r}_{\mathrm{c}}=0.05 \mathrm{gC} / \mathrm{cm}^{2} \mathrm{~s}, 100 \% \mathrm{O}\right.$, no H2O) 


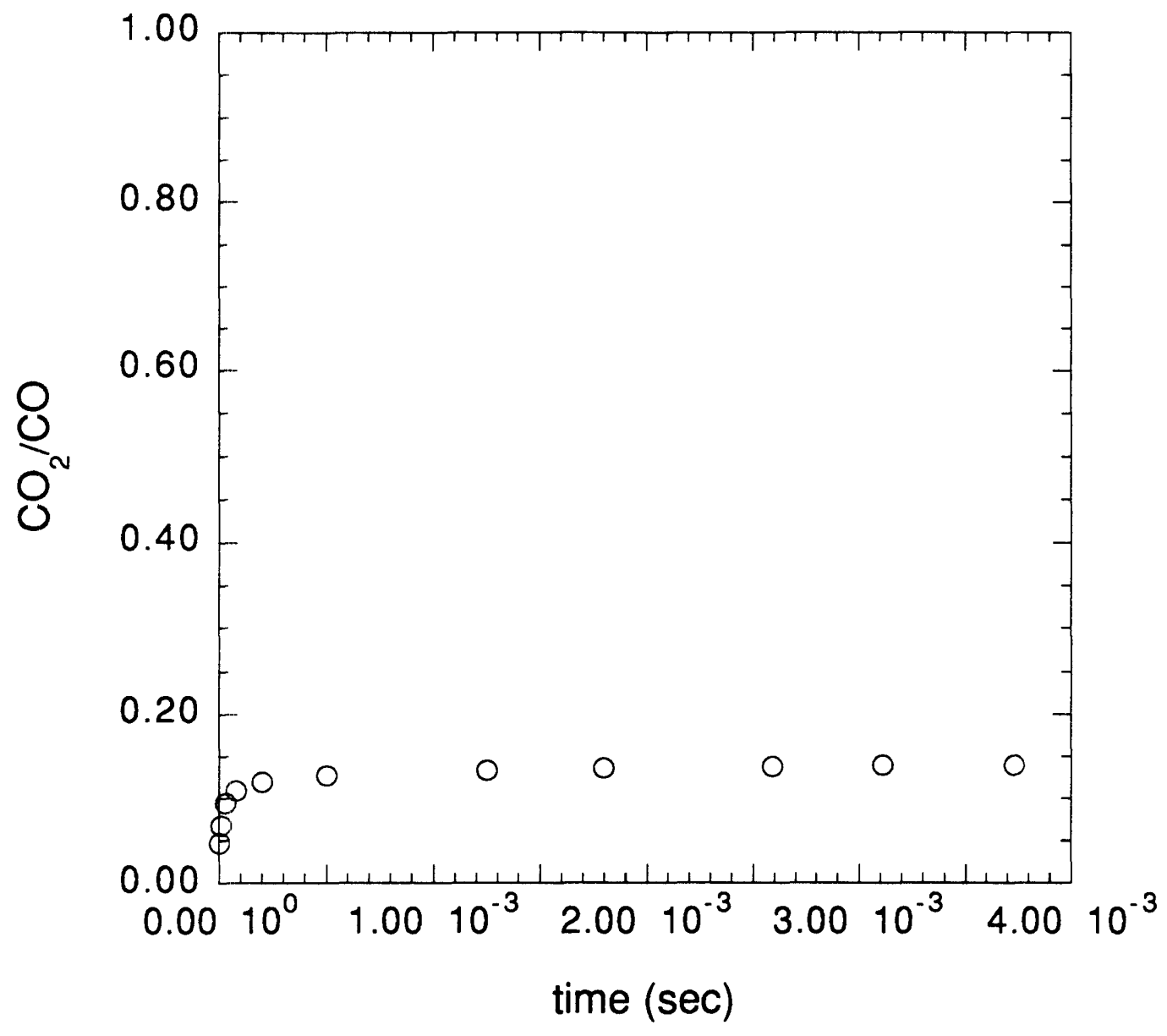

Fig.4.8 $\mathrm{CO} 2 / \mathrm{CO}$ ratio as a function of time $\left(\mathrm{T}_{\mathrm{p}}=2500 \mathrm{~K}, \mathrm{r}_{\mathrm{c}}=0.05 \mathrm{gC} / \mathrm{cm}^{2} \mathrm{~s}, 100 \%\right.$ O2, no H2O $)$ 


\subsubsection{High surrounding gas temperature with water vapor}

A case with $3.5 \%$ water vapor was modeled to see the effects of the water vapor on the gas phase $\mathrm{CO}$ oxidation. The $\mathrm{CO}_{2}$ and $\mathrm{CO}$ mass fraction distributions as a function of time are shown in Fig.4.9. The decrease in $\mathrm{CO}$ and the increase in $\mathrm{CO}_{2}$ as the time goes show that there is considerable $\mathrm{CO}$ oxidation in the gas phase. The $\mathrm{CO}_{2}$ generation is mostly near the particle surface.

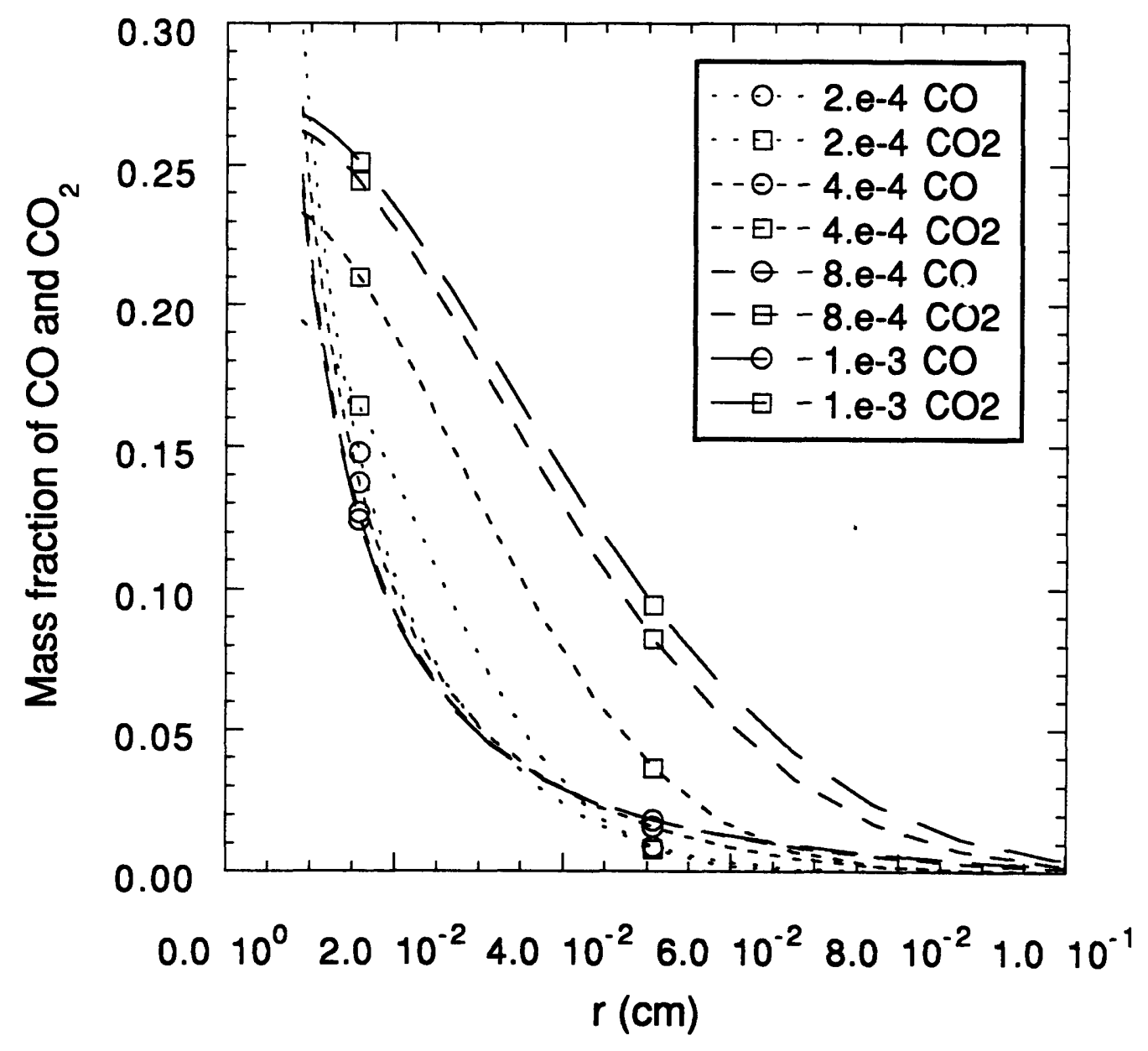

Fig.4.9 $\mathrm{CO} 2$ and $\mathrm{CO}$ mass fraction distribution as a function of time $\left(\mathrm{T}_{\mathrm{p}}=2500 \mathrm{~K}, \mathrm{r}_{\mathrm{c}}=0.05 \mathrm{gC} / \mathrm{cm}^{2} \mathrm{~s}, \mathrm{O} 2\right.$ with $\left.3.5 \% \mathrm{H} 2 \mathrm{O}\right)$ 


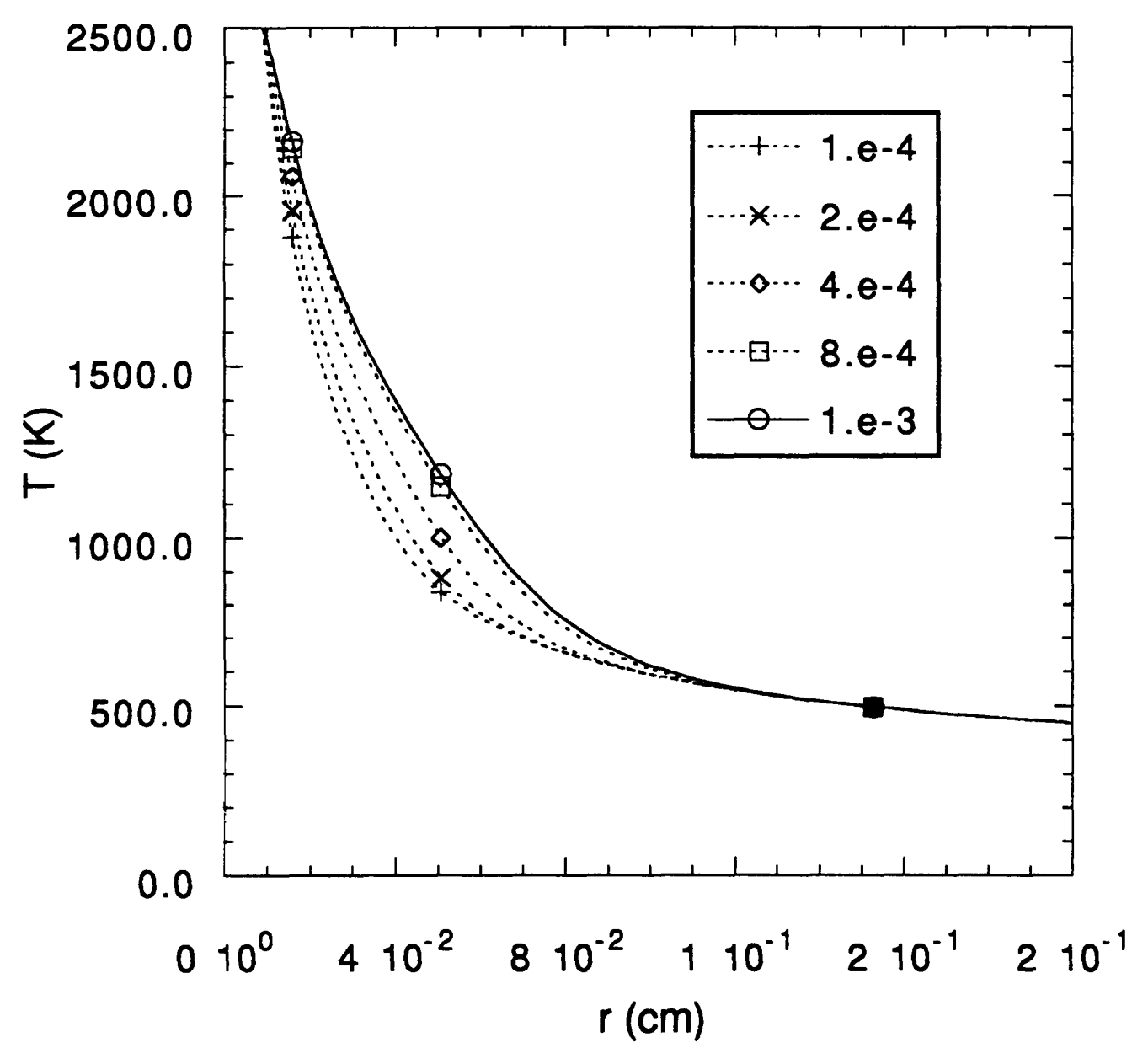

Fig.4.10 Temperature distribution as a function of time $\left(\mathrm{T}_{\mathrm{p}}=2500 \mathrm{~K}, \mathrm{r}_{\mathrm{c}}=0.05 \mathrm{gC} / \mathrm{cm}^{2} \mathrm{~s}, \mathrm{O} 2\right.$ with $\left.3.5 \% \mathrm{H} 2 \mathrm{O}\right)$

The temperature profile near the particle surface is show in Fig.4.10. The temperature gradient decrease with increasing time is due to the heat generated by $\mathrm{CO}$ oxidation reaction. That means less heat from the heterogeneous reaction can be transferred to the gas phase. 
The $\mathrm{CO}_{2} / \mathrm{CO}$ ratio as a function of time is shown in Fig.4.11. Although the $\mathrm{CO}_{2} / \mathrm{CO}$ ratio approaches a steady state value, the asymptotic value was calculated by curve fitting, to provide a value of 3.7 , corresponding to 2.35 in mole fraction ratio. The experimental measurement of $\mathrm{CO}_{2} / \mathrm{CO}$ ratio at $2500 \mathrm{~K}$ was 0.9 . The calculated $\mathrm{CO}_{2} / \mathrm{CO}$ ratio with $3.5 \%$ water vapor is 2.5 times higher than that of the experimental results.

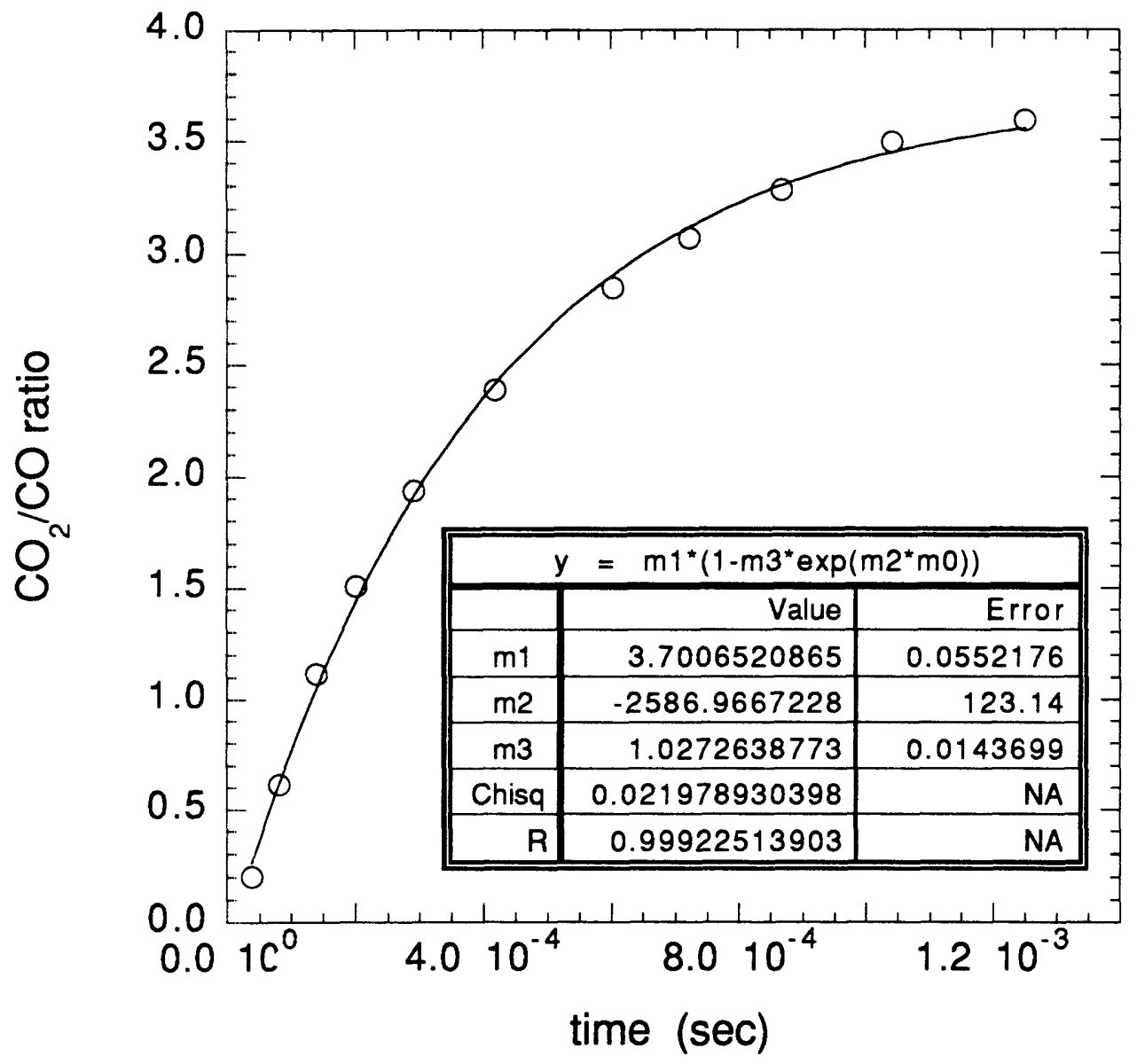

Fig.4.11 $\mathrm{CO} / \mathrm{CO}$ ratio as a function of time $\left(\mathrm{T}_{\mathrm{p}}=2500 \mathrm{~K}, \mathrm{r}_{\mathrm{c}}=0.05 \mathrm{gC} / \mathrm{cm}^{2} \mathrm{~s}, \mathrm{O} 2\right.$ with $\left.3.5 \% \mathrm{H} 2 \mathrm{O}\right)$ 
The temperature and mass fraction distributions of major species are shown in Fig.4.12. The oxygen mass fraction drops sharply near the particle surface, and the mass fraction of water vapor decreases due to its consumption by the $\mathrm{CO}$ oxidation reaction. The mass fraction distributions of other species are shown in Fig.4.13. Most of the radicals have a maximum at the particle surface except $\mathrm{HO}_{2}$. There are appreciable concentrations of $\mathrm{O}$ and $\mathrm{OH}$ radicals near the particle surface and their mass fractions are 0.012 and 0.097 respectively.

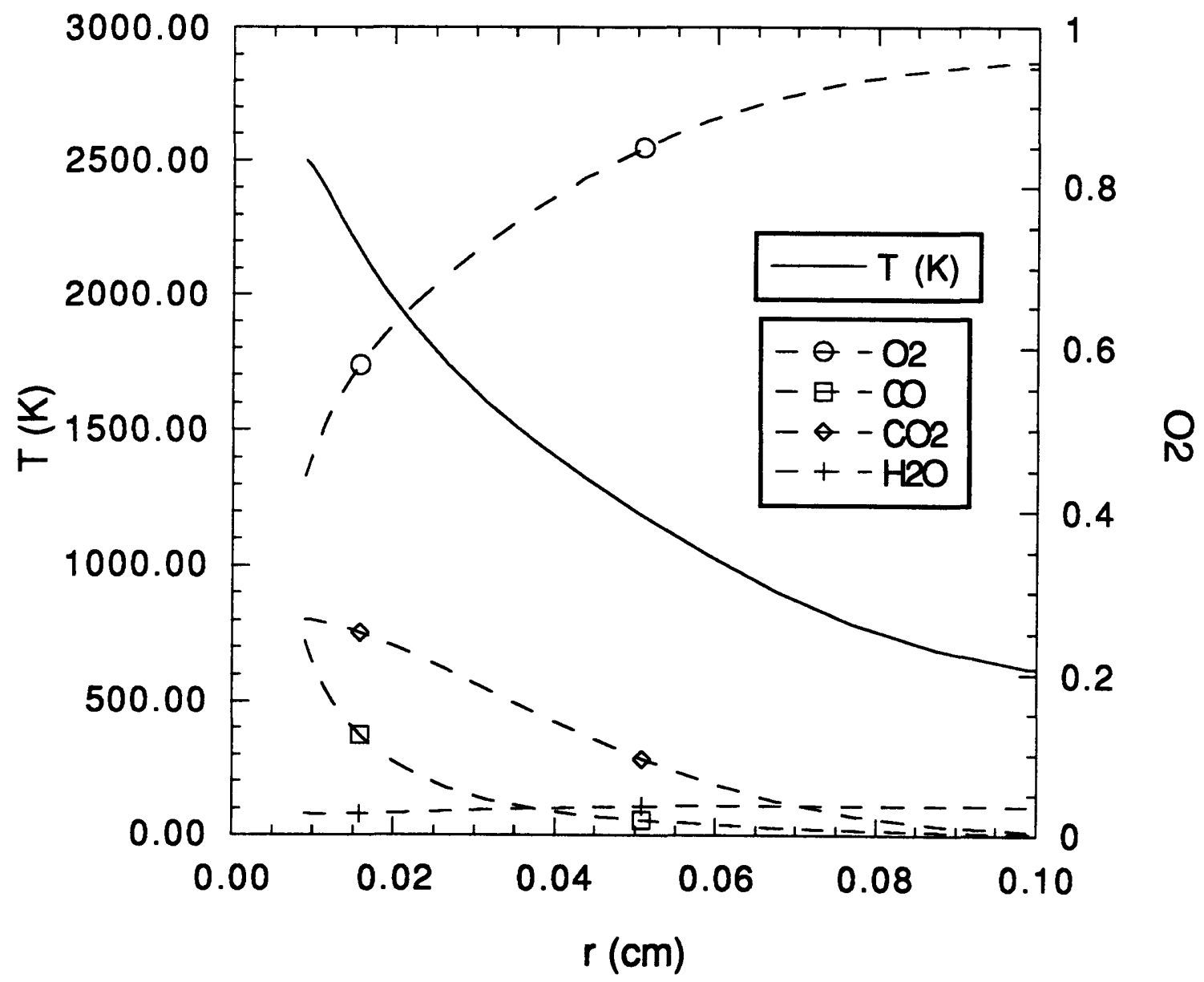

Fig.4.12 Temperature and mass fraction distribution after $1 \mathrm{~ms}$ $\left(\mathrm{T}_{\mathrm{p}}=2500 \mathrm{~K}, \mathrm{r}_{\mathrm{c}}=0.05 \mathrm{gC} / \mathrm{cm}^{2} \mathrm{~s}, \mathrm{O} 2\right.$ with $\left.3.5 \% \mathrm{H} 2 \mathrm{O}\right)$ 


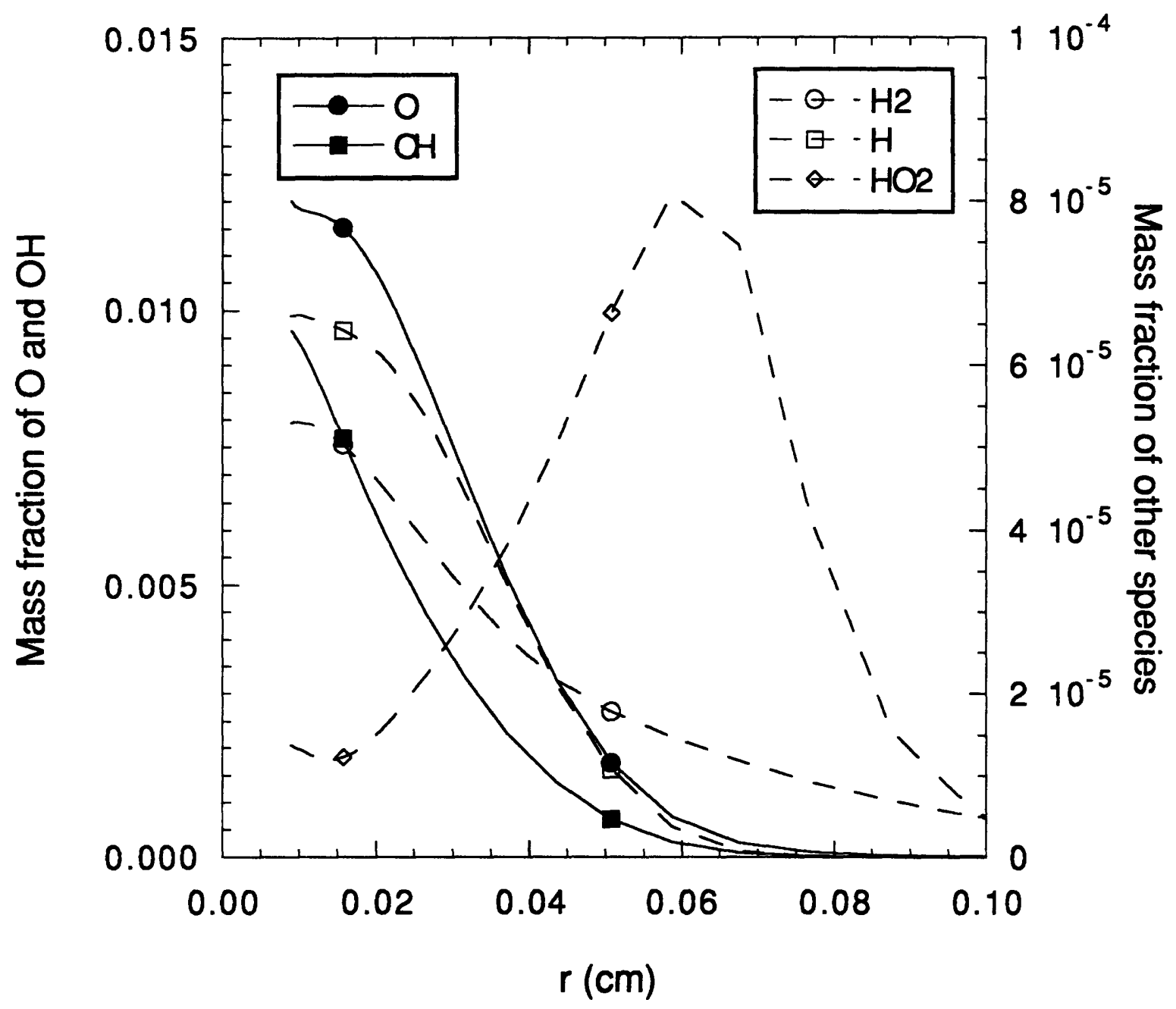

Fig.4.13 Mass fraction distributions including radicals after $1 \mathrm{~ms}$ $\left(\mathrm{T}_{\mathrm{p}}=2500 \mathrm{~K}, \mathrm{r}_{\mathrm{c}}=0.05 \mathrm{gC} / \mathrm{cm}^{2} \mathrm{~s}, \mathrm{O} 2\right.$ with $\left.3.5 \% \mathrm{H} 2 \mathrm{O}\right)$ 


\subsubsection{High surrounding gas temperature with internal ' $\mathrm{H}$ '}

Spherocarb has $0.74 \%$ of ' $\mathrm{H}$ ' internally. To see the effect of this amount of internally existing hydrogen on the $\mathrm{CO}_{2} / \mathrm{CO}$ ratio in the gas phase, a hydrogen flux from the carbon was introduced as a boundary condition. The mass fraction distributions of CO and $\mathrm{CO}_{2}$ as a function of time are shown in Fig.4.14. The $\mathrm{CO} / \mathrm{CO}$ ratio is smaller than that of $3.5 \%$ water vapor case.

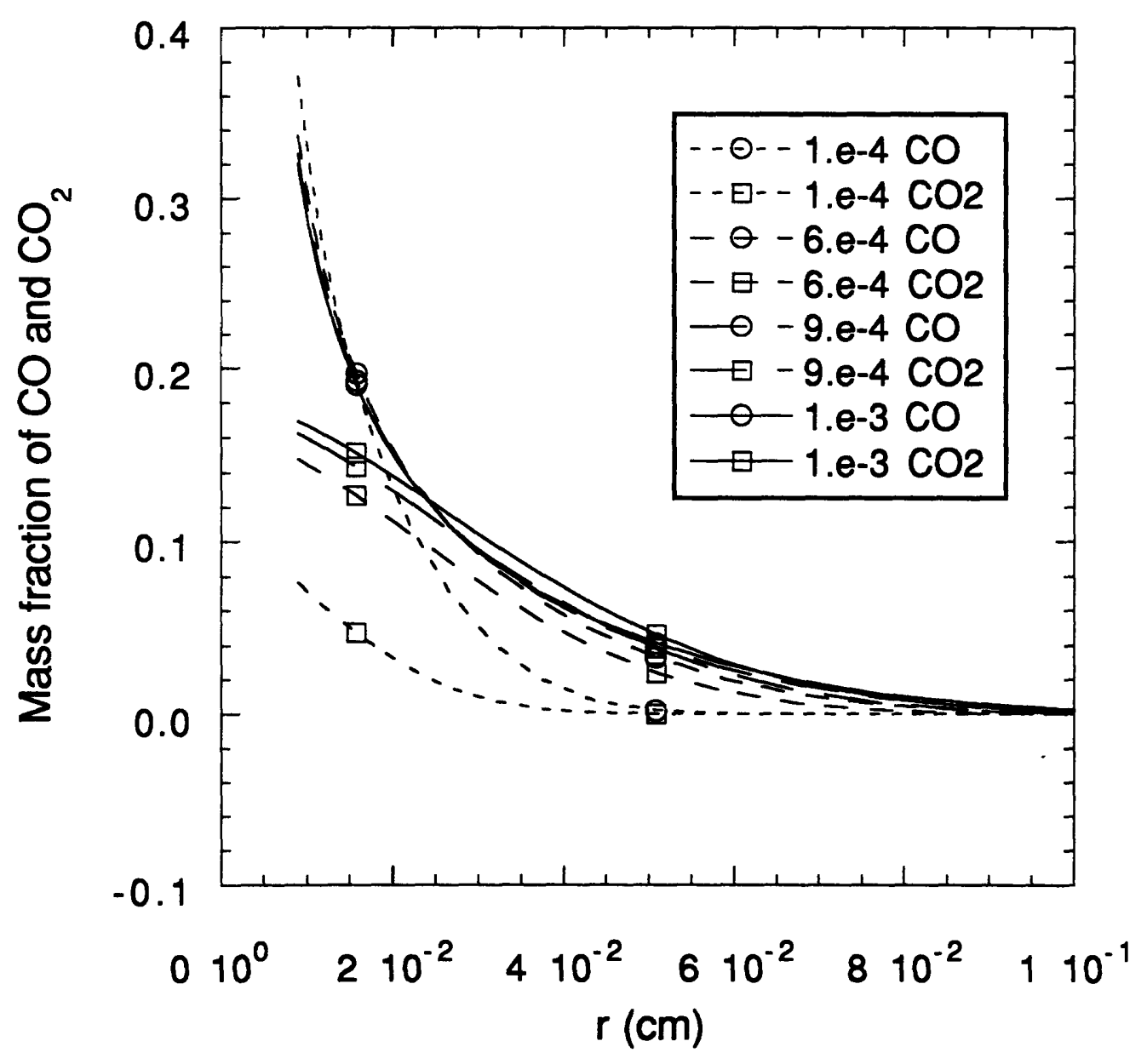

Fig.4.14 Mass fractions of $\mathrm{CO}$ and $\mathrm{CO}_{2}$ as a function of time $\left(\mathrm{T}_{\mathrm{p}}=2500 \mathrm{~K}, \mathrm{r}_{\mathrm{c}}=0.05 \mathrm{gC} / \mathrm{cm}^{2} \mathrm{~s}, \mathrm{O} 2\right.$ with internal ' $\mathrm{H}$ ') 


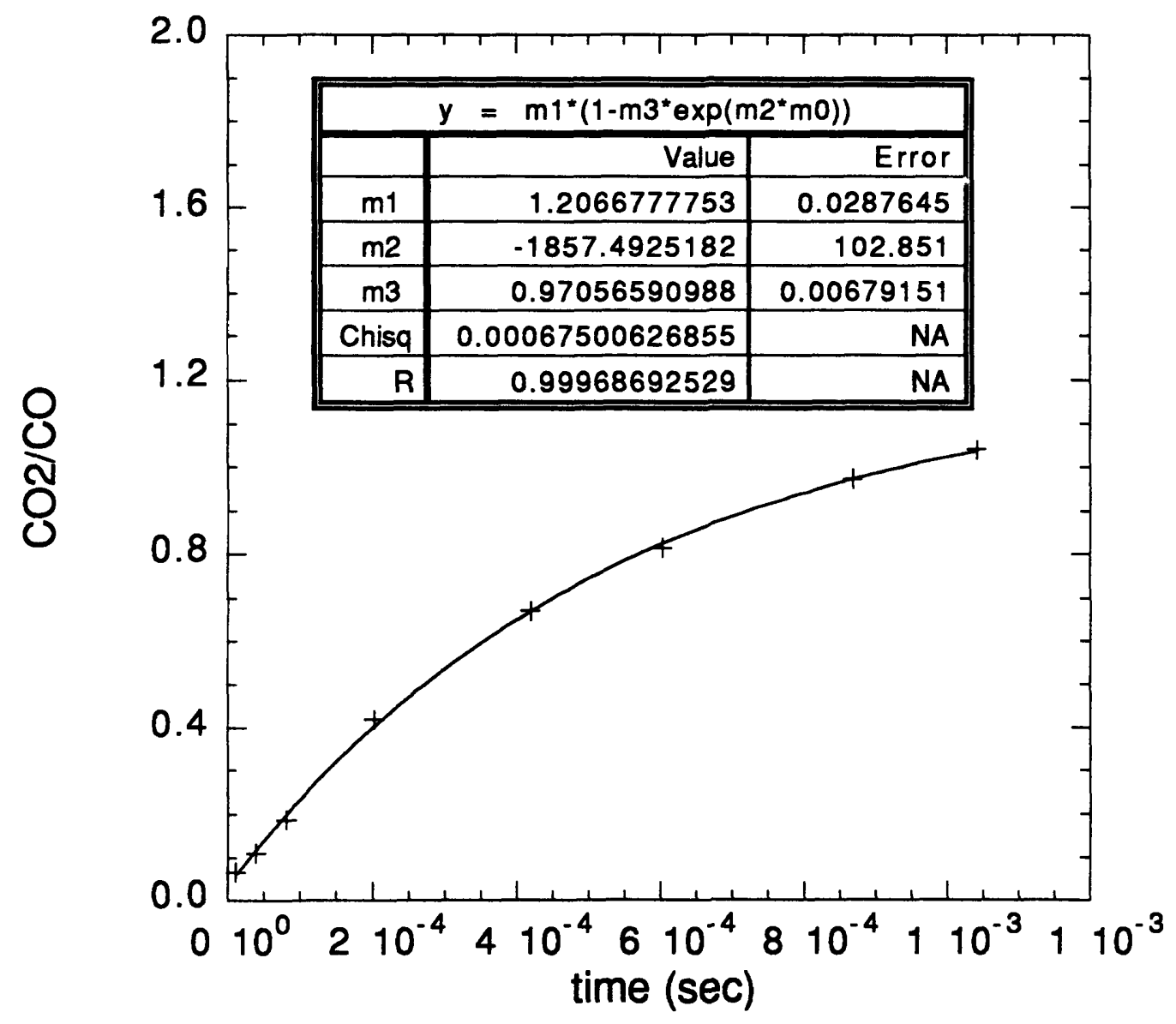

Fig.4.15 $\mathrm{CO} / \mathrm{CO}$ ratio as a function of time $\left(\mathrm{T}_{\mathrm{p}}=2500 \mathrm{~K}, \mathrm{r}_{\mathrm{c}}=0.05 \mathrm{gC} / \mathrm{cm}^{2} \mathrm{~s}, \mathrm{O} 2\right.$ with internal ' $\mathrm{H}$ ')

The results show that there are considerable $\mathrm{CO}$ oxidation but a little bit less than the $\mathrm{CO}_{2} / \mathrm{CO}$ ratio measured by the experiment. The asymptotic $\mathrm{CO}_{2} / \mathrm{CO}$ ratio is 1.2 corresponding to the value of 0.76 in mole fraction ratio. The mole fraction $\mathrm{CO}_{2} / \mathrm{CO}$ ratio from the experiment is $0.8-0.9$ at $2500 \mathrm{~K}$. The agreement between the two values is good. However, if we consider the fact that ' $\mathrm{H}$ ' is consumed early in the reaction, we need to have a more detailed knowledge of when ' $\mathrm{H}$ ' is evolved during the reaction to properly evaluate its role in the $\mathrm{CO}$ oxidation. 


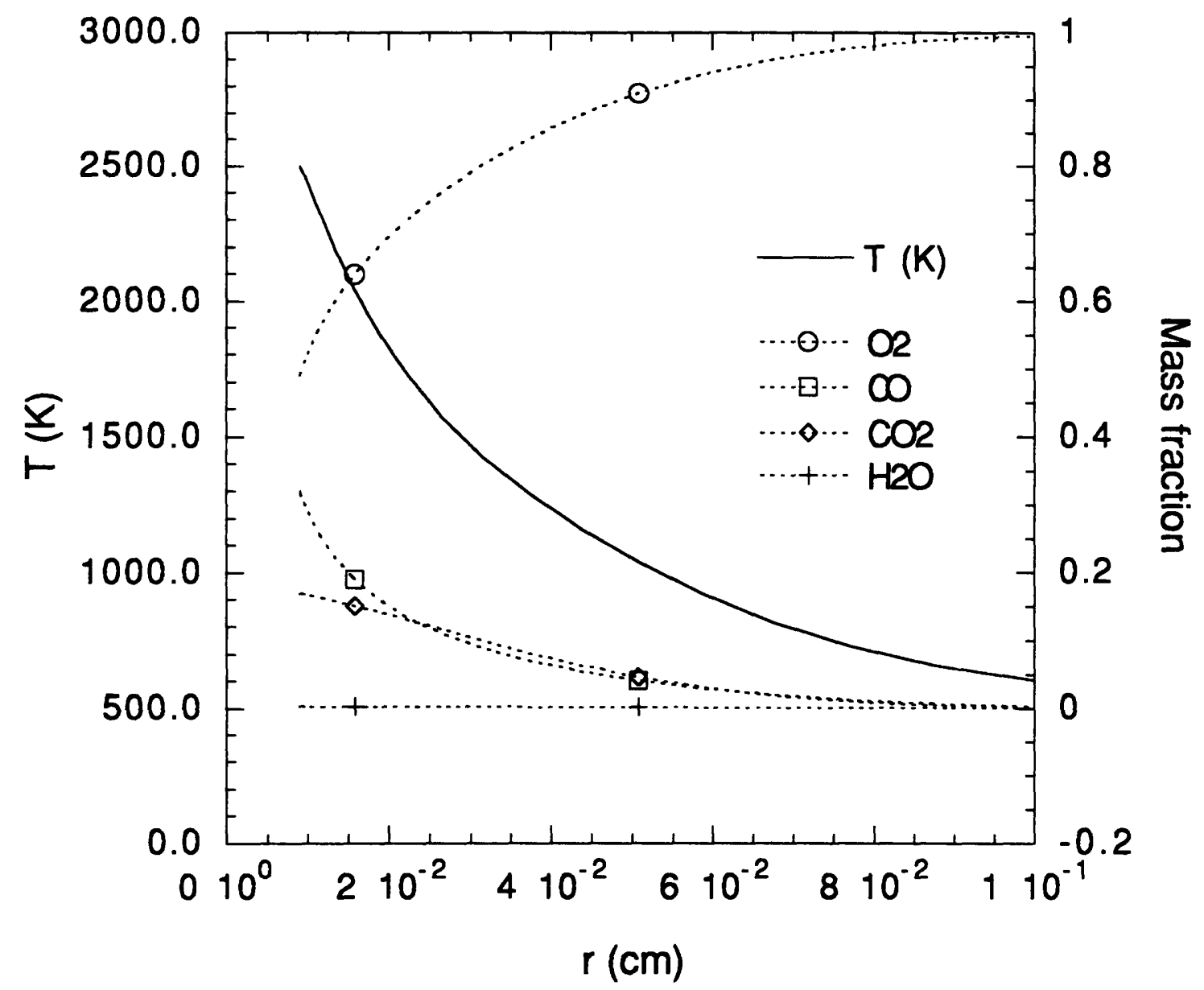

Fig.4.16 Temperature and mass fraction distribution after $1 \mathrm{~ms}$ $\left(\mathrm{T}_{\mathrm{p}}=2500 \mathrm{~K}, \mathrm{r}_{\mathrm{c}}=0.05 \mathrm{gC} / \mathrm{cm}^{2} \mathrm{~s}, \mathrm{O} 2\right.$ with internal ' $\mathrm{H}$ ')

The temperature and mass fraction distributions of major species are shown in Fig.4.16. The mass fraction of water vapor is much smaller than that of Fig.4.12, because the hydrogen flux from the char produce the water vapor mass fraction less than $3.5 \mathrm{wt} \%$. The mass fraction distributions of other species are shown in Fig.4.17. A difference between Fig.4.17 and Fig.4.13 is that the $\mathrm{OH}$ radical mass fraction is about a third of that 
from Fig.4.13. Because $\mathrm{CO}+\mathrm{OH}$ reaction is a major path to $\mathrm{CO}_{2}$ generation, the difference in $\mathrm{OH}$ radical level explains the $\mathrm{CO}_{2} / \mathrm{CO}$ difference between the two cases.

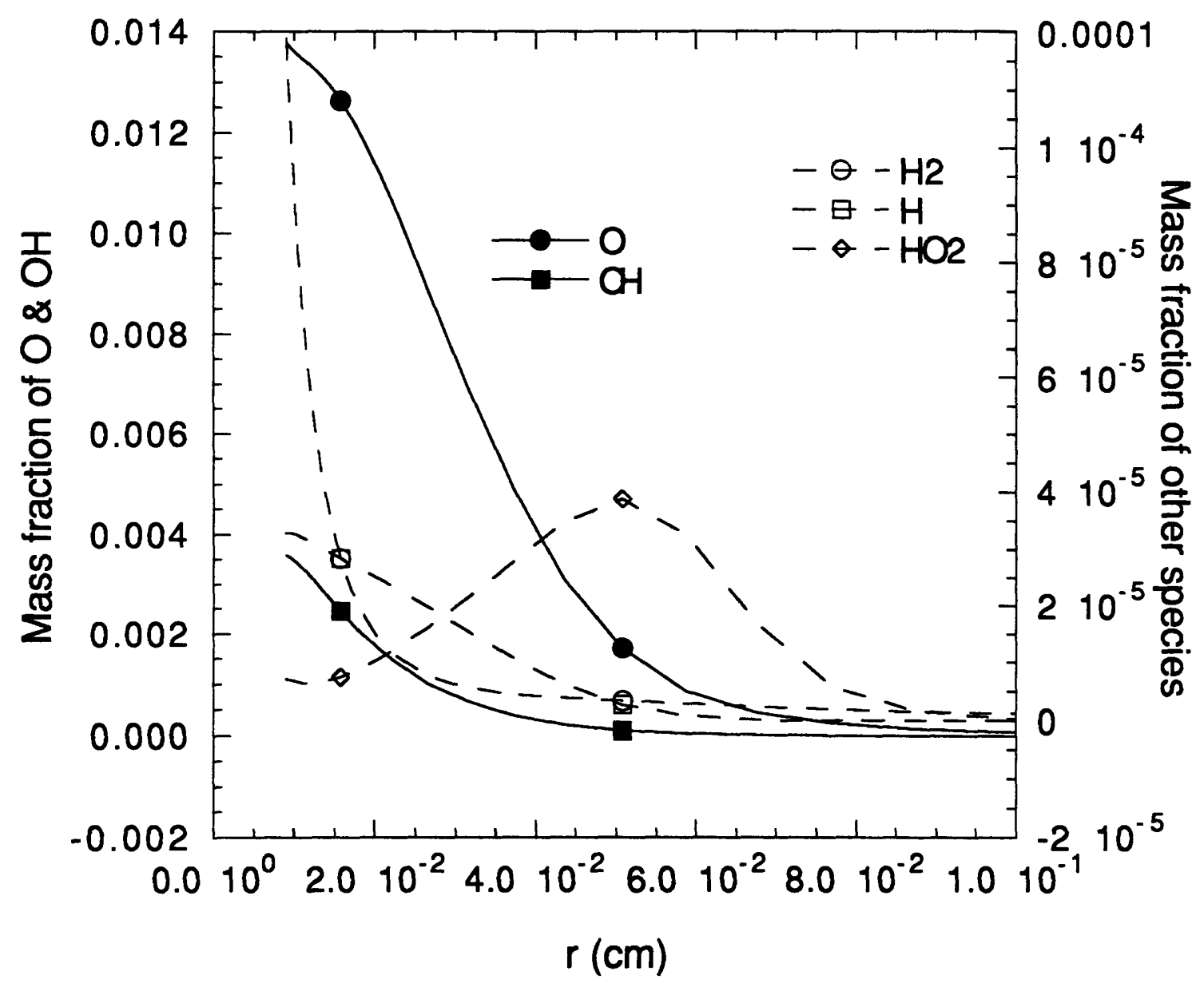

Fig.4.17 Mass fraction distributions including radicals after $1 \mathrm{~ms}$ $\left(\mathrm{T}_{\mathrm{p}}=2500 \mathrm{~K}, \mathrm{r}_{\mathrm{c}}=0.05 \mathrm{gC} / \mathrm{cm}^{2} \mathrm{~s}, \mathrm{O} 2\right.$ with internal $\left.\mathrm{H}^{\mathrm{H}}\right)$

\subsubsection{Time scale of gas phase diffusion and reaction}

Tognotti (Tognotti, 1990) made a qualitative analysis about the diffusion time and the reaction time in the gas phase boundary. It is worth to discuss about the gas phase reaction time scale. Based on his calculations, the time required to convert $10 \%$ of the $\mathrm{CO}$ to $\mathrm{CO}_{2}$ is 0.04 millisecond for a dry oxygen. And the diffusion time for a $200 \mu \mathrm{m}$ particle 
at $2000 \mathrm{~K}$ is about 0.03 millisecond. Although his calculation is not based on the boundary layer calculations, those numbers can give rough estimates for the diffusion and reaction

time. The reaction time increases to several milliseconds at $1500 \mathrm{~K}$ and to 100 milliseconds at $1200 \mathrm{~K}$.

The time spent to reach the steady state with $3.5 \%$ water vapor at $1250 \mathrm{~K}$ was about 0.4 millisecond in the modeling results. The time for the case of $100 \%$ dry oxygen at $2500 \mathrm{~K}$ is about 0.2 millisecond. Therefore, if there is negligible gas phase reaction, the steady state time is related to the diffusion time scale. The time for the case of oxygen with water vapor at $2500 \mathrm{~K}$ is approximately 1.1 millisecond, because there exists vigorous $\mathrm{CO}$ oxidation at this condition. The quasi-steady state burning time shown in Fig.2.1 was 38 milliseconds, so the use of a steady state temperature and a burning rate to calculate the gas phase reaction is valid when the particle is at its pseudo-steady state burning temperature. The reason why the internal ' $\mathrm{H}$ ' case has a longer time to stabilize than external water vapor case is that the water vapor mass fraction increases as ' $\mathrm{H}$ ' flux comes out of the particle in the beginning of the reaction. In the real situation, internal ' $\mathrm{H}$ ' will react earlier with oxygen to form water vapor, and carbon and remaining ' $\mathrm{H}$ ' will react with oxygen.

\subsubsection{Location of $\mathrm{CO}$ oxidation}

It is obvious that most of $\mathrm{CO}$ conversion occurs near the particle surface where the temperature is highest. The production rate of $\mathrm{CO}_{2}$ as a function of radial distance form the particle surface is shown in Fig.4.18. Most of the $\mathrm{CO}_{2}$ production happens within the thin layer.

In section 4.3.2 the $\mathrm{CO}$ oxidation with $3.5 \%$ water vapor at $1250 \mathrm{~K}$ was negligible while the experimental result show that the $\mathrm{CO}_{2} / \mathrm{CO}$ ratio is about 0.76 . There are two possibilities of the additional $\mathrm{CO}$ oxidation: one is homogeneous $\mathrm{CO}$ oxidation in the macropores in a Spherocarb and the other is the enhanced $\mathrm{CO}_{2}$ production in the heterogeneous reaction. We can check the possibility of the homogeneous $\mathrm{CO}$ oxidation in 
the pores by using the $\mathrm{CO}_{2}$ production rate at the particle surface. If the macropore volume inside the particle is big enough to account for the observed $\mathrm{CO}_{2} / \mathrm{CO}$ ratio, we may conclude the experimental result is due to the $\mathrm{CO}$ oxidation within the pores. If not, the only other possibility is the enhanced $\mathrm{CO}_{2}$ production by heterogeneous reaction.

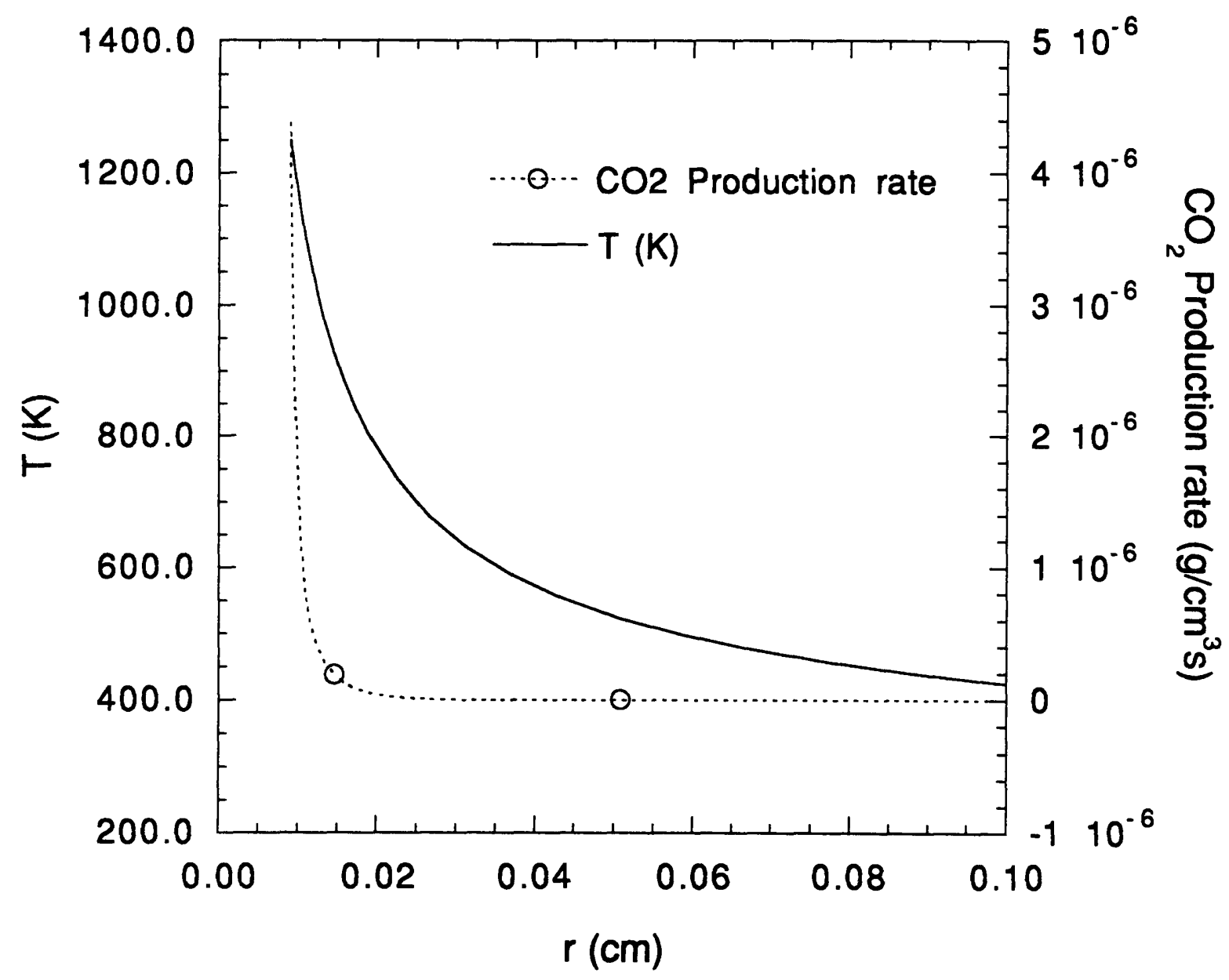

Fig.4.18 $\mathrm{CO} 2$ production rate distribution $\left(\mathrm{T}_{\mathrm{p}}=1250 \mathrm{~K}, \mathrm{r}_{\mathrm{c}}=0.005 \mathrm{gC} / \mathrm{cm}^{2} \mathrm{~s}, 3.5 \mathrm{wt} \% \mathrm{H} 2 \mathrm{O}\right)$ 


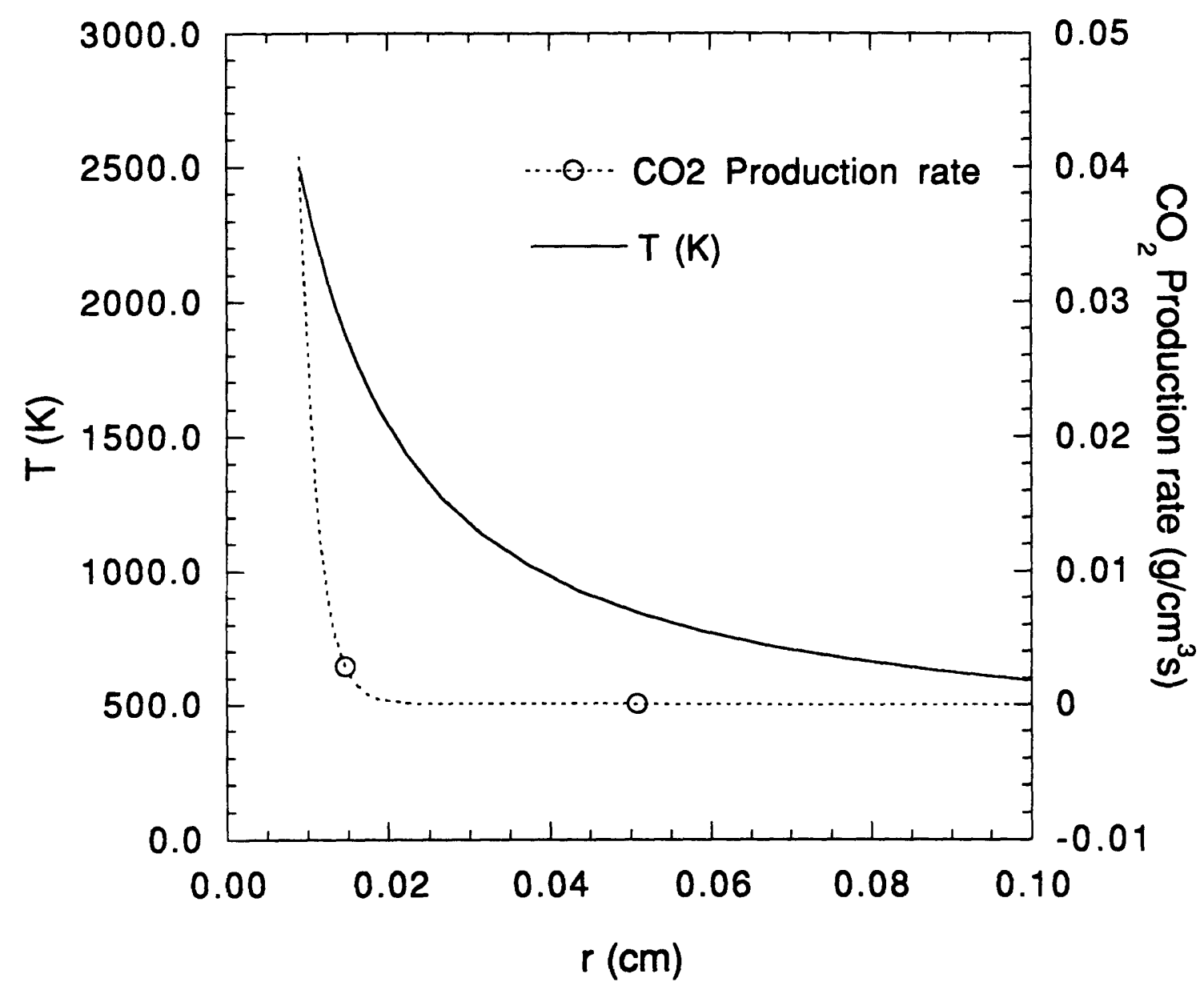

Fig.4.19 $\mathrm{CO} 2$ production rate distribution $\left(\mathrm{T}_{\mathrm{p}}=2500 \mathrm{~K}, \mathrm{r}_{\mathrm{C}}=0.05 \mathrm{gC} / \mathrm{cm}^{2} \mathrm{~s}, 100 \% 02\right.$, no $\left.\mathrm{H} 2 \mathrm{O}\right)$

At $1250 \mathrm{~K}$, the $\mathrm{CO}_{2}$ production rate at the particle surface is $1.0 \times 10^{-7} \mathrm{~mol} / \mathrm{cm}^{3} \mathrm{~s}$, and the amount of $\mathrm{CO}$ needed to be converted to get the experimental $\mathrm{CO}_{2} / \mathrm{CO}$ ratio is $1.03 \times 10^{-7} \mathrm{~mol} / \mathrm{s}$. Therefore, the volume needed is $1.03 \mathrm{~cm}^{3}$. This is much larger than the particle volume of $3 \times 10^{-6} \mathrm{~cm}^{3}$. At $2500 \mathrm{~K}$, the $\mathrm{CO}_{2}$ production rate at the particle surface is $9.26 \times 10^{-4} \mathrm{~mol} / \mathrm{cm}^{3} \mathrm{~s}$, and the amount of $\mathrm{CO}$ needs to be converted to get the experimental $\mathrm{CO}_{2} / \mathrm{CO}$ ratio is $1.63 \times 10^{-6} \mathrm{~mol} / \mathrm{s}$. The volume needed for the desired $\mathrm{CO}$ 
oxidation is $1.76 \times 10^{-3} \mathrm{~cm}^{3}$. Therefore, the possibility of $\mathrm{CO}$ oxidation in the pores inside the particle is negligible in both cases. 


\subsection{Summary}

A gas phase reaction model incorporating the full set of 28 elementary $\mathrm{C} / \mathrm{H} / \mathrm{O}$ reactions was developed. The model provided important insights of gas phase reaction and was used to reproduce the observed $\mathrm{CO}_{2} / \mathrm{CO}$ ratio measured by Tognotti (Tognotti et al., 1990) in an electrodynamic balance. We used a fully time-dependent approach to model the dynamic behavior of gas phase reactions with the Galerkin finite elements method for the spatial discretization.

[Table 4.2] Summary of modeling results (100\% oxygen partial pressure)

\begin{tabular}{|c||c|c|c|c|c|}
\hline Case & $\begin{array}{c}\% \mathrm{CO} \\
\text { conversion in } \\
\text { gas phase }\end{array}$ & $\begin{array}{c}\mathrm{CO}_{2} / \mathrm{CO} \\
\text { (calculated } \\
\text { by model) }\end{array}$ & $\begin{array}{c}\mathrm{CO}_{2} / \mathrm{CO} \\
\text { (experiment) }\end{array}$ & $\begin{array}{c}\mathrm{CO}_{2} / \mathrm{CO} \\
\text { from solid } \\
\text { (Tognotti) }\end{array}$ & $\begin{array}{c}\mathrm{CO}_{2} / \mathrm{CO} \\
\text { from solid } \\
\text { (Du) }\end{array}$ \\
\hline \hline $\begin{array}{c}1250 \mathrm{~K}, \\
3.5 \% \mathrm{H}_{2} \mathrm{O}\end{array}$ & $2.7 \%$ & 0.267 & 0.75 & 0.233 & 0.22 \\
\hline $\begin{array}{c}2500 \mathrm{~K}, \\
\text { no water }\end{array}$ & $2 \%$ & 0.089 & $0.8-0.9$ & $0.068^{*}$ & 0.13 \\
\hline $\begin{array}{c}2500 \mathrm{~K}, \\
\text { internal 'H' }\end{array}$ & $39 \%$ & 0.76 & & & \\
\hline $\begin{array}{c}2500 \mathrm{~K}, \\
3.5 \% \mathrm{H} 2 \mathrm{O}\end{array}$ & $68 \%$ & 2.35 & & & \\
\hline
\end{tabular}

This gas phase model can predict the gas species and the temperature distributions in the boundary layer, the $\mathrm{CO}_{2} / \mathrm{CO}$ ratio, and the location of $\mathrm{CO}$ oxidation. 
Different water vapor concentrations at low and high particle surface temperatures $(1250 \mathrm{~K}$ and $2500 \mathrm{~K})$ are used to see the effect of hydrogen containing species on CO oxidation in the gas phase. The particle diameter was $180 \mu \mathrm{m}$, and the bulk gas was a mixture of $100 \%$ oxygen and water vapor. The summary of the modeling results are shown in Table 4.2.

At a temperature of $1250 \mathrm{~K}$, there was no significant $\mathrm{CO}$ oxidation in the gas phase even with $3.5 \%$ water vapor due to the small size of the particle and the steep temperature gradient. The $\mathrm{CO}_{2} / \mathrm{CO}$ ratio calculated from the model was 0.267 in mole fraction ratio, and the $\mathrm{CO}_{2} / \mathrm{CO}$ ratio from the heterogeneous reaction at $1250 \mathrm{~K}$ is 0.233 . This calculation suggest that there is negligible $\mathrm{CO}$ oxidation in the gas phase. Estimates of gas phase reaction in the macropore could not account for the high $\mathrm{CO}_{2} / \mathrm{CO}$ ratio indicating that the presence of water vapor enhances the rate heterogeneous oxidation of $\mathrm{CO}$.

At a high temperature of $2500 \mathrm{~K}$, without hydrogen containing molecule the gas phase $\mathrm{CO}$ oxidation is negligible even at a very high surface temperature. The $\mathrm{CO}_{2} / \mathrm{CO}$ ratio was 0.089 in mole fraction ratio. The $\mathrm{CO}_{2} / \mathrm{CO}$ ratio from the heterogeneous reaction is 0.068 at $2500 \mathrm{~K}$. Only about $2 \%$ of $\mathrm{CO}$ from the heterogeneous reaction was converted to $\mathrm{CO}_{2}$ in the gas phase.

The effect of hydrogen containing component on the $\mathrm{CO}$ oxidation was significant. The external water vapor of $3.5 \%$ resulted in a $\mathrm{CO}_{2} / \mathrm{CO}$ ratio of 2.35 which is much higher than the experimental value. Spherocarb has $0.74 \%$ of ' $H$ ' internally. This hydrogen source was enough to explain the observed $\mathrm{CO}_{2} / \mathrm{CO}$ ratio, and the calculated $\mathrm{CO}_{2} / \mathrm{CO}$ ratio with internal ' $\mathrm{H}$ ' is 0.76 . The $\mathrm{CO}_{2} / \mathrm{CO}$ ratio from the experiments is $0.8-0.9$ at $2500 \mathrm{~K}$. The agreement between the two values was good.

The model successfully reproduced the $\mathrm{CO}_{2} / \mathrm{CO}$ ratio measured by Tognotti et al. The internal ' $\mathrm{H}$ ' of Spherocarb is important for the observed $\mathrm{CO} 2 / \mathrm{CO}$ at $2500 \mathrm{~K}$. At $1250 \mathrm{~K}$, the presence of water vapor enhances the rate heterogeneous oxidation of $\mathrm{CO}$, and the possibility of homogeneous CO oxidation in the macropore of Spherocarb is negligible. 


\section{Chapter 5}

\section{CO Oxidation in the Fluidized Bed}

\subsection{Background}

As we mentioned in Chapter 4, the $\mathrm{CO} / \mathrm{CO}_{2}$ ratio is an important parameter determining particle temperature, depending on the proximity to the surface of the gas phase reactions. By using a model developed for gas phase reaction, the location and the degree of $\mathrm{CO}$ oxidation in the gas phase can be calculated.

One of the objectives of fluidized bed combustion is to achieve the total conversion from the coal to carbon dioxide to get the maximum heat generation. The $\mathrm{CO}$ oxidation in the gas phase has been studied by a number of researchers. Some of the studies were already introduced in the previous chapter, and detailed or other studies of $\mathrm{CO}$ oxidation for a large size particle combustion in the fluidized bed will be discussed.

Amundson and coworkers (Amundson, 1978, Caram et al., 1981) have analyzed a model for diffusion and reaction in a stagnant boundary layer surrounding a burning carbon particle. It is well known that the water vapor in the gas phase enhances the $\mathrm{CO}$ oxidation, and it is reasonable to assume that increasing water vapor concentration increases $\mathrm{CO}$ oxidation. Adomeit et al. (Adomeit, 1977) have shown that there is negligible oxidation of $\mathrm{CO}$ in dry air, while at relative humidities of $10 \%$ or higher it is enhanced by a factor of 
about 5000 compared to the dry air reaction rate. Sundaresan and Amundson (Sundaresan et al.,1981) calculated CO oxidation as a function of temperature, particle size, and water vapor concentration. The conversion to $\mathrm{CO}_{2}$ is much higher for the large particles. Caram and Amundson (Caram, 1977) concluded that CO escapes to the bulk of the fluidized bed for particles of diameter less than $0.1 \mathrm{~mm}$. $\mathrm{CO}$ is considered to burn around the particle greater than $5 \mathrm{~mm}$. La Nauze (La Nauze, 1985) summarized the current understanding that a particle bigger than $3 \mathrm{~mm}$ will be surrounded by a $\mathrm{CO}$ flame, whereas for a particle smaller than $0.1 \mathrm{~mm}$ CO will escape the boundary layer. Most of them used the assumptions of the pseudo steady state, global reaction kinetics, constant thermodynamic and transport properties, and simplified one-film or two-film models to calculate the gas phase reactions.

The possibility of $\mathrm{CO}$ oxidation in the emulsion phase has been studied by Hayhurst (Hayhurst, 1990). He concluded that CO will not burn in the dense phase of a fluidized bed at temperatures below $1273 \mathrm{~K}$ due to inhibition of the gas phase oxidation reaction by the presence of the bed particles. Hesketh and Davidson (Hesketh, 1991) reached a similar conclusion.

The differences between a spherocarb combustion by laser heating and the coal char combustion in a fluidized bed reactor are: (1) the particle is heated by the hot external surrounding gas, (2) the particle size is 5-20 time bigger than that of a spherocarb, (3) there exist vigorous contacts between coal particles and bed particles.

Our purpose is to calculate the $\mathrm{CO}$ oxidation in the gas phase surrounding a single char particle using a gas phase reaction model developed in chapter 4. Conditions of (1) and (2) above are easy to incorporate, but the effects of the particle contacts on CO oxidation are hard to incorporate. The bed particle usually plays a role of quenching the $\mathrm{CO}$ oxidation. We need a model which can calculate the number of the bed particle with in the char particle boundary layer and the frequency of that existence to take the effects of 
particle-to-particle contacts into consideration. Here we assume, the $\mathrm{CO}$ oxidation reaction in the gas phase (here gas phase means gas surrounding a single char particle in the emulsion phase of a fluidized bed) is not affected by the particle-to-particle contacts. We use the carbon consumption rate calculated in chapter 3 - which incorporated mechanistic heat and mass transfer model to calculate carbon consumption rate- to give the influx from the char to the gas phase. 


\subsection{Experimental measurement of $\mathrm{CO}_{2} / \mathrm{CO}$ ratio}

The $\mathrm{CO}_{2} / \mathrm{CO}$ ratio measurement by Tullin (Tullin et al., 1993) are shown in Fig.5.1. The experimental procedures are introduced in chapter three. The measured $\mathrm{CO}_{2} / \mathrm{CO}$ ratio in the fluidized bed shows that almost all $\mathrm{CO}$ oxidized to $\mathrm{CO}_{2}$. The $\mathrm{CO} / \mathrm{CO}_{2}$ ratio is close to zero $\left(\mathrm{CO} / \mathrm{CO}_{2}\right.$ is used instead of $\mathrm{CO}_{2} / \mathrm{CO}$ in the figure.) in the beginning and in the middle of the reaction. At the end, the $\mathrm{CO}$ oxidation slows down and the $\mathrm{CO} / \mathrm{CO}_{2}$ ratio begins to rise. The challenge is to try to model the trend in $\mathrm{CO}$ emissions.

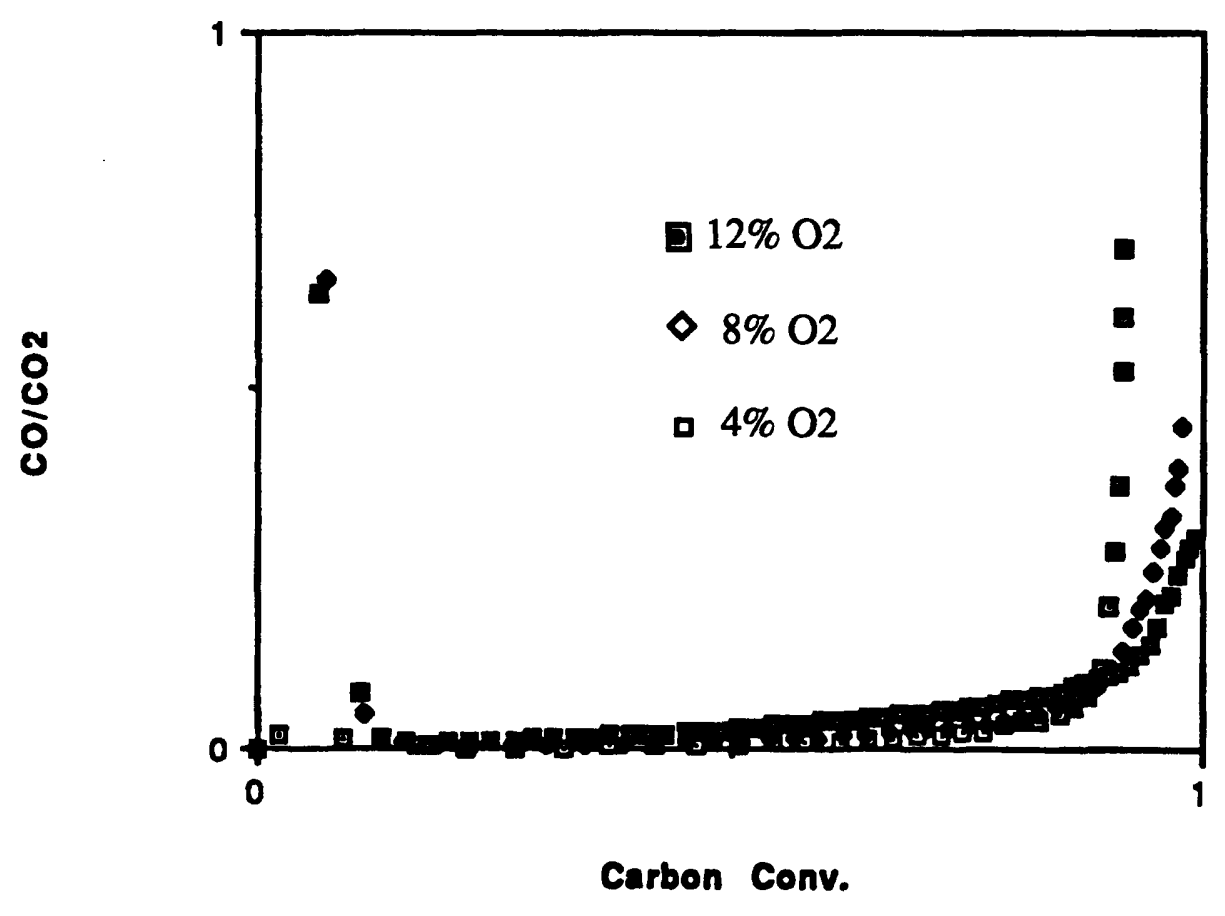

Fig.5.1 Experimental measurement of $\mathrm{CO} / \mathrm{CO}_{2}$ ratio as a function of conversion (1073 K, 4mm particle) 


\subsection{Modeling results}

\subsubsection{A $4 \mathrm{~mm}$ particle with $3.5 \%$ water vapor}

To study the effect of gas phase reactions on $\mathrm{CO}$ oxidation in the fluidized bed, the particle surface temperature and the bulk gas temperature were set as constants during the reaction. It was found that most of the char combustion occurs at pseudo-steady state temperature (chapter three). The boundary conditions were given by the carbon consumption rate calculated from the combustion model and the $\mathrm{CO}_{2} / \mathrm{CO}$ ratio was calculated by extrapolating Tognotti's measurements. The exact particle temperature should be calculated from the combined model of gas and solid phase reaction, however, here our major concern is to calculate the degree of $\mathrm{CO}$ oxidation in the gas phase at a given temperature. The water vapor mass fraction of 0.035 was used to simulate the moisture existing in the fluidized bed. Moisture may come from the oxidation of hydrogen in char or the moisture already existing in air.

The temperature distribution changes as a function of time are shown in Fig.5.2. In the beginning, the temperature profile shows a monotonic decrease. Due to the heat of $\mathrm{CO}$ oxidation, a temperature overshoot develops. It is clear that there exists a gas phase ignition. The difference between the maximum gas temperature and the particle temperature is up to $60 \mathrm{~K}$ and still increasing. The mass fraction distributions in the gas phase using 4 mm particle with 20\% oxygen partial pressure is shown in Fig.5.3. Due to the gas phase ignition most of $\mathrm{CO}$ is converted to $\mathrm{CO}_{2}$, as $\mathrm{CO}$ diffuses through the gas phase boundary. 


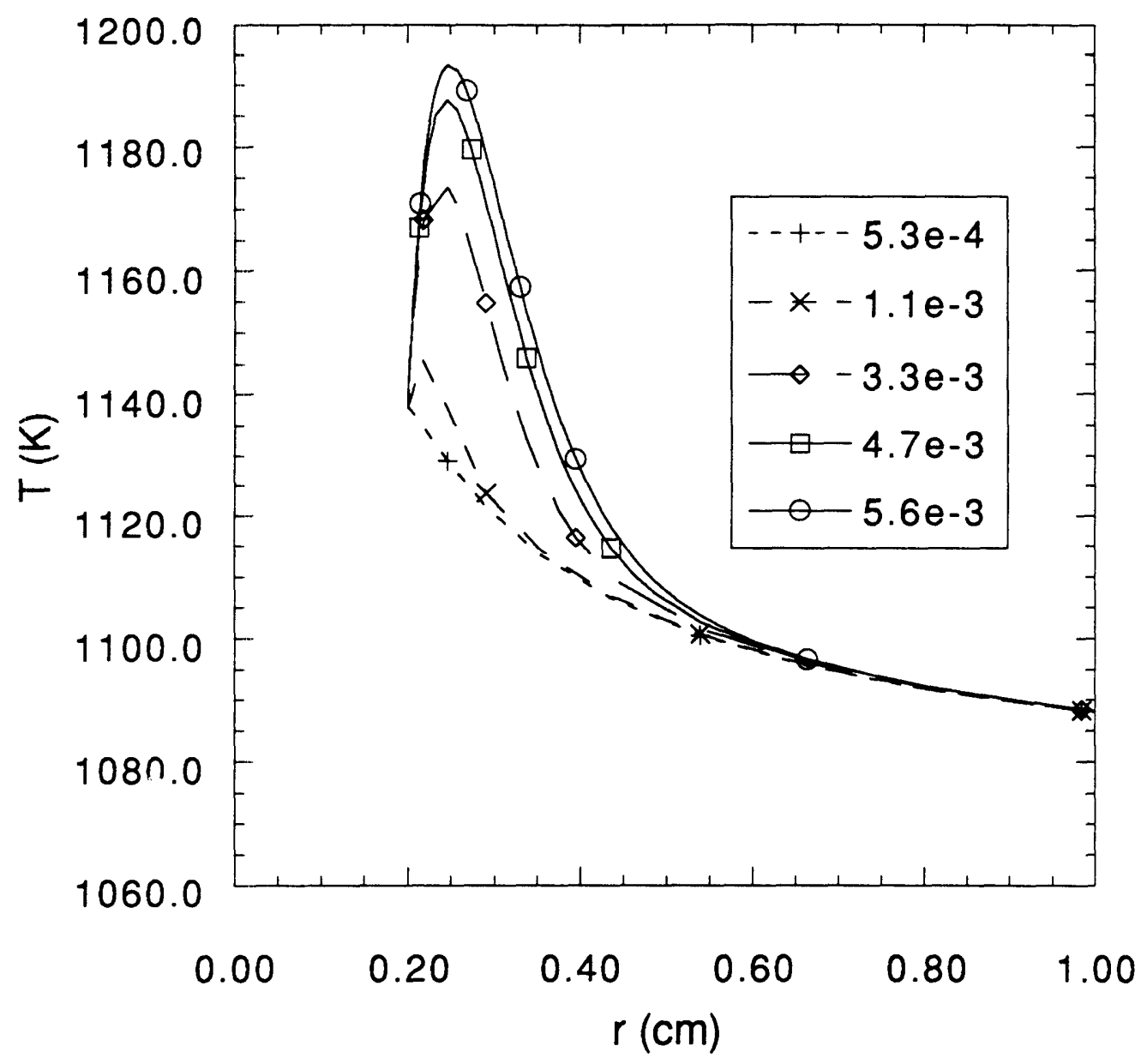

Fig.5.2 Temperature profile as a function of time $\left(\mathrm{d}_{\mathrm{O}}=4 \mathrm{~mm}, 20 \% \mathrm{P} \mathrm{O}_{2}, 3.5 \% \mathrm{H} 2 \mathrm{O}, \mathrm{r}_{\mathrm{c}}=2.2 \mathrm{e}-4 \mathrm{gC} / \mathrm{cm}^{2} \mathrm{~s}\right)$ 


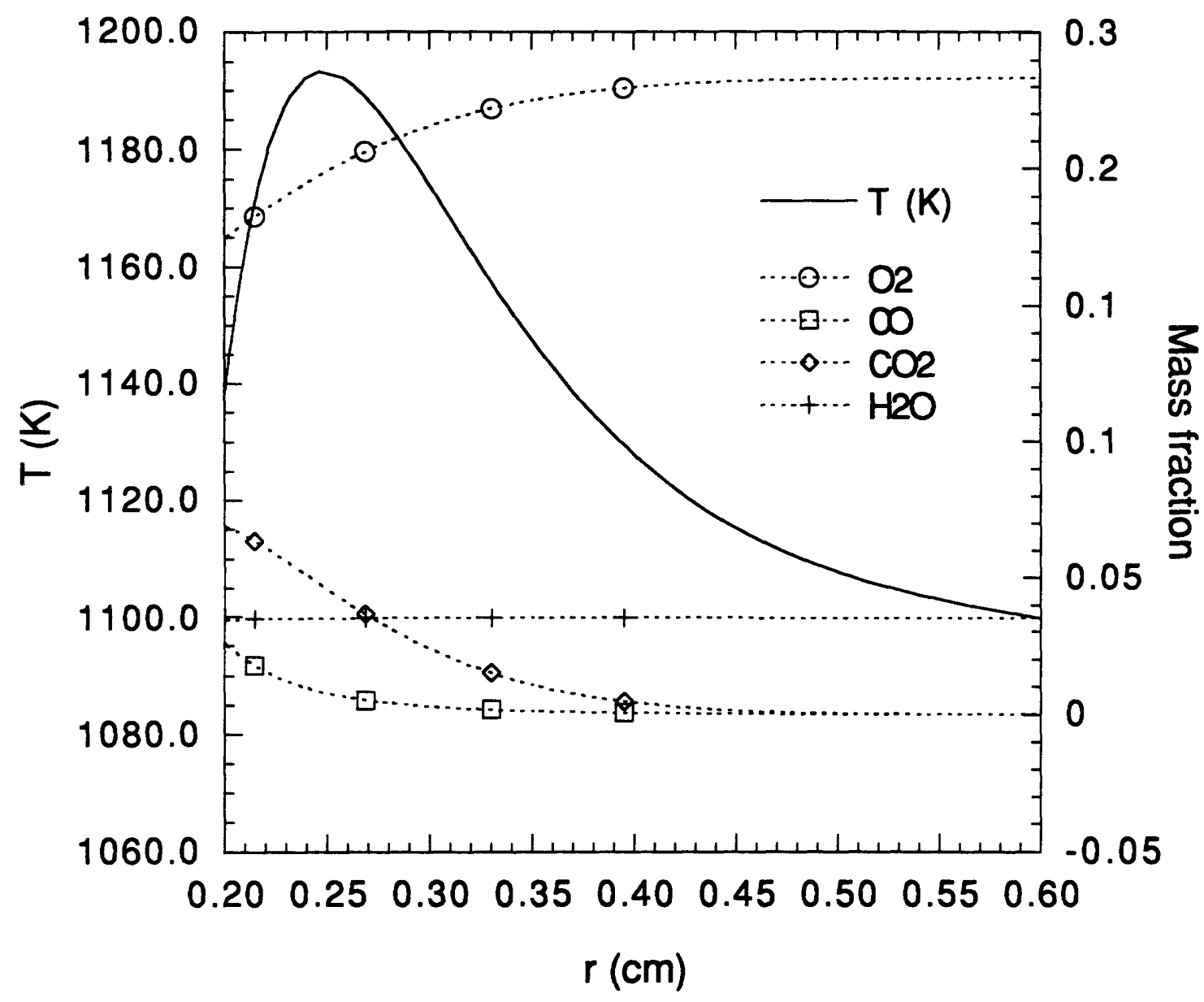

Fig.5.3 Temperature and Mass fraction distributions after $5.6 \mathrm{~ms}$ $\left(d_{0}=4 \mathrm{~mm}, 20 \%\right.$ P O2, $\left.\mathrm{r}_{\mathrm{C}}=2.2 \mathrm{e}-4 \mathrm{gC} / \mathrm{cm}^{2} \mathrm{~s}\right)$

\subsubsection{A $4 \mathrm{~mm}$ particle without water vapor}

According to Adomeit (Adomeit, 1977), there is negligible oxidation of CO in dry air. There are sources for water vapor in the fluidized bed, one possibility is from the oxidation of hydrogen in char or the another is from the moisture in air. In the previous 
chapter, we also found that the water vapor has a significant effect on $\mathrm{CO}$ oxidation in the gas phase surrounding a pulverized coal size particle.

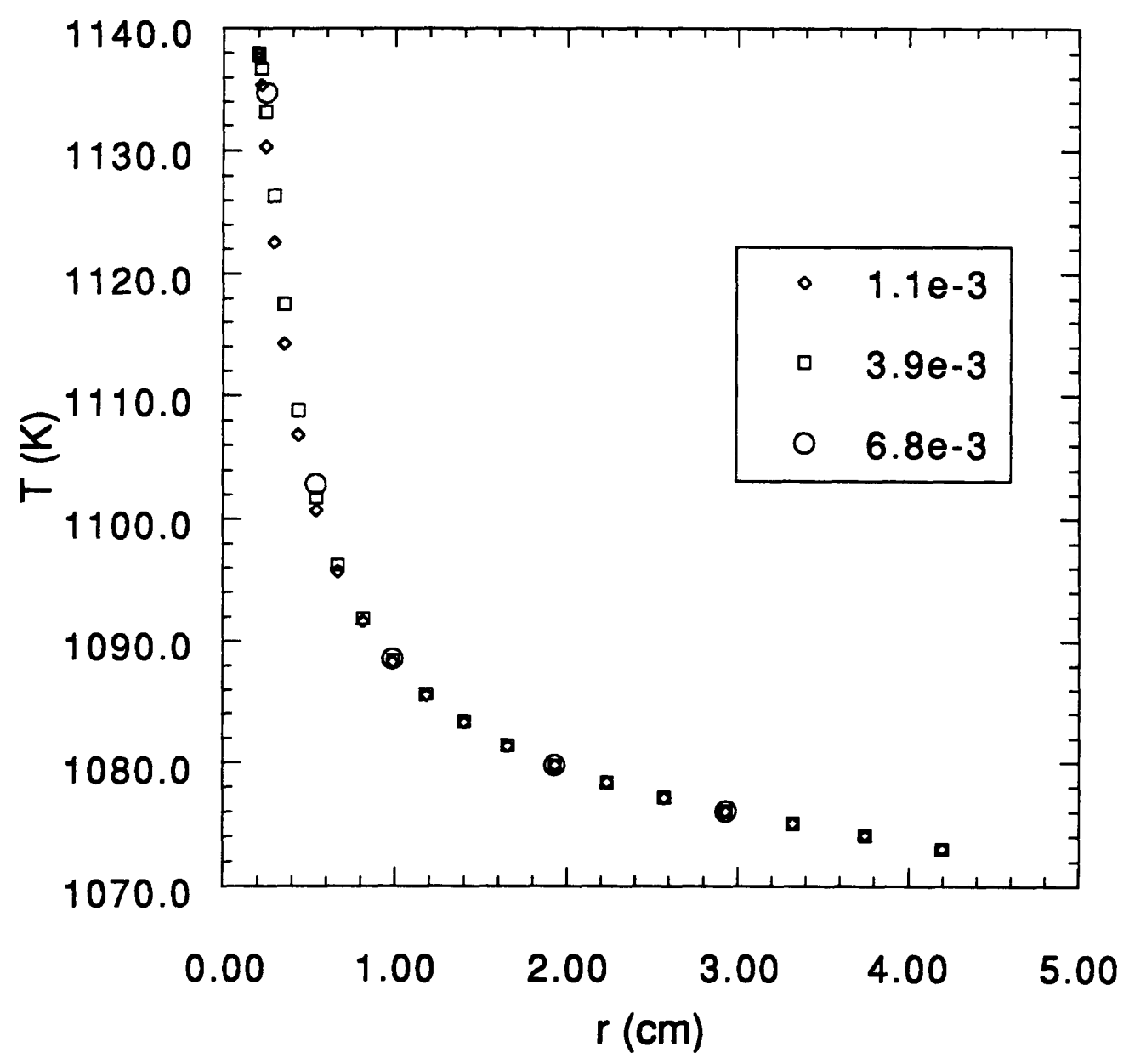

Fig.5.4 Temperature profile as a function of time $\left(\mathrm{d}_{\mathrm{O}}=4 \mathrm{~mm}, 20 \% \mathrm{P} \mathrm{O}_{2}\right.$, no $\left.\mathrm{H} 2 \mathrm{O}, \mathrm{r}_{\mathrm{c}}=2.2 \mathrm{e}-4 \mathrm{gC} / \mathrm{cm}^{2} \mathrm{~s}\right)$

A case without water vapor is calculated to study the effects of water vapor on $\mathrm{CO}$ oxidation in the gas phase. The temperature distributions as a function of time is shown in Fig.5.4. The temperature distribution changes little compared to the case with water vapor as time changes. There is no gas phase ignition without water vapor. Although $\mathrm{CO}$ can 
oxidize to $\mathrm{CO} 2$ via $\mathrm{CO}+\mathrm{O}$ reaction, this path is slow compared to the $\mathrm{CO}+\mathrm{OH}$ reaction and is too slow to bring gas phase ignition.

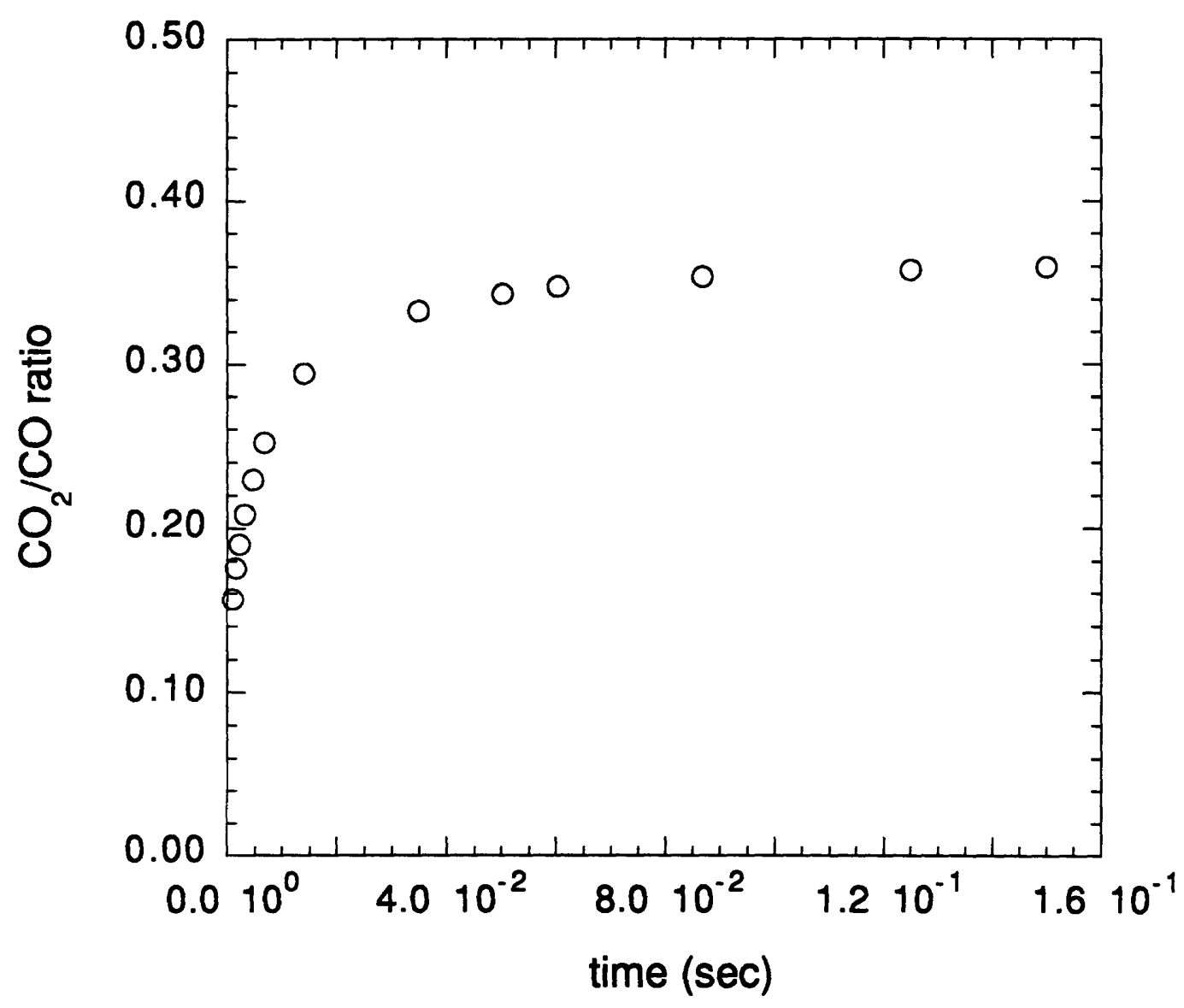

Fig.5.5 $\mathrm{CO}_{2} / \mathrm{CO}$ ratio as a function of time $\left(\mathrm{d}_{\mathrm{O}}=4 \mathrm{~mm}, 20 \% \mathrm{P} \mathrm{O}_{2}\right.$, no $\left.\mathrm{H} 2 \mathrm{O}, \mathrm{r}_{\mathrm{c}}=2.2 \mathrm{e}-4 \mathrm{gC} / \mathrm{cm}^{2} \mathrm{~s}\right)$

The $\mathrm{CO}_{2} / \mathrm{CO}$ ratio as a function of time is shown in Fig.5.5. In contrast to the $\mathrm{CO}_{2} / \mathrm{CO}$ ratio of the case with water (will be discussed in the next section), the $\mathrm{CO}_{2} / \mathrm{CO}$ ratio approaches a steady state value. The steady state $\mathrm{CO}_{2} / \mathrm{CO}$ mass fraction ratio is about 0.36 corresponding to a mole fraction ratio of 0.229 . The initial $\mathrm{CO}_{2} / \mathrm{CO}$ ratio from the heterogeneous reaction was 0.214 . Therefore, there is negligible $\mathrm{CO}$ oxidation without water vapor. 


\subsubsection{A 3mm particle with water vapor}

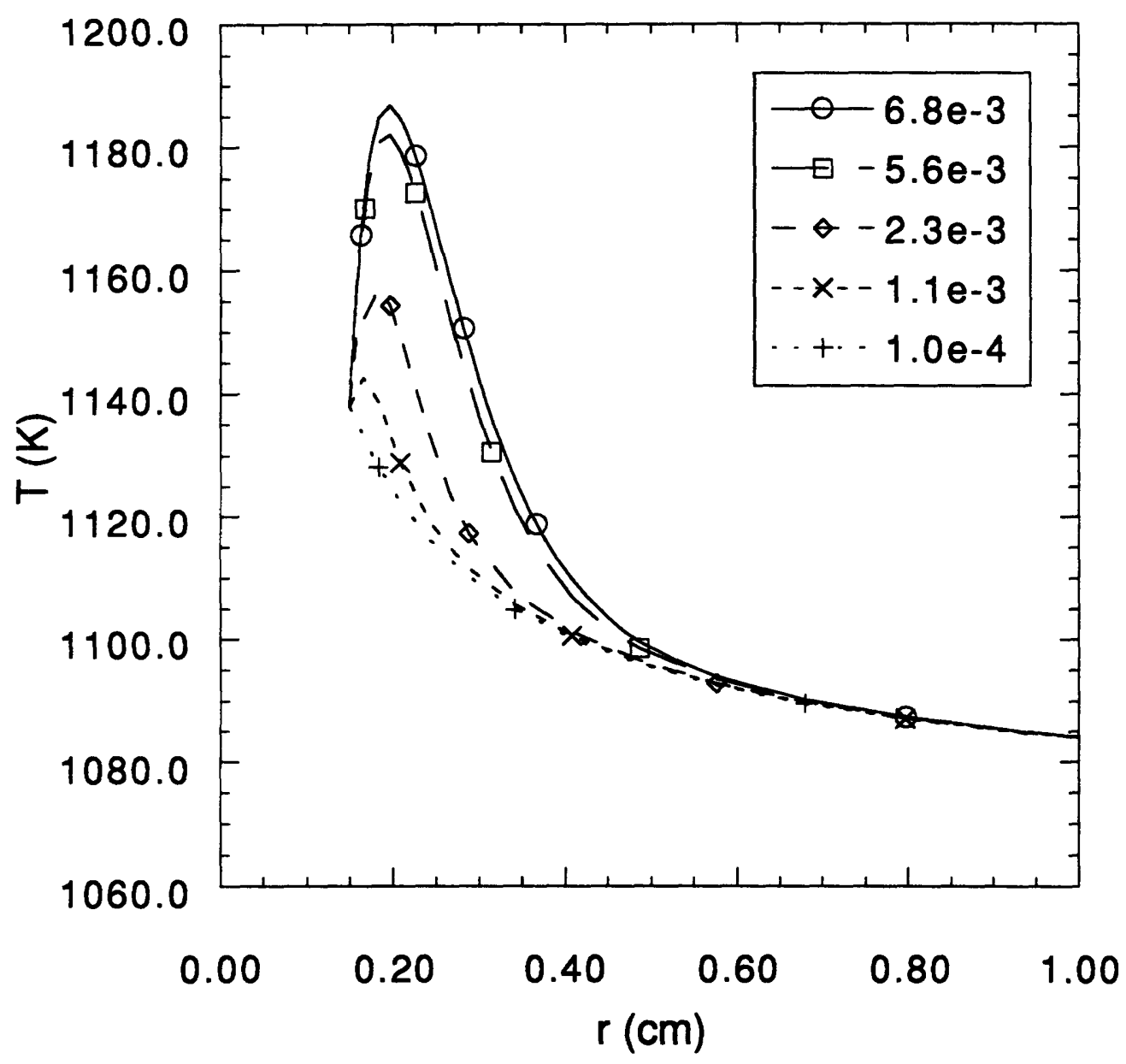

Fig.5.6 Temperature as a function of time $\left(\mathrm{d}_{\mathrm{O}}=3 \mathrm{~mm}, 20 \% \mathrm{P} \mathrm{O}_{2}, 3.5 \% \mathrm{H}_{2} \mathrm{O}, \mathrm{r}_{\mathrm{c}}=2.2 \mathrm{e}-4 \mathrm{gC} / \mathrm{cm}^{2} \mathrm{~s}\right)$

The use of a $3 \mathrm{~mm}$ particle shows the same tendency as $4 \mathrm{~mm}$ particle case except that the temperature overshoot was lower than for the $4 \mathrm{~mm}$ particle at the same time. The temperature distribution as a function of time is shown in Fig.5.6. The maximum temperature rises and moves away from the particle surface, as time increases. 


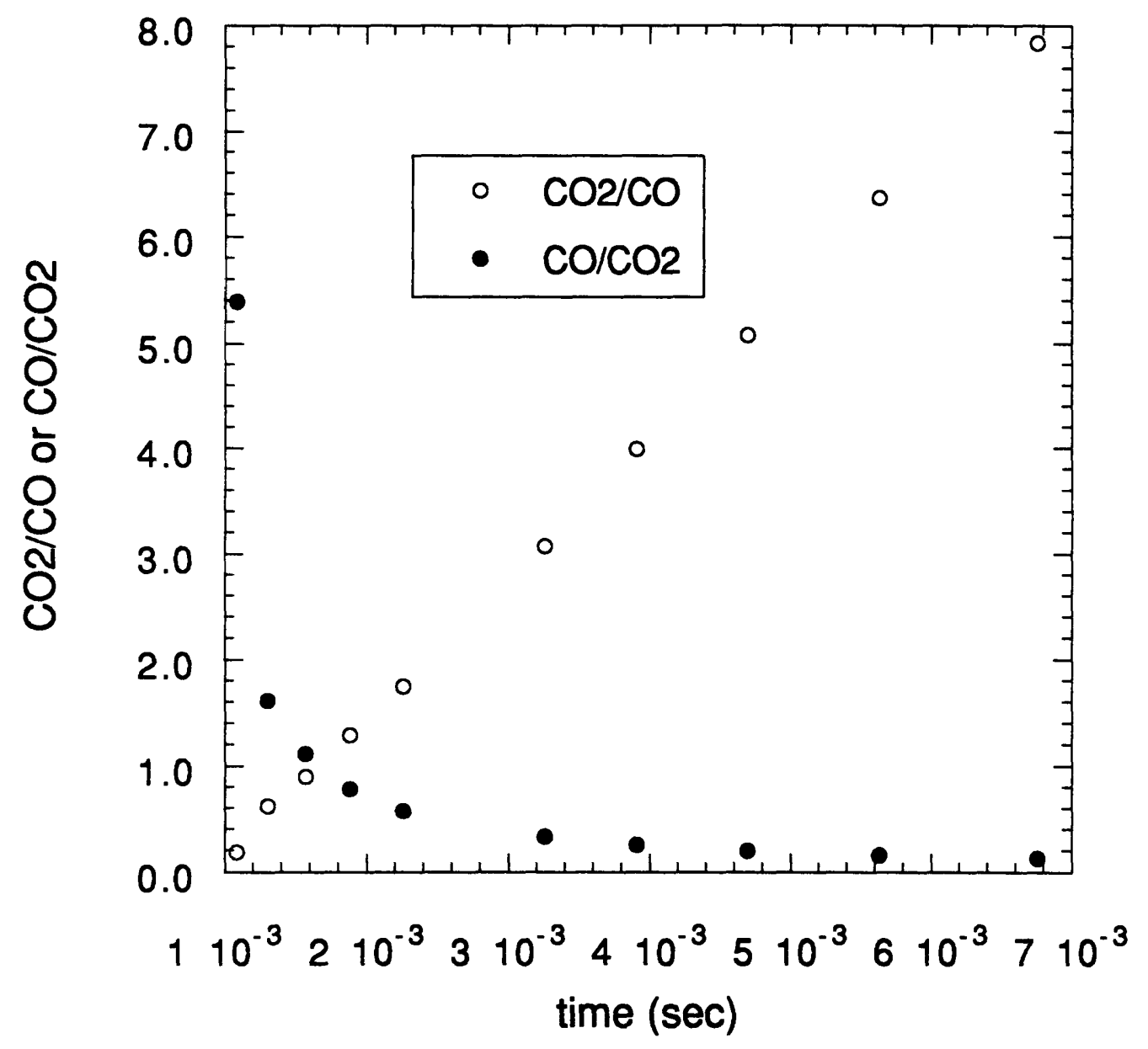

Fig.5.7 $\mathrm{CO}_{2} / \mathrm{CO}$ ratio and $\mathrm{CO} / \mathrm{CO}_{2}$ ratio at a distance of $0.2 \mathrm{~cm}$ from surface as a function of time $\left(d_{0}=3 \mathrm{~mm}, 20 \% \mathrm{O}, 3.5 \% \mathrm{H}_{2} \mathrm{O}\right)$

We studied the change with time of the $\mathrm{CO}_{2} / \mathrm{CO}$ ratio at approximately $0.2 \mathrm{~cm}$ away from the particle surface. The $\mathrm{CO}$ oxidation occurs not only near the particle surface but also away from the particle surface, because there is not a steep temperature gradient which can cool down the $\mathrm{CO}$ oxidation reaction. The $\mathrm{CO}_{2} / \mathrm{CO}$ ratio as a function of time is shown in Fig.5.7. The $\mathrm{CO}_{2} / \mathrm{CO}$ ratio increases linearly as the time increases. If the $\mathrm{CO}$ 
mass fraction approaches zero, the $\mathrm{CO}_{2} / \mathrm{CO}$ ratio can increase to an infinite value. Therefore, the $\mathrm{CO} / \mathrm{CO}_{2}$ ratio is also shown. The tendency shows that $\mathrm{CO}$ will continue to react until almost all $\mathrm{CO}$ will be converted to $\mathrm{CO}_{2}$. This is due to the gas phase ignition. The gas phase ignition raises gas temperatures which accelerates the reaction to produce more heat. This gas phase ignition will be terminated only if the particle diameter decreases below the critical diameter, and the $\mathrm{CO}_{2} / \mathrm{CO}$ ratio will drop accordingly.

\subsubsection{Particle size of $1 \mathrm{~mm}, 0.5 \mathrm{~mm}, 0.25 \mathrm{~mm}$ with water vapor}

The particle size of $1 \mathrm{~mm}$ is used to see the effects of a smaller particle size. The diffusion velocity is proportional to the inverse of the particle diameter. The higher diffusion velocity from a smaller particle means less time is available for the $\mathrm{CO}$ to undergo the gas phase reaction. The temperature distributions as a function of time are shown in Fig.5.8. At this particle size the temperature overshoot is small compared to those for bigger particles, although there still exists a gas phase ignition. The $\mathrm{CO}_{2} / \mathrm{CO}$ ratio (approximately at $R_{O}+d_{0}$ ) as a function of time is shown in Fig.5.9. In the beginning the $\mathrm{CO}_{2} / \mathrm{CO}$ ratio increases slowly which is from the diffusion of the heterogeneous reaction products, and the $\mathrm{CO}_{2} / \mathrm{CO}$ ratio increases linearly after gas phase ignition takes place. The rate of increase is slower than that of a bigger particle. 


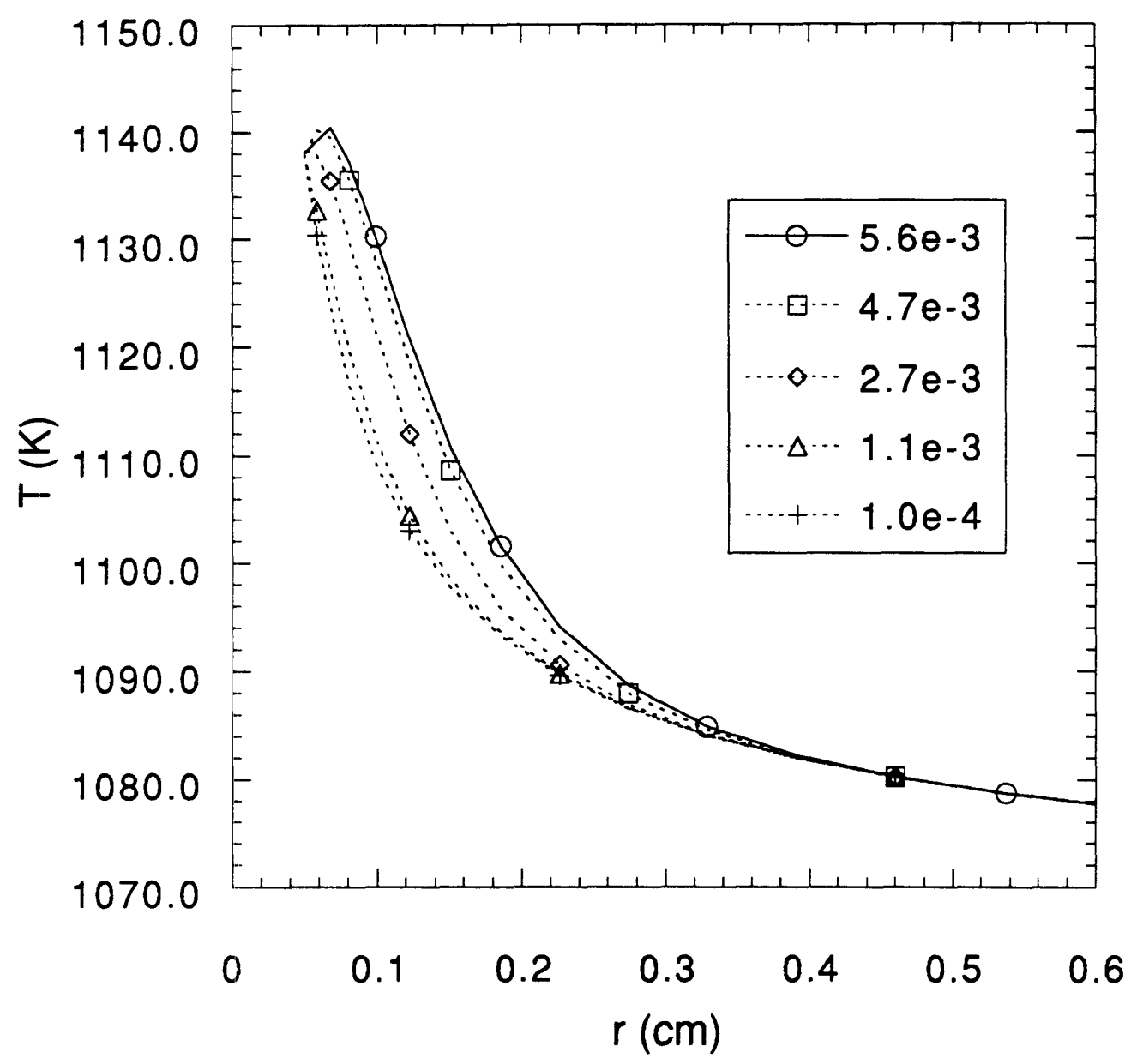

Fig.5.8 Temperature as a function of time $\left(\mathrm{d}_{\mathrm{O}}=1 \mathrm{~mm}, 20 \% \mathrm{P} \mathrm{O}_{2}, 3.5 \% \mathrm{H}_{2} \mathrm{O}, \mathrm{r}_{\mathrm{C}}=2.2 \mathrm{e}-4 \mathrm{gC} / \mathrm{cm}^{2} \mathrm{~s}\right)$ 


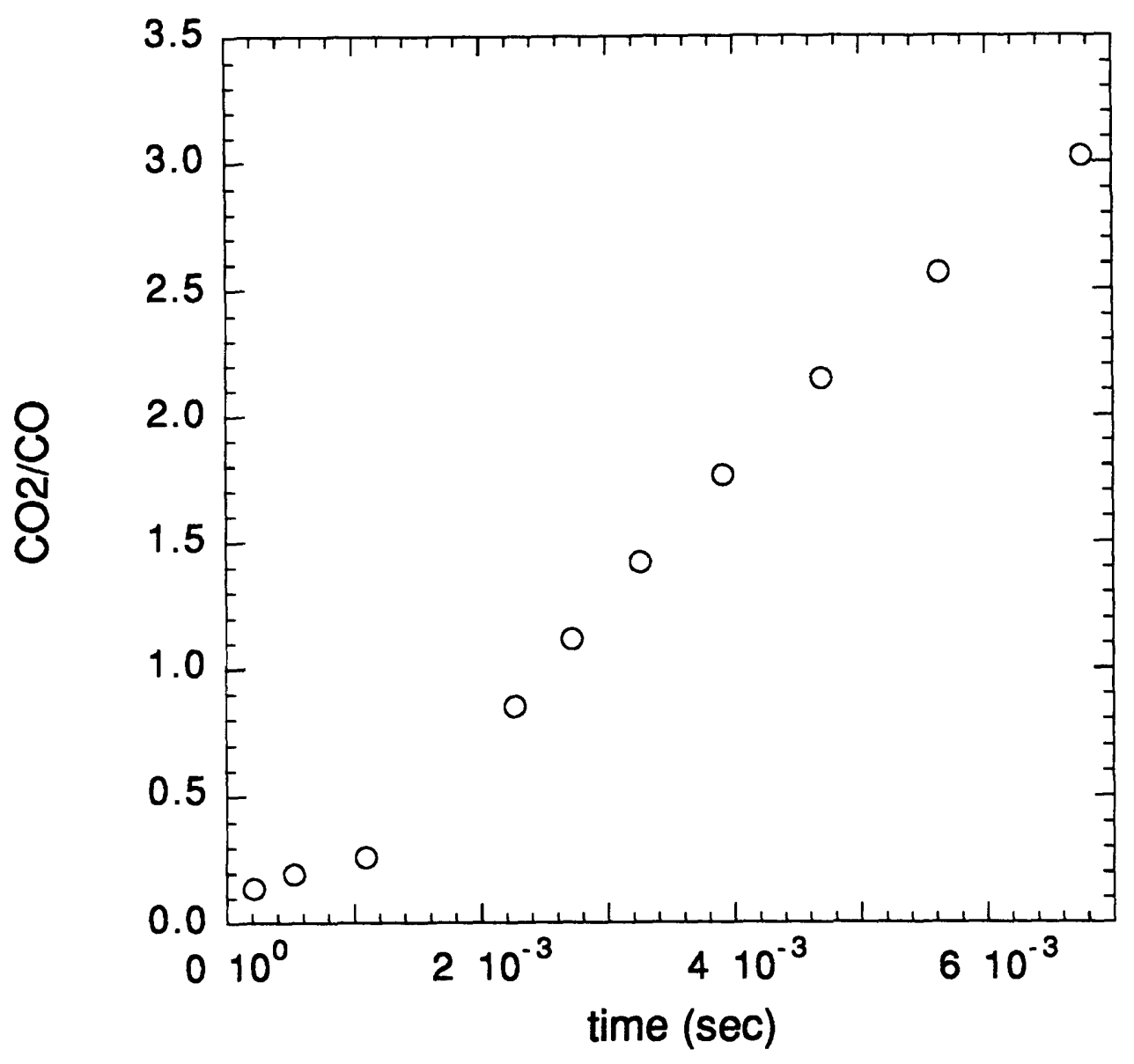

Fig.5.9 $\mathrm{CO}_{2} / \mathrm{CO}$ ratio as a function of time

$$
\left(d_{0}=1 \mathrm{~mm}, 20 \% \mathrm{O}, 3.5 \% \mathrm{H}_{2} \mathrm{O}\right)
$$

The temperature distribution as a function of time for a $0.5 \mathrm{~mm}$ particle is shown in Fig.5.10. There is no gas phase ignition, but the temperature rises a little due to the $\mathrm{CO}$ oxidation reaction. At a particle size of $0.5 \mathrm{~mm}$, the gas phase reaction shows an intermediate behavior. The $\mathrm{CO}_{2} / \mathrm{CO}$ ratio (approximately at $\mathrm{R}_{\mathbf{O}}+\mathrm{d}_{\mathrm{O}}$ ) as a function of time is shown in Fig.5.11. The $\mathrm{CO}_{2} / \mathrm{CO}$ ratio from the gas phase reaction (after $1.5 \mathrm{msec}$ ) is not increasing linearly and seems to approach an asymptotic value which is contrast to the case 
of bigger particle sizes. This is due to the absence of the gas phase ignition for a $0.5 \mathrm{~mm}$ particle.

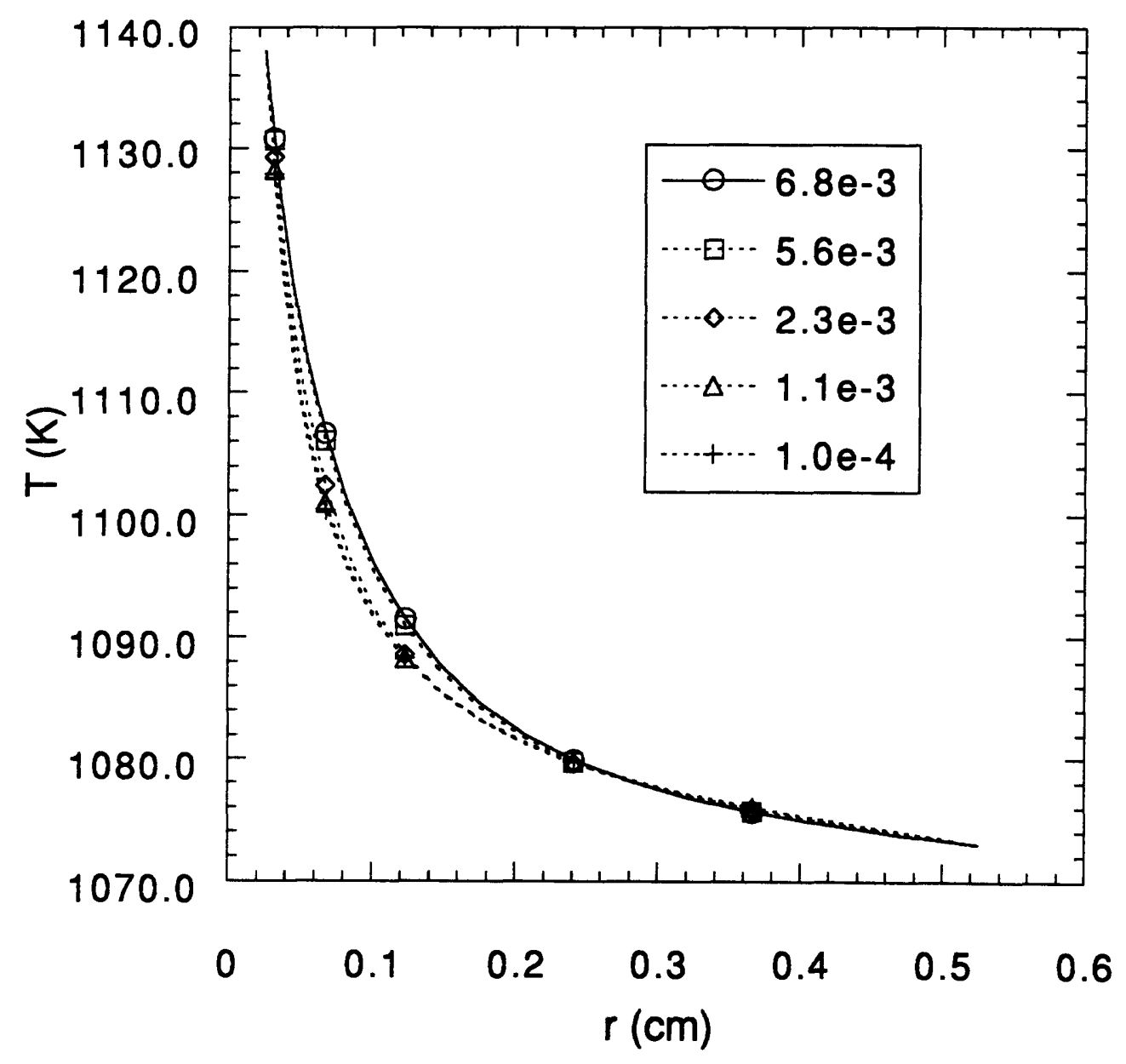

Fig.5.10 Temperature as a function of time $\left(\mathrm{d}_{\mathrm{O}}=0.5 \mathrm{~mm}, 20 \% \mathrm{P} \mathrm{O}_{2}, 3.5 \% \mathrm{H}_{2} \mathrm{O}, \mathrm{r}_{\mathrm{c}}=2.2 \mathrm{e}-4 \mathrm{gC} / \mathrm{cm}^{2} \mathrm{~s}\right)$ 


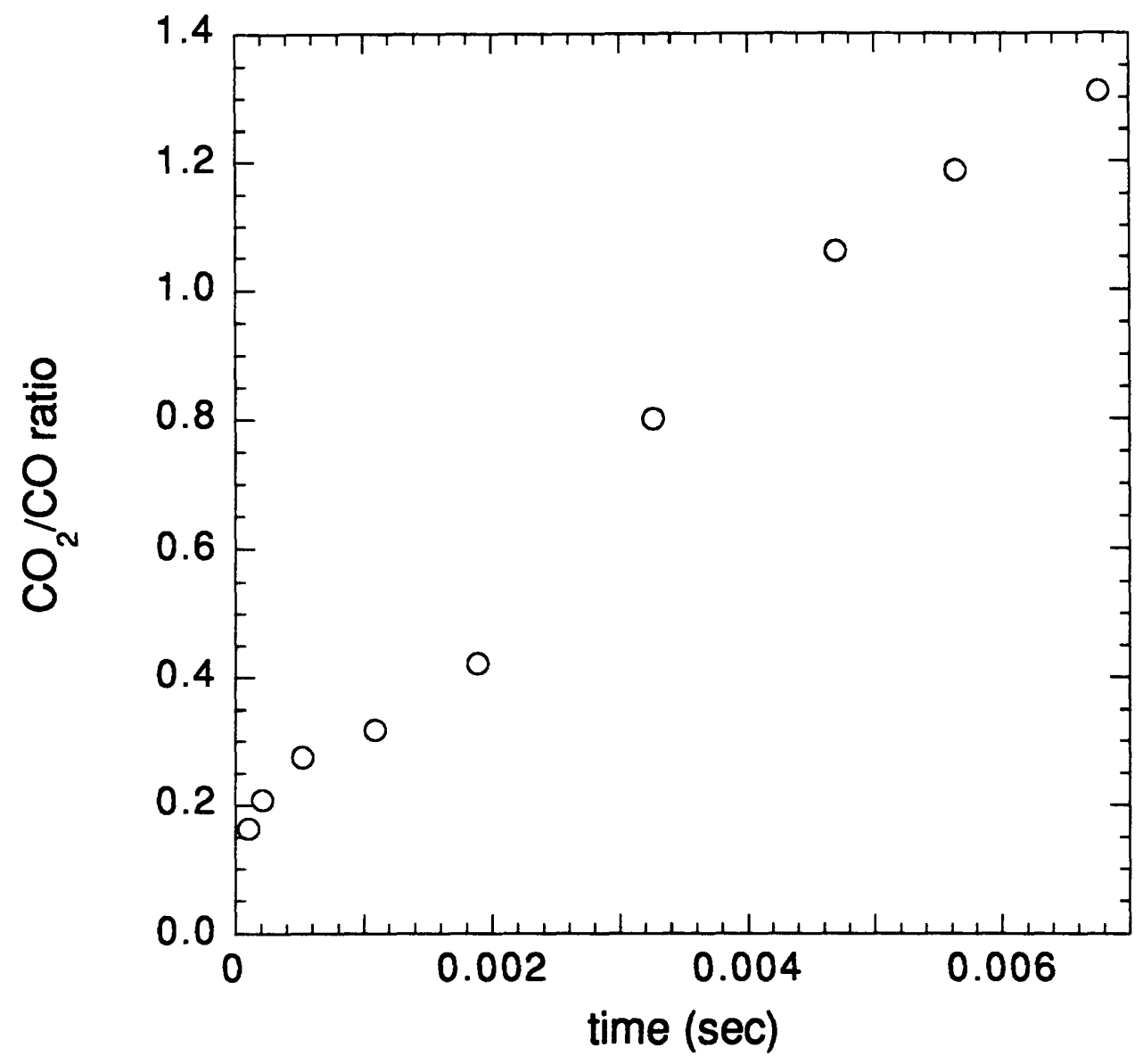

Fig.5.11 $\mathrm{CO}_{2} / \mathrm{CO}$ ratio as a function of time at a distance of $0.5 \mathrm{~mm}$ from the surface $\left(d_{0}=0.5 \mathrm{~mm}, 20 \% 02,3.5 \% \mathrm{H}_{2} \mathrm{O}\right)$

The temperature distribution as a function of time for a $0.25 \mathrm{~mm}$ particle is shown in Fig.5.12. Due to the small particle size, there is no gas phase ignition and negligible CO oxidation. The diffusion velocity increases as the particle size shrinks, and $\mathrm{CO}$ has less time to convert to $\mathrm{CO}_{2}$. 


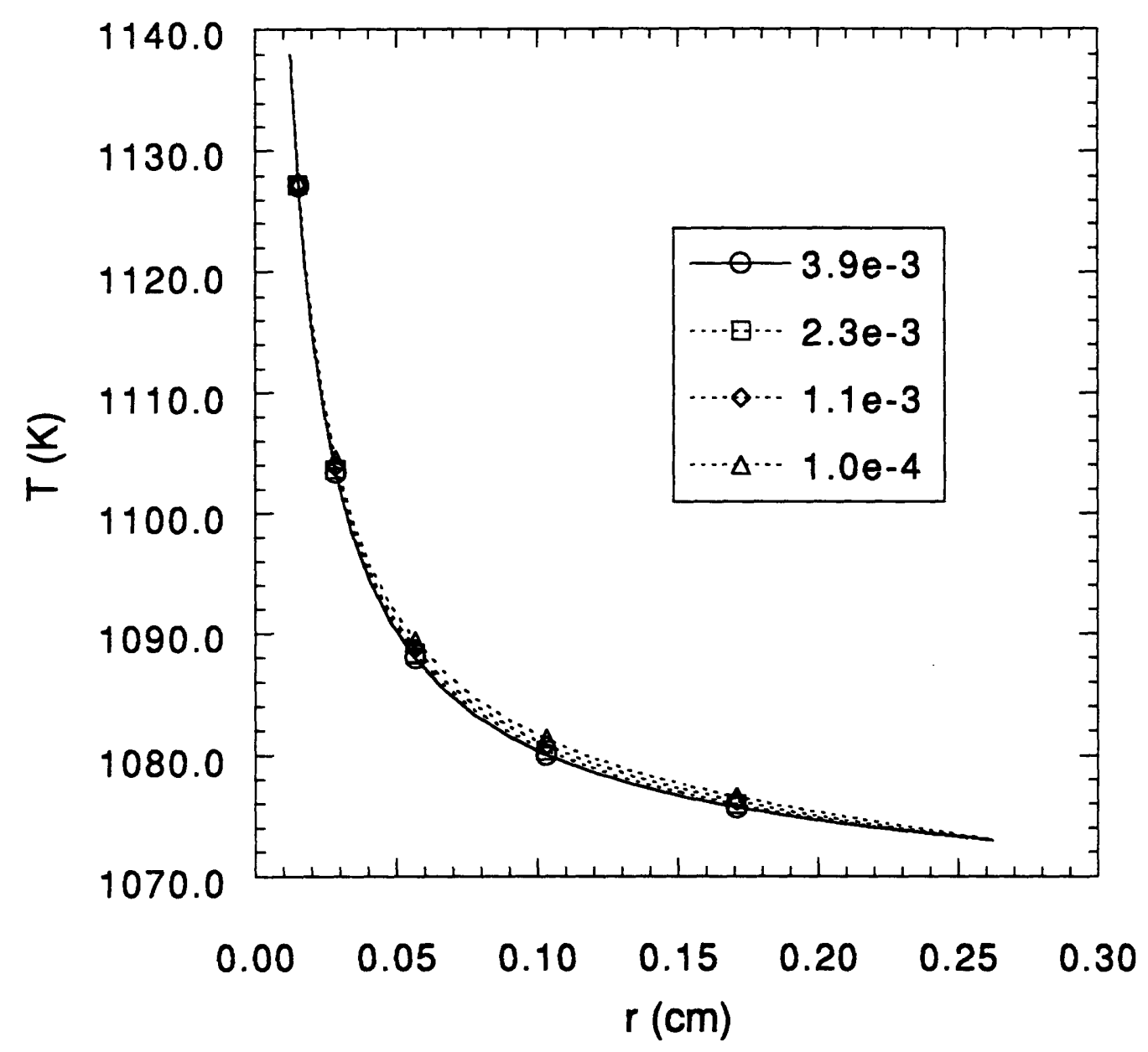

Fig.5.12 Temperature as a function of time $\left(d_{0}=0.25 \mathrm{~mm}, 20 \% \mathrm{P} \mathrm{O}_{2}, 3.5 \% \mathrm{H}_{2} \mathrm{O}, \mathrm{r}_{\mathrm{C}}=2.2 \mathrm{e}-4 \mathrm{gC} / \mathrm{cm}^{2} \mathrm{~s}\right)$

\subsubsection{Effects of lower bulk gas temperature}

The bulk gas temperature of $873 \mathrm{~K}$ was used to see the effects of surrounding gas temperature on $\mathrm{CO}$ oxidation in Fig.5.13. There was no gas phase ignition and no $\mathrm{CO}$ oxidation. Even with the water vapor and a big particle size, the surrounding gas temperature is too low to bring any gas phase reaction. 


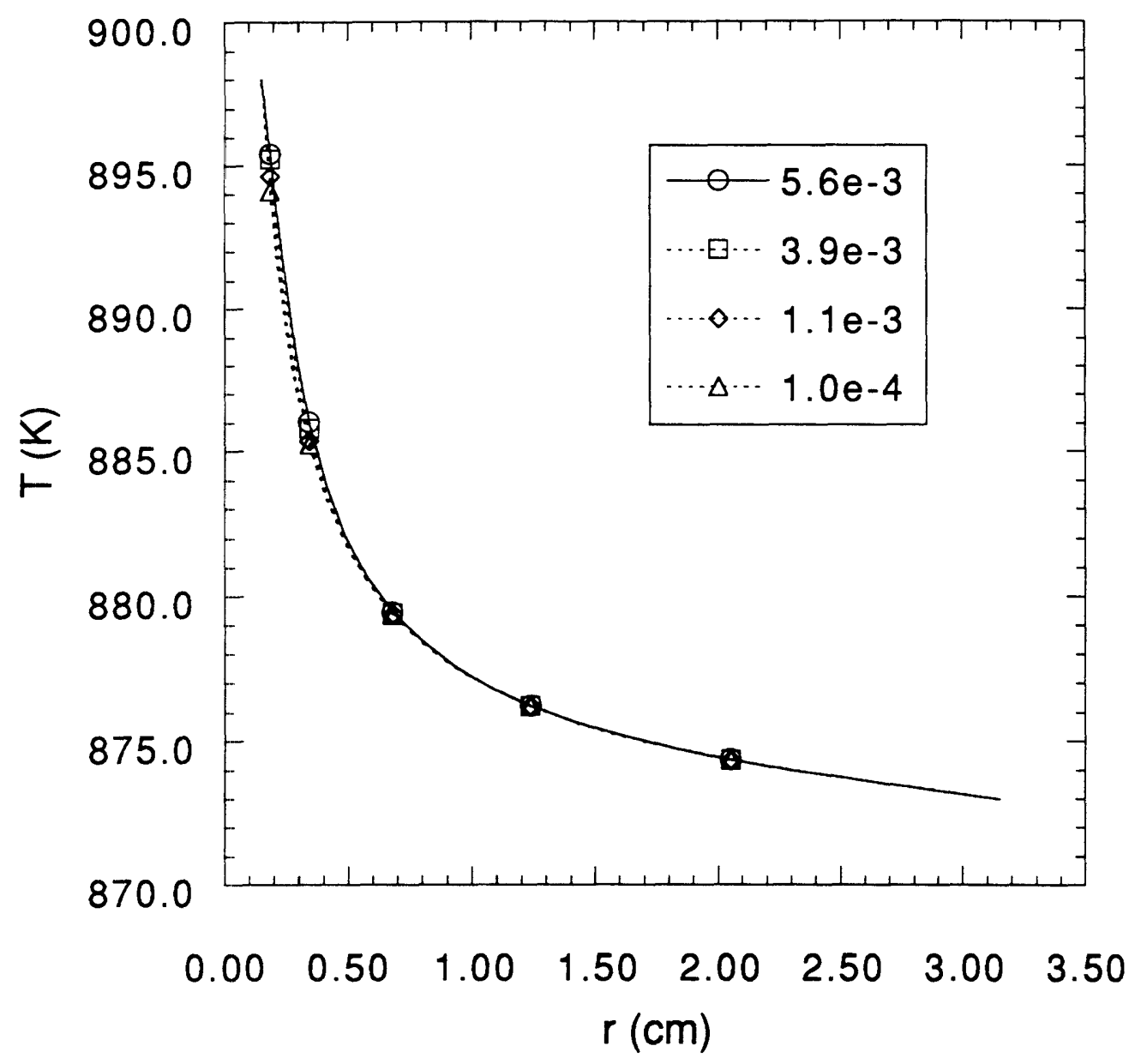

Fig.5.13 Temperature as a function of time $\left(\mathrm{d}_{\mathrm{o}}=3 \mathrm{~mm}, 20 \% \mathrm{P} \mathrm{O}_{2}, 3.5 \% \mathrm{H}_{2} \mathrm{O}, \mathrm{r}_{\mathrm{c}}=0.74 \mathrm{e}-4 \mathrm{gC} / \mathrm{cm}^{2} \mathrm{~s}, \mathrm{~T}_{\mathrm{g}}=873 \mathrm{~K}\right)$ 


\subsection{Summary}

The $\mathrm{CO}$ oxidation in the gas phase surrounding a single char in a fluidized bed was studied. Complete conversion of $\mathrm{CO}$ and $\mathrm{CO}_{2}$ was found at the higher surrounding gas temperature $(1073 \mathrm{~K})$ and the larger particle size $\left(\mathrm{d}_{\mathrm{o}}>0.5 \mathrm{~mm}\right)$.

There is no gas phase ignition without water vapor. Although $\mathrm{CO}$ can oxidize to $\mathrm{CO} 2$ via $\mathrm{CO}+\mathrm{O}$ reaction, this path is slow compared to that involving the $\mathrm{CO}+\mathrm{OH}$ reaction.

Due to the heat of $\mathrm{CO}$ oxidation, the temperature overshoot develops for the particle size of $4 \mathrm{~mm}$ and $3 \mathrm{~mm}$, as time progresses. It is clear that there exists a gas phase ignition at these particle sizes. The difference between the maximum gas temperature and the particle temperature is up to $60-70 \mathrm{~K}$ depending the particle size. The tendency shows that $\mathrm{CO}$ will continue to react until almost all $\mathrm{CO}$ will be converted to $\mathrm{CO}_{2}$. This is due to the gas phase ignition. Once the gas phase ignited, more heat is generated to raise the gas temperature and that accelerates the reaction to produce more heat. The gas phase ignition has a significant effect on $\mathrm{CO}_{2} / \mathrm{CO}$ ratio. The gas phase ignition is influenced by the particle diameter, the water vapor concentration, and the surrounding gas temperature. This gas phase ignition will be terminated only if the particle diameter decreases below a critical diameter, and the $\mathrm{CO}_{2} / \mathrm{CO}$ ratio will drop accordingly. At $1 \mathrm{~mm}$ particle size, the temperature overshoot decreases to several degrees. At $0.5 \mathrm{~mm}$ particle size, there is no gas phase ignition but the $\mathrm{CO}$ oxidation is still observed. The extinction diameter is between $0.25 \mathrm{~mm}$ and $0.5 \mathrm{~mm}$. The surrounding gas temperature has a significant effect on the gas phase ignition. At $873 \mathrm{~K}$, there is no gas phase ignition. 


\section{Chapter 6}

\section{Summary, Conclusion,}

\section{and Recommendation}

\subsection{A temperature profile model and a gas phase model}

A model incorporating intrinsic surface reaction, internal pore diffusion, and external mass transfer was developed to predict a transient temperature profile during a single char particle combustion. The $\mathrm{CO}_{2} / \mathrm{CO}$ ratio from the heterogeneous reaction measured by Tognotti (Tognotti et al., 1990) was used to calculate the heat of reaction during the char combustion. The additional heat transfer due to gas phase $\mathrm{CO}$ oxidation was not considered, but the effects of Stefan flow were included. The internal surface area evolution of Spherocarb, which was important for a particle ignition, was considered. A first order intrinsic reaction for oxygen was used.

This model provides useful information for particle ignition, burning temperature profile, combustion time, and carbon consumption rate. 
A gas phase reaction model incorporating the full set of 28 elementary $\mathrm{C} / \mathrm{H} / \mathrm{O}$ reactions was developed. This model calculated the gas phase $\mathrm{CO}$ oxidation reaction in the boundary layer at two different particle temperatures of $1250 \mathrm{~K}$ and $2500 \mathrm{~K}$ by using the carbon consumption rate and the burning temperature at the pseudo-steady state calculated from the temperature profile model, but the transient heating was not included. We used a fully time-dependent approach to model the dynamic behavior of gas phase reactions. The Galerkin finite elements method was employed to resolve the spatial discretization.

This gas phase model can predict the gas species and the temperature distributions in the boundary layer, the $\mathrm{CO}_{2} / \mathrm{CO}$ ratio, and the location of $\mathrm{CO}$ oxidation.

These models were applied to the ignition temperature profile and the $\mathrm{CO}_{2} / \mathrm{CO}$ ratio obtained by Tognotti in an electrodynamic balance for $180 \mu \mathrm{m}$ Spherocarb particles and to the combustion rate data measured by Tullin in a fluidized bed combustor for $4 \mathrm{~mm}$ Newlands char particles.

\subsection{Temperature profile of a single char combustion in an electrodynamic balance}

The temperature profile predicted by the model without gas phase reaction corresponds well with Tognotti's measurements of ignition temperature (1300K), maximum temperature $(2500 \mathrm{~K})$, and combustion time ( 38 milliseconds) of a single char ignition in an electrodynamic balance.

Oxygen partial pressure has a large effect on the shape of the temperature profile. Increasing oxygen partial pressure reduces combustion time and increases maximum temperature. Ignition of a particle is dependent on oxygen partial pressure. 
Change of particle diameter does not have a large impact on the maximum temperature rise, but has a considerable effect on the combustion time. If we calculate the volume of the particle for each diameter, the combustion time is approximately proportional to the volume although the other factors like heat and mass transfer changes due to particle size also play a role on the combustion.

Particle ignition occurs when the diffusion limitation inside the particle is low. The BET surface area is dominated by the surface area of pore diameter less than $10 \mathrm{~nm}$, which has lower reactivity due to its graphitized nature. The macropore surface area was used, which makes a higher effectiveness factor, to explain the temperature profile measured in the experiment. When $S_{\operatorname{mac}}$ (macropore surface area percentage out of total internal surface area) is $0.5 \%$, the profile is close to the experimental one. Although there is a need for much more intense study of the internal structure and the reactivity according to the pore sizes, the results suggest a probable explanation of the observed temperature profile during the combustion.

Effects of mineral catalyst on the temperature profile has been studied by using a reaction kinetics model developed by $\mathrm{Du}$ ( $\mathrm{Du}$ et al., 1991). The $\mathrm{CO}_{2} / \mathrm{CO}$ ratio increases significantly by adding $\mathrm{Ca}$ even at low temperatures. Adding $\mathrm{Ca}$ increased $\mathrm{CO}_{2}$ generation and the maximum temperature of the particle significantly. If we consider gas phase reactions, the maximum temperature will be lower than the predicted value due to $\mathrm{O} 2$ disassociation and other radical generation reactions. The addition of mineral catalyst promotes heterogeneous $\mathrm{CO}_{2}$ formation and raises the particle temperature. However, the duration of the carbon combustion does not decrease much due to the mass transfer limitation at these temperature range $(T>3000 \mathrm{~K})$. 


\subsection{Modeling of CO oxidation in the gas phase in an electrodynamic balance}

The gas phase model provided information on the importance of gas phase reaction and was used to reproduce the observed $\mathrm{CO}_{2} / \mathrm{CO}$ ratio measured by Tognotti (Tognotti et al., 1990) in an electrodynamic balance. Different water vapor concentrations at low and high particle surface temperatures $(1250 \mathrm{~K}$ and $2500 \mathrm{~K})$ are used to see the effect of hydrogen containing species on $\mathrm{CO}$ oxidation in the gas phase. The particle diameter was $180 \mu \mathrm{m}$, and the bulk gas was a mixture of $100 \%$ oxygen and water vapor. The effect of hydrogen containing species on the $\mathrm{CO}$ oxidation was found to be significant.

At a temperature of $1250 \mathrm{~K}$, there was no significant $\mathrm{CO}$ oxidation in the gas phase even with $3.5 \%$ water vapor due to the small size of the particle and the steep temperature gradient. The $\mathrm{CO}_{2} / \mathrm{CO}$ ratio calculated from the model was 0.267 in mole fraction ratio, and the $\mathrm{CO}_{2} / \mathrm{CO}$ ratio from the heterogeneous reaction at $1250 \mathrm{~K}$ is 0.233 . This calculation suggest that there is negligible $\mathrm{CO}$ oxidation in the gas phase but the experimental results showed a higher $\mathrm{CO}_{2} / \mathrm{CO}$ ratio of 0.8 for $3.5 \%$ water vapor. Estimates of gas phase reaction in the macropore could not account for the high $\mathrm{CO}_{2} / \mathrm{CO}$ ratio indicating that the presence of water vapor may enhance the rate of heterogeneous oxidation of $\mathrm{CO}$.

At a high temperature of $2500 \mathrm{~K}$, without hydrogen containing molecule the gas phase $\mathrm{CO}$ oxidation is negligible even at a very high surface temperature. The $\mathrm{CO}_{2} / \mathrm{CO}$ ratio was 0.089 in mole fraction ratio. The $\mathrm{CO}_{2} / \mathrm{CO}$ ratio from the heterogeneous reaction is 0.068 at $2500 \mathrm{~K}$. Only about $2 \%$ of $\mathrm{CO}$ from the heterogeneous reaction was converted to $\mathrm{CO}_{2}$ in the gas phase.

The effect of hydrogen containing components on the $\mathrm{CO}$ oxidation was significant. The external water vapor of $3.5 \%$ resulted in a $\mathrm{CO}_{2} / \mathrm{CO}$ ratio of 2.35 which is much higher than the experimental value. Spherocarb has $0.74 \%$ of ' $\mathrm{H}$ ' internally. This hydrogen source was enough to explain the observed $\mathrm{CO}_{2} / \mathrm{CO}$ ratio, and the calculated $\mathrm{CO}_{2} / \mathrm{CO}$ ratio 
with internal ' $\mathrm{H}$ ' is 0.76 . The $\mathrm{CO}_{2} / \mathrm{CO}$ ratio from the experiments is $0.8-0.9$ at $2500 \mathrm{~K}$. The agreement between the two values was good.

\subsection{Combustion and temperature profile in a fluidized bed reactor}

For the fluidized bed conditions, Tullin's measurements of combustion rate for various temperatures and oxygen concentrations were matched using an activation energy and an intrinsic reaction order for oxygen as parameters and using the non-steady state mechanistic heat and mass transfer model.

A half intrinsic order for $\mathrm{O}_{2}$, a pre-exponential factor of 0.35 , and an activation energy of $20 \mathrm{kcal} / \mathrm{mol}$ are found to be appropriate to represent the char combustion in the fluidized bed combustion in this temperature range (1023-1123K) when we apply La Nauze's heat and mass transfer model.

The heat and mass transfer model proposed by Agarwal et al. was used to incorporated the effects of bed material and particle motion during the char combustion. The Sherwood number is estimated about 0.8 , which means that the external mass transfer to the particle surface is limited by the bed particles which are smaller than the char particle. On the contrary, the Nusselt number is high, because the small size bed particles enhance the heat removal from the particle by making the contact to the particle surface easier.

The half order intrinsic reaction, the pre-exponential factor of 0.39 , and the activation energy of $20 \mathrm{kcal} / \mathrm{mol}$ were adequate values at this temperature range (1023$1123 \mathrm{~K})$, and the oxygen partial pressures (2-20\%). The heat transfer coefficient calculated by this model is about $50 \%-100 \%$ higher than the value predicted by La Nauze's model.

The initial temperature rise is approximately proportional to the oxygen partial pressure, and the slope is $300 \mathrm{~K} / \mathrm{atm}$ at $1073 \mathrm{~K}$. The excess temperature increases as the 
oxygen partial pressure and the surrounding gas temperature increase, and it is as large as $83 \mathrm{~K}$ at $21 \%$ and $1123 \mathrm{~K}$.

\subsection{CO oxidation in the gas phase in a fluidized bed reactor}

The gas phase model was applied for the conditions in the fluidized bed, and the gas phase $\mathrm{CO}$ oxidation and the temperature overshoot was calculated in the boundary layer of a single particle. The effect of water vapor, surrounding gas temperature, and particle diameter on the gas phase ignition and $\mathrm{CO}$ oxidation was significant.

There is no gas phase ignition without water vapor. Although $\mathrm{CO}$ can oxidize to $\mathrm{CO}_{2}$ via the $\mathrm{CO}+\mathrm{O}$ reaction, this path is slow compared to that of $\mathrm{CO}+\mathrm{OH}$ reaction and is insufficient to cause gas phase ignition.

Due to the heat of $\mathrm{CO}$ oxidation, a temperature overshoot develops for the particle size bigger than $1 \mathrm{~mm}$, as time progresses. It is clear that a gas phase ignition occurs at these particle sizes. The difference between the maximum gas temperature and the particle temperature is up to $60-70 \mathrm{~K}$ depending the particle size. The tendency shows that $\mathrm{CO}$ will continue to react until almost all $\mathrm{CO}$ is converted to $\mathrm{CO}_{2}$. This is due to the gas phase ignition. This gas phase ignition will be terminated only if the particle diameter decreases lower than the critical diameter, and the $\mathrm{CO}_{2} / \mathrm{CO}$ ratio will drop accordingly. At $1 \mathrm{~mm}$ particle size, the temperature overshoot decreases to several degrees. The extinction diameter is between $1 \mathrm{~mm}$ and $0.25 \mathrm{~mm}$. The surrounding gas temperature has a significant effect on the gas phase ignition. At $873 \mathrm{~K}$, there is no gas phase ignition. 


\subsection{Recommendations}

Overall, these models proved to be powerful tools for achieving more detailed understanding of char particle combustion and for guidance for additional modeling and experimental work.

A study of the effects of different pore sizes on the char combustion and the gaseous products will be necessary to investigate the role of macro and meso pores on particle combustion. The possibility of homogeneous $\mathrm{CO}$ oxidation in the macro or meso pores are negligible based on the calculations, but should be checked by performing experiments with a macropore char and a micropore char. Also, the experiments of particle ignition with two different pore size chars can provide information about the effect of internal diffusion limitation on the particle ignition. The experiments with different pore size particles and measurements of the resultant $\mathrm{CO}_{2} / \mathrm{CO}$ ratio will enlighten the uncertainties of the char combustion.

Although the gas phase model can predict the $\mathrm{CO}$ oxidation at the pseudo steady state temperature, a combined model will better serve the region where the combustion is unsteady: especially the ignition and the extinction of a particle. A modification to accelerate the time integration step of the program will be necessary to achieve this. The program can easily incorporate a different reaction set, like NO formation in the gas phase, and produce useful information for NOx generation during the char combustion. And, modeling of liquid fuel combustion can also be done with a little modification. 


\section{Appendices}

\section{A.1 Program for the temperature profile model}

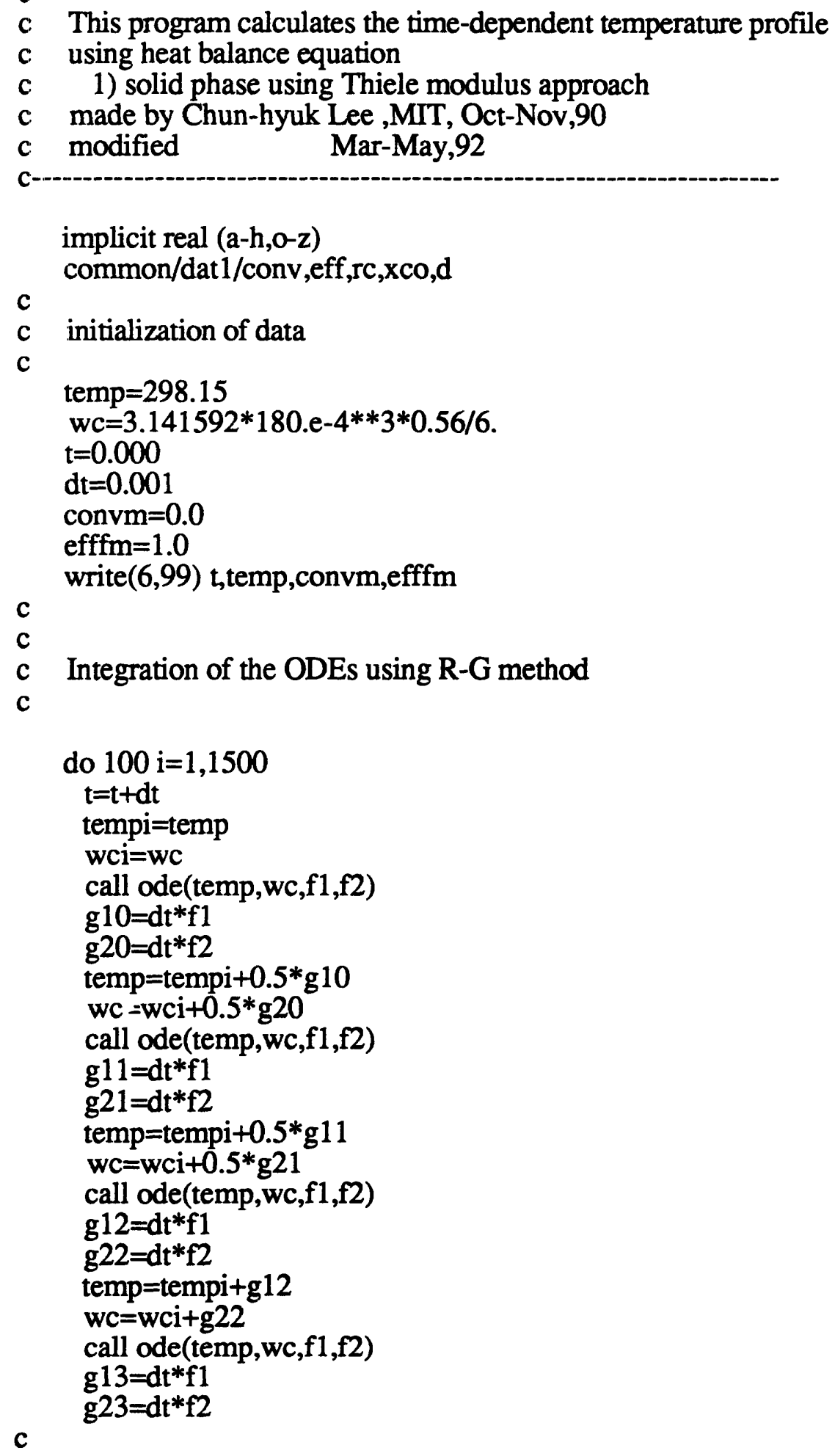


c Adjusting the dt to catch the steep temperature change

c

dtemp $=\left(\mathrm{g} 10+2{ }^{*} \mathrm{~g} 11+2 .{ }^{*} \mathrm{~g} 12+\mathrm{g} 13\right) / 6$.

if (dabs (dtemp).gt.50.) dt=dt/5.

if (dabs (dtemp).gt. 10.) dt=dt/2.

if (dabs(dtemp).lt.1.) dt=dt*2.

temp $=$ tempi+dtemp

c

$\mathrm{wc}=\mathrm{wci}+\left(\mathrm{g} 20+2 \cdot{ }^{*} \mathrm{~g} 21+2 .{ }^{*} \mathrm{~g} 22+\mathrm{g} 23\right) / 6$.

c

call ode(temp,wc,f1,f2)

convm $=$ conv

efffm=eff

write $(6,99) \mathrm{t}$,temp,convm,rc

99 format $(\mathrm{e} 12.6, \mathrm{f} 10.4, \mathrm{f} 9.5, \mathrm{e} 15.6)$

100 continue

stop

end

c

c Subroutine calculating temperature and weight change

c of the particle

c

subroutine ode(temp, wc, f1,f2)

implicit real (a-h,o-z)

real lo,lo0

common/dat1/conv,eff,rc,xco,d

c initial diameter

$\mathrm{d} 0=180 . \mathrm{e}-4$

c initial density

$100=0.56$

pei $=3.141592$

wc $0=$ pei*d0**3*lo0/6.

c power of the mass ratio

$\mathrm{a}=0.25$

$b=(1 .-a) / 3$.

c gas coefficinet

$\mathrm{rg}=1.987$

$\mathrm{rgc}=82.05$

cc----initializing data-

$\operatorname{tg}=298.15$

c x:conversion tor:tortuisity wo2:molecular weight of $\mathrm{O} 2$

c po2:partial pressure of $\mathrm{O} 2(\mathrm{~atm})$

tor $=3$.

wo $2=32$.

$\mathrm{po} 2=1.0$

$\mathrm{emm}=0.85$

sig $=5.676 \mathrm{e}-12$

abs $=0.85$

c $\quad \mathrm{smac}=0.01$

$\mathrm{smac}=0.005$ 
c $\quad$ pmac $=0.39$

pmac $=0.375$

flux $=300$.

c if ((temp.gt.1300.).or.(f1.lt.0.)) flux $=0$.

if ((temp.gt.1350.).or.(f1.lt.0.)) flux $=0$.

cc--

c calculate conversion

$\mathrm{x}=1$. $-\mathrm{wc} / \mathrm{wc0}$

conv $=\mathrm{x}$

c calculate $\mathrm{CO}$ rxn fraction

$\mathrm{xco}=1 . /(1 .+0.02 * \mathrm{po} 2 * * 0.21 * \exp (6000 . /($ rg*temp $)))$

c stoichiometric const

$\mathrm{xx}=12.011 *(1 .+\mathrm{xco})$

c intrinsic rxn rate coefficient

$\mathrm{rks}=0.184 * \exp (-33000 . /(\mathrm{rg} *$ temp $)) / \mathrm{smac}$

c external mass transfer coefficient

$\mathrm{d}=\mathrm{d} 0 *(1 .-\mathrm{x}) * * \mathrm{~b}$

$10=100 *(1 .-\mathrm{x}) * * \mathrm{a}$

$\mathrm{tm}=($ temp $+\mathrm{tg}) / 2$.

c calculate correction for mass transfer due to stefan flow factm $=(2 .-\mathrm{xco}) * \log (2 . /(2 .-\mathrm{xco})) / \mathrm{xco}$

$\mathrm{db}=1.0255 \mathrm{e}-5 * \operatorname{tm} * * 1.75$

$\mathrm{rkg}=2 . * \mathrm{db} /(\mathrm{d} * \mathrm{rgc} * \mathrm{tm}) * \mathrm{xx} *$ factm

por $=(1 .-10 / 2.15) *$ pmac

c sg: internal surface area

c $\quad \mathrm{sg}=(4.85 * \mathrm{x} * * 3-5.5566 * \mathrm{x} * * 2+0.8215 * \mathrm{x}+0.8688) * 1 . e 7$

c Surface area fitted by 7 th order polynomia $\left(500 \mathrm{~m}^{\wedge} 2 / \mathrm{g}\right)$

$\mathrm{Sg}=1 . e 4 *(920.9089+2661.0706 * \mathrm{x}-27273.1303 * \mathrm{x} * * 2+112965.3388 * \mathrm{x} * * 3$

\# $\quad-253322.8987 * x * * 4+312434.9020 * x * * 5-199151.1856 * x * * 6$

\# $\left.+51245.1435 * x^{* * 7}\right) * \operatorname{smac}$

c calculate thiele modulus

$\mathrm{dk}=19400{ }^{*}$ por $/\left(\mathrm{sg}^{*} \mathrm{lo}\right) *($ temp/wo2 $) * * 0.5$

$\mathrm{dbp}=1.0255 \mathrm{e}-5 *$ temp $* * 1.75$

$\mathrm{de}=1 . /(1 . / \mathrm{dbp}+1 . / \mathrm{dk})$

$\operatorname{deff}=$ por*de/tor

$\mathrm{pi}=(\mathrm{d} / 6) *.\left(\mathrm{lo}^{*} \mathrm{sg}{ }^{*} \mathrm{rks}{ }^{*} \mathrm{rgc} *\right.$ temp/(deff*xx $\left.)\right)^{* *} 0.5$

c calculate effectiveness factor

if (pi.lt.1.e-3) then eff $=1.0$

elseif (pi.gt.1.e3) then

$$
\text { eff }=1 . / \mathrm{pi}
$$

else

eff $=\left(1 . / \tanh \left(3 .{ }^{*}\right.\right.$ pi $)-1 . /\left(3 .{ }^{*}\right.$ pi $\left.)\right) / p i$

endif

c calculate carbon consumption rate

$\mathrm{rc}=\mathrm{po} 2 /(1 . / \mathrm{rkg}+1 . /($ eff*rks*sg*lo*d/6.))

c calculate convective heat transfer coefficient

$\mathrm{ck}=10.4 \mathrm{e}-5+5.56 \mathrm{e}-7 * \mathrm{tm}$

$\mathrm{h}=2 . * \mathrm{ck} / \mathrm{d}$

c calculate heat of rxn

heat $1=-(-26416+3.21 *($ temp $-\operatorname{tg})+0.24 \mathrm{e}-3 *($ temp $* * 2-\operatorname{tg} * * 2)$

$\left.\&+0.09 \mathrm{e} 5^{*}(1 . / \mathrm{tg}-1 . / \mathrm{temp})\right) * 4.184 / 12.011$

heat $2=-(-94051+3.41 *($ temp-tg $)+0.55 \mathrm{e}-3 *($ temp $* * 2-\operatorname{tg} * * 2)$ 


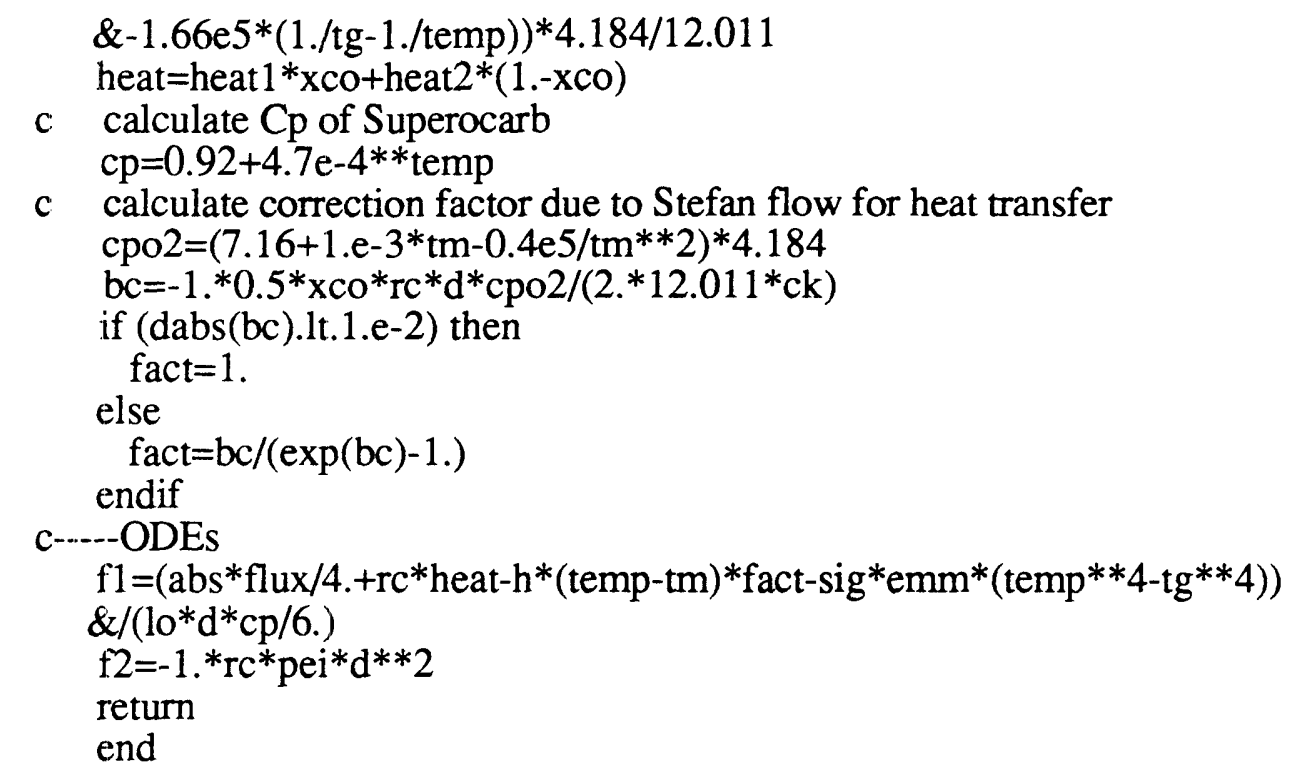




\section{A.2 Program for the temperature profile in the fluidized bed}

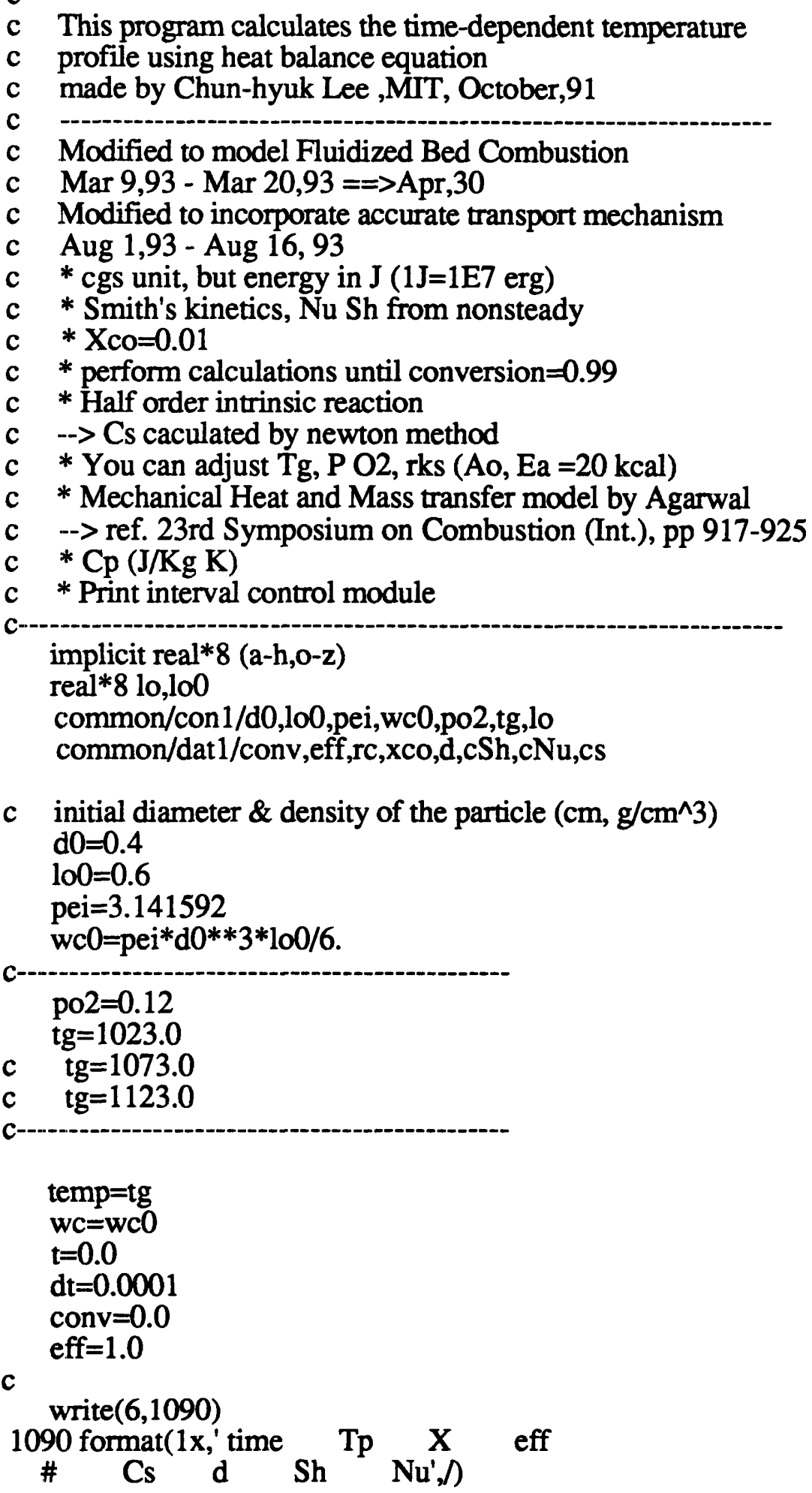




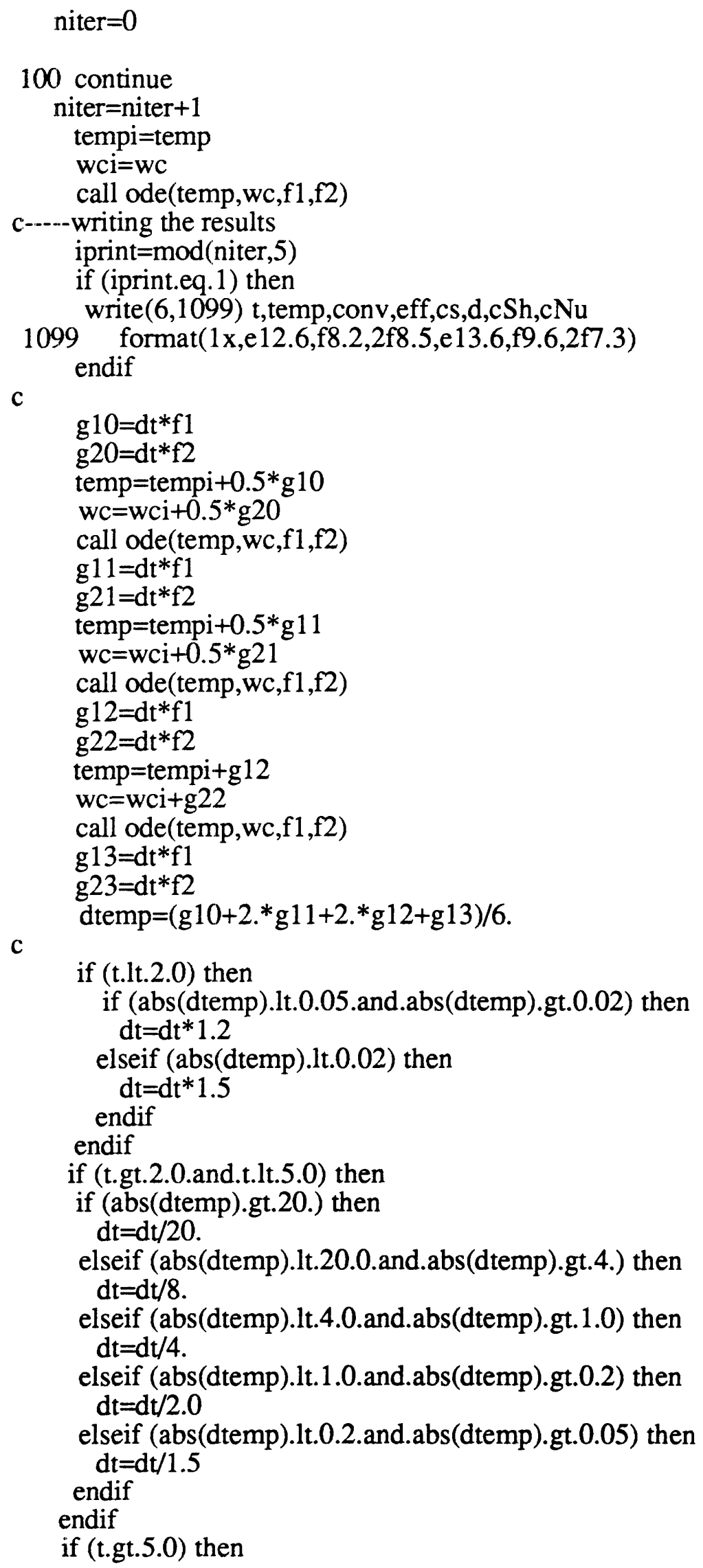




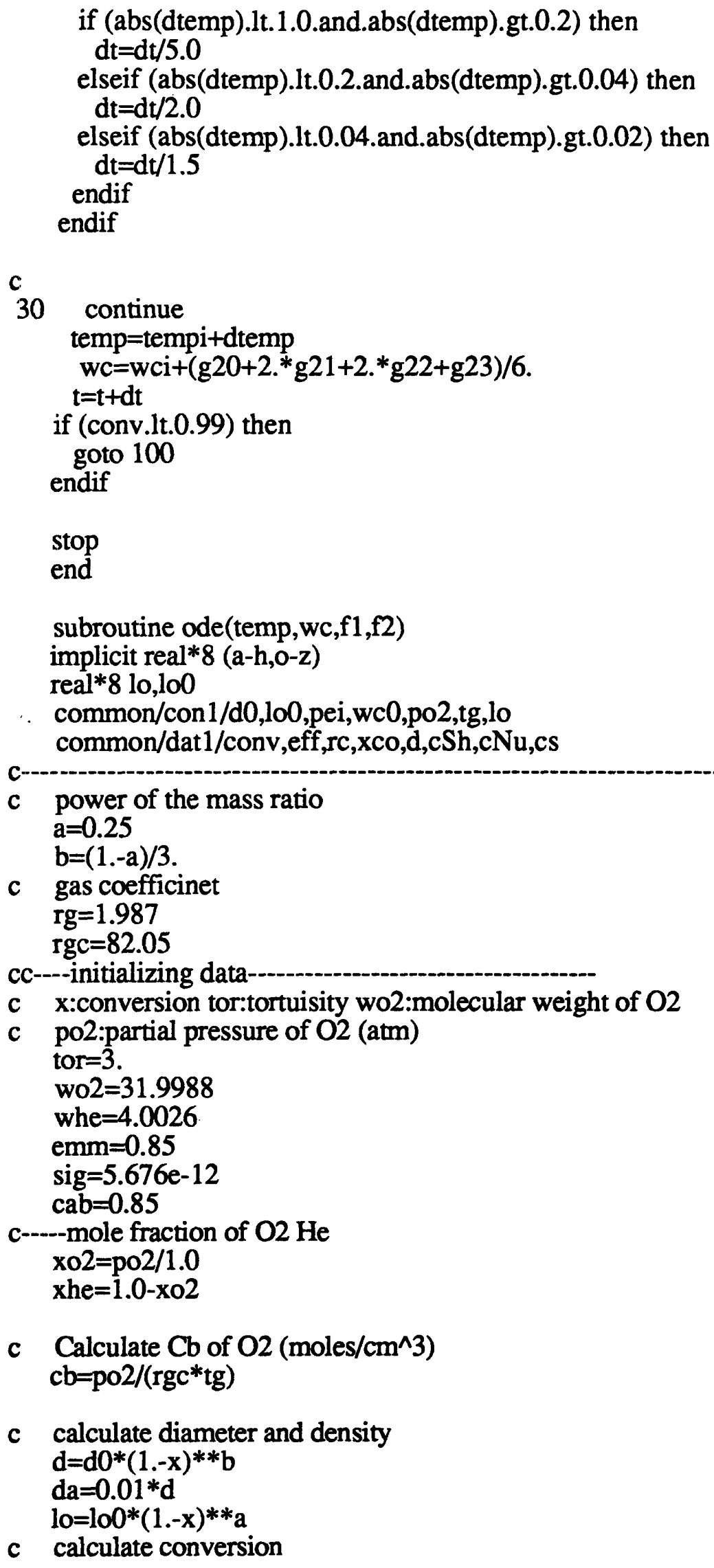

c Calculate $\mathrm{Cb}$ of $\mathrm{O} 2\left(\mathrm{moles} / \mathrm{cm}^{\wedge} 3\right.$ ) $\mathrm{cb}=\mathrm{po} 2 /(\mathrm{rgc} * \mathrm{tg})$

c calculate diameter and density $\mathrm{d}=\mathrm{d} 0 *(1 .-\mathrm{x})^{* *} \mathrm{~b}$

$\mathrm{da}=0.01 * \mathrm{~d}$ $\mathrm{lo}=\mathrm{lo} 0 *(1 .-\mathrm{x})^{* * a}$

c calculate conversion 


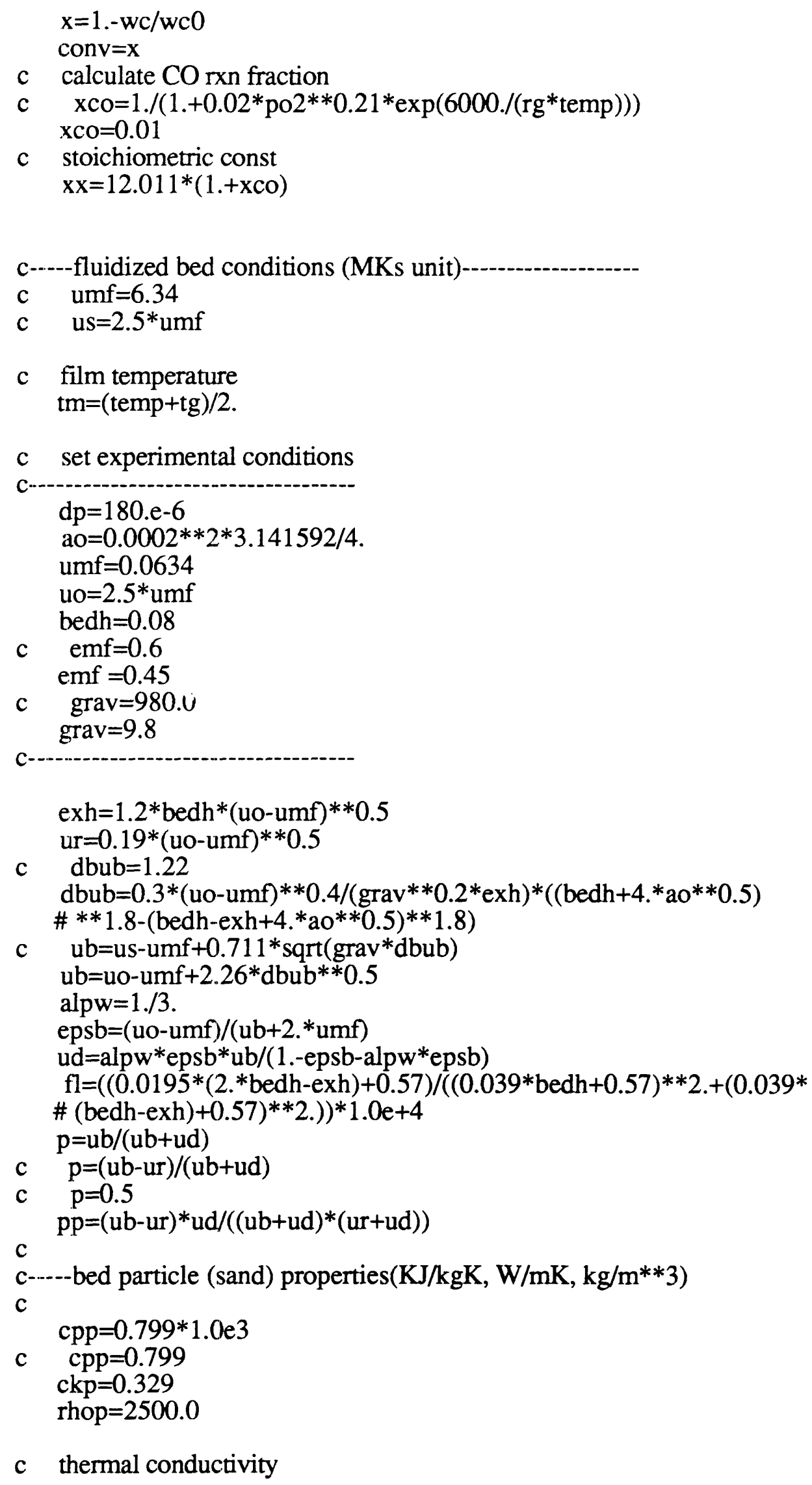

c thermal conductivity 
cko2 $=\exp (-2.13+2.99 * \log (\mathrm{tm})-0.287 *(\log (\mathrm{tm})) * * 2$.

\# $+0.0124 *(\log (\mathrm{tm})) * * 3$.

ckhe $=\exp (4.2+1.45 * \log (\mathrm{tm})-0.121 *(\log (\mathrm{tm})) * * 2$.

\# $+0.00607 *(\log (\mathrm{tm})) * * 3$.

c $\mathrm{ck}=0.5 *(\mathrm{xo} 2 * \mathrm{cko} 2+\mathrm{xhe} * \mathrm{ckhe}+1 . /(\mathrm{xo} 2 / \mathrm{cko} 2+\mathrm{xhe} / \mathrm{ckhe})) * 1.0 \mathrm{e}-7$

$\mathrm{ck}=0.5 *(\mathrm{xo} 2 * \mathrm{cko} 2+\mathrm{xhe} * \mathrm{ckhe}+1 . /(\mathrm{xo} 2 / \mathrm{cko} 2+\mathrm{xhe} / \mathrm{ckhe})) * 1.0 \mathrm{e}-5$

$\mathrm{ckg}=\mathrm{ck}$

c ENTER DATA FOR CP OF HE, O2

cpo2 $=\left(7.16+1 . e-3 *\right.$ tm $\left.-0.4 \mathrm{e} 5 / \mathrm{tm}^{* * 2}\right) * 4.184$

cphe $=12.48$

$\mathrm{cpg}=\left(\mathrm{xo} 2 * \mathrm{cpo} 2+\mathrm{xhe}{ }^{*} \mathrm{cphe}\right) /\left(\mathrm{xo}^{*} *\right.$ wo $2+\mathrm{xhe} *$ whe $) * 1.0 \mathrm{e} 3$

c $\mathrm{cpg}=\left(\mathrm{xo} 2 * \mathrm{cpo} 2+\mathrm{xhe} \mathrm{e}^{*} \mathrm{cphe}\right) /\left(\mathrm{xo} 2 *\right.$ wo $2+\mathrm{xhe} \mathrm{w}^{*}$ whe $)$

rhog $=1.0 *\left(\mathrm{xo}^{*} *\right.$ wo $2+\mathrm{xhe} *$ whe $) /(\mathrm{rgc} * \operatorname{tg}) * 1.0 \mathrm{e} 3$

alpha $=\mathrm{ck} /(\mathrm{rhog} * \mathrm{cpg})$

c alpha $=\mathrm{ck} /(\mathrm{rhog} * \mathrm{cpg} * 1000.0)$

$\mathrm{psi}=0.63 *(\mathrm{ckp} / \mathrm{ck}) * * 0.18$

ckeo $=$ ck* $\left(1 .+(1 .-\mathrm{emf}) *(1 .-\mathrm{ck} / \mathrm{ckp}) *\left(\mathrm{ck} / \mathrm{ckp}+0.28 * \mathrm{emf}^{* *} \mathrm{psi}\right) * *(-1).\right)$

cke $=$ ckeo+0.1*rhog* ${ }^{*}$ cpg ${ }^{*}$ dp*umf

rhoe $=$ rhop $*(1 .-$ emf $)+$ emf*rhog

$\mathrm{qu}=(1 .-0.9 *(1 .-\mathrm{emf}) * *(2 . / 3) *.(\mathrm{emf}-0.25) * *(1 . / 3)) * *.(-1$.

zet $=5.3 *\left(\mathrm{emf} /(1 .-\mathrm{emf}) * * 0.3 / \mathrm{qu}^{* *} 2.0\right.$

c calculate gas mixture viscosity

viso2 $=\exp (-16.0+2.17 * \log (\mathrm{tm})-0.198 *(\log (\mathrm{tm})) * * 2 .+0.00854 *$

\# $(\log (\mathrm{tm}))^{* * 3}$.)

vishe $=\exp (-14.0+1.45 * \log (\mathrm{tm})-0.121 *(\log (\mathrm{tm})) * * 2 .+0.00607 *$

\# $(\log (\mathrm{tm}))^{* * 3}$. $)$

p12=(1.+(viso $2 /$ vishe $) * * 0.5 *($ whe $/$ wo 2$) * * 0.25) * * 2$

\# /(8.*(1.+(wo2/whe $)))^{* * 0} 0.5$

p21 $=$ p $12 *$ vishe*wo $2 /($ viso $2 *$ whe $)$

visg $=($ xo $2 *$ viso $2 /(\mathrm{xo} 2+\mathrm{xhe} * \mathrm{p} 12)+\mathrm{xhe} * \mathrm{vishe} /(\mathrm{xhe}+\mathrm{xo} 2 * \mathrm{p} 21)) * 0.1$

c Reynolds \& Prantl numbers

ree $=$ da $^{*}$ umf*rhog/visg

reb $=3 . * \mathrm{da}^{*}$ umf $*$ rhog/visg

$\mathrm{pr}=\mathrm{visg} /(\mathrm{rhog} *$ alpha)

c drag coeff.

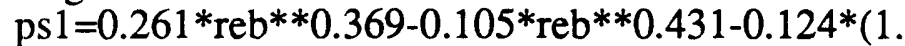

$\#+(\log 10(\mathrm{reb})) * * 2) * *.(-1$.

$\mathrm{cda}=(24 . / \mathrm{reb}) * 10 . * * \mathrm{ps} 1$

ps $2=0.261 * \mathrm{ree}^{* *} 0.369-0.105 * \mathrm{ree}^{* *} 0.431-0.124 *(1$.

$\#+(\log 10($ ree $)) * * 2) * *.(-1$.

cdea $=(24 . /$ ree $) *\left(2 . * z^{*} t^{*}(1 .-\right.$ emf $) / \mathrm{qu}+(10 . * *$ ps $\left.2-1).\right)$

c calculate heat transfer coeff.

$\mathrm{t} 2=\mathrm{fl} * *(-1 . / 3). * \mathrm{ub}^{* *}(-2 . / 3) *.(\mathrm{ub}-\mathrm{ur}) /(\mathrm{ud}+\mathrm{ur})$

$\mathrm{p} 8=8$.

hpcu $=\left(\mathrm{dp} /(\mathrm{p} 8 * \mathrm{ckg})+0.5^{*}\left(\mathrm{pei}^{*} \mathrm{t} 2 /\left(\mathrm{cke}^{*} \mathrm{rhoe}^{*} \mathrm{cpp}\right)\right)^{* *} 0.5\right) * *(-1$.

hpcd $=\left(\mathrm{dp} /(\mathrm{p} 8 * \mathrm{ckg})+0.5 *\left(\right.\right.$ pei $^{*} \mathrm{exh} /(\mathrm{ud} *$ cke* rhoe*cpp $\left.)\right) * * 0.5$

\# $)^{* *}(-1$.

hgc $=\mathrm{ckg} / \mathrm{da} *\left(2 .{ }^{*} \mathrm{cke} / \mathrm{ckg}+0.693 *\left(\left(1 .+\mathrm{ree}^{*} \mathrm{pr}\right) * *(1 . / 3)-1.\right) /\right.$

\# (ree*pr)**(1./3.)*(cdea/8.)**(1./3.)*(qu*ree/emf $)^{* *}(2 . / 3$.

$\left.\#{ }^{*} \mathrm{pr}^{* *}(1 . / 3).\right)$ 


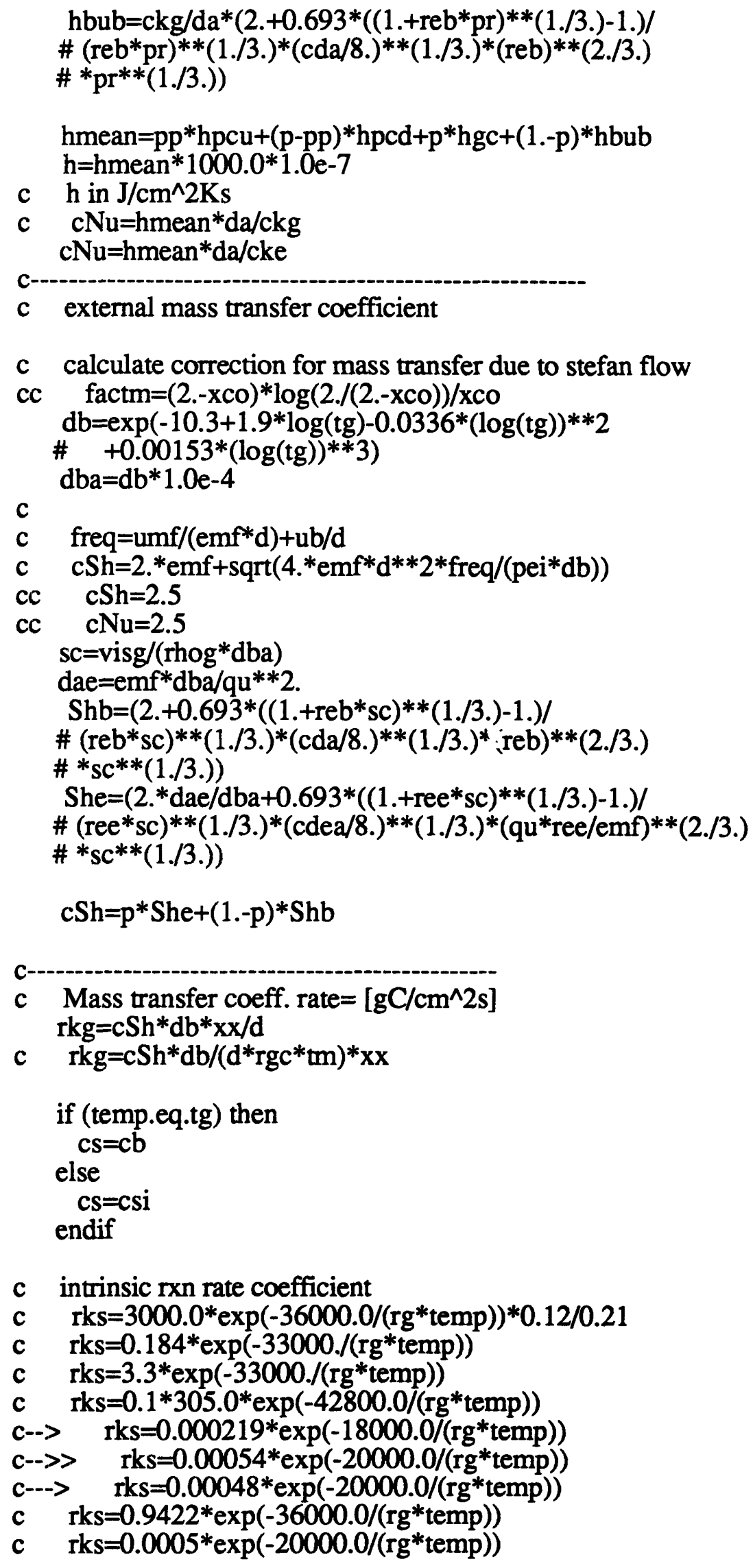


c rks $=0.0081738 * \exp (-20000.0 /(\mathrm{rg} *$ temp $))$

c rks $=0.569 * \exp (-20000.0 /(\mathrm{rg} *$ temp $))$

c rks $=0.35 * \exp (-20000.0 /(\mathrm{rg} *$ temp $))$

$\mathrm{rks}=0.39 * \exp (-20000.0 /(\mathrm{rg} *$ temp $))$

C

por $=(1 .-10 / 2.15)$

c sg: internal surface area

c $\quad \mathrm{sg}=(4.85 * \mathrm{x} * * 3-5.5566 * \mathrm{x} * * 2+0.8215 * \mathrm{x}+0.8688) * 1 . \mathrm{e} 7$

c Surface area fitted by 7 th order polynomia $\left(500 \mathrm{~m}^{\wedge} 2 / \mathrm{g}\right)$

$\mathrm{Sg}=1 . \mathrm{e} 4 *(920.9089+2661.0706 * \mathrm{x}-27273.1303 * \mathrm{x} * * 2+112965.3388 * \mathrm{x} * * 3$

\# $\quad-253322.8987 * \mathrm{x} * * 4+312434.9020 * \mathrm{x} * * 5-199151.1856 * \mathrm{x} * 6$

$\# \quad+51245.1435 * \mathrm{x} * * 7) / 920.9089 * 500.0$

c calculate thiele modulus

$\mathrm{dk}=19400{ }^{*}$ por $/(\mathrm{sg} *$ lo $) *($ temp/wo2)**0.5

$\mathrm{dbp}=\exp (-10.3+1.9 * \log ($ temp $)-0.0336 *(\log ($ temp $)) * * 2$

$\#+0.00153 *(\log ($ temp $)) * * 3)$

$\mathrm{de}=1 . /(1 . / \mathrm{dbp}+1 . / \mathrm{dk})$

$\operatorname{deff}=$ por*de/tor

c $\mathrm{pi}=(\mathrm{d} / 6) *.\left(\mathrm{lo}^{*} \mathrm{sg} *\right.$ rks $*$ rgc*temp/(deff*xx $){ }^{* * 0.5}$

c $9 \mathrm{pi}=(\mathrm{d} / 6). *\left(10 * \mathrm{sg}^{*} \mathrm{rks} /(\operatorname{deff} * \mathrm{xx} * \mathrm{cs})\right)^{* * 0.5}$

$9 \mathrm{pi}=(\mathrm{d} / 6) *.\left(10^{*} \mathrm{sg} * \mathrm{rks} /\left(\operatorname{deff} \mathrm{xx}^{*} \mathrm{cs}^{* *} 0.5\right)\right) * * 0.5$

c calculate effectiveness factor

if (pi.lt.1.e-3) then eff $=1.0$

elseif (pi.gt.1.e3) then eff $=1 . / \mathrm{pi}$

else

eff $=\left(1 . / \tanh \left(3 .^{*}\right.\right.$ pi $\left.)-1 . /\left(3 .{ }^{*} \mathrm{pi}\right)\right) / \mathrm{pi}$

endif

c calculating cs by Newton method

$\mathrm{coA}=\mathrm{rkg}$

coB $=$ rks*lo*sg*d*eff/6.

$\mathrm{coC}=-\mathrm{rkg} * \mathrm{cb}$

$\operatorname{cs} \mathrm{x}=\mathrm{cs}$

niter $=0$

77 niter=niter +1

$\operatorname{delcs} x=-(\operatorname{coA} * \operatorname{cs} x+\operatorname{coB} * \operatorname{cs} x * * 0.5-\operatorname{coC}) /\left(\operatorname{coA}+\operatorname{coB} /\left(2 .{ }^{*} \operatorname{cs} x^{* *} 0.5\right)\right)$

if (niter.gt.20) then write $(6, *)$ ' Cs does not converge!' goto 88

endif

if (abs(delcsx).gt.5.0e-3) then cs $\mathrm{X}=\mathrm{csX}+$ delcs $\mathrm{x}$ goto 77

endif

88 csnew $=$ cs $x$

c adjusting cs 
ecs $=($ csnew-cs $) / c s$

if (abs(ecs).gt.1.e-3) then

$\mathrm{cs}=\mathrm{csnew}$

goto 9

endif

$\mathrm{cs}=\mathrm{csnew}$

$\mathrm{csi}=\mathrm{cs}$

c calculate carbon consumption rate

$\mathrm{rc}=\mathrm{rks} * \mathrm{cs} * * 0.5 * \mathrm{lo} * \mathrm{sg} * \mathrm{~d} * \mathrm{eff} / 6$.

c $\quad \mathrm{rc}=\mathrm{po} 2 /(1 . / \mathrm{rkg}+1 . /($ eff*rks*sg*lo*d/6.))

c write $(6,1111)$ rkg,rks

c 1111 format(1x,'rkg=', e12.5,'rks= ',e12.5)

c $\quad \mathrm{Nu}=2.0+\operatorname{sqrt}\left(4 .{ }^{*}\right.$ freq $* \mathrm{~d} * * 2 /($ pei*alpha $)$ )

c $\mathrm{h}=\mathrm{cNu} \mathrm{Nu}^{*} \mathrm{ck} / \mathrm{d}$

c calculate heat of $\mathrm{rxn}$

heat $1=-\left(-26416+3.21 *(\right.$ temp-tg $)+0.24 \mathrm{e}-3 *\left(\right.$ temp $^{* * 2-\operatorname{tg} * * 2)}$

$\&+0.09 \mathrm{e} 5 *(1 . / \mathrm{tg}-1 . / \mathrm{temp})) * 4.184 / 12.011$

heat $2=-(-94051+3.41 *($ temp-tg $)+0.55 \mathrm{e}-3 *($ temp $* * 2-\operatorname{tg} * * 2)$

\&-1.66e5*(1./tg-1./temp) )*4.184/12.011

heat $=$ heat $1 * x c 0+$ heat $2 *(1 .-x c 0)$

c calculate $\mathrm{Cp}$ of Superocarb

$c p=0.92+4.7 e-4 * *$ temp

c calculate correction factor due to Stefan flow for heat transfer

c $\quad$ cpo $2=(7.16+1 . \mathrm{e}-3 * \mathrm{tm}-0.4 \mathrm{e} 5 / \mathrm{tm} * * 2) * 4.184$

c $\quad \mathrm{bc}=-1 . * 0.5 * \mathrm{xco} * \mathrm{rc} * \mathrm{~d} * \mathrm{cpo} 2 /(2 . * 12.011 * \mathrm{ck})$

c if $(\mathrm{abs}(\mathrm{bc}) \cdot \mathrm{lt} \cdot 1 . \mathrm{e}-2)$ then

fact $=1$.

c else

c $\quad$ fact $=b c /(\exp (b c)-1$. $)$

c endif

c-----ODEs

$\mathrm{f} 1=(\mathrm{rc} *$ heat-h*(temp-tg)*fact-sig*emm*(temp**4-tg**4))

\& $/(10 * d * c p / 6$.

$\mathrm{f} 2=-1 . *{ }_{\mathrm{rc}}^{*}$ pei*d**2

c write $(6, *)$ 'heat $=$ ', heat

return

end 


\section{A.3 Program for the gas phase model}

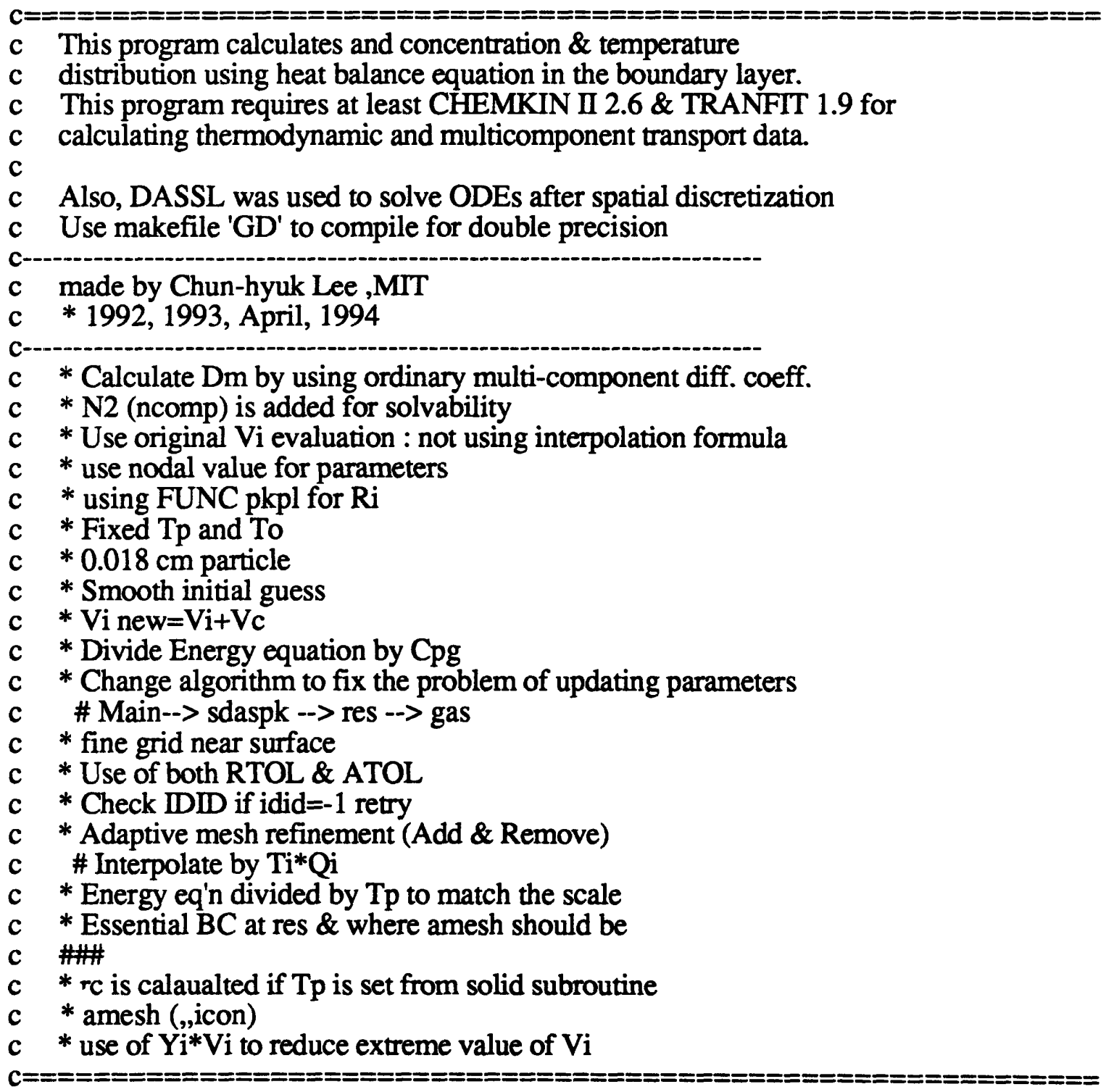

implicit real (a-h,o-z)

external res

c\#\#\# PARAMETERS FOR DASSL \#\#\#\#\#\#\#\#

c MAXM: max no. of mesh

c MAXNEQ: ncomp*MAXM

c-

PARAMETER $(M A X M=150, M X O R D=5, M A X L=5, M X N E Q=M A X M * 16$,

* $\quad$ MXML $=1$, MXMU = 1)

PARAMETER (LENRW $=50+(2 * \mathrm{MXML}+\mathrm{MXMU}+10) * \mathrm{MXNEQ}+2 *(\mathrm{MXNEQ} /$ 


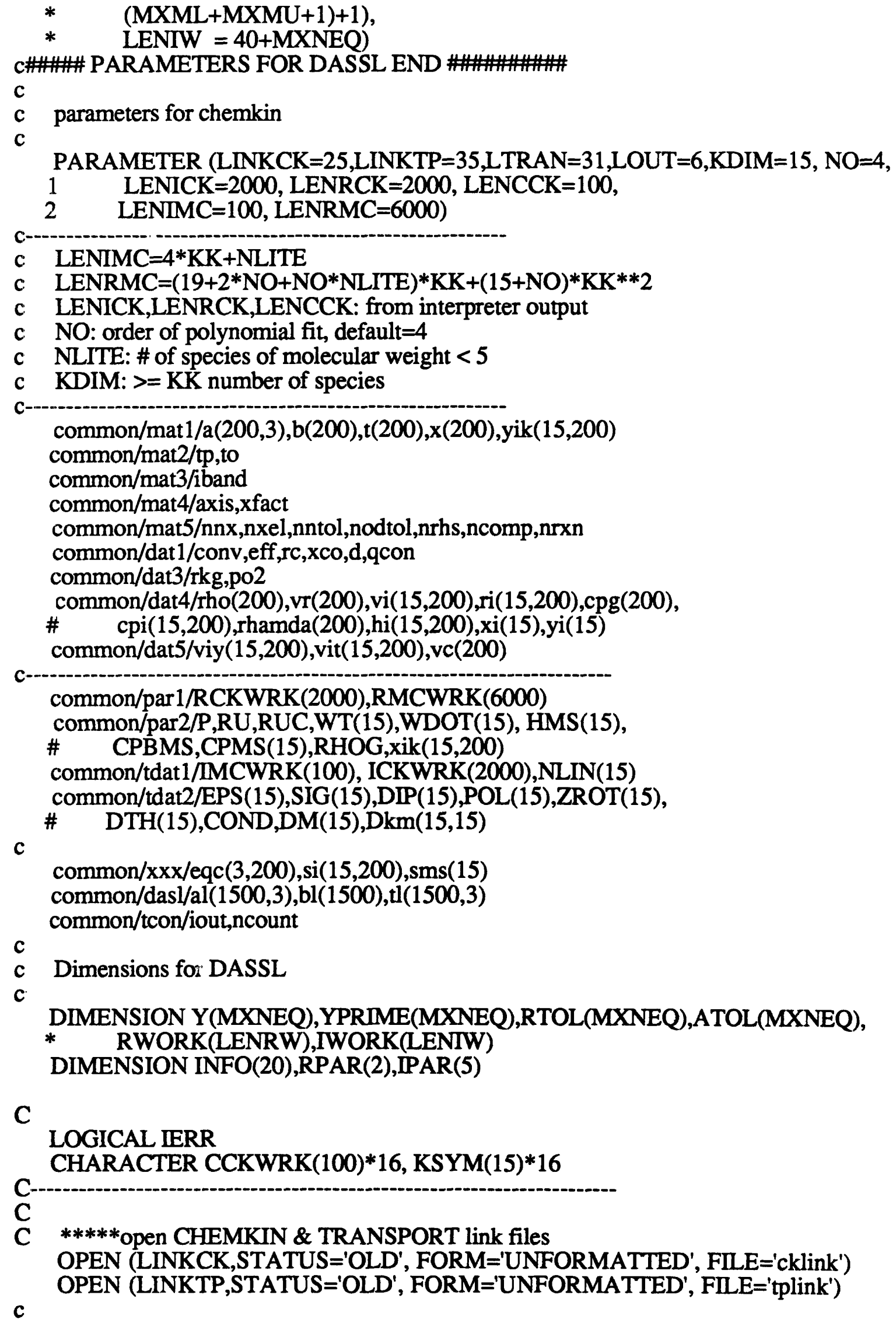




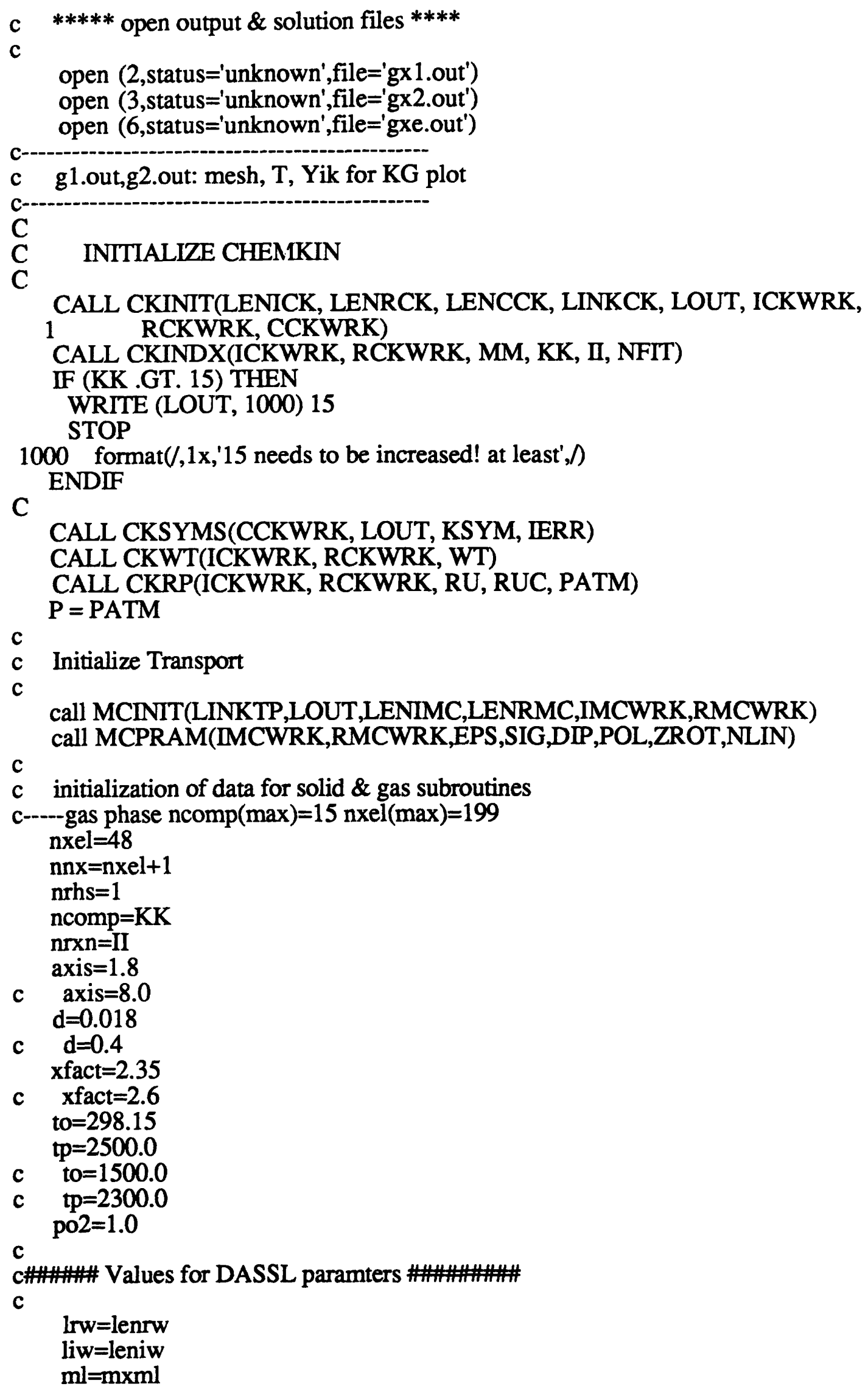




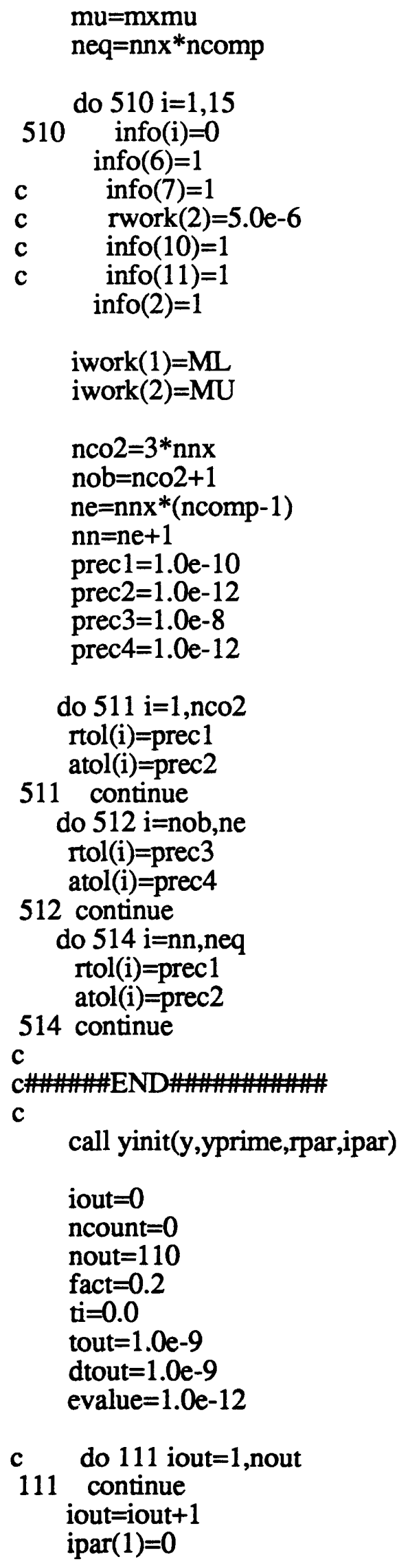


$\operatorname{ipar}(2)=0$

c\#\#\# Routine for DASPK

call ddassl(res,neq,ti,y,yprime,tout,info,rtol,atol,

\# idid,rwork,lrw,iwork,liw,rpar,ipar,jac)

write $\left(6,{ }^{*}\right)$ 'idid= ',idid

if (idid.eq. -1 ) then

iout $=$ iout -1

icon $=0$

c adjust mesh to have more grids where $\mathrm{dT}$ is big

call amesh(y,yprime,icon)

if (icon.eq. 1) then

write $(6, *)$ 'Number of meshes(nnx)= ', nnx

neq $=$ nnx $*$ ncomp

$\mathrm{ne}=\mathrm{nnx} *($ ncomp- 1$)$

$\mathrm{nn}=\mathrm{ne}+1$

nco $2=3 * n n x$

nob $=$ nco $2+1$

do $521 \mathrm{i}=1$,nco 2

rtol $(i)=$ prec 1

atol(i) $=$ prec 2

521 continue

do $522 \mathrm{i}=$ nob,ne

$\operatorname{rtol}(\mathrm{i})=\operatorname{prec} 3$

atol $(\mathrm{i})=$ prec 4

522 continue

do $524 \mathrm{i}=\mathrm{nn}$,neq

rtol(i) $=$ prec 1

atol $(\mathrm{i})=$ prec 2

524 continue

info $(1)=0$

goto 111

elseif (icon.eq.0) then

info $(1)=1$

goto 111

endif

elseif (idid.eq.3) then write $\left(6,{ }^{*}\right)$ 'Program finished successfully!'

elseif (idid.eq. -2$)$ then write $\left(6,{ }^{*}\right)$ 'error limit adjusted!'

else

write $\left(6,{ }^{*}\right)$ 'error occurred !'

stop

endif 


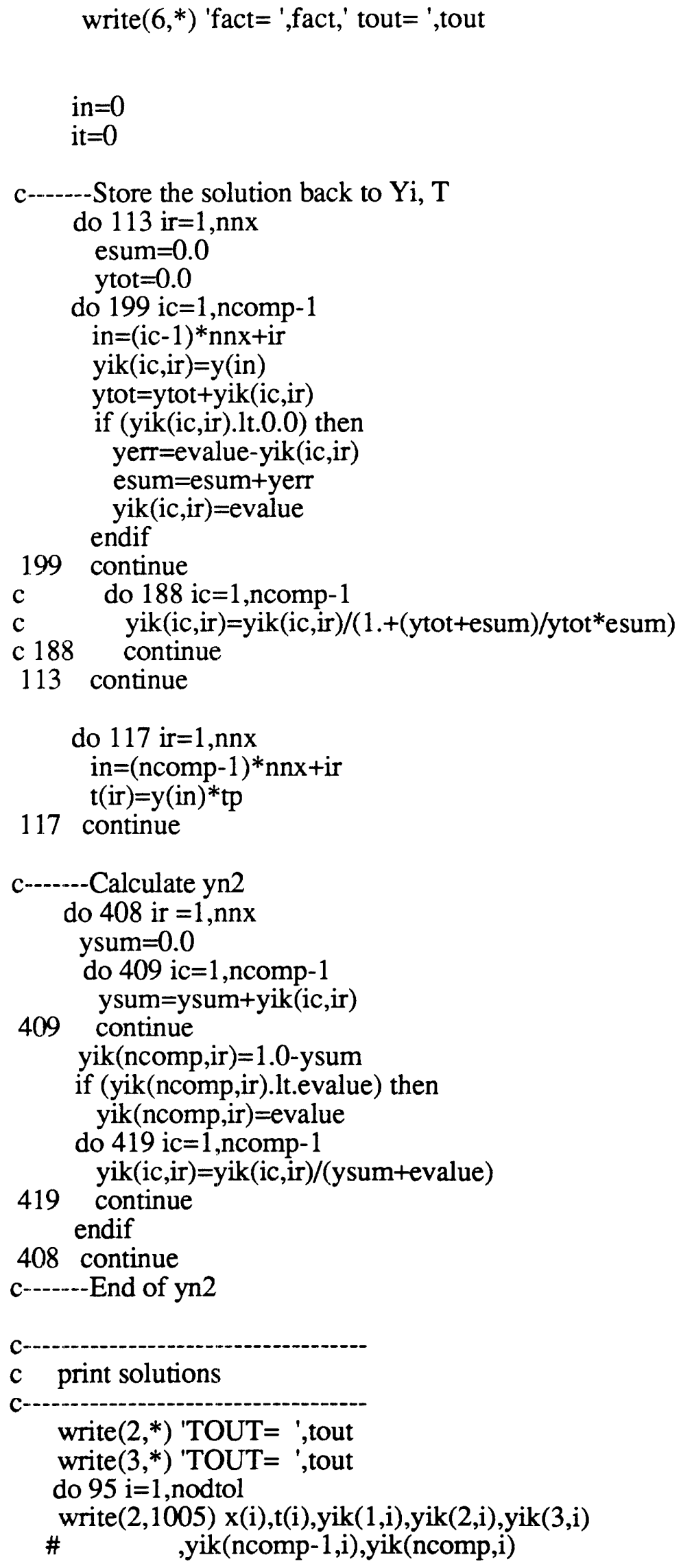




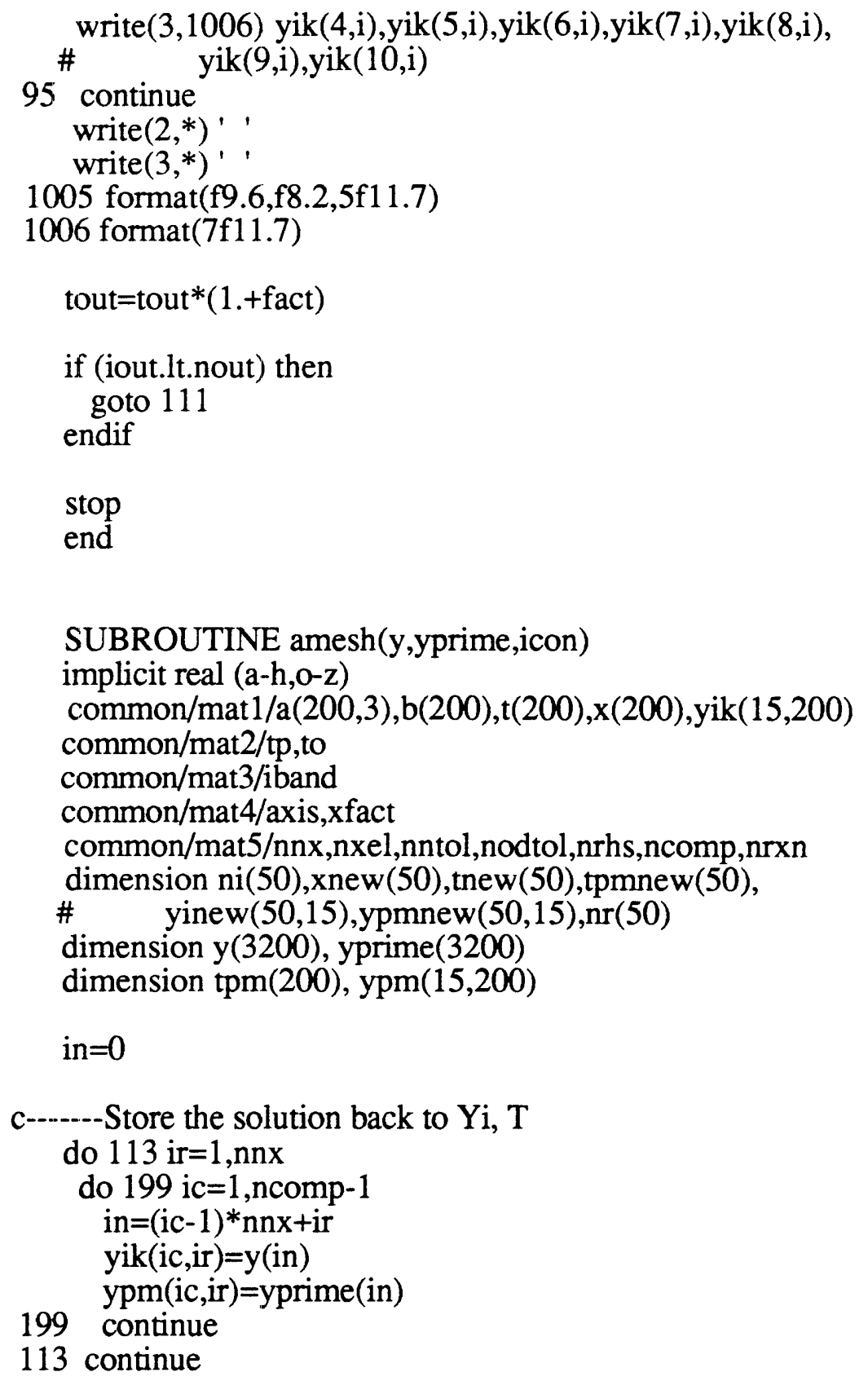

do $117 \mathrm{ir}=1$, nnx in $=($ ncomp -1$) * n n x+i r$ $\mathrm{t}($ ir $)=\mathrm{y}($ in $) * \mathrm{tp}$ tpm(ir)=yprime $($ in $)$

117 continue

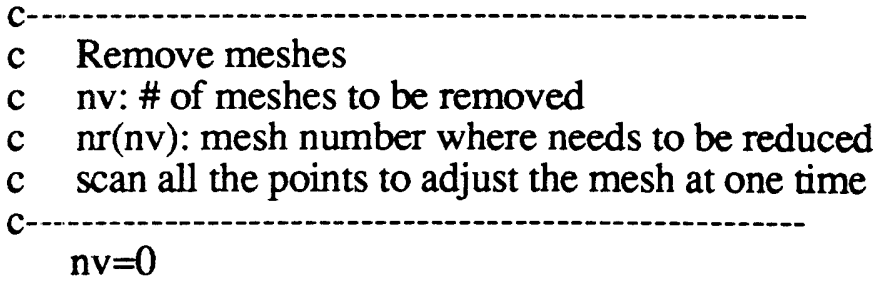


do $248 \mathrm{mi}=1,50$

$\mathrm{nr}(\mathrm{mi})=0$

248 continue

$\mathrm{dtmin}=0.05^{*}($ tp-to $) /$ float(nxel)

do $250 \mathrm{i}=1$,nxel

$\mathrm{dtdr}=\mathrm{abs}(\mathrm{t}(\mathrm{i})-\mathrm{t}(\mathrm{i}+1))$

if (dtdr.lt.dtmin) then

ndi=i-nr(nv)

if(ndi.ge.2) then

$\mathrm{nv}=\mathrm{nv}+1$

$\mathrm{nr}(\mathrm{nv})=\mathrm{i}$

write $(6, *)$ 'nv= ',nv,' $n r=$ ',i

endif

endif

250 continue

c if (nv.eq.1) go to 285

$\mathrm{nXv}=\mathrm{nv}$

c remove meshes

if (nv.gt.0) then

$\mathrm{nxel}=\mathrm{nxel}-\mathrm{nxv}$

$\mathrm{nnx}=\mathrm{nnx}-\mathrm{nxv}$

$\mathrm{nv}=1$

do $260 \mathrm{ip}=1, \mathrm{nnx}$

$n r n v=n r(n v)$

$\mathrm{ik}=\mathrm{ip}+\mathrm{nv}-1$

if (ik.eq.nrnv) then

$x(i p)=x(i p+n v)$

$\mathrm{t}(\mathrm{ip})=\mathrm{t}(\mathrm{ip}+\mathrm{nv})$

tpm(ip) $=\operatorname{tpm}(\mathrm{ip}+\mathrm{nv})$

do $270 \mathrm{ic}=1$, ncomp

yik $(i c, i p)=y i k(i c, i p+n v)$

$\mathrm{ypm}(\mathrm{ic}, \mathrm{ip})=\mathrm{ypm}(\mathrm{ic}, \mathrm{ip}+\mathrm{nv})$

270 continue

$n v=n v+1$

else

$x(i p)=x(i p+n v-1)$

$t(i p)=t(i p+n v-1)$

$\operatorname{tpm}(\mathrm{ip})=\operatorname{tpm}(\mathrm{ip}+\mathrm{nv}-1)$

do $280 \mathrm{ic}=1$,ncomp-1

yik $(i c, i p)=y i k(i c, i p+n v-1)$

280

$\operatorname{ypm}(\mathrm{ic}, \mathrm{ip})=\mathrm{ypm}(\mathrm{ic}, \mathrm{ip}+\mathrm{nv}-1)$ 
endif

260 continue

endif

c 285 continue

c-.---insert meshes

$\mathrm{nz}=0$

do $298 \mathrm{mi}=1,50$

$\mathrm{ni}(\mathrm{mi})=0$

298 continue

$\mathrm{dtmax}=4.0 *($ tp-to $) /$ float $($ nxel $)$

do $300 \mathrm{i}=1$,nxel

$\mathrm{dtdr}=\mathrm{abs}(\mathrm{t}(\mathrm{i})-\mathrm{t}(\mathrm{i}+1))$

if (dtdr.gt.dtmax) then

$\mathrm{nz}=\mathrm{nz}+1$

$\operatorname{ni}(\mathrm{nz})=\mathrm{i}$

write $(6, *)$ 'nz= ',nz,' ni= ',i

c nz: \# of meshes to be inserted

c ni: mesh number where needs to be increased

c scan all the points to adjust the mesh at one time

c-.-.-.-calculate med value

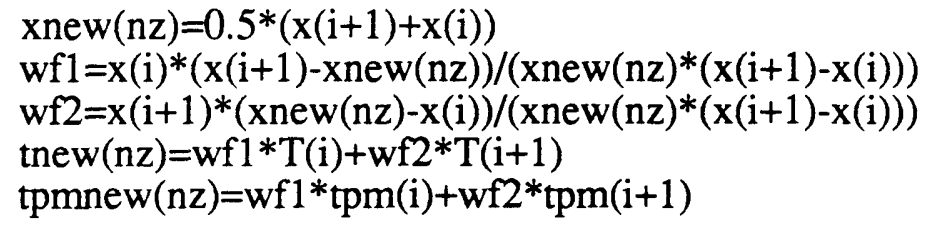

do 310 ic $=1$,ncomp-1

yinew $(\mathrm{nz}, \mathrm{ic})=\mathrm{wf} 1 * \mathrm{yik}(\mathrm{ic}, \mathrm{i})+\mathrm{wf} 2 *$ yik $(\mathrm{ic}, \mathrm{i}+1)$

310 continue ypmnew $(n z, i c)=w f 1 * y p m(i c, i)+w f 2 * y p m(i c, i+1)$

endif

300 continue

$\mathrm{nx}=\mathrm{nz}$

c insert meshes

if (nz.gt.0) then

do 320 is $=1$, nnx

$\mathrm{ip}=\mathrm{nnx}-\mathrm{is}+1$

$\operatorname{nin} z=\operatorname{ni}(\mathrm{nz})$

if (ip.eq.ninz) then

$x(\mathrm{ip}+\mathrm{nz})=\mathrm{xnew}(\mathrm{nz})$

$\mathrm{t}(\mathrm{ip}+\mathrm{nz})=\operatorname{tnew}(\mathrm{nz})$

$\operatorname{tpm}(\mathrm{ip}+\mathrm{nz})=\mathrm{tpmnew}(\mathrm{nz})$ 


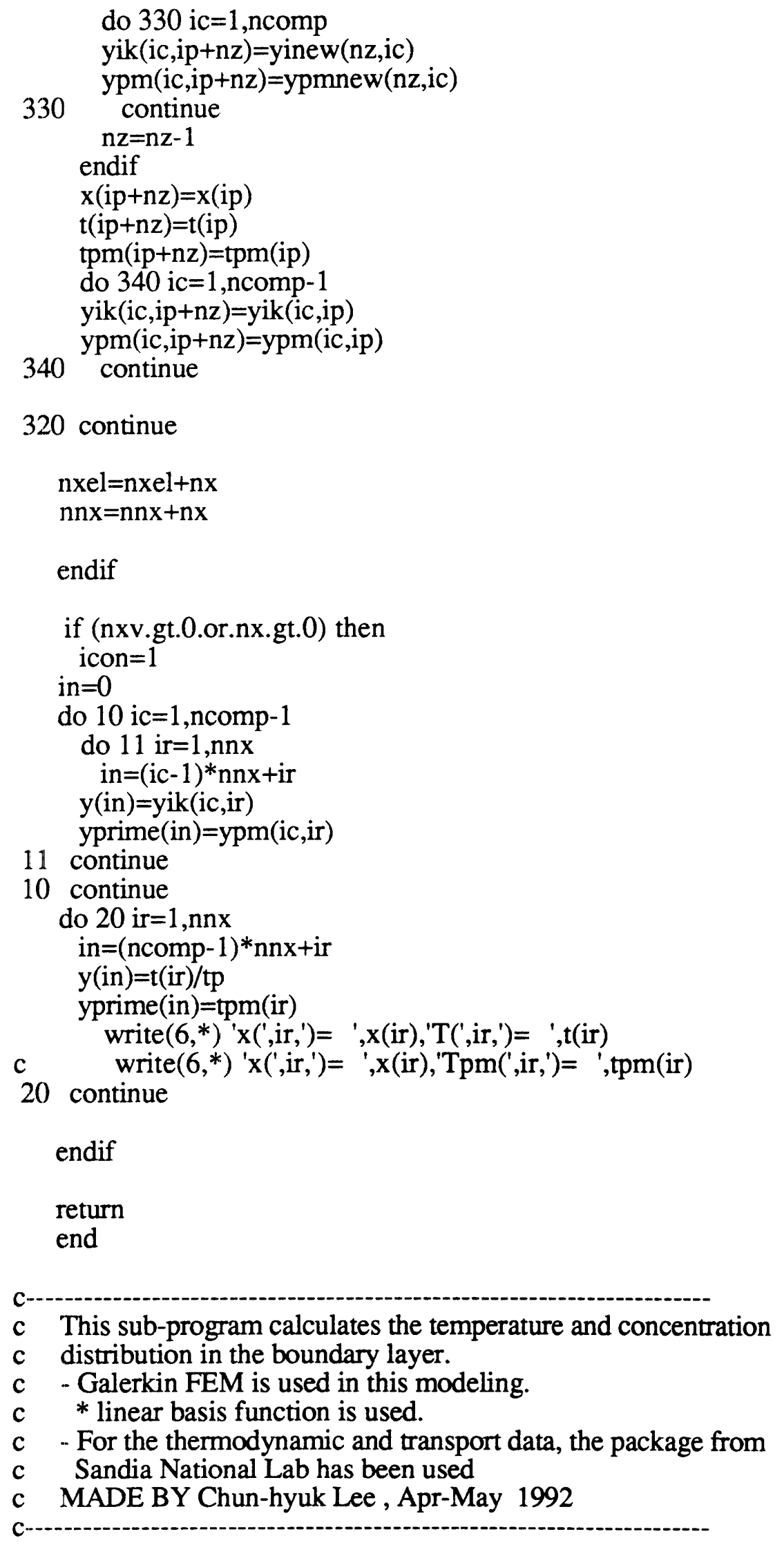




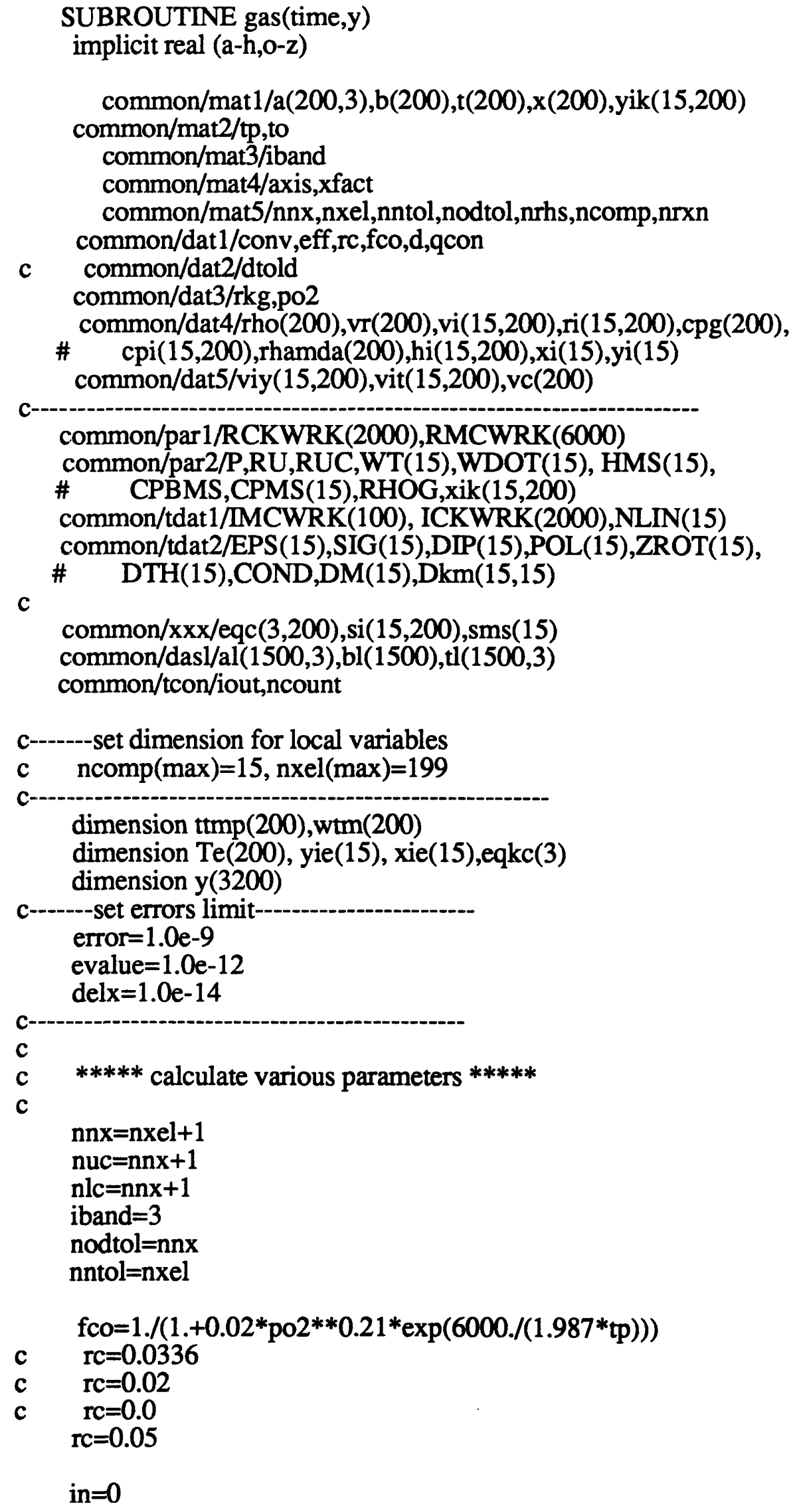


$\mathrm{it}=0$

c------Store the solution back to $\mathrm{Yi}, \mathrm{T}$

do $113 \mathrm{ir}=1, \mathrm{nnx}$

esum $=0.0$

ytot $=0.0$

do $199 \mathrm{ic}=1$,ncomp-1

in $=(\mathrm{ic}-1) * \mathrm{nnx}+\mathrm{ir}$

$y i k(i c, i r)=y($ in $)$

ytot $=y$ tot + yik $(\mathrm{ic}$, ir $)$

if (yik(ic,ir).lt.0.0) then

yerr=evalue-yik(ic,ir)

esum=esum + yerr

yik $(\mathrm{ic}, \mathrm{ir})=$ evalue

endif

199 continue

c do $188 \mathrm{ic}=1$,ncomp-1

c $\quad$ yik $($ ic, ir $)=y i k(i c, i r) /\left(1 .+(\right.$ ytot+esum $) / y t o{ }^{*}$ esum $)$

c 188 continue

113 continue

do $117 \mathrm{ir}=1, \mathrm{nnx}$

in $=(\text { ncomp }-1)^{*} \mathrm{nnx}+\mathrm{ir}$

c $\quad t($ ir $)=y($ in $)$

$t(i r)=y($ in $) * t p$

117 continue

c-------Calculate yn2

do 408 ir $=1, \mathrm{nnx}$

ysum $=0.0$

do 409 ic=1,ncomp-1

ysum=ysum+yik(ic,ir)

409 continue

yik(ncomp,ir) $=1.0$-ysum

if (yik(ncomp,ir).lt.evalue) then

yik (ncomp,ir)=evalue

do 419 ic $=1$,ncomp-1

yik(ic,ir)=yik (ic,ir)/(ysum+evalue $)$

419 continue

endif

408 continue

c------End of yn2

c $\quad * * * * *$ form the matrix a and the vector $\mathrm{b} * * * * *$

c

c

$* * * * *$ iterate over components $* * * * *$

$$
\begin{aligned}
& \operatorname{sum} 1=0.0 \\
& \operatorname{sum} 2=0.0
\end{aligned}
$$

c

c ---- call CHEMKIN \& TRANSPORT subroutines -----

c

do $77 \mathrm{ir}=1$, nnx

do $771 \mathrm{ic}=1$, ncomp

yi (ic) $=y i k(i c, i r)$ 

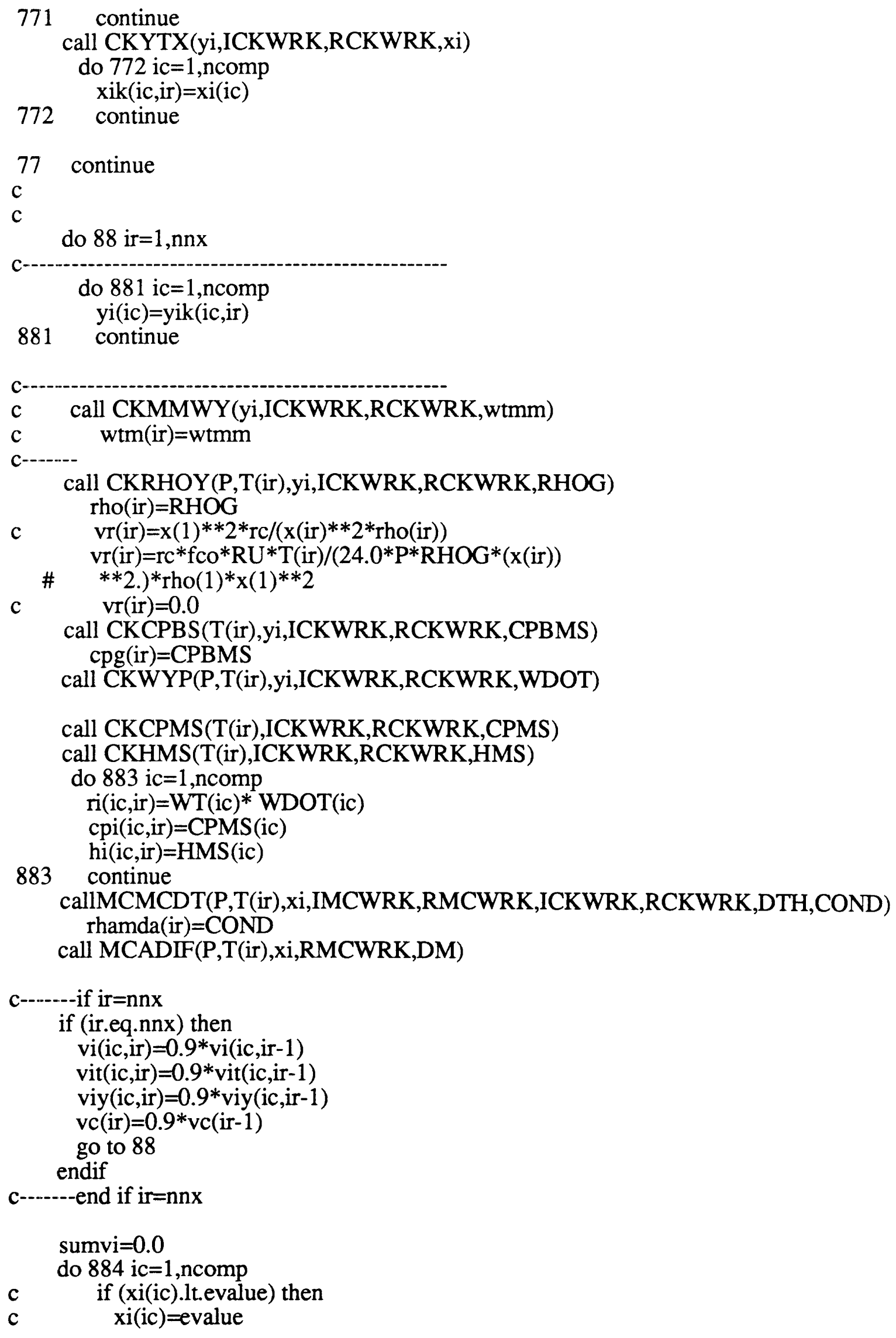


$$
\begin{array}{ll}
c & \text { endif } \\
c & \text { if (yi(ic).lt.evalue) then } \\
c & \text { yi(ic)=evalue } \\
c & \text { endif }
\end{array}
$$

c-----calculate yik $\& \mathrm{~T}$ at $\mathrm{x}+\mathrm{dx}$ value

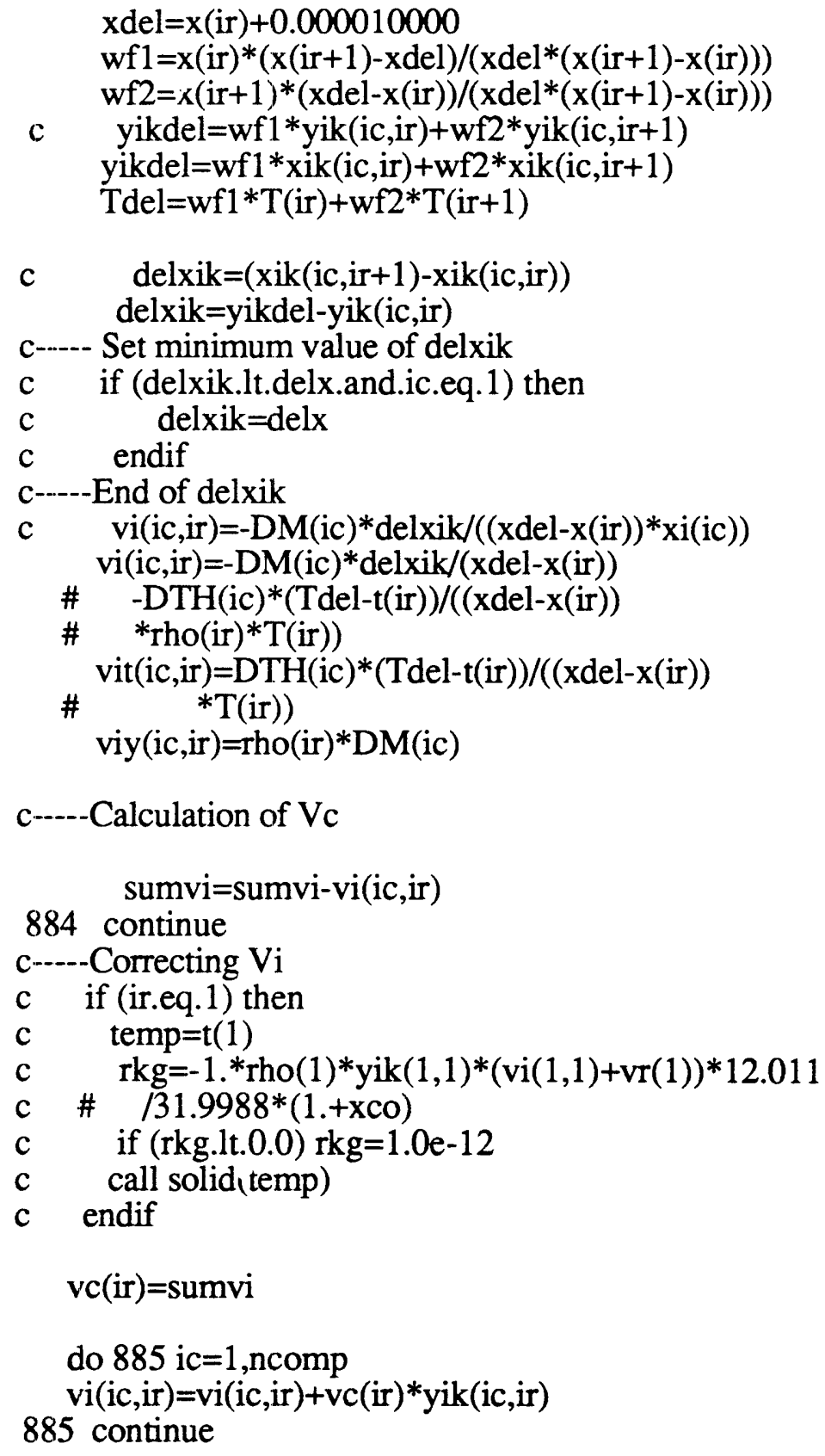




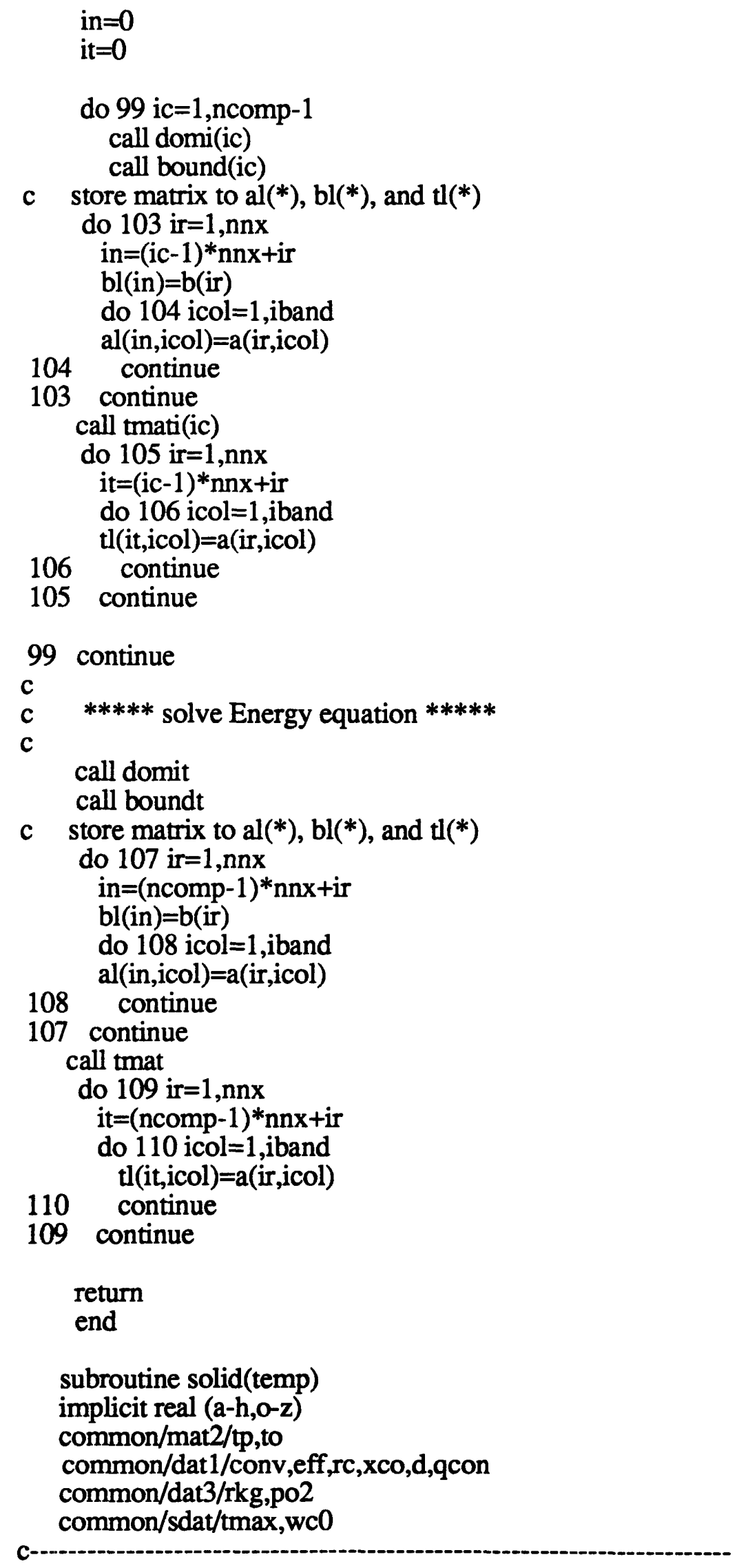




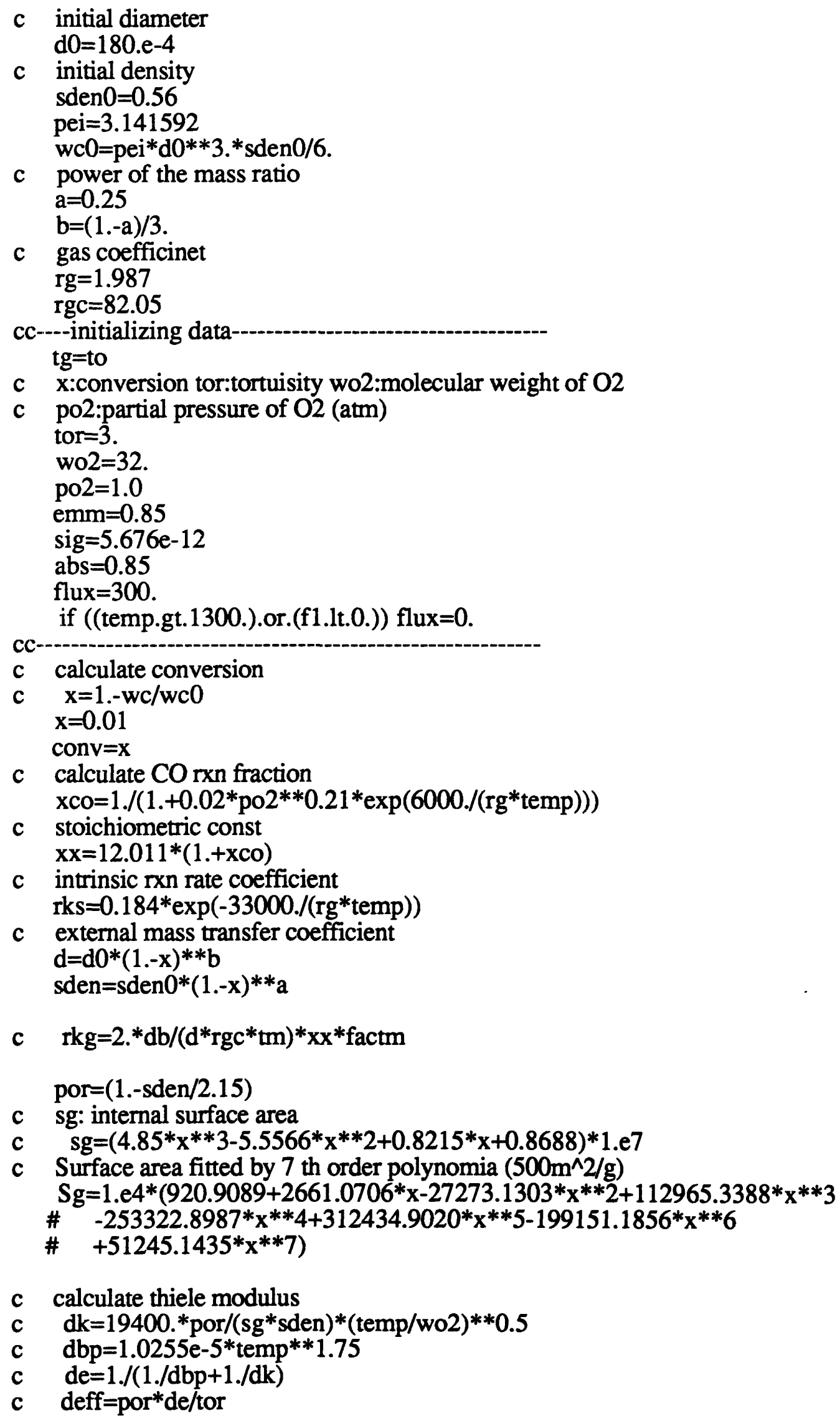




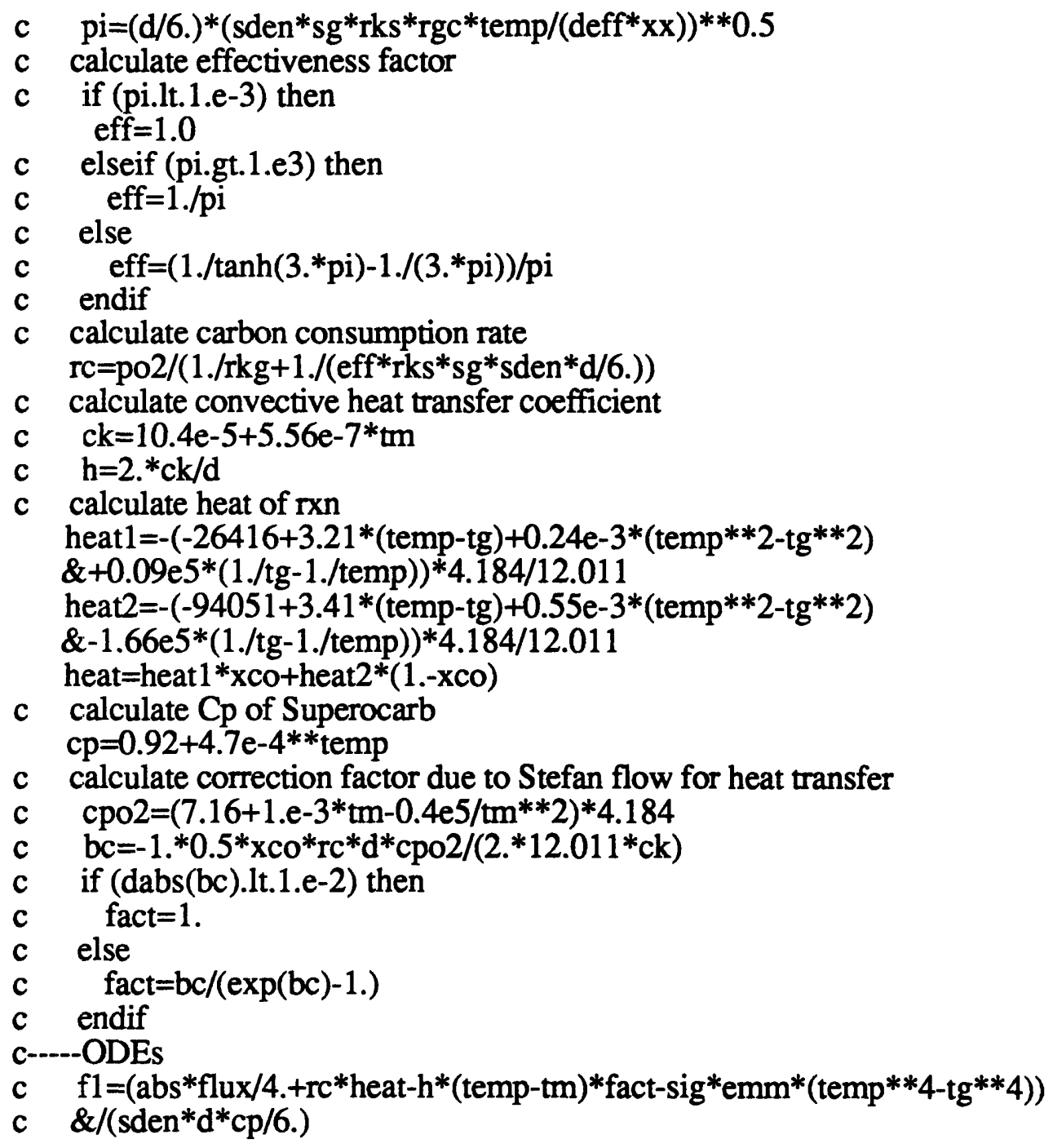

return

end

c

c

c

subroutine domi(ic)

implicit real (a-h,o-z)

common/mat1/a(200,3),b(200),t(200),x(200),yik(15,200)

common/mat $3 /$ iband

common/mat5/nnx,nxel,nntol,nodtol,nrhs,ncomp,nrxn

common/dat4/rho(200), vr(200),vi(15,200), ri(15,200), $\operatorname{cpg}(200)$,

\# $\quad$ cpi(15,200),rhamda(200),hi(15,200),xi(15),yi(15)

common/dat5/viy(15,200),vit(15,200),vc(200)

dimension temp $(2,2)$, temp1(2)

dimension $\mathrm{nm}(2)$

c

c $\quad * * * * *$ initialize the stiffness matrix and load vector 


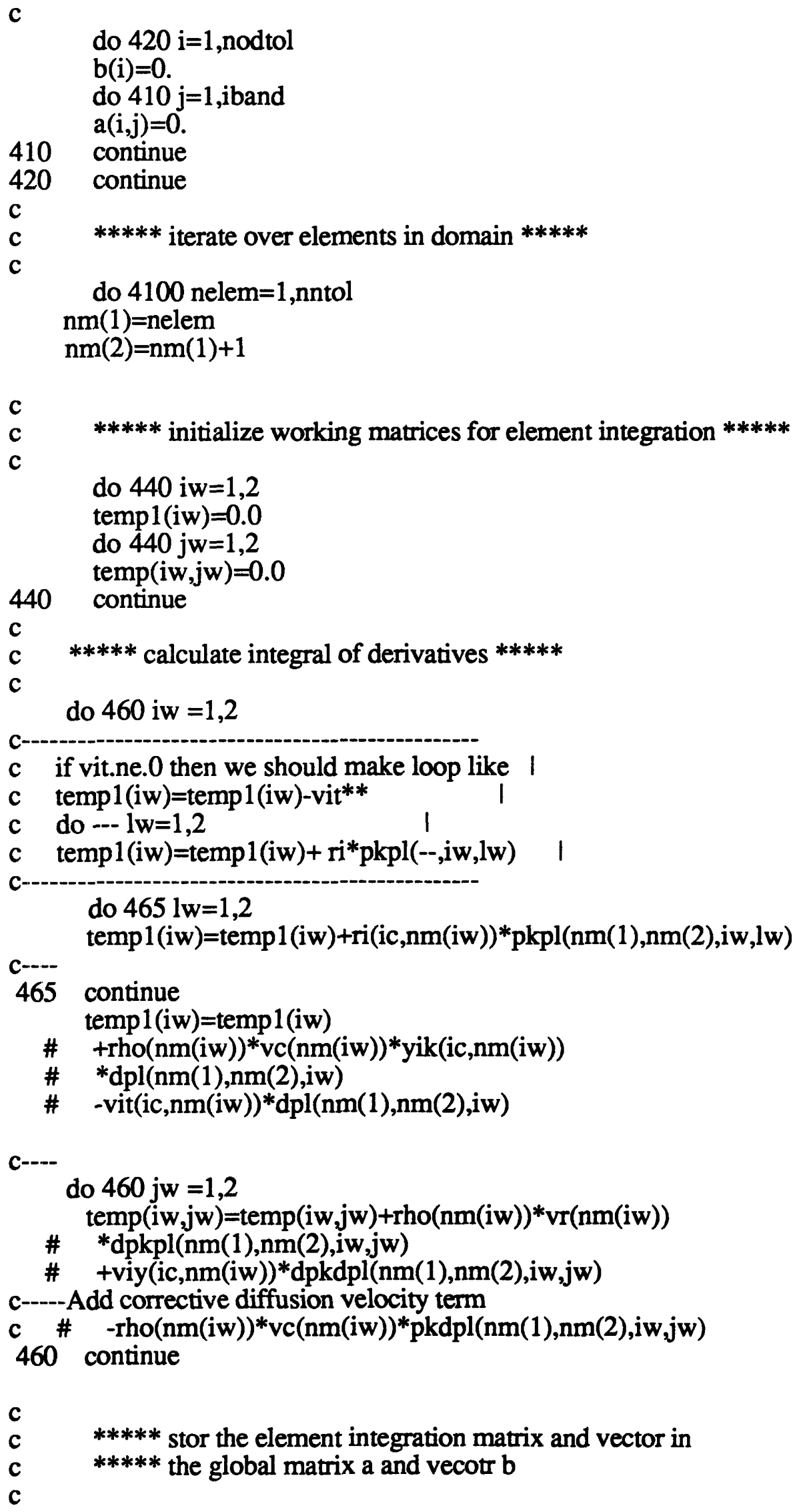




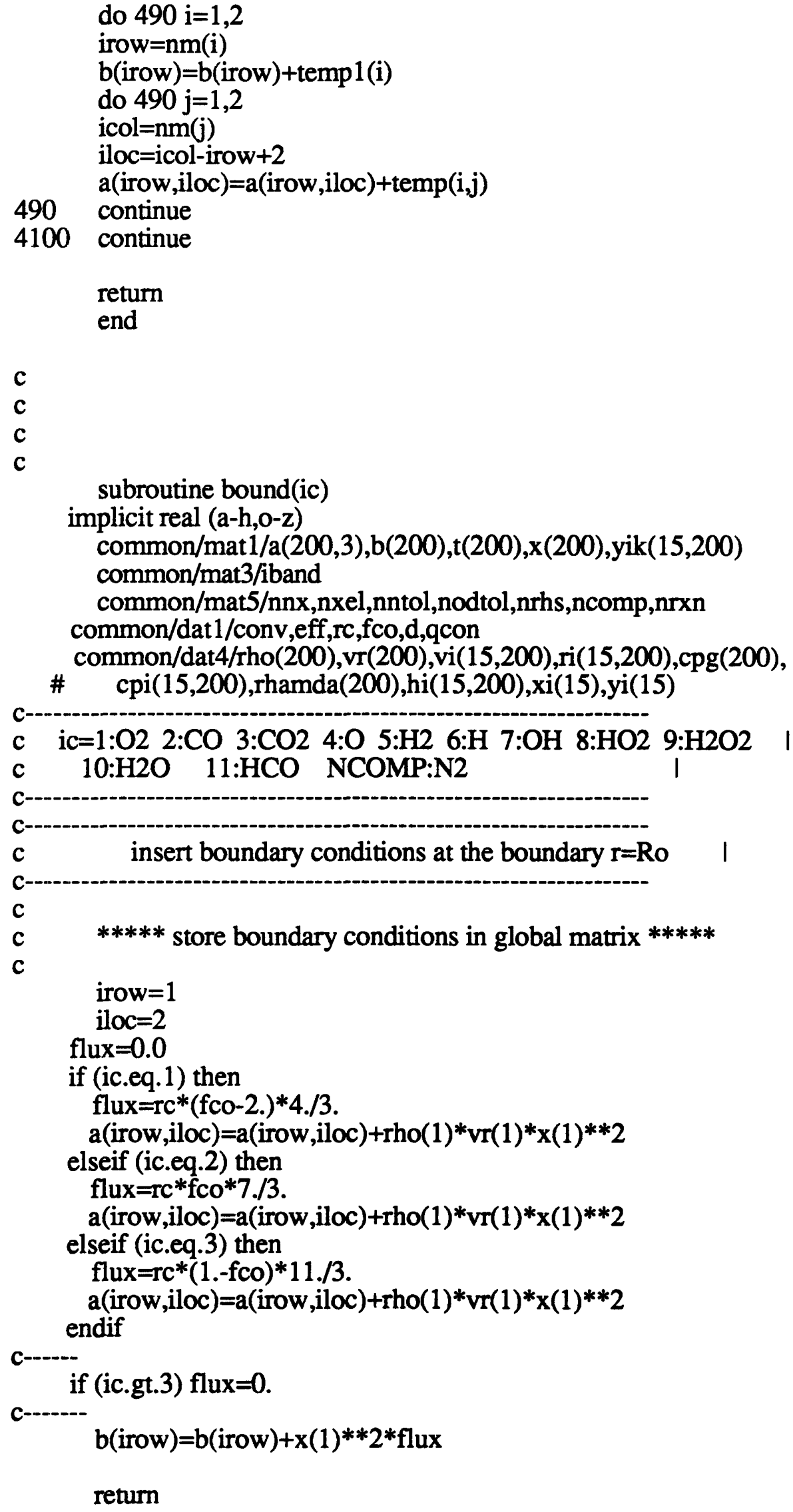


end

c

c

c

c

c

c

10

20

c

c

c

do 100 nelem $=1$,nntol

$\mathrm{nm}(1)=$ nelem

$\mathrm{nm}(2)=\mathrm{nm}(1)+1$

c

c $\quad * * * * *$ initialize working matrices for element integration $* * * * *$

c

do $40 \mathrm{iw}=1,2$

temp1(iw) $=0.0$

do $40 \mathrm{jw}=1,2$

temp $(\mathrm{iw}, \mathrm{jw})=0.0$

40 continue

c

c

c

do $60 \mathrm{iw}=1,2$

c $\quad \operatorname{sum} 1=0.0$

c do 62 icc $=1$, ncomp

c sum1=sum1+ri(icc,nm(1))*hi(icc,nm(1))

c 62 continue

c temp1(iw)=temp1(iw)-sum $1 * \operatorname{pl}(\mathrm{nm}(1), \mathrm{nm}(2), \mathrm{iw})$

do $601 \mathrm{lw}=1,2$ 


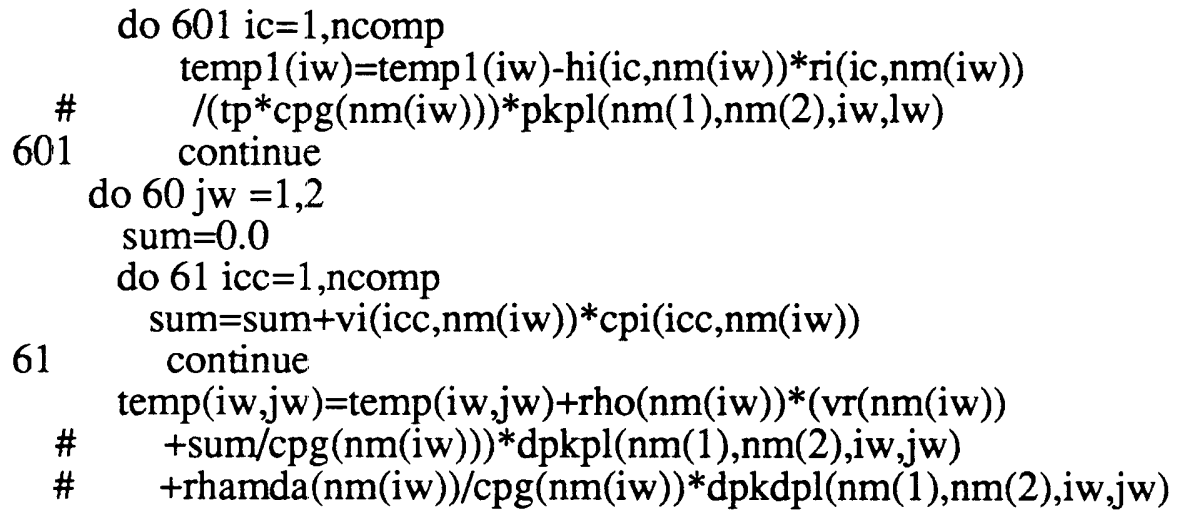

60 continue

c
c
c
c

c $\quad * * * * *$ stor the element integration matrix and vector in

c $\quad * * * * *$ the global matrix $\mathrm{a}$ and vecotr $\mathrm{b}$

do $90 \mathrm{i}=1,2$

irow $=\mathrm{nm}(\mathrm{i})$

$b($ irow $)=b($ irow $)+$ temp 1 (i)

do $90 \mathrm{j}=1,2$

$\mathrm{icol}=\mathrm{nm}(\mathrm{j})$

iloc=icol-irow +2

90 continue

100 continue

return

end

c

C

c

c

subroutine boundt

implicit real (a-h,o-z)

common/mat1/a(200,3),b(200),t(200),x(200),yik(15,200)

common/mat $2 /$ tp,to

common/mat $3 /$ iband

common/mat5/nnx,nxel,nntol,nodtol,nrhs,ncomp,nrxn

c insert boundary conditions at the boundary $r=$ Ro

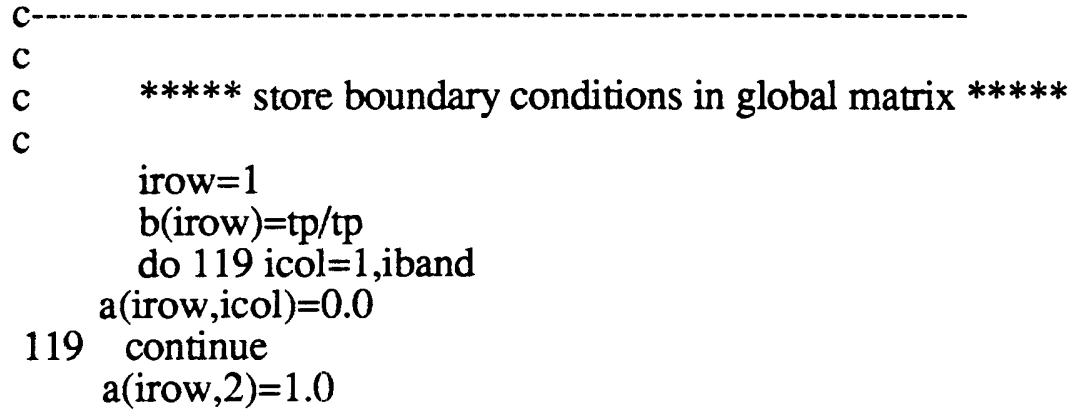

c $\quad * * * * *$ store boundary conditions in global matrix $* * * * *$

c

irow $=1$

$\mathrm{b}($ irow $)=\mathrm{tp} / \mathrm{tp}$

do 119 icol $=1$, iband

a (irow, icol $)=0.0$

119 continue

$\mathrm{a}($ irow, 2$)=1.0$ 


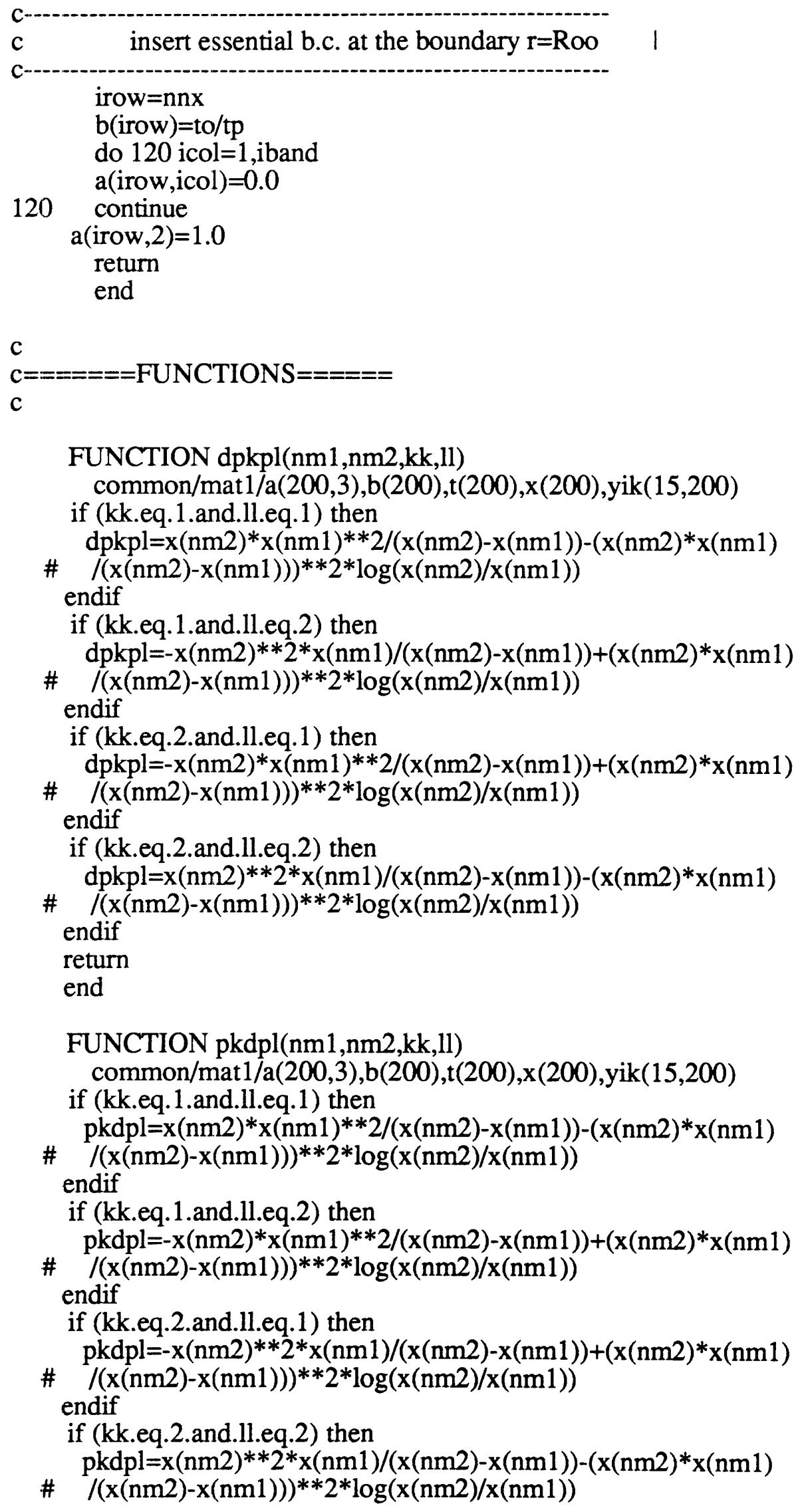

FUNCTION pkdpl(nm1,nm2,kk,ll) common/mat $1 / \mathrm{a}(200,3), \mathrm{b}(200), \mathrm{t}(200), \mathrm{x}(200), \mathrm{yik}(15,200)$

if (kk.eq.1.and.11.eq.1) then $\mathrm{pkdpl}=\mathrm{x}(\mathrm{nm} 2) * \mathrm{x}(\mathrm{nm} 1)^{* *} 2 /(\mathrm{x}(\mathrm{nm} 2)-\mathrm{x}(\mathrm{nm} 1))-(\mathrm{x}(\mathrm{nm} 2) * \mathrm{x}(\mathrm{nm} 1)$

\# $/(\mathrm{x}(\mathrm{nm} 2)-\mathrm{x}(\mathrm{nm} 1)))^{* *} 2 * \log (\mathrm{x}(\mathrm{nm} 2) / \mathrm{x}(\mathrm{nm} 1))$

endif

if (kk.eq.1.and.11.eq.2) then $\mathrm{pkdpl}=-\mathrm{x}(\mathrm{nm} 2)^{*} \mathrm{x}(\mathrm{nm} 1)^{* *} 2 /(\mathrm{x}(\mathrm{nm} 2)-\mathrm{x}(\mathrm{nm} 1))+(\mathrm{x}(\mathrm{nm} 2) * \mathrm{x}(\mathrm{nm} 1)$

\# $/(\mathrm{x}(\mathrm{nm} 2)-\mathrm{x}(\mathrm{nm} 1)))^{* *} 2 * \log (\mathrm{x}(\mathrm{nm} 2) / \mathrm{x}(\mathrm{nm} 1))$

endif

if (kk.eq.2.and.11.eq.1) then $\mathrm{pkdpl}=-\mathrm{x}(\mathrm{nm} 2)^{* * 2 *} \mathrm{x}(\mathrm{nm} 1) /(\mathrm{x}(\mathrm{nm} 2)-\mathrm{x}(\mathrm{nm} 1))+(\mathrm{x}(\mathrm{nm} 2) * \mathrm{x}(\mathrm{nm} 1)$

\# $/(\mathrm{x}(\mathrm{nm} 2)-\mathrm{x}(\mathrm{nm} 1))) * * 2 * \log (\mathrm{x}(\mathrm{nm} 2) / \mathrm{x}(\mathrm{nm} 1))$

endif

if (kk.eq.2.and.11.eq.2) then $\mathrm{pkdpl}=\mathrm{x}(\mathrm{nm} 2)^{* *} 2^{*} \mathrm{x}(\mathrm{nm} 1) /(\mathrm{x}(\mathrm{nm} 2)-\mathrm{x}(\mathrm{nm} 1))-(\mathrm{x}(\mathrm{nm} 2) * \mathrm{x}(\mathrm{nm} 1)$

\# $/(\mathrm{x}(\mathrm{nm} 2)-\mathrm{x}(\mathrm{nm} 1)))^{* *} 2 * \log (\mathrm{x}(\mathrm{nm} 2) / \mathrm{x}(\mathrm{nm} 1))$ 
endif

return

end

FUNCTION pl(nm1,nm2,11)

common/mat $1 / \mathrm{a}(200,3), \mathrm{b}(200), \mathrm{t}(200), \mathrm{x}(200), \mathrm{yik}(15,200)$

if (ll.eq.1) then

$\mathrm{pl}=\mathrm{x}(\mathrm{nm} 2) * \mathrm{x}(\mathrm{nm} 1) * 0.5 *(\mathrm{x}(\mathrm{nm} 1)+\mathrm{x}(\mathrm{nm} 2))$

\# $-\left(\mathrm{x}(\mathrm{nm} 1)^{* *} 2+\mathrm{x}(\mathrm{nm} 1)^{*} \mathrm{x}(\mathrm{nm} 2)+\mathrm{x}(\mathrm{nm} 2)^{* *} 2\right)$

endif

if (ll.eq.2) then

$\mathrm{pl}=-\mathrm{x}(\mathrm{nm} 2) * \mathrm{x}(\mathrm{nm} 1) * 0.5 *(\mathrm{x}(\mathrm{nm} 1)+\mathrm{x}(\mathrm{nm} 2))$

$\#+\left(\mathrm{x}(\mathrm{nm} 1) * * 2+\mathrm{x}(\mathrm{nm} 1)^{*} \mathrm{x}(\mathrm{nm} 2)+\mathrm{x}(\mathrm{nm} 2)^{* *} 2\right)$

endif

return

end

FUNCTION dp1(nm1,nm2,11) common/mat $1 / \mathrm{a}(200,3), \mathrm{b}(200), \mathrm{t}(200), \mathrm{x}(200), \mathrm{yik}(15,200)$

if (ll.eq.1) then $\mathrm{dpl}=-1 . * \mathrm{x}(\mathrm{nm} 2) * \mathrm{x}(\mathrm{nm} 1)$

endif

if (ll.eq.2) then

$$
\mathrm{dpl}=\mathrm{x}(\mathrm{nm} 2) * \mathrm{x}(\mathrm{nm} 1)
$$

endif

return

end

FUNCTION dpkdpl(nm1,nm2,kk,ll)

common/mat $1 / \mathrm{a}(200,3), \mathrm{b}(200), \mathrm{t}(200), \mathrm{x}(200), \mathrm{yik}(15,200)$

if (kk.eq.1.and.ll.eq.1) then

dpkdpl $=x(n m 2) * x(n m 1) /(x(n m 2)-x(n m 1))$

endif

if (kk.eq.1.and.1l.eq.2) then

dpkdpl $=-x(n m 2) * x(n m 1) /(x(n m 2)-x(n m 1))$

endif

if (kk.eq.2.and.11.eq.1) then

dpkdpl $=-x(n m 2) * x(n m 1) /(x(n m 2)-x(n m 1))$

endif

if (kk.eq.2.and.11.eq.2) then

dpkdpl $=x(n m 2) * x(n m 1) /(x(n m 2)-x(n m 1))$

endif

return

end

FUNCTION pkpl(nm1,nm2,kk,ll)

common/mat $1 / \mathrm{a}(200,3), \mathrm{b}(200), \mathrm{t}(200), \mathrm{x}(200), \mathrm{yik}(15,200)$

if (kk.eq.1.and.11.eq.1) then

$\mathrm{pkpl}=1 . /(\mathrm{x}(\mathrm{nm} 2)-\mathrm{x}(\mathrm{nm} 1)) *\left(\mathrm{x}(\mathrm{nm} 2) * * 2 * \mathrm{x}(\mathrm{nm} 1)^{* *} 2-\mathrm{x}(\mathrm{nm} 2)\right.$

\# $* \mathrm{x}(\mathrm{nm} 1)^{* *} 2 *(\mathrm{x}(\mathrm{nm} 1)+\mathrm{x}(\mathrm{nm} 2))+(1 . / 3). * \mathrm{x}(\mathrm{nm} 1) * * 2 *(\mathrm{x}(\mathrm{nm} 2) * * 2+$

$\left.\left.\# \quad x(\mathrm{~nm} 1) * x(\mathrm{~nm} 2)+\mathrm{x}(\mathrm{nm} 1)^{* *} 2\right)\right)$

endif

if ((kk.eq.1.and.1l.eq.2).or.(kk.eq.2.and.1l.eq.1)) then

$\mathrm{pkpl}=1 . /(\mathrm{x}(\mathrm{nm} 2)-\mathrm{x}(\mathrm{nm} 1)) *(-1 . / 3 . * \mathrm{x}(\mathrm{nm} 1) * \mathrm{x}(\mathrm{nm} 2) *(\mathrm{x}(\mathrm{nm} 1) * * 2+$ 


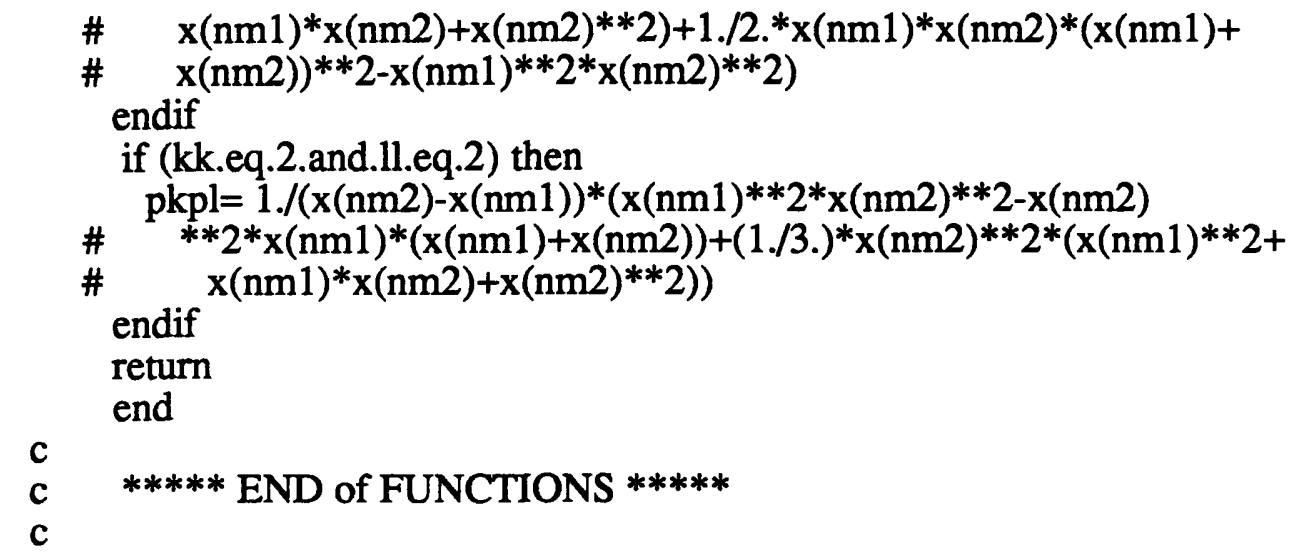

c-----Subroutines for time dependent calculation

\section{SUBROUTINE tmati(ic)}

implicit real (a-h,o-z)

common/mat1/a(200,3),b(200),t(200),x(200),yik(15,200)

common/mat $3 /$ iband

common/mat5/nnx,nxel,nntol,nodtol,nrhs,ncomp,nrxn common/dat4/rho(200),vr(200),vi(15,200),ri(15,200),cpg(200),

\# cpi(15,200),rhamda(200),hi(15,200),xi(15),yi(15)

dimension temp(2,2),temp1(2)

dimension $\mathrm{nm}(2)$

c

C

$* * * * *$ initialize the stiffness matrix and load vector $* * * * *$

C

do $20 \mathrm{i}=1$, nodtol

do $10 \mathrm{j}=1$,iband

10

$a(i, j)=0$.

c

c continue

c

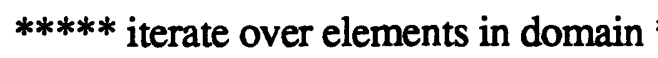

c

c

$* * * * *$ initialize working matrices for element integration $* * * * *$

c

do $40 \mathrm{iw}=1,2$

c temp1(iw) $=0.0$

do $40 \mathrm{jw}=1,2$

temp $(\mathrm{iw}, \mathrm{jw})=0.0$

40 continue

c

c

$* * * * *$ calculate integral of derivatives $* * * * *$ 


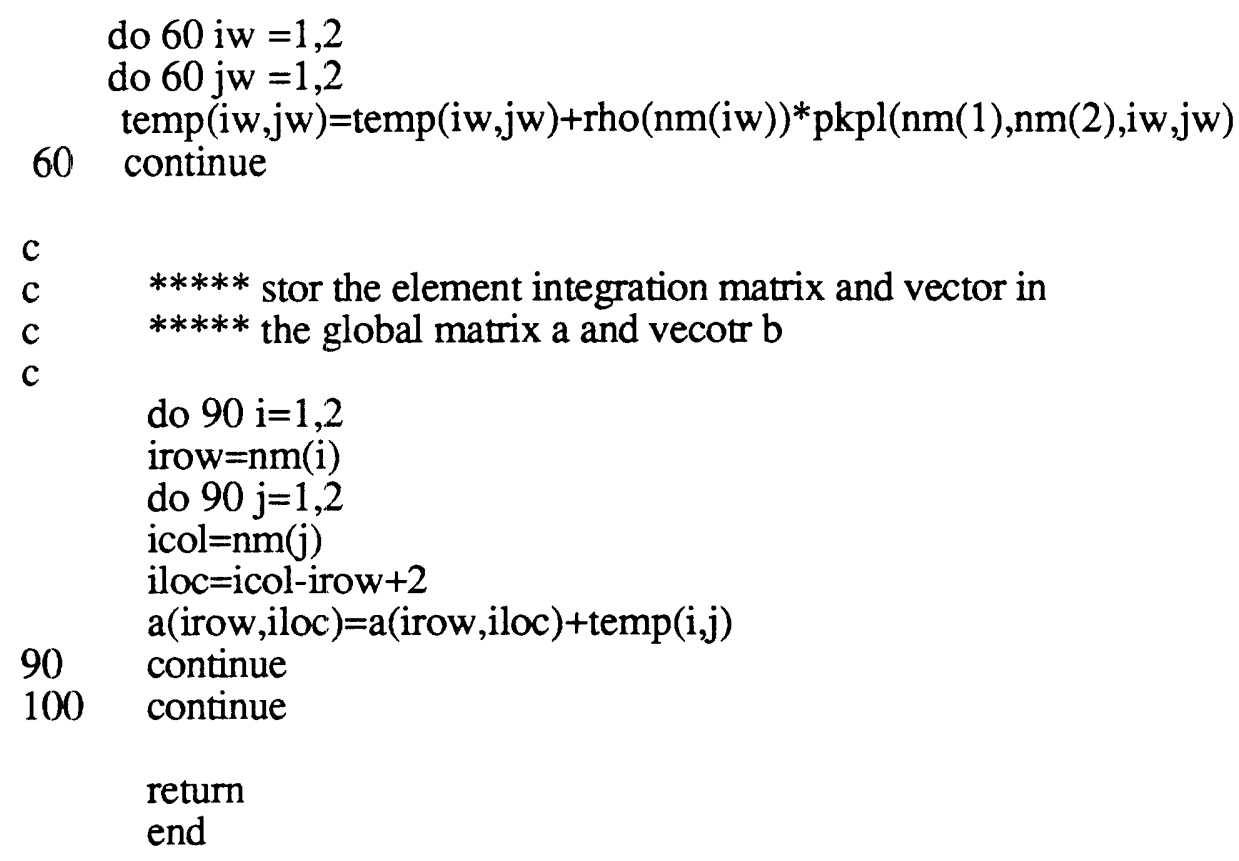

\section{SUBROUTINE tmat}

implicit real (a-h,o-z)

common/mat1/a(200,3),b(200),t(200),x(200),yik(15,200)

common/mat $3 /$ iband

common/mat5/nnx,nxel,nntol,nodtol,nrhs,ncomp,nrxn common/dat4/rho(200),vr(200),vi(15,200),ri(15,200), cpg(200),

\# cpi(15,200),rhamda(200),hi(15,200),xi(15),yi(15)

dimension temp (2,2),temp1(2)

dimension $\mathrm{nm}(2)$

c

c

c

$* * * * *$ initialize the stiffness matrix and load vector $* * * * *$

do $20 \mathrm{i}=1$,nodtol

do $10 \mathrm{j}=1$,iband

$\mathrm{a}(\mathrm{i}, \mathrm{j})=0$.

10 continue

20 continue

c

c

c

$* * * * *$ iterate over elements in domain $* * * * *$

do 100 nelem $=1$,nntol

$\mathrm{nm}(1)=$ nelem

$\mathrm{nm}(2)=\mathrm{nm}(1)+1$

c

c $\quad * * * * *$ initialize working matrices for element integration $* * * * *$

c

do $40 \mathrm{iw}=1,2$

do $40 \mathrm{jw}=1,2$

temp $(\mathrm{iw}, \mathrm{jw})=0.0$ 


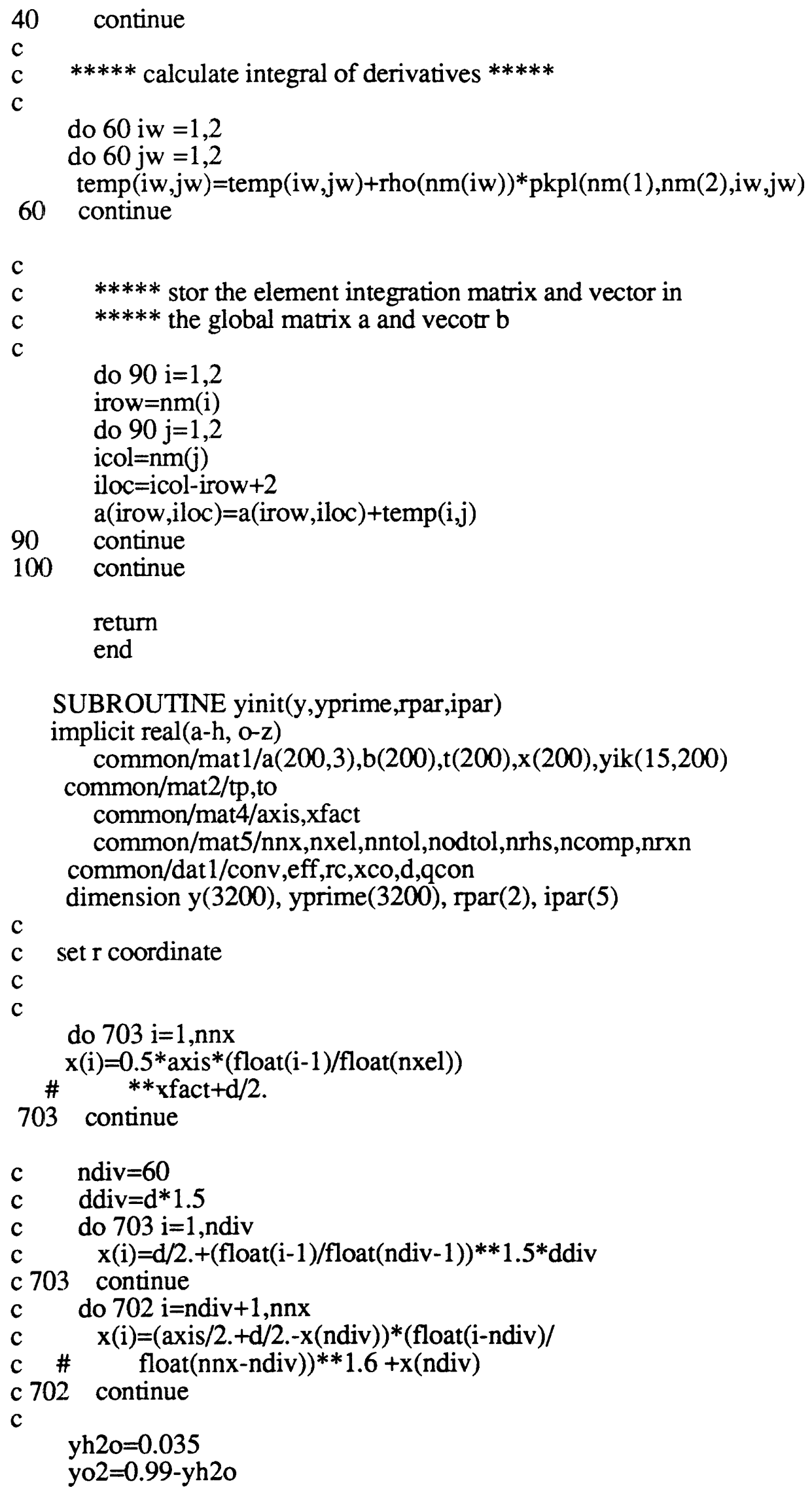




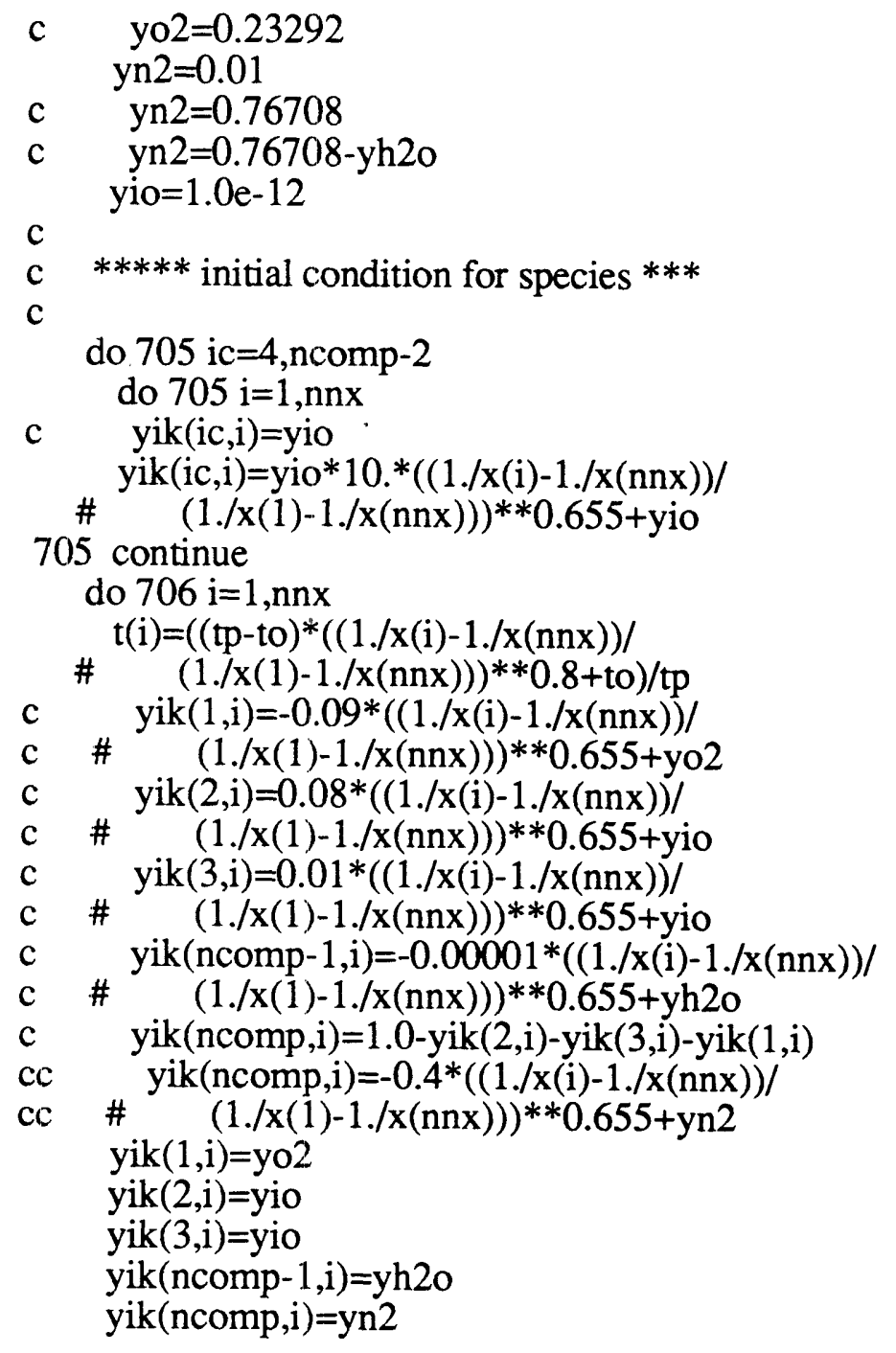

706 continue

in $=0$

do $10 \mathrm{ic}=1$, ncomp-1

do $11 \mathrm{ir}=1$, $\mathrm{nnx}$

in $=(\mathrm{ic}-1) * \mathrm{nnx}+\mathrm{ir}$

$y($ in $)=y i k(i c, i r)$

yprime (in) $=0.0$

11 continue

10 continue

do $20 \mathrm{ir}=1, \mathrm{nnx}$

in $=($ ncomp -1$) * n n x+i r$

$y($ in $)=t$ (ir)

yprime (in) $=0.0$

20 continue

return

end 
SUBROUTINE res(t,y,yprime,delta,ires,rpar,ipar) implicit real(a-h,o-z) common/mat $2 /$ tp,to common/mat5/nnx,nxel,nntol,nodtol,nrhs,ncomp,nrxn common/dasl/al $(1500,3), \mathrm{bl}(1500), \mathrm{tl}(1500,3)$ dimension y(3200),yprime(3200),rpar(2),ipar(5),delta(3200)

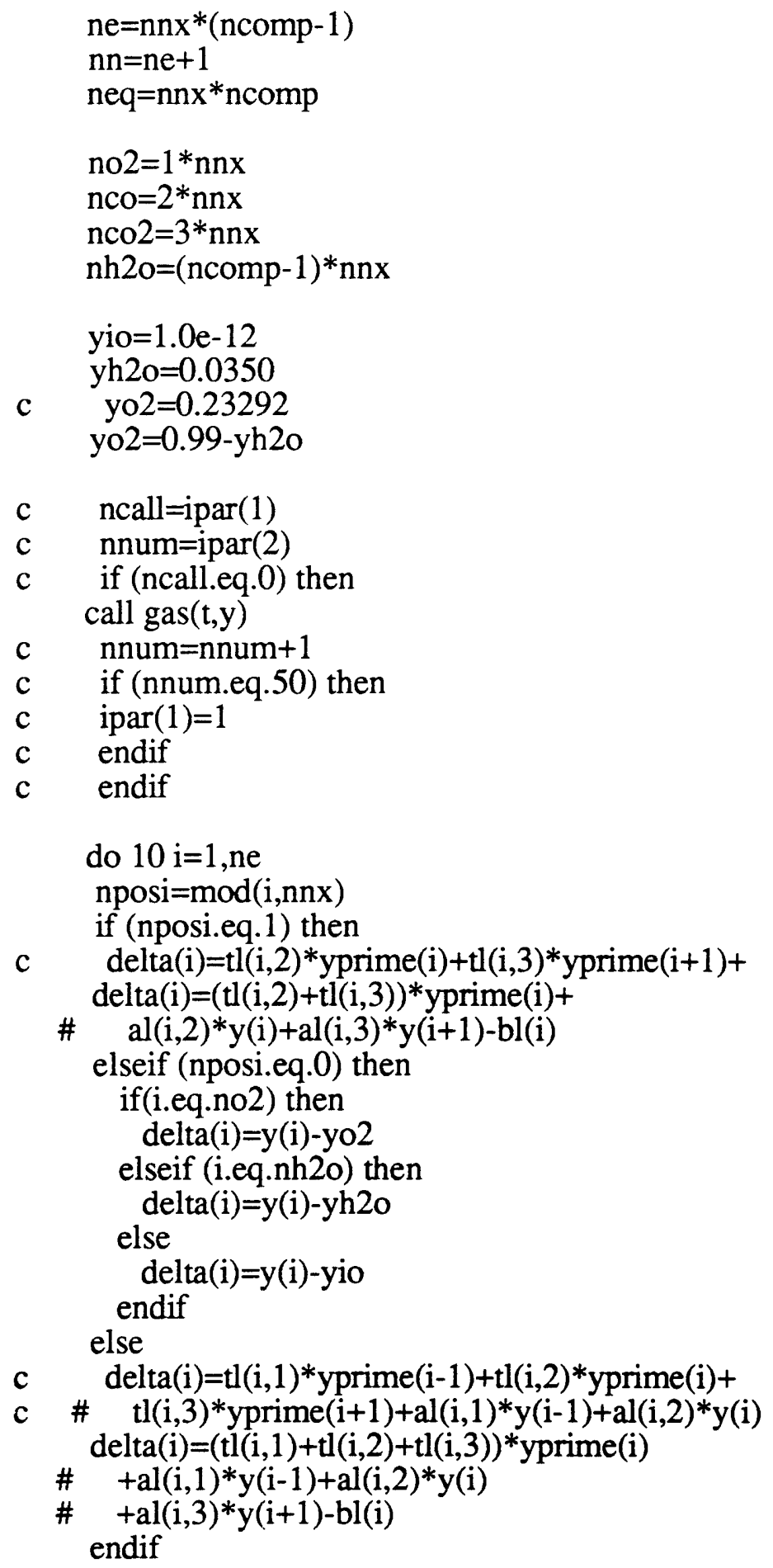


10 continue

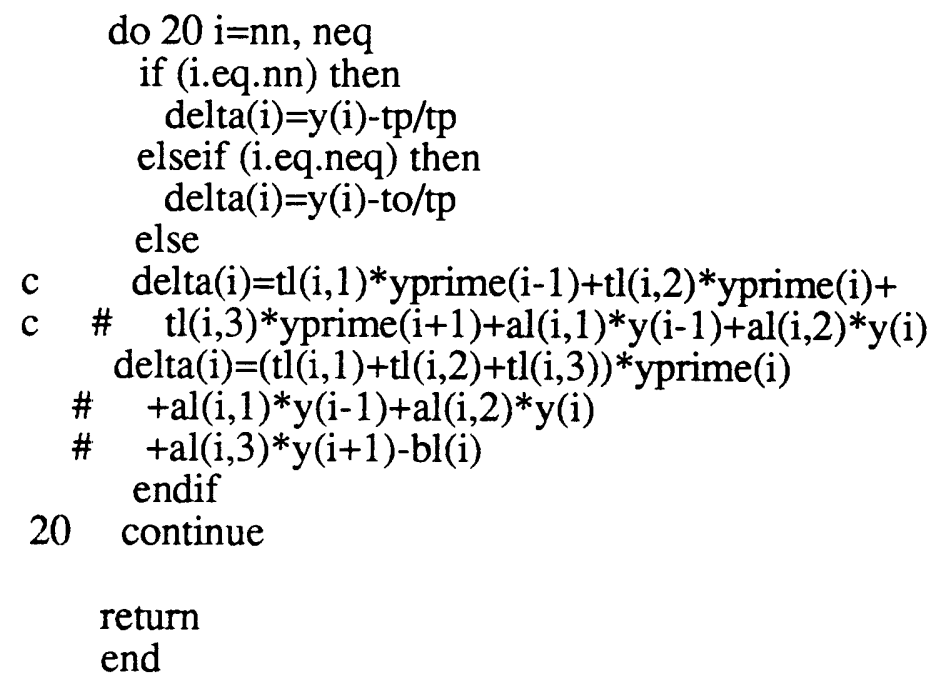




\section{Nomenclature}

[subscript]

' $b$ ' means bulk property

' $b u b$ ' means bubble

' $d$ ' means downward

' $e$ ' means effective property

' $g$ ' means gas mixture in the boundary layer

' $g c$ ' means gas convective

' $i$ ' means the $\mathrm{i}$-th species in the gas mixture

' $O$ ' means at time equals zero

' $p c$ ' means particle convective

' $s$ ' means surface

' $u$ ' means upward

[symbol]

$A$ external surface area

$A_{O} \quad$ pre-exponential factor

$A_{c} \quad$ cross-sectional area of the particle

C concentration

$C_{p, i} \quad$ specific heat of ' $i$ ' th species

$C_{p, g} \quad$ gas mixture specific heat at constant pressure

$D \quad$ gas diffusivity $\left(=D_{g}\right)$

$D_{i j} \quad$ binary diffusion coefficient

$D_{\text {im }}$ multi-component diffusion coefficient

$D^{T} \quad$ thermal diffusivity

$d$ diameter of the particle

$d_{p} \quad$ diameter of the bed particle

$E, E_{a}$ activation energy

$f \quad$ characteristic frequency of non-steady state heat and mass transfer

$f_{g} \quad$ characteristic frequency due to gas convective transfer

$f_{p} \quad$ characteristic frequency due to particle convective transfer

fh factor in heat transfer due to Stefan flow

$f_{m} \quad$ factor in mass transfer due to Stefan flow

$H$ bed height 
$H_{i} \quad$ specific enthalpy

$-\Delta H$ heat of reaction $[\mathrm{J} / \mathrm{g}]$

$h \quad$ convective heat transfer coefficient

I laser heating flux

$\underline{k} b \quad$ thermal conductivity at the gas phase

$k^{\prime} g$ mass transfer rate coefficient based on concentration

$k_{g}$ mass transfer rate coefficient based on partial pressure (in Ch.2), mass transfer coefficient (in Ch.3)

$k_{s}^{\prime} \quad$ intrinsic reaction rate coefficient based on concentration

$k_{S} \quad$ intrinsic reaction rate coefficient based on partial pressure

$m$ mass of the particle

$M \quad$ molecular weight

$\not 7$ mean molecular weight

$M_{C} \quad$ molecular weight of carbon

$P \quad$ pressure

$p \quad$ probability that particles is in the emulsion phase during one whole circulation

$p^{\prime} \quad$ probability in the emulsion phase during its rise

$Q_{a b s}$ absorption efficiency of laser heating flux

$R \quad$ gas coefficient

$R_{i} \quad$ mass production rate

$\boldsymbol{R}_{\boldsymbol{O}} \quad$ particle radius

$r$ radial coordinate

$r_{c}$ carbon consumption rate (based on the external surface area) $\left[\mathrm{gC} / \mathrm{cm}^{2} \mathrm{~s}\right]$

$r_{s}$ intrinsic reaction rate (based on internal surface area) $\left[\mathrm{gC} / \mathrm{cm}^{2} \mathrm{~s}\right]$

$S_{g} \quad$ BET surface area $\left[\mathrm{m}^{2} / \mathrm{g}\right]$

$T$ temperature

$T_{g} \quad$ ambient gas and wall temperature

$T_{m}$ mean temperature of $T_{p}$ and $T_{g}$

$T_{o} \quad$ temperature at $\mathrm{t}=0$

$T_{p} \quad$ particle temperature

$t$ time

$U_{B} \quad\left(=\mathrm{u}_{\mathrm{b}}\right)$ bubble rising velocity

$U_{D}$ particle descending velocity

$U_{R} \quad$ particle rising velocity

$U_{m f}$ minimum fluidization velocity

$v_{r} \quad$ fluid velocity in ' $r$ ' direction

$V_{i} \quad$ diffusion velocity of ' $\mathrm{i}$ ' th species 
$V_{C} \quad$ corrective diffusion velocity

$X_{c o}$ reaction fraction of $\mathrm{CO}=\left(\mathrm{CO}_{2} / \mathrm{CO}+1\right)^{-1}$

$X \quad$ penetration depth

$X_{i} \quad$ mole fraction of ' $i$ ' th species

$Y_{i} \quad$ mass fraction of ' $i$ ' th species

$\alpha \quad$ nodal value (in Ch.4), wake fraction (in Ch.3)

e effective thermal diffusivity (in Ch.3)

$\chi \quad$ grams of carbon consumed per mole of $\mathrm{O}_{2}$ reacted

$\varepsilon \quad$ emissivity of the particle.

$\varepsilon_{\mathrm{mf}}$ bed voidage at the minimum fluidization velocity

b bed voidage occupied by bubble

$\Phi$ basis function for Galerkin finite element method

$\phi \quad$ Thiele modulus

$\eta \quad$ effectiveness factor

$\varphi$ moles of $\mathrm{O}_{2}$ reacted per one mole carbon consumed

$\lambda_{g} \quad$ thermal conductivity

$\rho_{g} \quad$ density of the gas mixture in the boundary layer

$\sigma \quad$ Stefan-Boltzman constant 


\section{References}

Adomeit, G., Mohiuddin, G., Peters, N., 16th Symposium(International) on Combustion, p 731, The Combustion Institute, Pittsburgh, 1977.

Agarwal, P.K., "Transport phenomena in Multi-particle system-IV. Heat Transfer to a Large Moving Particle in Gas Fluidized Bed of Smaller Particles", Chemical Engineering Science, Vol. 46, No.4, pp. 1115-1127, 1991.

Amundson, N.R., Arri, L.E., AIChE J. 24(1), 87, 1978.

Arthur, J., Trans. Faraday Soc., 47, 164, 1951.

Bar-ziv, E., Jones, D.B., Spjut, R.E., Dudek, D.R., Sarofim, A.F., and Longwell, J. P., Combustion and Flames 75, pp 81-106, 1989.

Bar-Ziv, E., and Sarofim A.F., The Electrodynamic Chamber, MIT,1990.

Basu, P., Broughton, J., and Elliot, D.E., "Combustion of a Single Coal Particle in Fluidized Bed", Proc. Fluidized Combustion Conf., London, Inst. of Fuel Symp. Ser. I, A3-1, 1975

Bird, R.B., Stewart, W.E., and Lightfoot, E.N., Transport Phenomena, pp 566-574, John Wiley and Sons, 1960.

Caram, H.S. and Amundson, N.R., Ind. Eng. Chem. Fundam., 16, 171, 1977. 
Caram, H.S. and Amundson, N.R., "Diffusion and Reaction in a Stagnant Boundary Layer around a Carbon Particle", Chem. Eng. Sci., pp919-929, 1981.

Cavendish, J.C., and Oh, S.H., "A Computationally Efficient Galerkin Technique for Approximating Transient Diffusion-Reaction Equation in Composite Media", The Chemical Engineering Journal, 17, 1979

Cho, S.Y., Yetter, R.A., and Dryer,F.L., "Computer Model for Chemically Reactive Flow with Complex Chemistry / Multi-component Molecular diffusion / Heterogeneous Processes", Journal of Computational Physics, Vol 102, No. 1 Sep, 1992.

Coffee, T.P., and Heimerl, J.M., Combustion and Flame, 43, 273, 1981.

Davidson, J.F., and Harrison, D., Fluidised Particles, Cambridge Unversity Press, Cambridge, 1963.

Du, Z., Ph.D. Thesis, "Kinetic Modeling of Carbon Oxidation", Department of Mechanical Engineering, MIT., 1990

Du, Z., Sarofim, A.F., Longwell, J.P., and Mims C.A., "Kinetic Measurement and Modeling of Carbon Oxidation", Energy and Fuels, 5, 1991

Dudek, D., Ph.D. Thesis, "Single Particle, High Temperature, Gas-solid Reactions in an Electrodynamic Balance", Department of Chemical Engineering, MIT, 1989 
Finlayson, B.C., Nonlinear Analysis in Chemical Engineering, McGraw-Hill, 1980

Floess, J.K., Longwell, J.P., and Sarofim, A.F., "Intrinsic Reaction Kinetics of Microporous Carbons, 1. Noncatalyzed Chars", Energy \& Fuels 2, 18, 1988.

Graham, K.A., Ph.D. Thesis, Department of Chemical Engineering, MIT, 1990.

Hayhurst, A.N., and Tucker, R.F., "The Combustion of Carbon Monoxide in a Two-zone Fluidized Bed", Combustion and Flame, 79, pp 175-189, 1990

Hesketh, R.P., and Davidson, J.F., "Combustion of Methane and Propane in an Incipiently Fluidized Bed", Combustion and Flame, 85, pp 449-467, 1991

Hurt, R.H., Ph.D. Thesis, "Chemical and Physical Phenomena Determining Carbon Gasification Reactivity", Department of Chemical Engineering, MIT, 1987.

Hurt, R.H., " Reactivity Distributions and Extinction Phenomena in Coal Char Combustion", Sandia National Laboratory Report WSS/CI 93-019, 1993.

Johnson, C., Numerical Solution of Partial Differential Equations by the Finite Element Method, Cambridge University Press, Cambridge, 1987.

Jones, D.B., Ph.D. Thesis, "Carbon Oxidation in an Electrodynamic Balance", Department of Mechanical Engineering, MIT, 1989. 
Kurylko, L., and Essenhigh R.H., "Steady and Unsteady Combustion of Carbon", 14th Symposium (International) on Combustion, The Combustion Institute, Pittsburgh, pp 1375-1386, 1973.

La Nauze, R.D., "Fundamentals of Coal Combustion in Fluidised Beds", Chem. Eng. Res. Des., Vol 63, January, pp. 3-33, 1985.

Lee, J.C., Yetter, R.A., Dryer, F.L., "Transient Numerical Modeling of Carbon Particle Ignition and Oxidation", MAE Report \# T1980, August, 1993.

Levendis, Y.A., Nam, S.W., Lowenberg, M., Flagan, R.C., and Gavalas, G.R., " Catalysis of the Combustion of Synthetic Char Particles by Various Forms of Calcium Additives", Energy \& Fuels, Vol 3, No.1, pp28-37, 1989.

Linjewile, T.M., and Agarwal, P.K., " Heat Transfer Behavior and Temperatures of Freely Moving Burning Carbonaceous Particles in Fluidized Beds", 23rd Symposium, The Combustion Institute, pp. 917-925, 1990.

Linjewile, T.M., Ph.D. Thesis, University of Adelaide, Australia, 1993.

Longwell, J.P., Sarofim, A.F., Bar-ziv, E. and Lee, C.H., DOE Report, DOE/PC/89774$3,1990$.

Maloney, D.J., Monazam, E.R., Woodruff, S.D., and Lawson, L.O., Combustion and Flame 84, pp 210-220,1991. 
Mitchell, R.E., Glarborg, P.,and Coltrin, M.E., Twenty-Third Symposium (International) on Combustion, The Combustion Institute, pp1169-1176, 1990.

Nienow, A.J., Rowe, P.N., and Chiba, T., "Mixing and segregation of a small proportion of large particles in the gas fluidized beds of considerably smaller ones", AIChE. Symp. Ser. 176, 74, pp 45-53, 1978.

Otterbein, M., and Bonnetain, L., Carbon 6, 877, 1968.

Phillips, R., Vastola, F.J., and Waler, P.L. Jr., Carbon 8, 205, 1970.

Prins, W., Ph.D. Thesis, "Fluidized Bed Combustion of a Single Carbon Particle", Twente University, The Netherands, 1987

Rossberg, M.Z., Elektrochem. 60, 952, 1956.

Smith, I.W., The Intrinsic Reactivity of Carbon to Oxygen, Fuel 57, 409, 1978.

Smith, I.W., EPA Report, EPA-600/8-90-049, 1980.

Spjut, R.E., PhD Thesis, Heat Transfer to and Position Control of Electrodynamically Suspended Micron-sized Particles, Department of Mechanical Engineering, MIT, 1985.

Sundaresan, S., and Amundson N.R., Ind. Eng. Chem. Fundam., 19, pp 351-357, 1980.

Sundaresan, S., and Amundson N.R., AIChE J., 27, No. 4, pp 679-686, 1981. 
Tognotti, L., Sarofim, A.F., and Longwell, J.P., Twenty-Third Symposium (International) on Combustion, The Combustion Institute, Pittsburgh, 1990.

Tullin, C.J., Sarofim, A.F., and Beer, J.M. , " Formation of NO and $\mathrm{N}_{2} \mathrm{O}$ in Coal Combustion: The Relative importance of Volatile and Char Nitrogen", Proceedings of 12th Int. Conf. on Fluidized Bed Combustion, Journal of the Institute of Energy, pp 599-609. 1993.

Tullin, C.J., Shakti, G., Sarofim, A.F., and Beer, J.M., " NO and $\mathrm{N}_{2} \mathrm{O}$ Formation for Coal Combustion in a Fluidized Bed: Effect of Carbon Conversion and Bed Temperature", Energy and Fuels, Vol 7 , No.6, 1993.

Tyler, R. J., Intrinsic Reactivity of Petroleum Coke to Oxygen, Fuel 65, 235, 1986.

Waters, B.J., Squire, R.G., Laurendeau, N.M., Combustion Sci. and Tech. Vol. 62, pp. 187-209, 1988a.

Waters, B.J., Mitchell, R.E., Squires, R.G., and Laurendeau, N.M., Twenty-Second Symposium (International) on Combustion, p. 17, The Combustion Institute, Pittsburgh, $1988 \mathrm{~b}$.

Yetter, R.A., Dryer, F.L., and Rabitz, H., Combustion Sci. Tech., vol 79, pp 97-128, 1991. 